Portland State University

PDXScholar

Fall 1-1-2012

\title{
Biosynthesis of Marineosin, a Spiroaminal Undecylprodiginine Natural Product
}

Shaimaa Mohamed Salem

Portland State University

Follow this and additional works at: https://pdxscholar.library.pdx.edu/open_access_etds

Part of the Other Chemistry Commons

Let us know how access to this document benefits you.

\section{Recommended Citation}

Salem, Shaimaa Mohamed, "Biosynthesis of Marineosin, a Spiroaminal Undecylprodiginine Natural Product" (2012). Dissertations and Theses. Paper 936.

https://doi.org/10.15760/etd.936

This Dissertation is brought to you for free and open access. It has been accepted for inclusion in Dissertations and Theses by an authorized administrator of PDXScholar. Please contact us if we can make this document more accessible: pdxscholar@pdx.edu. 
Biosynthesis of Marineosin, a Spiroaminal Undecylprodiginine Natural Product

by

Shaimaa Mohamed Salem

A dissertation submitted in partial fulfillment of the requirements of the degree of

\author{
Doctor of Philosophy \\ in \\ Chemistry
}

Dissertation Committee:

Kevin A. Reynolds, Chair

David H. Peyton

Dirk Iwata-Reuyl

Robert Strongin

Kenneth Stedman

Portland State University

2012 


\begin{abstract}
Marineosins $A$ and $B$ are two spiroaminal-ring containing tripyrrole compounds isolated from the marine actinomycete, Streptomyces CNQ-617, and were found to possess potent and selective cytotoxic activity against leukemia and melanoma. Marineosins belong to the prodiginines class of natural products, examples of which are undecylprodiginine and streptorubin B. Unlike marineosins, prodiginines structures are characterized by the presence of fully conjugated tripyrrole nucleus linked to an alkyl chain (that lacks any oxygen). Cyclic prodiginines arise from an oxidative cyclization of the alkyl chain onto the tripyrrole, a step catalyzed by Rieske-oxygenase like enzymes such as RedG. The biosynthesis of prodiginines is directed via the red gene cluster. The unique structural differences between marineosin and other prodiginines spurred the proposal of a number of hypotheses for its biosynthesis, none of which have been experimentally tested. A red gene cluster homolog which has only one extra dehydratase-encoding gene; marA has been identified from the genomic library of Streptomyces CNQ-617, and the identified cluster was proposed to direct the biosynthesis of marineosin. In this study, the identified putative gene cluster was expressed in the heterologous host, S. venezuelae, and marineosin production in the new strain; JND2 was confirmed via LC/MS and ${ }^{1} \mathrm{H}-\mathrm{NMR}$. The new engineered strain also produces a myriad of marineosin related shunt metabolites and pathway intermediates. This study hence presents the first identified gene cluster proved to direct the biosynthesis of marineosin; the mar
\end{abstract}


gene cluster and proves that the cloned cluster encodes most, if not all the enzymes required to direct the biosynthesis of marineosin.

Deletion of the Rieske-oxygenase encoding gene; marG (a RedG homolog) from the mar gene cluster led to the accumulation of 2-hydroxyundecylprodiginine; G410 with an $\mathrm{m} / \mathrm{z} 410.28$ and molecular formula $\mathrm{C}_{25} \mathrm{H}_{35} \mathrm{O}_{2} \mathrm{~N}_{3}$. This data proves that MarG is not responsible for the introduction of the spiromaminal ring oxygen on the alkyl chain, but is required for catalyzing macrocyclic ring formation between C-8 and C-9 of G410. Undecylprodiginine production in marG deletion mutant was not observed which indicates that undecylprodiginine is likely not an intermediate along the pathway for marineosin biosynthesis, and indicates that the spiroaminal ring oxygen is introduced early in the pathway, possibly due to the incorporation of a 3-hydroxy-butyric acid starter unit.

Deletion of the dehydratase-encoding gene; marA, from the mar gene cluster led to the accumulation of compounds JN408 and JN422 with $\mathrm{m} / \mathrm{z} 408.26$ and 422.24 and molecular formulae $\mathrm{C}_{25} \mathrm{H}_{33} \mathrm{O}_{2} \mathrm{~N}_{3}$, and $\mathrm{C}_{25} \mathrm{H}_{31} \mathrm{O}_{3} \mathrm{~N}_{3}$, respectively. Purification and structure elucidation of JN408 proves it to be an oxidized marineosin analog which has fully aromatic tripyrrole rings while; purification and structure elucidation of JN422 proves it to be a 9-keto-JN408 derivative. Both JN408 and JN422 compounds have a spiroaminal ring which indicates that MarA does not catalyze spiroaminal ring formation but catalyzes the reduction of pyrrole ring B of JN408 to yield marineosin. Therefore, we are proposing that MarA acts as a dehydrogenase, rather than a dehydratase. We are proposing 
that the intramolecular spiroaminal ring formation is catalyzed by either MarG or occurs non-enzymatically. JN422 is a shunt metabolite produced due to promiscuous activity of either MarG or an unidentified oxidase in the mar cluster, possibly MarT.

From the data generated in this study, we present the first experimentally supported pathway for the biosynthesis of marineosin and the opportunity to generate novel compounds with potentially useful biological activities. 
To the memory of my parents,

Without their love and support, nothing in my life would have been possible 


\section{ACKNOWLEDGEMENTS}

I would like to convey my sincere gratitude to Dr. Kevin Reynolds for granting me the opportunity to join his research group. His supervision, enthusiasm, and encouragement made this dissertation possible. I am also thankful to all members of the Reynolds group for sharing their expertise with me and for creating a positive atmosphere for learning and working. I would like to express my warmest thanks to Dr. Galina Florova for her valuable insights, and Dr. Papireddy Kancharla for helping with interpretation of NMR spectra. My sincere thanks and appreciation goes to my advisory committee; Dr. David Peyton, Dr. Dirk Iwata-Reuyl, Dr. Kenneth Stedman, and Dr. Robert Strongin for their generous time, support and constructive criticism. Special thanks to Dr. Peyton for dedicating the time and effort to help me in NMR data acquisition.

I would like to thank the chemistry department of Portland State University for providing a unique learning environment and wealth of research resources. I would like to specially thank the NMR facility personnel; Cheryl Hudson and Robert Jensen as well as the Mass Spectrometry facility director; Dr. Andrea DeBarber and Wilbes Mbiya for their help, valuable time and effort. I am also thankful to Dr. Andrea Goforth for helping me with IR-spectra acquisition.

Finally, I am greatly indebted to my family and friends, especially my parents for their love and support throughout the years. I humbly offer my deepest thanks to my husband; Dr. Sherif Elshahawi and my children; Janna and Nour-Eldin Elshahawi, whose unconditional love, trust and support is my elixir of life. 


\section{Table of Contents}

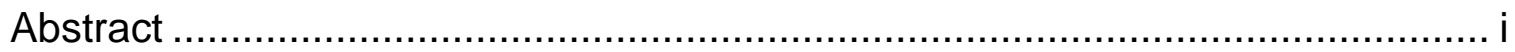

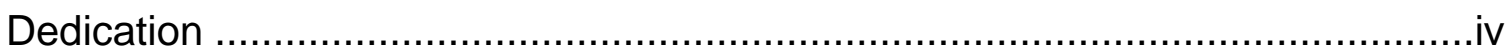

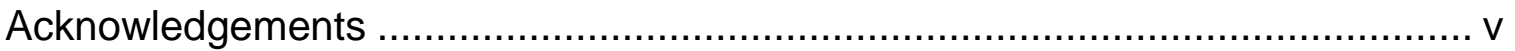

List of Tables ..............................................................................................

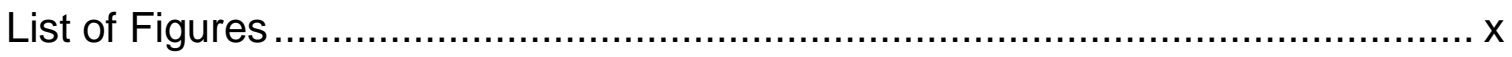

List of Abbreviations ..........................................................................

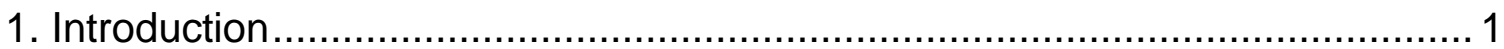

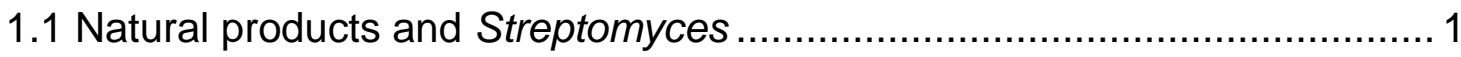

1.2 Biosynthesis of natural products....................................................... 4

1.3 Study of natural products biosynthesis ................................................ 6

1.4 Prodiginines family of natural products................................................. 11

1.5 Marineosins, new undecylprodiginine analogs ................................... 18

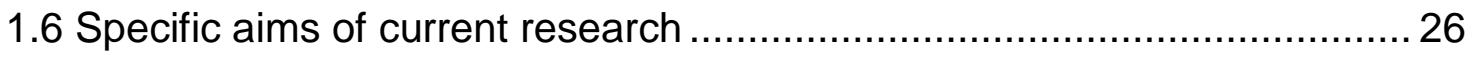

2. The identification of the gene cluster responsible for the biosynthesis of marineosin: The mar cluster. ....................................................................... 28

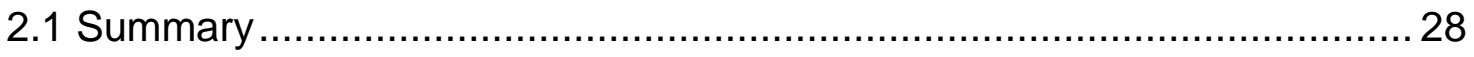

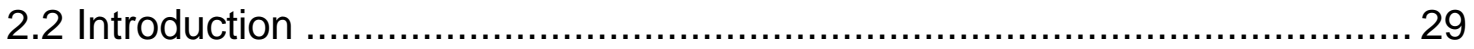

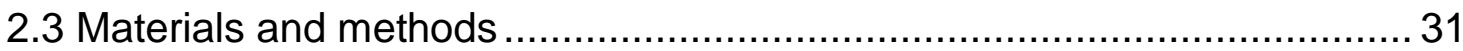

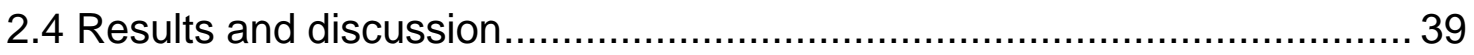

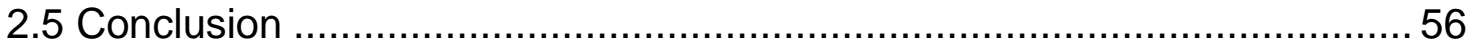

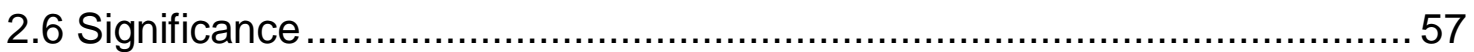

3. Probing the role of the oxidase, MarG and The dehydratase, MarA in the

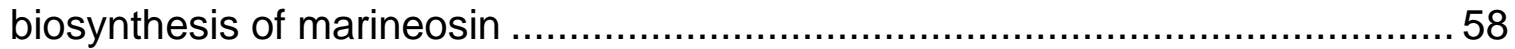

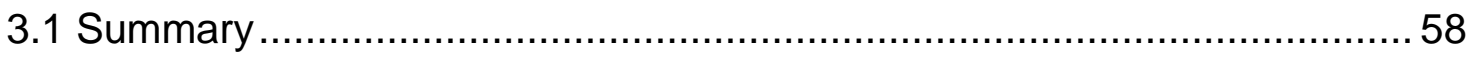

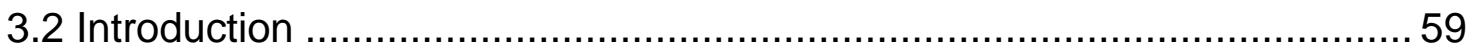

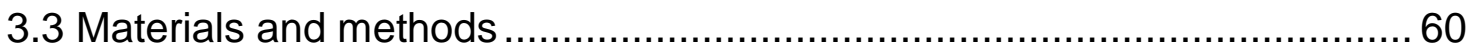

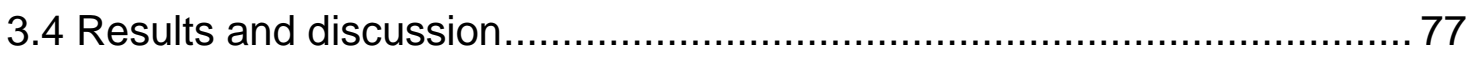


3.4.1 The role of MarG and MarA in the biosynthesis of marineosin.

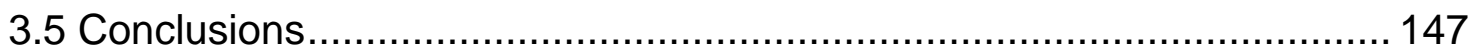

4. Conclusions and future work recommendations ...................................... 150

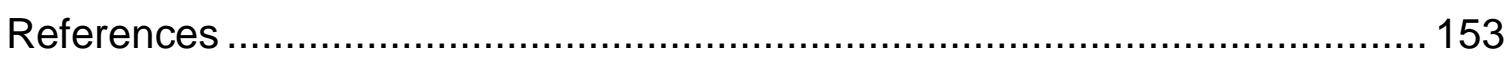




\section{LIST OF TABLES}

Table 1: A comparison between the genes of the putative mar cluster and its red

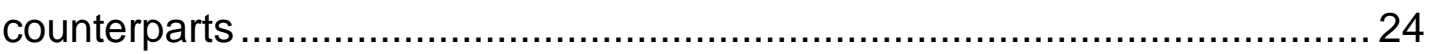

Table 2: HPLC gradient used for first purification of marineosin ......................... 38

Table 3: HPLC gradient used in second purification of marineosin ....................39

Table 4: Primers used for PCR amplification of aadA gene from plJ788 ............60

Table 5: Protocol used in PCR amplification of aadA gene ................................6 60

Table 6: Primers used for disruption of marG and marA genes........................ 61

Table 7: PCR protocol used in targeted disruption of marG and marA genes .... 61

Table 8: Primers used to verify marG and marA gene deletions ....................... 64

Table 9: HPLC conditions used in the LC/MS analysis of $S$. venezuelae JND2 $\Delta G$

Table 10: HPLC conditions used in the LC/MS analysis of S. venezuelae

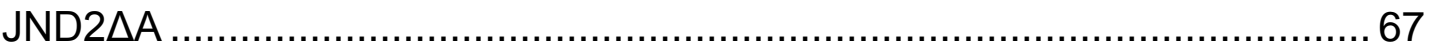

Table 11: HPLC conditions for first round of G410 purification .........................69

Table 12: HPLC method for final purification of G410 …............................. 71

Table 13: HPLC method used in the purification of JN422 and JN408 from S.

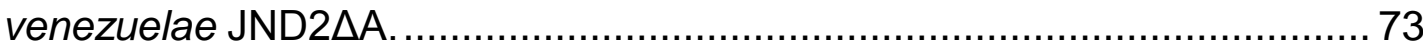

Table 14: NMR Spectral data for G410 (600 MHz, Acetone-d6) and side by side comparison of G410 and UP 103

Table 15: NMR Spectral data for JN408 and JN422 (600 MHz, Acetone-d6) ... 128 
Table 16: Selected COSY $(H \leftrightarrow H)$ and TOCSY $(H \leftrightarrow H)$ NMR correlations for JN408

Table 17: Selected COSY $(H \leftrightarrow H)$ and TOCSY $(H \leftrightarrow H)$ NMR correlations for

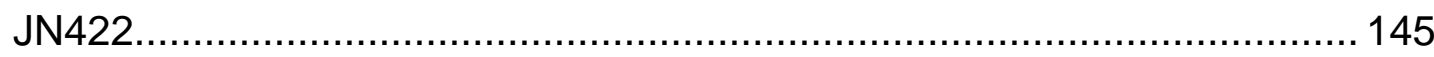

Table 18: NMR Spectral data for JN422 (600 MHz, Acetone-d6) and selected

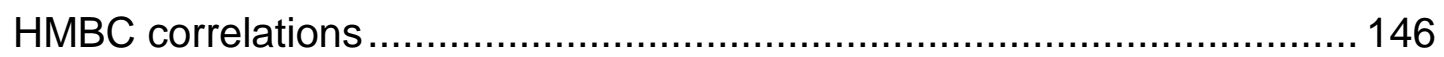




\section{LIST OF FIGURES}

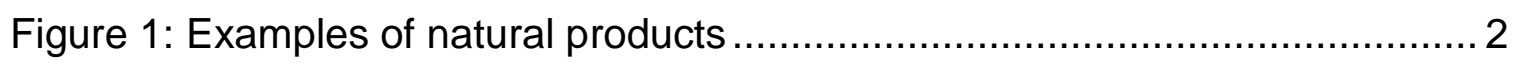

Figure 2: Life cycle of Streptomyces lividans................................................ 3

Figure 3: The modular PKS of pikromycin, an example of type I PKS ................. 5

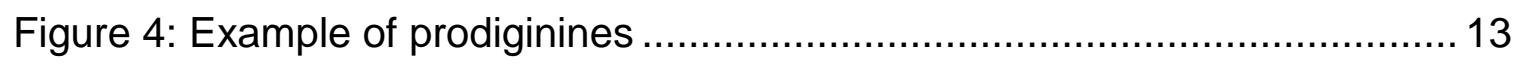

Figure 5: The bifurcated pathway leading to the biosynthesis of undecylprodiginine and streptorubin B in S. coelicolor A(3)2 .................... 14

Figure 6: The red gene cluster responsible for the biosynthesis of undecylprodiginine and streptorubin B in S. coelicolor A(3)2 .................... 15

Figure 7: Fenical's hypothesis for the biosynthesis of marineosin .................... 19

Figure 8: Snider's hypothesis for the biosynthesis of marineosin .....................21

Figure 9: A comparison between the red gene cluster and the putative mar cluster 23

Figure 10: Examples of spiroaminal compounds ........................................... 30

Figure 11: Recombination strategy employed to generate an integrative mar gene cluster 33

Figure 12: SPA agar plates showing change in phenotype of wild type $S$. venezuelae (left panel, grey) as a result of expression of the mar gene cluster to yield S. venezuelae JND2 (right panel, red).

Figure 13: A comparison between the total ion spectrum of wild type $S$. venezuelae (top panel) and S. venezuelae JND2 (bottom panel) 41 
Figure 14: A comparison between the MS/MS profile of marineosin standard (top panel) and the compound with $\mathrm{m} / \mathrm{z} 410.28$ in S. venezuelae JND2 extract

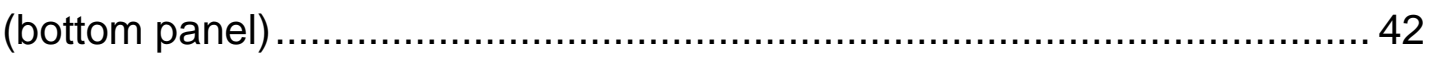

Figure 15: Fragment ions observed in the MS/MS profile of marineosin ........... 43

Figure 16: An LC/MS comparison between marineosin standard and JND2 extract 44

Figure 17: HPLC purification of marineosin from S. venezuelae JND2 47

Figure 18: ${ }^{1} \mathrm{H}-\mathrm{NMR}$ of marineosin from $\mathrm{S}$. venezuelae JND2. 47

Figure 19: Hypotheses explaining the biosynthetic origin of the spiroaminal oxygen of marineosin 50

Figure 20: The LC-UV/MS profile of $S$. venezuelae JND2. 52

Figure 21: Mechanism and comparison between the MS/MS profile of undecylprodiginine standard (top panel) and marineosin (bottom panel).... 55 Figure 22: Recombination strategy used to generate $S$. venezuelae JND2 $\Delta$ G (top panel) and S. venezuelae JND2 $\Delta$ A (bottom panel)................................... 63

Figure 23: First HPLC purification of G410 .............................................. 70

Figure 24: Preparative TLC for purification of G410 …................................. 70

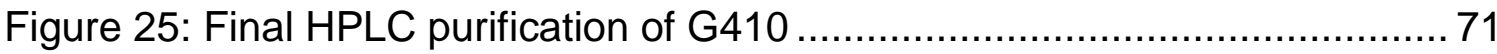

Figure 26: First HPLC purification of JN422 and JN408 from from S. venezuelae

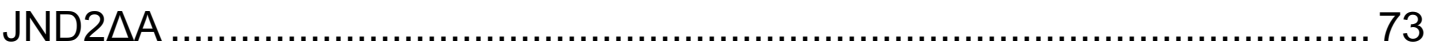

Figure 27: Second HPLC purification of JN422 (top panel) and JN408 (bottom

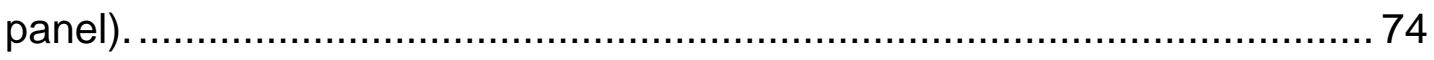


Figure 28: HPLC chromatogram of pure JN422 …........................................ 75

Figure 29: HPLC chromatogram of pure JN408 ……................................. 76

Figure 30: Sequence alignment of MarG and RedG with other Rieske-

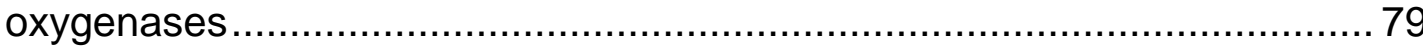

Figure 31: Structure of roseophilin and metacycloprodiginine: two cyclic

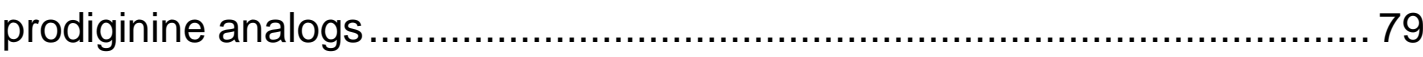

Figure 32: Confirmation of marG replacement, from pMAR cosmid, with aadA

gene conferring resistance to spectinomycin antibiotic ............................. 81

Figure 33: Comparison among the MS profiles of $S$. venezuelae JND2 $\Delta G$ (top

panel), JND2 strain (middle) and wild type S. venezuelae (bottom)............. 82

Figure 34: EIC of $m / z 410.28$ in $S$. venezuelae JND2 $\Delta$ G (top panel) and $S$.

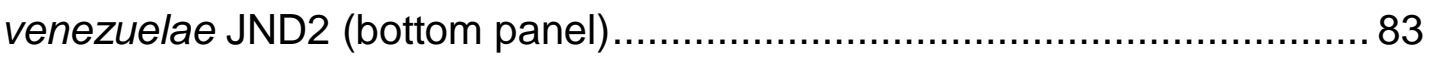

Figure 35: The LC-UV/MS profile of S. venezuelae JND2 $\Delta$ G......................... 84

Figure 36: Structure of 2-hydroxy-undecylprodiginine, G410 ......................... 85

Figure 37: HPLC chromatogram of 95\% pure G410 ................................... 86

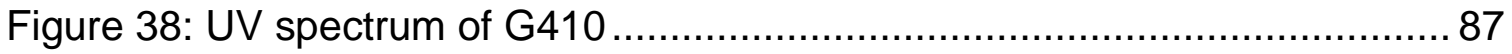

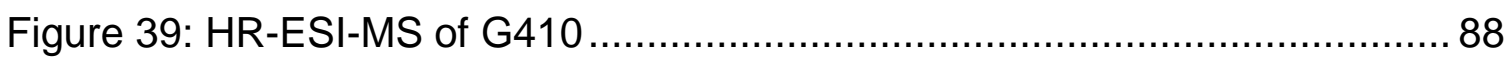

Figure 40: Comparison between the acquired (top panel) mass and isotope pattern of G410 and predicted mass and isotope pattern for predicted

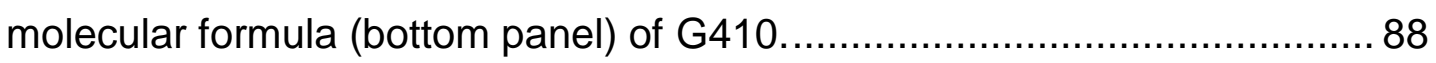

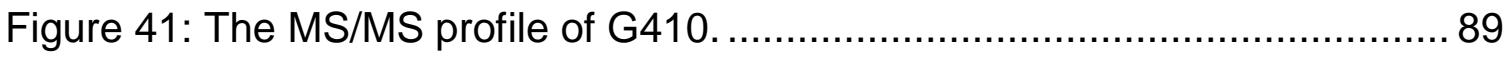

Figure 42: Fragment ions observed in the MS/MS profile of G410 ….............. 89 
Figure 43: IR spectrum of G410

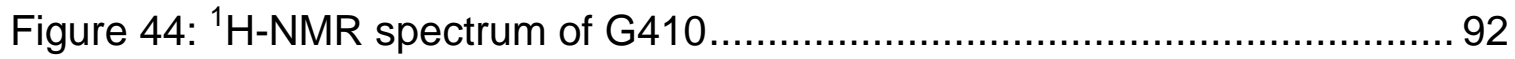

Figure 45: ${ }^{1} \mathrm{H}-\mathrm{NMR}$ spectrum of the $\mathrm{HCl}$ salt of undecylprodiginine standard .... 93

Figure 46: ${ }^{1} \mathrm{H}-{ }^{1} \mathrm{H} 2 \mathrm{D}$ TOCSY correlations among aromatic protons of G410 and

UP

Figure 47: ${ }^{1} \mathrm{H}-{ }^{1} \mathrm{H} 2 \mathrm{D}$ TOCSY NMR spectrum of G410 (top panel) and UP (bottom panel) - aromatic region expanded. 95

Figure 48: Comparison between the methyl protons at C-24 in undecylprodiginine (red, top) and G410 (blue, bottom) 97

Figure 49: ${ }^{1} \mathrm{H}-{ }^{1} \mathrm{H}$ 2D COSY NMR correlations between C-22, C-23, and C-24 .. 99

Figure 50: ${ }^{1} \mathrm{H}-{ }^{1} \mathrm{H}$ 2D TOCSY correlations among C-22, C-23 and C-24 .......... 100

Figure $51:{ }^{1} \mathrm{H}-{ }^{1} \mathrm{H} 2 \mathrm{D}$ TOCSY correlations of the aliphatic region of undecylprodiginine 101

Figure 52: Full ${ }^{1} \mathrm{H}-{ }^{1} \mathrm{H}$ 2D TOCSY correlations and spectrum of G410. The bold bonds indicate $16 \mathrm{H}$ integrated into one large peak at $1.3 \mathrm{ppm}$ 104

Figure 53: Full ${ }^{1} \mathrm{H}-{ }^{1} \mathrm{H}$ 2D TOCSY correlations and spectrum of undecylprodiginine. 105

Figure 54: Hypotheses explaining the biosynthesis of G410 107

Figure 55: Graphical summary of conserved domain hits obtained after NCBI CDD search 108

Figure 56: Confirmation of marA replacement, from pMAR cosmid, with aadA gene conferring resistance to spectinomycin antibiotic 109 
Figure 57: Comparison between the MS profiles of $S$. venezuelae JND2 $\Delta$ A (top panel), and JND2 strain (bottom panel). 110

Figure 58: LC-UV/MS analysis of $S$. venezuelae JND2 $\triangle \mathrm{A}$ 111

Figure 59: Structures of JN408 and JN422, produced by S. venezuelae JND2 $\Delta$ A 112

Figure 60: HPLC chromatogram of JN408 (top panel) and JN422 (bottom panel)

Figure 61: UV spectrum of JN408 (top panel) and JN422 (bottom panel) ........ 114

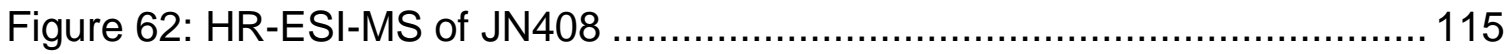

Figure 63: Comparison between the acquired mass and isotope pattern (top

panel) and the predicted mass (bottom panel) for JN408 ....................... 116

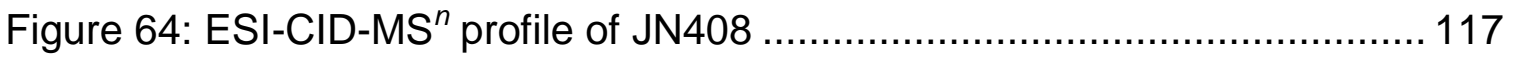

Figure 65: Fragment ions observed in the MS/MS profile of JN408 ............... 118

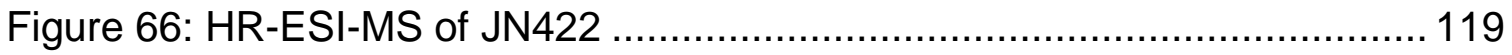

Figure 67: Comparison between the acquired mass and isotope pattern (top

panel) and the predicted mass (bottom panel) for JN422 ....................... 119

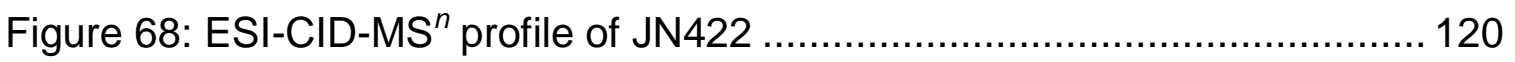

Figure 69: Fragment ions observed in the MS/MS profile of JN422 ............... 121

Figure 70: The IR spectrum of JN408 (top panel) and JN422 (bottom panel) .. 123

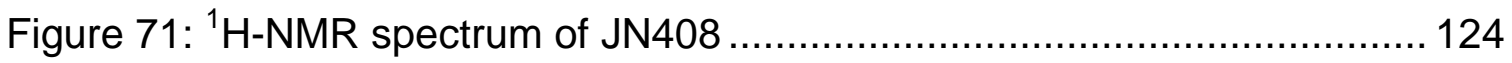

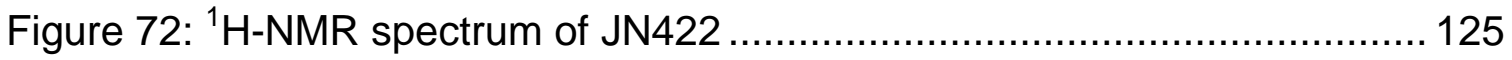

Figure 73: 2D HSQC spectrum of JN408 ……........................................ 126 
Figure 74: 2D HSQCED spectrum of JN408 (top panel) and JN422 (bottom panel)

Figure $75:{ }^{1} \mathrm{H}-{ }^{1} \mathrm{H} 2 \mathrm{D}$ TOCSY spectrum of $\mathrm{JN} 408$ 130

Figure 76: ${ }^{1} \mathrm{H}-{ }^{1} \mathrm{H} 2 \mathrm{D}$ TOCSY spectrum of JN422 showing correrlations between aromatic protons 131

Figure 77: 2D HSQCED spectrum of JN408 - aliphatic region expanded. 132

Figure 78: 2D HSQCED spectrum of JN422 - aliphatic region expanded 133

Figure 79: Selected ${ }^{1} \mathrm{H}-{ }^{1} \mathrm{H} 2 \mathrm{D}$ TOCSY correlations (top panel) and spectrum (bottom) of JN422 - aliphatic region expanded

Figure 80: Selected 2D HMBC $\left({ }^{1} \mathrm{H}^{13} \mathrm{C}\right)$ correlation (top panel) and spectrum (bottom panel) of JN422 - aliphatic region expanded. 135

Figure 81: Selected ${ }^{1} \mathrm{H}-{ }^{1} \mathrm{H} 2 \mathrm{D}$ TOCSY correlations (top panel) and spectrum (bottom) of JN408- aliphatic region expanded 136

Figure 82: ${ }^{1} \mathrm{H}-{ }^{1} \mathrm{H} 2 \mathrm{D}$ TOCSY spectrum of $\mathrm{JN} 422$ showing correlations between

C14 and C15 138

Figure 83: A) ${ }^{1} \mathrm{H}-{ }^{1} \mathrm{H}$ 2D COSY correlations of JN408. B) 2D COSY NMR spectrum of JN422 139

Figure 84: A) Selected COSY $(H \leftrightarrow H$; bold lines $)$ and TOCSY $(H \leftrightarrow H$; double arrows) NMR correlations for JN408. B) 2D TOCSY NMR spectrum of JN408. 140

Figure 85: A) 1H-1H 2D COSY correlations of JN422. B) 2D COSY NMR spectrum of JN422 142 
Figure 86: A) Selected COSY $(H \leftrightarrow H$; bold lines $)$ and TOCSY $(H \leftrightarrow H$; double arrows) NMR correlations for JN422. B) 2D TOCSY NMR spectrum of JN422

Figure 87: A) Selected HMBC (1H $\rightarrow 13 C)$ NMR correlations for JN422. B) 2D HMBC spectrum of JN422

Figure 88: Scheme for the biosynthesis of marineosin 149 


\section{LIST OF ABBREVIATIONS}

\begin{tabular}{|c|c|}
\hline ACP & Acyl carrier protein \\
\hline CID & Collision induced dissociation \\
\hline CoA & Coenzyme A \\
\hline COSY & Correlation spectroscopy \\
\hline DNA & Deoxyribonucleic acid \\
\hline ESI & Electrospray ionization \\
\hline HMBC & Heteronuclear multiple-bond correlation \\
\hline HPLC & High performance liquid chromtography \\
\hline HSQC & Heteronuclear single quantum coherence \\
\hline IR & Infra-red spectroscopy \\
\hline MS & Mass spectrometry \\
\hline NMR & Nuclear magnetic resonance spectroscopy \\
\hline O.D & Optical density \\
\hline PCR & polymerase chain reaction \\
\hline PKS & Polyketide synthases \\
\hline TOCSY & Total correlation spectroscopy \\
\hline UV & Ultraviolet \\
\hline
\end{tabular}




\section{INTRODUCTION}

\subsection{NATURAL PRODUCTS AND STREPTOMYCES}

Secondary metabolites or natural products are small organic molecules that are naturally produced by plants, fungi, algae, soft corals, sponges and bacteria. Although natural products do not play an explicit role in the vegetative growth of the producing organism, many scientists believe that secondary metabolites play a role in increasing the survivability and the adaptation of the producer organism in its complex environment by eliminating competing organisms [1], abstracting necessary metals from the environment [2], or mediating cell to cell contact [3]. Natural products possess a wide variety of clinical and pharmacological applications where they serve as antibiotics such as erythromycin A (1), antifungals such as amphotericin B (2), immunosuppressant such as rapamycin (3), hypolipidemics such as lovastatin (4) and anticancer drugs such as doxorubicin (5) compounds (Figure 1). Natural products account for about $47 \%$ of the drugs approved by the FDA for treatment of cancer [4] and natural products isolated from the genus; Streptomyces accounts for about two thirds of the world's antibiotics [5].

Streptomyces is a Gram-positive actinobacteria that can be found in terrestrial or marine environments and is characterized by high $\mathrm{G}+\mathrm{C}$ percent DNA as compared to other Gram-positive bacteria such as Bacillus and Streptococcus [6]. 


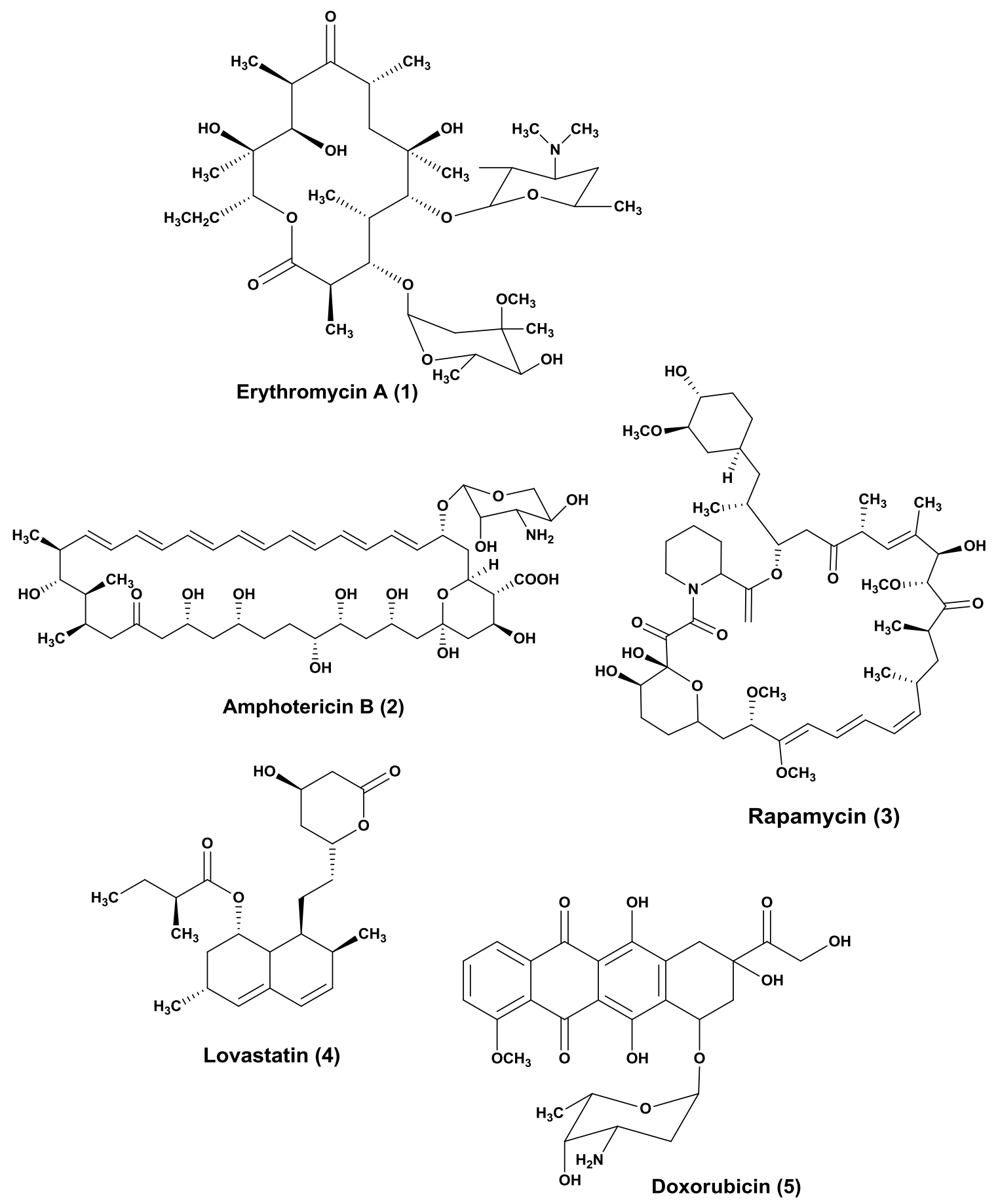

Figure 1: Examples of Natural Products 
Unlike other bacteria, Streptomyces colonies consist of differentiated cells and the life cycle [6] begins when a spore germinates one or more germ tubes that develop vegetative or substrate mycelia. Due to nutrition requirements, the vegetative mycelia branches out to form aerial mycelia that will be later compartmentalized via sporulation septa to form new spores [6].
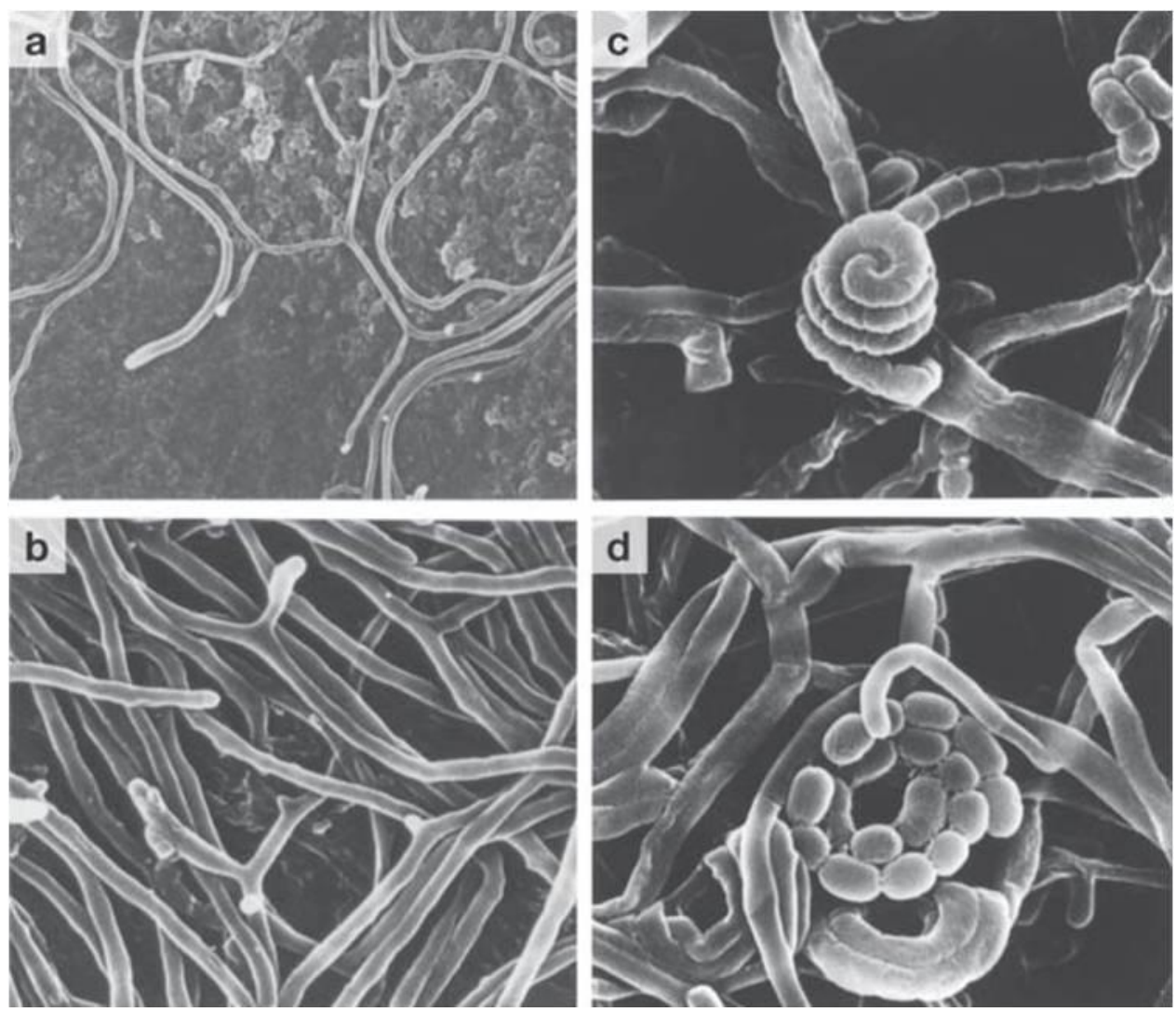

Figure 2: Life Cycle of Streptomyces lividans. Scanning electron micrographs showing a. vegetative mycelia, b. vegetative mycelia branching into aerial mycelia, c. sporulation septa is formed in the aerial hyphae, $d$. spore chains. The figure is adapted from reference 6 .

The importance of Actinomycetes to biomedical research and drug discovery comes from the ability of these bacteria to produce enormous numbers of 
structurally diverse antibiotics that by 2002 , it was estimated that 8700 antibiotics were isolated from terrestrial Streptomyces versus 7800 antibiotics from all other bacteria and fungi combined [7].

\subsection{BIOSYNTHESIS OF NATURAL PRODUCTS}

Natural products are biosynthesized via complex dedicated enzymatic machinery encoded by genes adjacent to each other in the organism's genome to form a biosynthetic gene cluster. The dedicated biosynthetic machinery utilizes common primary metabolites such as dicarboxylic acid thioesters, fatty acids, sugars and amino acids. The structural diversity and complexity of natural products is best manifested in two classes of natural products: polyketides and non-ribosomal peptides synthesized by polyketide synthases (PKS) and non-ribosomal peptide synthetases (NRPS), respectively. A type I PKS (Figure 3) is a megasynthase or a multifunctional multienzyme complex that catalyzes multiple head to tail decarboxylative condensations or Claisen condensation of dicarboxylic acid thioesters to form a polyketide in a manner analogous to fatty acid biosynthesis. There are four main domains (Figure 3 ) required for the biosynthesis of a polyketide: acyltransferase (AT), acyl carrier protein (ACP), ketide synthase (KS), and a thioesterase (TE) domain. The biosynthesis of a polyketide usually starts with the loading of a starter unit such as acetyl, propionyl, or butryl-CoA onto the $\mathrm{N}$-terminal ACP domain via the adjacent AT domain. The chain is then elongated by 2 carbons via a decarboxylative condensation between the tethered acyl-ACP 
and one dicarboxylic acid thioester extender unit molecule such as malonyl-CoA in a reaction catalyzed by the KS domain. After several cycles of elongation, the polyketide is released from the PKS megasynthase by the TE domain to yield either a linear or cyclic product (Figure 3).

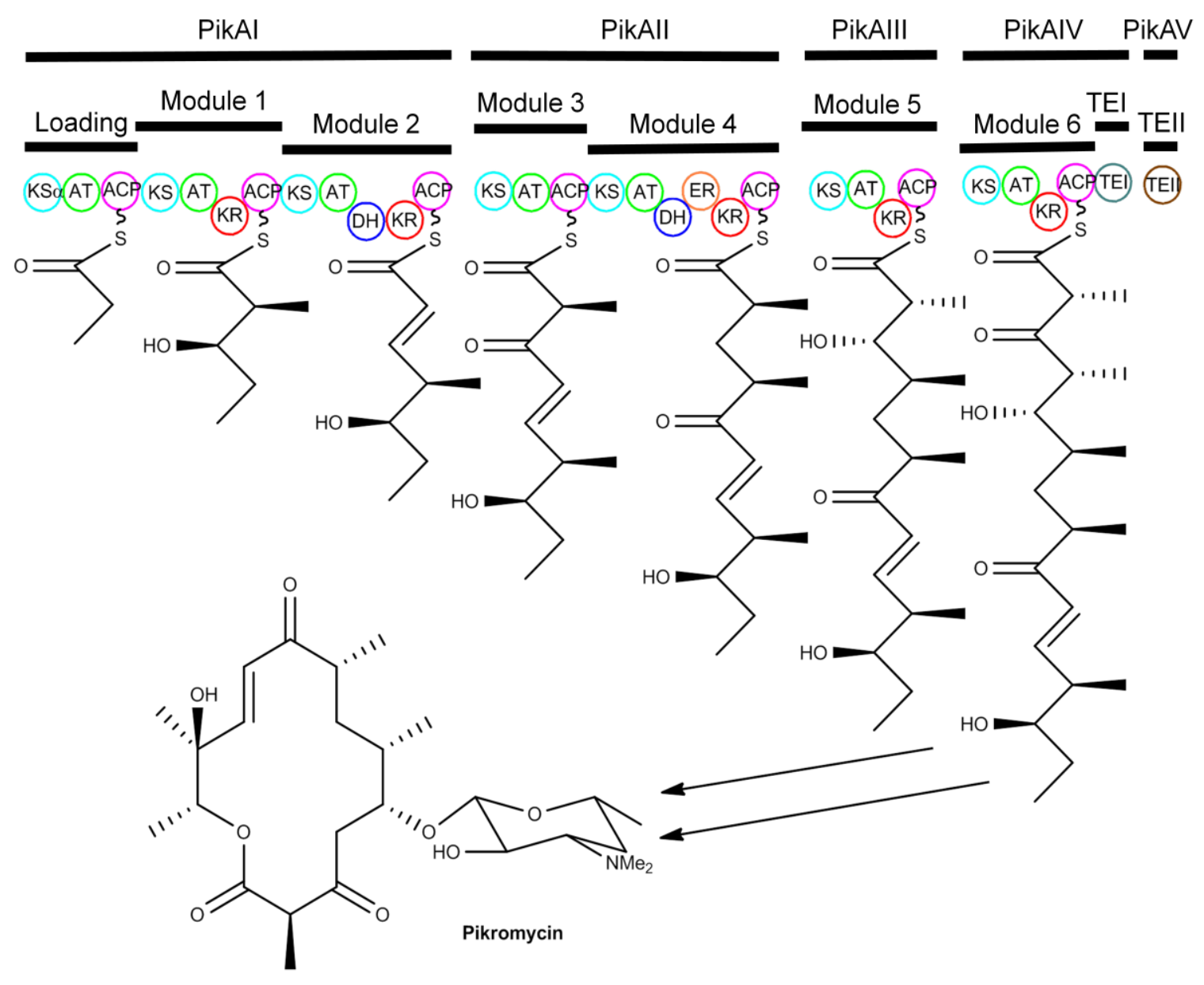

Figure 3: The Modular PKS of Pikromycin, an Example of Type I PKS

In type I PKS systems, an additional ketoreductase (KR) domain (module 1, Figure 3) can reduce a keto group into a hydroxyl group and then a dehydratase 
(DH) domain (module 2, Figure 3) can catalyze double bond formation via the elimination of water from the polyketide. An enoyl-reductase (ER) domain (module 4, Figure 3) can then fully reduce the growing polyketide [8], [9]. It should be noted that for the ACP domain to be functional, it has to be posttranslationally modified from the inactive apo form to the active holo form by a separate enzyme called phosphopantetheinyltransferase (PPTase). PPTase transfers a 4'-phosphopantetheine group from Coenzyme A (CoA) to a highly conserved serine residue in the ACP domain. The long and flexible phosphopantetheine arm provides a terminal sulfhydryl group that carries the growing polyketide chain via a thioster bond and transfers the tethered polyketide chain among the PKS domains. The biosynthetic gene clusters usually encode other enzymes that do not participate in the biosynthesis but rather play a regulatory role and/or confer resistance to the natural product in question to protect the producing organism [1], [10]. Examples of polyketides biosynthesized via type I PKS are: pikromycin (Figure 3), erythromycin (1) (Figure 1) antibiotics and the cholesterol lowering agent; lovastatin (4) (Figure 1).

\subsection{STUDY OF NATURAL PRODUCTS BIOSYNTHESIS}

The proven clinical and economic value of natural products has fueled the search for tools to aid in understanding their biosynthesis as well as enabling the biosynthetic engineering of analogs of better pharmacological activity, improved 
bioavailability or reduced toxicity. Some of the tools to study the biosynthesis of a natural product of microbial origin are outlined below:

i) Isotope tracer studies:

As mentioned in section 1.2, natural products are made of building blocks that can be provided through primary metabolism such as fatty acids and amino acids. Therefore, feeding the growing microorganism with stable isotope-labeled precursors can be used to identify the general biosynthetic origin of a natural product since the incorporation of the isotope-labeled precursor in the natural product skeleton results in unique coupling and labeling patterns [11]. Such incorporation patterns can suggest the involvement of a particular pathway in the biosynthesis of the secondary metabolite such as the shikimic acid pathway involved in the biosynthesis of hygromycin from Streptomyces hygroscopicus [12] and phoslactomycin from Streptomyces sp. strain HK803 [13]. Stable isotopelabeling can even lead to the discovery of new pathways such as the discovery of the non-mevalonate pathway involved in the biosynthesis of isoprenoids after feeding $\left[{ }^{13} \mathrm{C}_{1}\right]$-glucose isotopomers and $\left[{ }^{13} \mathrm{C}\right]$-acetate isotopomers to eubacteria producing the isoprenoids, hopanoids [14].

ii) The construction, characterization and screening of genomic libraries:

A genomic library for a microorganism can be generated from its total or genomic DNA (gDNA) using cosmid, fosmid, or BAC vectors depending on the insert size and whether heterologous expression of a particular gene cluster is required [15], 
[16]. The genomic libraries can then be screened for the gene cluster presumed to be responsible for the biosynthesis of a particular secondary metabolite using specific probes. The probes are usually short radio-labeled DNA sequences homologous to gene(s) specific to the cluster required and are amplified from the organism's gDNA using degenerate primers using PCR. For example; the use of the $c h c A$ gene probe for the screening of the genomic library of Streptomyces sp. strain HK803 to identify the gene cluster encoding the biosynthesis of phoslactomycin [13], [17]. More recent screening techniques include the use of non-radioactive probes, antibodies, and PCR methods [18].

iii) The heterologous expression of gene clusters:

Heterologous expression of a biosynthetic gene cluster seeks the production of the natural product in question in an organism other than the original producer by introducing the genes presumed to be involved in the biosynthesis to the new organism. When successful, heterologous expression provides unequivocal evidence of the responsibility of the gene cluster expressed in the biosynthesis of the natural product in question. It also indicates that all the genes required for the biosynthesis are present in the cluster as well as any regulatory and resistanceconferring genes. Choosing E. coli or Streptomyces species as heterologous hosts allow rapid genetic manipulations of the gene cluster via Red/ET-mediated recombination [19], [20], to further study the biosynthesis of the compound and facilitates engineering of other analogs. Heterologous expression can also 
facilitate the over-expression of pathway-specific regulatory genes and therefore enhance the production of the secondary metabolite in question [21], [22]. One of the techniques employed in the heterologous expression of a particular gene cluster in Streptomyces involves modifying the BAC or cosmid vector carrying the cluster by including phage $\Phi \mathrm{C} 31$ integration functions to allow for site-specific integration of the pathway in the Streptomyces genome [23]. The presence of oriT, an origin of transfer in the cosmid carrying the gene cluster facilitates DNA mobilization between E.coli and Streptomyces via conjugation [24] and the presence of an antibiotic resistance-conferring gene or an antibiotic resistance marker such as tet; which encodes resistance to tetracycline, would allow for selection of exconjugants actively expressing the gene cluster [25]. The use of $\underline{\boldsymbol{E}}$.

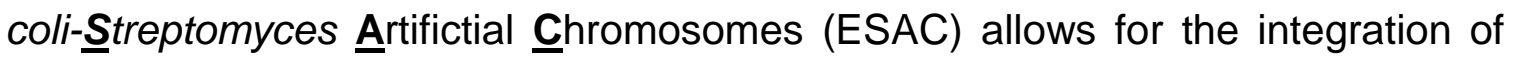
DNA fragments $>100 \mathrm{~kb}$ in Streptomyces [26], [27].

\section{iv) Gene deletion and/or replacement studies:}

The deletion or replacement of individual genes along a biosynthetic pathway can be used to probe the role of the deleted genes in the biosynthesis in vivo. In this process, a particular gene can be completely deleted or replaced with another gene that confers resistance to a certain antibiotic such as ampicillin via PCR-targeted recombination or Red/ET-mediated recombination [16], [19], [20]. Gene deletion or replacement generates a mutant inefficient or totally incapable of producing the natural product in question. Comparing the metabolite pool of 
the resultant mutant with the wild type organism pinpoints any intermediates, precursors or shunt metabolites accumulated due to the gene deletion and thus proposes a role for that gene in the biosynthesis of the natural product. Gene deletion experiments can be followed by complementation of the mutant strain with either the needed precursor or a precursor analog (chemical complementation); or with an expression plasmid carrying the deleted gene or another gene homolog (genetic complementation) to either rescue the production of the natural product itself or produce an engineered analog.

\section{v) Protein expression of individual genes:}

In order to assess substrate specificity in vitro and to provide a detailed kinetic analysis of individual enzymes participating in the biosynthesis of a certain natural product, their respective genes can be expressed in a heterologous host such as E.coli, followed by enzyme purification. A variety of high-level expression vectors are now available to allow gene expression under the influence of the bacteriophage T7 polymerase promoter [28]. The development of the HisTag technology allows the fusion of 6 histidine amino acid residues to either the $\mathrm{N}$ - or C-terminal end of the expressed protein which facilitates the purification of the recombinant protein by affinity chromatography using metal chelation resins [29]. After purification, the proteins can be used in a number of assays depending on the reactions they catalyze to monitor the substrate specificity as well as the rate by which they catalyze their reactions. The in vitro assays using the expressed 
enzymes provide greater and more valuable insight into the mechanistic role of the individual enzyme in the biosynthetic process as a whole.

\subsection{PRODIGININES FAMILY OF NATURAL PRODUCTS}

\subsubsection{History and Significance}

Prodiginines (also known as prodigiosins) are tripyrrole red-colored compounds (Figure 4) isolated from Serratia marcescens, Streptomyces coelicolor A3(2), Hahella chejuensis and many other terrestrial and marine microorganisms [30]. These compounds are thought to be responsible for a number of prodigious miracles linked to the appearance of blood on bread and other starchy foods in the middle ages [31]. Prodiginines can either be linear, like prodigiosin (6) (Figure 4) and undecylprodiginine (7) (Figure 4), or cyclic like streptorubin B (8) (Figure 4), metacycloprodigiosin (9) (Figure 4) and marineosins (10 and 11) (Figure 4). Prodiginines have excellent cytotoxic activity against a wide variety of cancer cell lines via inducing apoptosis [32], facilitating oxidative DNA cleavage by intercalating $\mathrm{Cu}$ (II) and DNA [33], and by other mechanisms. Due to their unique and selective mode of action as anticancer compounds, GX15-070 or obatoclax (12) (Figure 4); a synthetic prodiginine analog is in phase 1 and 2 clinical trials by Gemin-X pharmaceuticals [34]. Prodiginines also possess potent immunosuppressant activity via inhibition of $\mathrm{T}$ lymphocytes-mediated antibody response [35-37] which spurred the synthesis of many prodiginine analogs of which; PNU-156804 (13) (Figure 4) was found to be the most potent with unique 
immunosuppressant activity, minimal cytotoxicity and improved therapeutic index [36], [37]. Prodiginines also possess strong antibacterial and antimalarial activities [38]. 
(O)

Prodigiosin (6)<smiles>CCCCC1CCCCCCc2cc1c(/C=C1/N=C(c3ccc[nH]3)C=C1OC)[nH]2</smiles>

Streptorubin B (8)

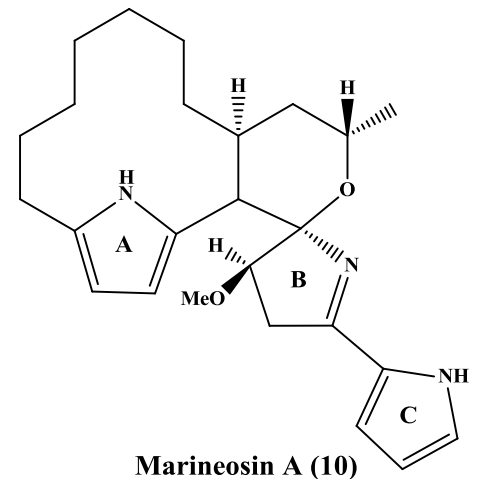

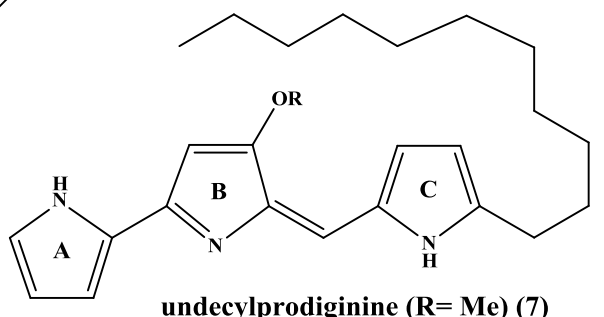

PNU-156804 (R= Benzyl) (13)<smiles></smiles>

Metacycloprodiginine (9)

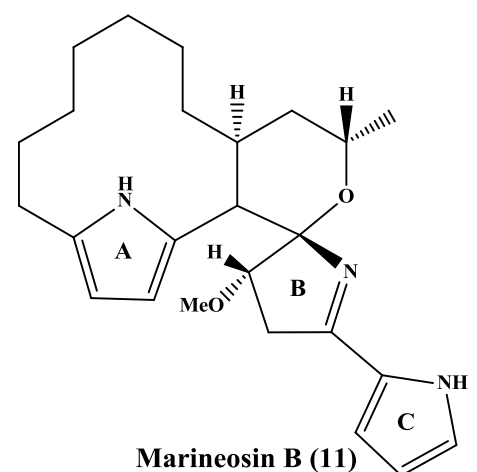

Marineosin B (11)<smiles>COC1=CC(c2cc3ccccc3[nH]2)=N/C1=C/c1[nH]c(C)cc1C</smiles>

GX-15-070 (Obatoclax) (12)

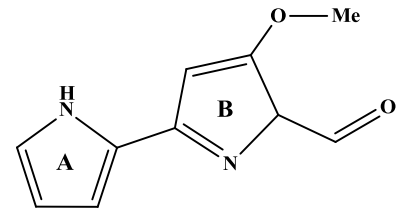

4-methoxy-[2-2'-bipyrrole]-5-carboxaldehyde subunit (14) (MBP subunit)

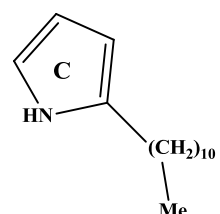

2-undecylpyrrole subunit (15) (2-UP subunit)

Figure 4: Example of Prodiginines 


\subsubsection{Biosynthesis:}

The biosynthesis of undecylprodiginine (7) (Figure 4), a linear prodiginine isolated from $S$. coelicolor $A 3(2)$, was initially probed using isotope labeling studies in the early 1970s. It has now been shown that undecylprodiginine (7) (Figure 4) is biosynthesized via a bifurcated pathway (Figure 5) that involves the condensation of 2 subunits; 2-undecylpyrrole (2-UP) (Figure 4, 10) and 4methoxy-[2, 2'-bipyrrole]-5-carboxaldehyde (MBP) (Figure 4, 9) subunits [39-42]. Feeding of stable isotope-labeled precursors showed that the 2-UP subunit (Figure 4,10 ) is derived from seven acetate molecules and one L-glycine while the MBP subunit (Figure 4,9) is derived from one molecule of acetate, one Lproline, one L-serine and a methyl group derived from L-methionine amino acid.

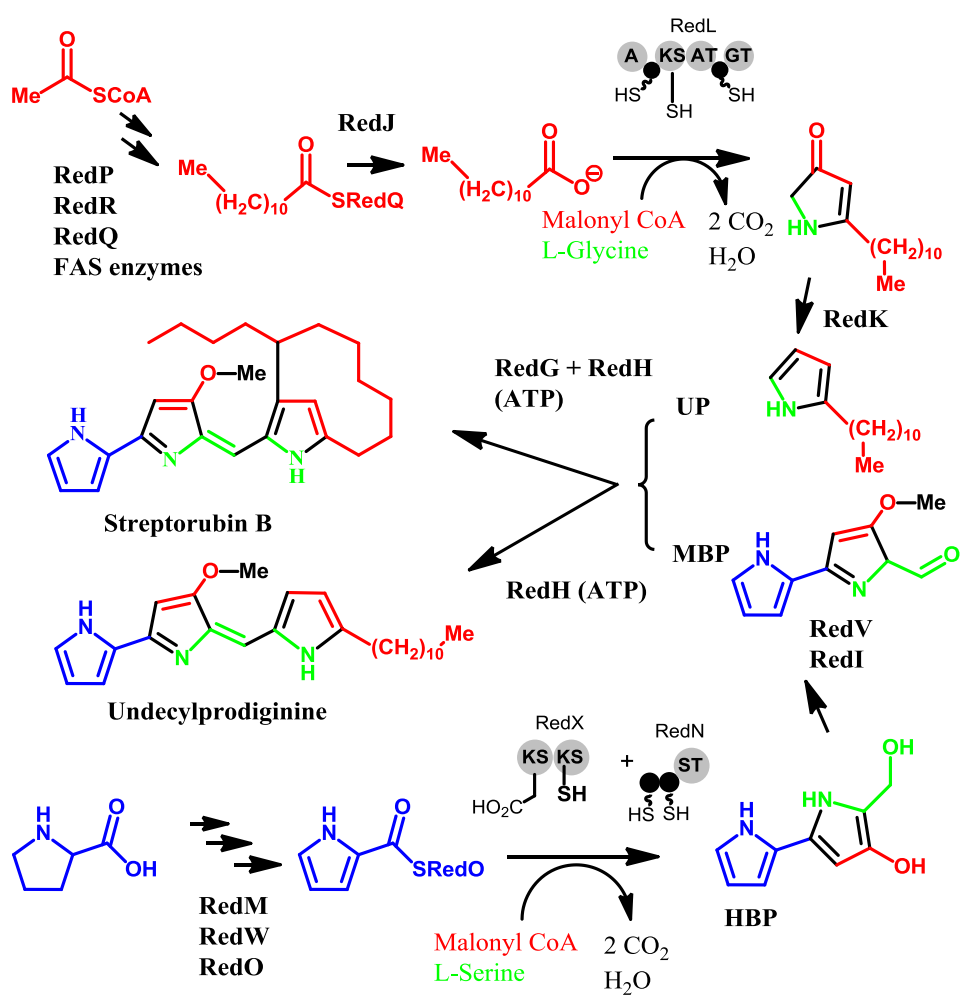

Figure 5: The bifurcated pathway leading to the biosynthesis of undecylprodiginine and streptorubin B in S. coelicolor A(3)2 
The gene cluster responsible for the biosynthesis of undecylprodiginine and streptorubin B (Figure 4, 2 and 3 respectively) in S. coelicolor A(3)2, known as the red cluster was cloned and expressed in the heterologous host Streptomyces parvulus in 1990 [43], [44]. The complete sequencing of the red cluster was achieved in 2002 as part of the genome sequencing project of $S$. coelicolor $\mathrm{A}(3) 2$ [45]. The red cluster (Figure 6) is arranged in four transcription units consisting of 23 genes two of which are regulatory; redD and redZ (Figure 6). Most of the genes involved in the biosynthesis of undecylprodiginine and streptorubin B were characterized via gene deletion and feeding experiments, as well as some enzymatic studies. The red genes were assigned as either involved in the biosynthesis of the MBP subunit (Figure 4, 9) or the 2-UP subunit (Figure 4, 10). The genes involved in the biosynthesis of the MBP subunit (9) were found to be redM, $O, W, X, N, \mathrm{~V}, \mathrm{U}$ and redl while the genes involved the 2-UP subunit (10) biosynthesis are redP, R, Q, J, L, J and redK. The condensation of the two subunits to form undecylprodiginine is catalyzed by redH, while the cyclization of undecylprodiginine into streptorubin B is catalyzed by redG [46-51].

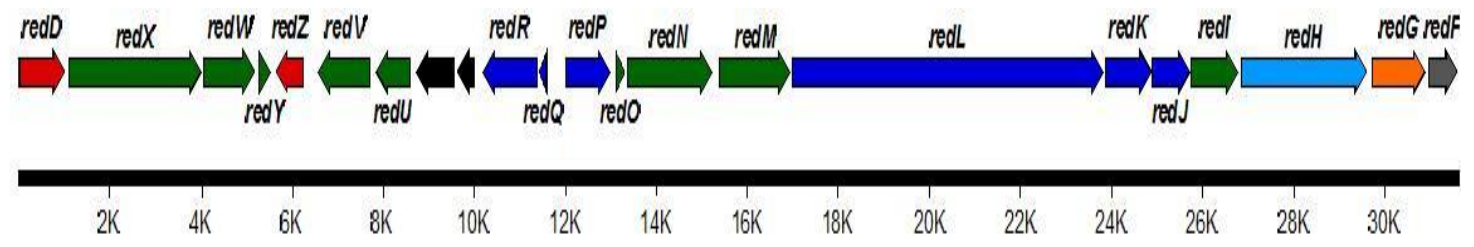

Figure 6: The red gene cluster responsible for the biosynthesis of undecylprodiginine and streptorubin B in S. coelicolor A(3)2. Red color is for regulatory proteins, green, genes involved in the biosynthesis of the MBP subunit, dark blue, genes involved in the biosynthesis of the 2-UP subunit, light blue, condensation of the MBP and 2-UP subunits, orange, genes involved in oxidative cyclization, grey, genes encoding membrane proteins, black, genes encoding hypothetical proteins. 
An outline of the biosynthesis is summarized below:

The biosynthesis of the MBP subunit (9): The biosynthesis of the MBP subunit (Figure 5) starts with the activation of L-proline amino acid as an adenylate intermediate by RedM which is then passed over to the PCP (peptidyl carrier protein); RedO. The tethered L-proline is then oxidized by RedW to form pyrrolyl2-carboxyl-S-RedO which is extended by 2 carbons via a decarboxylative condensation of malonyl-CoA with pyrrolyl-2-carboxyl-S-RedO catalyzed by RedX; a ketosynthase (KS) (Figure 5). The resultant pyrrolyl- $\beta$-ketothioester is condensed with L-serine amino acid residue with the release of $\mathrm{CO}_{2}$ in a reaction catalyzed by the PLP-dependent a-oxoamine synthase (OAS) domain of RedN to give 4-hydroxy-2,2'-bipyrrole-4-methanol (HBM). Methylation of HBM is catalyzed by Redl; an S-adenosylmethionine (SAM)-dependent methyl transferase. The post-translational phosphopantetheinylation of RedO and the two ACP domains of RedN (to convert them from the apo- inactive form to the holo- active form) is proposed to be catalyzed RedU [30], [48].

b. The biosynthesis of the 2-UP subunit (10): the biosynthesis of the dodecanoic acid moiety (Figure 5) of the 2-UP subunit (10) of prodiginines portrays a great level of interplay between fatty acid biosynthesis; a primary metabolic process and secondary metabolism. As mentioned above, the 2-UP subunit (10) consists of one L-glycine amino acid residue and seven acetate molecules arranged head to tail in a manner analogous to fatty acid biosynthesis catalyzed by type II fatty acid synthases (Fas/Fab enzymes). It is proposed that the biosynthesis of 2-UP 
(Figure 5) is initiated by RedP (a FabH homolog) which catalyzes the decarboxylative condensation of one molecule of acetyl-CoA with malonyl-RedQ (or malonyl-ACP) to yield 3-keto-butyryl-RedQ that will be fully reduced into butyryl-RedQ via the FAS enzymes, since homologs of such enzymes are completely absent from the red cluster. The resultant 3-keto-butyryl-RedQ is then elongated by six malonyl-CoA extender units in a reaction catalyzed by RedR ( $\mathrm{a}$ FabF homolog). In each round of elongation, it is proposed that the acyl chain is fully reduced by the aid of FAS enzymes to yield dodecanoyl-RedQ (Figure 5). RedJ (a type II thioesterase) has been shown to hydrolyze the acyl chain of RedQ to produce free dodecanoic acid which is the substrate for the multifunctional protein; RedL (Figure 5). RedL catalyzes one more round of acyl chain elongation with malonyl-CoA to yield 3-ketomyristoyl-ACP which is then condensed with L-glycine amino acid residue with the elimination of $\mathrm{CO}_{2}$ to produce 4-keto-2-undecylpyrroline. Finally, RedK reduces 4-keto-2undecylpyrroline into 4-hydroxyl-2-undecylpyrroline which spontaneously looses $\mathrm{H}_{2} \mathrm{O}$ to yield the 2-UP subunit (Figure 5).

The two subunits, MBP (14) and 2-UP (15), are then condensed to yield undecylprodiginine via RedH, which is proposed to do so by catalyzing an ATPdependent phosphorylation of the aldehyde oxygen of the MBP subunit (14), which facilitates a nucleophilic attack by C5 of 2-UP (15) to yield undecylprodiginine (7) [51]. The conversion of undecylprodiginine into the cyclic 
analog; streptorubin B (8) is mediated by RedG; a $\mathrm{Fe}_{2} \mathrm{~S}_{2}$ Rieske oxygenase-like enzyme [52].

\subsection{MARINEOSINS, NEW UNDECYLPRODIGININE ANALOGS}

\subsubsection{Structure and discovery}

Marineosins A and B (Figure 4) (10 and 11), are natural prodiginine analogs isolated from the marine Streptomyces related strain; CNQ-617. Marineosin A was found to have a potent cytotoxic activity against human colon cancer cell line, $\mathrm{HCT}-116$ with an $\mathrm{IC}_{50}$ of $0.5 \mu \mathrm{m}$. In the $\mathrm{NCl}-60$ anticancer drug screening, marineosin A had a broad anticancer activity with great selectivity against leukemia and melanoma [53]. Structurally, marineosins are very distinct from other prodiginines due to the presence of an unusual spiroaminal ring and a reduced pyrrole ring. The biosynthetic origin of these structural differences is not readily explained by the current understanding of the biosynthesis of prodiginines (Figure 5) and the enzymes involved have not yet been identified.

\subsubsection{Biosynthesis hypotheses}

The potent anticancer activity of marineosin and its intriguing structure spurred the proposal of a number of hypotheses to explain its biosynthesis. The first hypothesis (Figure 7) was proposed by Fenical and co-workers in 2008 where, they proposed that the MBP subunit normally biosynthesized in most prodiginines is condensed with a 2-UP subunit analog; 2-keto-undec-3enylpyrrole to yield an enone-derivative of undecylprodiginine. A hetero-Diels- 
Alder cyclization of the enone-undecylprodiginine intermediate would form the tetrahydropyran and spiroaminal ring concomitantly [53] (Figure 7).<smiles>CC(=O)/C=C/CCCCCCCc1ccc[nH]1</smiles>
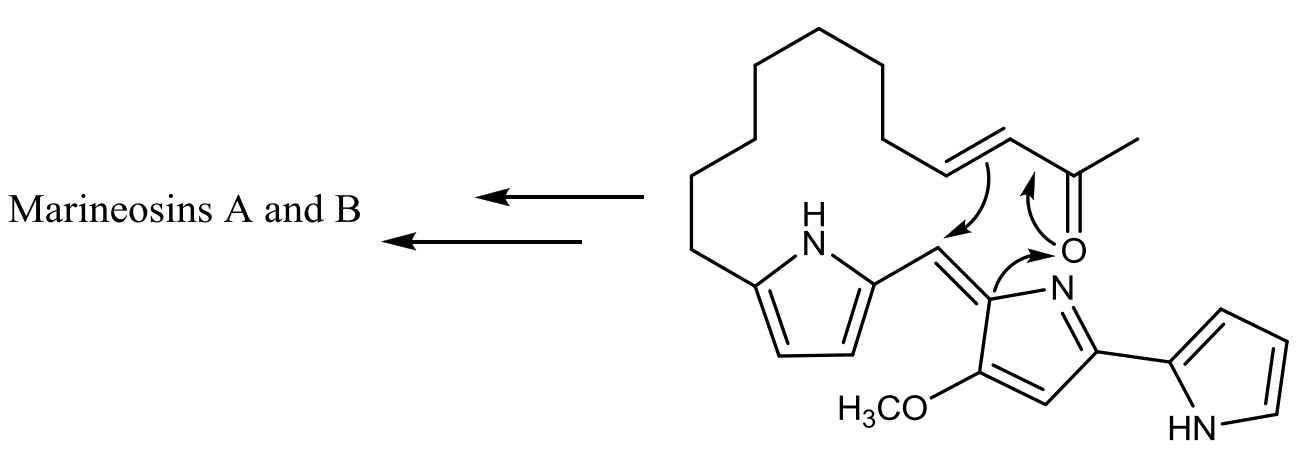

Figure 7: Fenical's Hypothesis for the Biosynthesis of Marineosin. Fenical and co-workers postulates the formation of enone-undecylprodiginine intermediate [53].

The above hypothesis was put to the test in the beginning of 2010 when Lindsay and co-workers tried to synthesize marineosin using Fenical's proposal [54]. Lindsay's group synthesized the enone-undecylprodiginine intermediate and attempted to produce marineosin through the hetero- Diels-Alder cyclization as proposed by Fenical and co-workers but they were not successful [54]. Molecular modeling studies by Lindsay and co-workers further revealed that the intramolecular Diel-Alder reaction is energetically unfavorable and cannot be 
accomplished synthetically, however, they did not rule out the possibility that such cyclization could be accomplished via enzymatic catalysis [54]. In late 2010, another hypothesis for the biosynthesis of marineosin was postulated by Snider and co-workers [55]. Snider's hypothesis involves the formation of a macrocyclic free radical (Figure 8 ) in a reaction catalyzed by a RedG-analog. The macrocyclic free radical will be hydroxylated by the same proposed RedG-analog to form a macrocyclic alcohol intermediate which undergoes a number of hydride shifts to yield marineosins A and B [55].

It should be noted that there is no experimental evidence supporting either of the hypotheses proposed by either Fenical's group or Snider's group. The enoneundecylprodiginine intermediate postulated by Fenical's group was never isolated and the enzymes required for its biosynthesis cannot be determined from our current understanding for the biosynthesis of prodiginines. Though appealing, Snider's group's hypothesis is not well supported by the current theories of action of RedG homologs in the cyclization of prodiginines [52]. Therefore, the identification of the gene cluster involved in the biosynthesis of marineosin is necessary to provide an experimentally supported proposal for the biosynthesis of marineosin. 

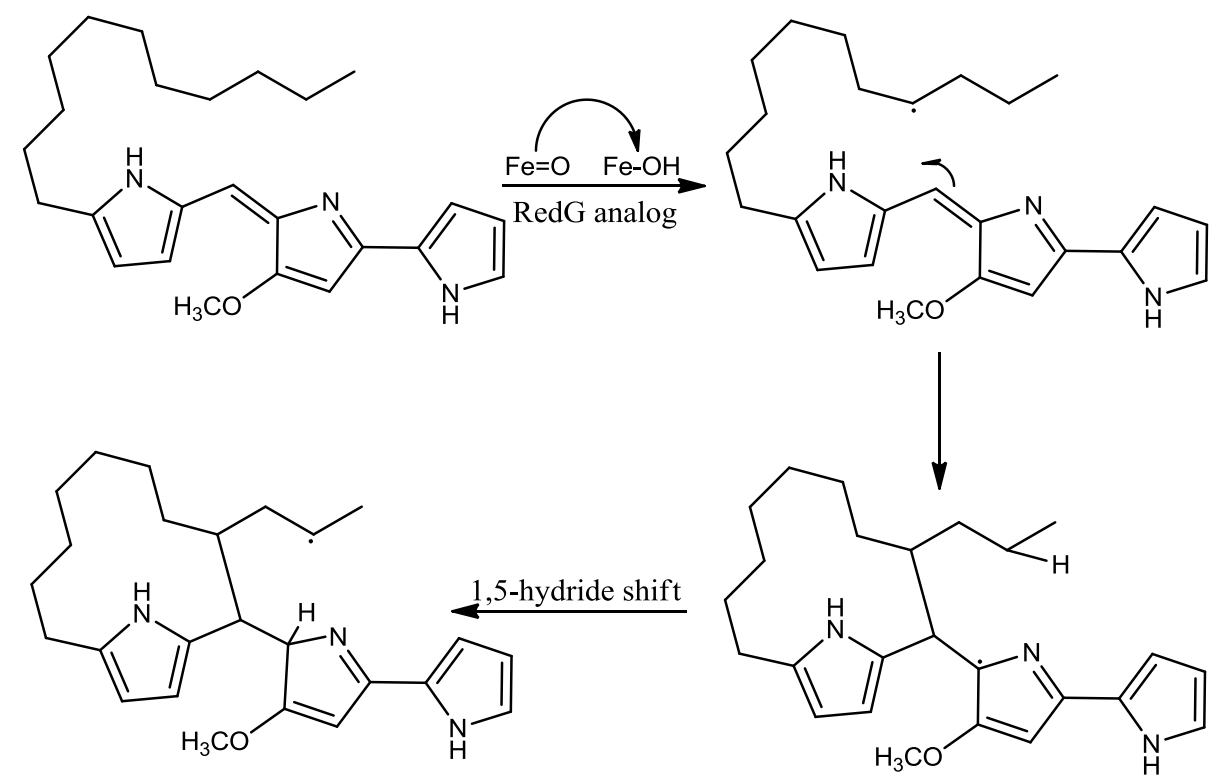<smiles>CC(=O)OCC(C)CC(C)C(F)(F)F</smiles><smiles>COC1=CC(c2ccc[nH]2)=NC1(C(C)C)C1CCCCCCCc2ccc([nH]2)C1C(CC(C)C)CC(C)O</smiles>

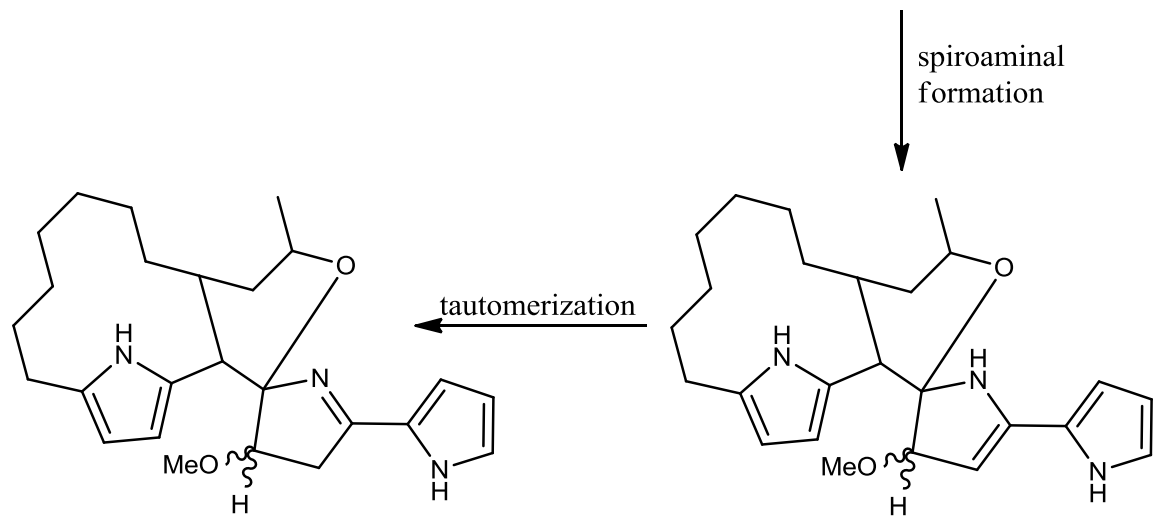

Figure 8: Snider's Hypothesis for the Biosynthesis of Marineosin. Snider and co-workers postulates the formation of a macrocyclic free radical that undergoes a number of hydride shifts mediated by a RedG homolog [55]. 


\subsubsection{The identification of a hypothetical gene cluster}

A SuperCos1 genomic library of Streptomyces CNQ-617 (marineosins-producing strain) was constructed in E.coli by Reynolds and co-workers (unpublished data). Screening of the genomic library for a red cluster homolog was performed using a ${ }^{32} \mathrm{P}$-labelled probe generated by PCR amplification of a redW homolog named marW using degenerate primers. RedW (Figure 5) starts the biosynthesis of prodiginines by catalyzing the oxidation of L-proline into pyrroline, a committed step in the biosynthesis of the MBP subunit (Figure 4) (14) of prodiginines [48]. A RedW homolog is proposed to be essential for the biosynthesis of marineosin. Cosmids positive for marW were further screened using a ${ }^{32} \mathrm{P}$-labelled probe generated by PCR amplification of a redG homolog named marG using degenerate primers. RedG (Figure 5) is a Rieske-oxygenase that culminates the biosynthesis of streptorubin B (Figure 4) (8), a cyclic prodiginine analog by catalyzing the cyclization of the acyl chain of undecylprodiginine (Figure 4) (7) [52]. A RedG homolog is also proposed to be essential for the biosynthesis of marineosin. The screening of the genomic cosmid library of Streptomyces CNQ617 using redW and redG homologs led to the identification of the cosmid $8 \mathrm{~A} 7$ that carries the entire gene cluster proposed to be involved in the biosynthesis of marineosin; a putative mar cluster together with about $6 \mathrm{kbp}$ of DNA, apparently encoding primary metabolic genes (unpublished data). Shotgun sequencing of the putative mar cluster revealed a gene assembly almost identical to that of the red cluster (Figure 9) with the presence of only one extra gene; marA. The MarA 
enzyme shares $\sim 56 \%$ identity to a monoamine oxidase C (Mao C) like dehydratase from Streptomyces hygroscopicus and was therefore annotated as a dehydratase.

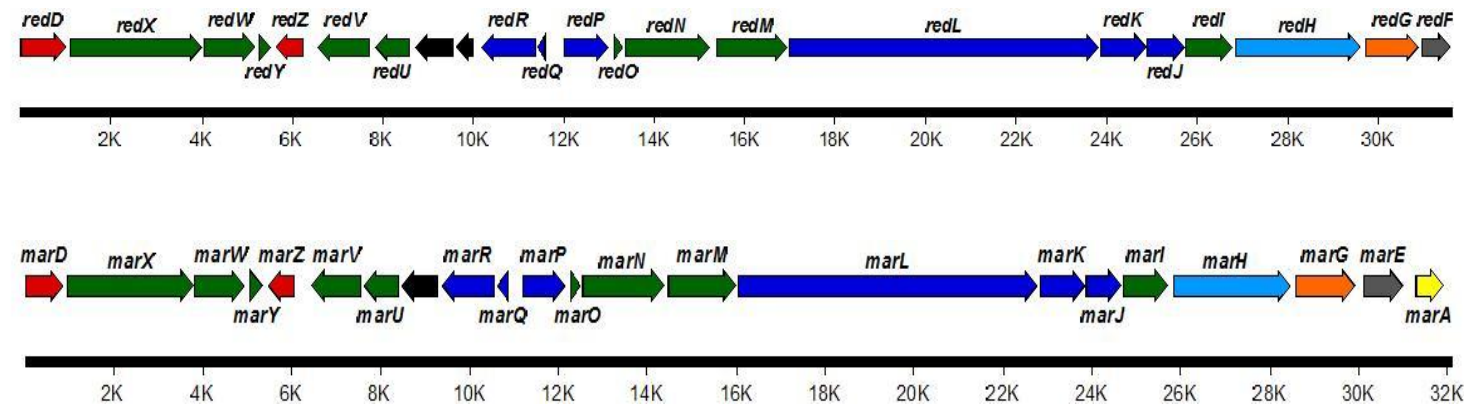

Figure 9: A comparison between the red gene cluster and the putative mar cluster. The mar cluster (bottom panel) compared to the red gene cluster (top panel). Red color is for regulatory proteins, green, involved in the biosynthesis of the MBP subunit, dark blue, involved in the biosynthesis of the 2-UP subunit, light blue, condensation of the MBP and 2-UP subunits, orange, oxidative cyclization, yellow, dehydratase, grey, membrane protein, black, hypothetical proteins.

The marA gene is proposed to be involved in the biosynthesis of the tetrahydropyran ring while another gene, marG is proposed to catalyze the reductive cyclization of the acyl chain of marineosin. MarG shares a $65 \%$ identity to its red cluster counterpart RedG. The striking degree of homology among the putative mar genes and their red genes counterparts (Table 1) together with the abundance of the red cluster in several terrestrial and marine organisms raises two major concerns. The first is whether or not the identified gene cluster is truly responsible for the biosynthesis of marineosin and not another prodiginine analog. The second is whether or not an extra tailoring enzyme is required for the biosynthesis of marineosin which is not included in the 8A7 cosmid. 
Table 1: A comparison between the genes of the putative mar cluster and its red counterparts:

\begin{tabular}{|c|c|}
\hline MarD & $\begin{array}{l}\text { RedD, a TetR family transcriptional regulator, Streptomyces griseus. Identities = } \\
150 / 264(56 \%), \text { Positives }=181 / 264(68 \%)\end{array}$ \\
\hline MarX & $\begin{array}{l}\text { RedX, Streptomyces coelicolor A3(2), a polyketide synthase. Identities = 79/987 } \\
(58 \%) \text {, Positives }=675 / 987(68 \%)\end{array}$ \\
\hline MarW & $\begin{array}{l}\text { RedW, Streptomyces coelicolor A3(2), an acyl-CoA dehydrogenase. Identities = } \\
304 / 388(78 \%) \text {, Positives = 332/388 }(85 \%)\end{array}$ \\
\hline MarY & $\begin{array}{l}\text { RedY, Streptomyces coelicolor A3(2), unknown function. Identities = 60/104 (57\%), } \\
\text { Positives }=73 / 104(70 \%)\end{array}$ \\
\hline MarZ & $\begin{array}{l}\text { RedZ, Streptomyces coelicolor A3(2), a response regulator. Identities = 111/206 } \\
(53 \%) \text {, Positives = 149/206 }(72 \%)\end{array}$ \\
\hline MarV & $\begin{array}{l}\text { RedV, Streptomyces coelicolor A3(2), unknown function. Identities = 192/350 (54\%), } \\
\text { Positives }=230 / 350(65 \%)\end{array}$ \\
\hline MarU & $\begin{array}{l}\text { RedU, Streptomyces coelicolor A3(2), hypothetical protein. Identities = 146/246 } \\
(59 \%), \text { Positives = 169/246 (68\%) }\end{array}$ \\
\hline MarT & $\begin{array}{l}\text { RedT, Streptomyces coelicolor A3(2), hypothetical protein. Identities = 181/278 } \\
(65 \%), \text { Positives }=211 / 278(75 \%)\end{array}$ \\
\hline MarR & $\begin{array}{l}\text { RedR, Streptomyces coelicolor A3(2), 3-oxoacyl-[acyl-carrier-protein] synthase II. } \\
\text { Identities }=181 / 278(65 \%) \text {, Positives }=211 / 278(75 \%)\end{array}$ \\
\hline
\end{tabular}




\begin{tabular}{|c|c|}
\hline MarQ & $\begin{array}{l}\text { RedQ, Streptomyces coelicolor A3(2), acyl carrier protein. Identities = 55/80 }(68 \%) \text {, } \\
\text { Positives }=62 / 80(77 \%)\end{array}$ \\
\hline MarP & $\begin{array}{l}\text { RedP, Streptomyces coelicolor A3(2), 3-oxoacyl-(acyl carrier protein) synthase III. } \\
\text { Identities }=212 / 286(74 \%), \text { Positives }=239 / 286(83 \%)\end{array}$ \\
\hline MarO & $\begin{array}{l}\text { RedO, Streptomyces coelicolor A3(2), putative peptidyl carrier protein. Identities = } \\
63 / 87(72 \%), \text { Positives }=71 / 87(81 \%)\end{array}$ \\
\hline MarN & $\begin{array}{l}\text { RedN, Streptomyces coelicolor A3(2), 8-amino-7-oxononanoate synthase. Identities = } \\
465 / 641(72 \%) \text {, Positives = 515/641 }(80 \%)\end{array}$ \\
\hline MarM & $\begin{array}{l}\text { RedM, Streptomyces coelicolor A3(2), peptide synthase. Identities = 368/529 } \\
(69 \%), \text { Positives }=408 / 529(77 \%)\end{array}$ \\
\hline MarL & $\begin{array}{l}\text { RedL, Streptomyces coelicolor A3(2), polyketide synthase. Identities = 1095/1822 } \\
(60 \%), \text { Positives }=1258 / 1822(69 \%)\end{array}$ \\
\hline MarK & $\begin{array}{l}\text { RedK, Streptomyces coelicolor A3(2), oxidoreductase. Identities = 243/346 }(70 \%) \text {, } \\
\text { Positives }=280 / 346(80 \%)\end{array}$ \\
\hline MarJ & $\begin{array}{l}\text { RedJ, Streptomyces coelicolor A3(2), thioesterase. Identities = 164/252 (65\%), } \\
\text { Positives }=180 / 252(71 \%)\end{array}$ \\
\hline Marl & $\begin{array}{l}\text { Redl, Streptomyces coelicolor A3(2), methyltransferase. Identities = 248/346 }(71 \%) \text {, } \\
\text { Positives }=291 / 346(84 \%)\end{array}$ \\
\hline
\end{tabular}




\begin{tabular}{|c|l|}
\hline MarH & $\begin{array}{l}\text { RedH, Streptomyces coelicolor A3(2), phosphoenolpyruvate-utilizing enzyme. } \\
\text { Identities }=642 / 916(70 \%), \text { Positives = 736/916 (80\%) }\end{array}$ \\
\hline MarG & $\begin{array}{l}\text { RedG, Streptomyces coelicolor A3(2), oxidase. Identities = 218/334 (65\%), Positives } \\
=269 / 334(80 \%)\end{array}$ \\
\hline MarE & $\begin{array}{l}\text { RedE, Streptomyces coelicolor A3(2), a hypothetical protein. Identities = 221/284 } \\
(77 \%), \text { Positives }=248 / 284(87 \%)\end{array}$ \\
\hline MarA & $\begin{array}{l}\text { Monoamine oxidase C (MaoC) like dehydratase, Streptomyces hygroscopicus. } \\
\text { Identities = 85/151 (56\%), Positives = 111/151 (73\%) }\end{array}$ \\
\hline
\end{tabular}

\subsection{SPECIFIC AIMS OF CURRENT RESEARCH}

Up to date, the total chemical synthesis of marineosins is still incomplete [54], [55]. There is no experimental evidence supporting the biosynthetic hypotheses provided by either Fenical's or Lindsley's group and there is also no experimental evidence that the gene cluster identified by Reynolds and co-workers is indeed responsible for the biosynthesis of marineosin. The objective of the present research is to investigate the key steps leading to the biosynthesis of marineosin and to provide an experimentally supported proposal for its biosynthesis which paves the road for the directed biosynthesis of marineosin analogs. 
This objective will be achieved through the following specific aims:

1) Determination of the role played by the putative gene cluster identified by Reynolds and co-workers in the biosynthesis of marineosin or other prodiginine analogs via expression in a heterologous host.

2) Probing the role of marG, encoding a Rieske oxygenase in the biosynthesis of marineosin, via gene replacement experiments followed by characterization and structure elucidation of the accumulated intermediates/shunt metabolites accumulated using mass spectrometry and NMR.

3) Probing the role of marA, encoding a dehydratase potentially involved in the biosynthesis of marineosin, via gene replacement experiments followed by characterization and structure elucidation of the intermediates/shunt metabolites accumulated using mass spectrometry and NMR.

4) Provide a proposal for the biosynthesis of marineosin that is experimentally supported by the genetic replacement experiments and analysis of the metabolite pool of the mutants generated in aims 2 and 3 . 


\section{THE IDENTIFICATION OF THE GENE CLUSTER RESPONSIBLE FOR THE \\ BIOSYNTHESIS OF MARINEOSIN: THE MAR CLUSTER.}

\subsection{SUMMARY}

The screening of a SuperCos1 genomic library of Streptomyces CNQ-617 - the marineosin producer, led to the identification of a cosmid clone that carries a gene cluster that may direct the biosynthesis of marineosin. Gene annotation of the putative mar cluster revealed a gene assembly similar to that of the red cluster responsible for the biosynthesis of undecylprodiginine and streptorubin B in S. coelicolor A3(2) (Figure 9) (Reynolds KA and co-workers, unpublished work). Whether or not the identified gene cluster is indeed involved in the biosynthesis of marineosin and whether it contains all the genes required for the biosynthesis was never shown.

In this research, the SuperCos 1 cosmid; $8 \mathrm{~A} 7$ carrying the putative mar cluster was expressed in the heterologous host; Streptomyces venezuelae and the production of marineosin was confirmed via LC/UV, LC/UV-MS, Tandem mass spectrometry and ${ }^{1} \mathrm{H}-\mathrm{NMR}$. This study is the first direct evidence that the gene cluster identified by Reynolds KA and co-workers is the one responsible for the biosynthesis of marineosin and therefore, paves the road for a thorough evaluation of the biosynthesis of marineosin and the engineering of marineosin analogs via genetic and chemical complementation experiments. The newly engineered strain Streptomyces venezuelae JND2 produces $\sim 2 \mathrm{mg} / \mathrm{L}$ of marineosin. The engineered strain also produces a number of marineosin 
analogs named JN408, JN422 and JN424 characterized with $\lambda$ max $320 \mathrm{~nm}$ and have $[\mathrm{M}+\mathrm{H}]^{+}$of $\mathrm{m} / \mathrm{z} 408.28,422.26$, and 424.28 corresponding to molecular formulae of $\mathrm{C}_{25} \mathrm{H}_{34} \mathrm{O}_{2} \mathrm{~N}_{3}, \mathrm{C}_{25} \mathrm{H}_{32} \mathrm{O}_{3} \mathrm{~N}_{3}$, and $\mathrm{C}_{25} \mathrm{H}_{34} \mathrm{O}_{3} \mathrm{~N}_{3}$, respectively. These compounds can be either pathway intermediates or shunt metabolites formed due to accumulation of intermediates along the pathway.

In addition, other red-colored compounds with a $\lambda$ max of $530 \mathrm{~nm}$, were also observed in the engineered strain. No tri-oxygenated red-colored compounds were observed in S. venezuelae JND2 which suggests that additional oxidation steps can occur later in the biosynthetic pathway, after loss of tripyrrole conjugation. All observed compounds were absent from the control $S$. venezueale acetone extract.

Based on the results of our studies, we propose four hypotheses that can explain the biosynthetic origin of the spiroaminal moiety of marineosin.

\subsection{INTRODUCTION}

As described in section 1.5, marineosins $A$ and $B$ are two prodiginine analogs isolated from a true marine Streptomyces with a strong and selective cytotoxic activity against colon cancer and leukemia [53]. Marineosins are characterized by the presence of an intriguing spiroaminal ring and a reduced pyrrole ring that cannot be explained based on the bifurcated pathway established for the biosynthesis of other prodiginines (Figure 5). Spiroaminal ring containing natural 
products are characterized by numerous biological activities such as the immunosuppressant sanglifehrin (Figure 10), (16) [56] the antiviral crambescidin<smiles>CC[C@H]1CC(C)[C@@]2(NC1=O)O[C@H](CC(C)(C)C)[C@@H](C)C=C2C</smiles>

Sanglifehrin B (16)

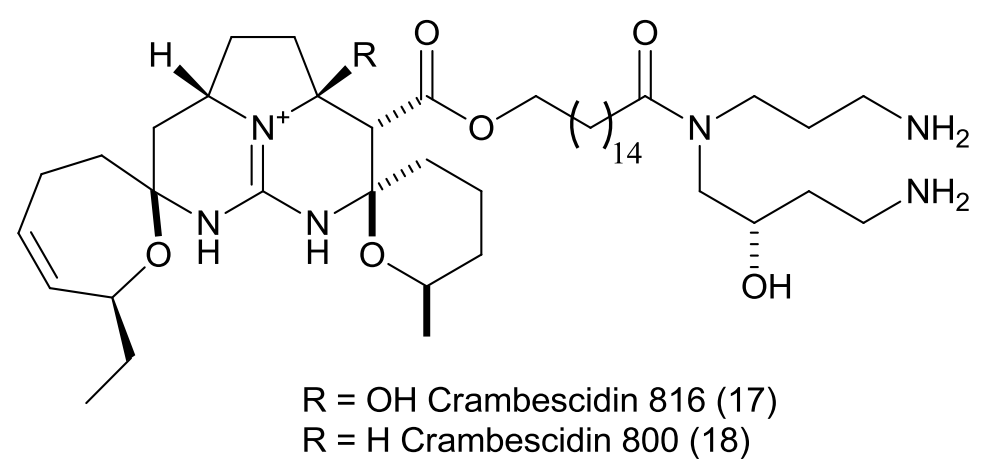<smiles>O=C1NC(=O)[C@]2(N1)O[C@H](CO)[C@@H](O)[C@H]2O</smiles>

Hydantocidin (19)

Figure 10: Examples of spiroaminal compounds

alkaloids (Figure 10) (17 and 18) with activity against herpes simplex virus type1 (HSV-1) and human immunodeficiency virus (HIV) [57], [58] in addition to the herbicidal hydantocidin (Figure 10) (19) [59]. Although the total synthesis of spiroaminals was reported several times [55], [57], [59], [60], [61], [62], the biosynthesis of this important class of natural products has been generally neglected. The intriguing structure of marineosin spurred the proposal of numerous hypotheses discussing its biosynthesis but no experimental data was ever provided. A putative gene cluster similar to that of the red cluster 
responsible for the biosynthesis of undecylprodiginine and streptorubin B was identified by Reynolds and co-workers after construction of a SuperCos 1 genomic library of Streptomyces CNQ-617 however; its role in the biosynthesis of marineosin was not established experimentally.

\subsection{MATERIALS AND METHODS}

\subsubsection{Antibiotics, enzymes and chemicals}

All antibiotics, chemicals and HPLC-grade solvents were purchased from SigmaAldrich (St. Louis, MO) unless otherwise stated. Primers for PCR were purchased from Integrated DNA Technologies (Coralville, IA). Marineosin standard was kindly provided by Dr. William Fenical (Scripps Institute of Oceanography, San Diego, CA). Phusion high-fidelity DNA polymerase was purchased from New England Biolabs (Ipswich, MA). Platinum High Fidelity polymerase supermix was purchased from Invitrogen.

\subsubsection{Bacterial strains and culture conditions}

The E. coli strain harboring the $\lambda$-RED plasmid known as BW25113/plJ790 and the methylation deficient E. coli donor strain ET12567/pUZ8002 were provided by the John Innes Institute (Norwich, UK) and have been described previously in literature [19].

E. coli BW25113/plJ790 was grown at $30^{\circ} \mathrm{C}$ in Lysogeny Broth (LB) media [63] and super optimal broth (SOB) media [64], each containing $25 \mu \mathrm{g} / \mathrm{ml}$ of 
chloramphenicol while E. coli ET12567/pUZ8002 was grown at $37^{\circ} \mathrm{C}$ in LB media containing $25 \mu \mathrm{g} / \mathrm{ml}$ kanamycin and $25 \mu \mathrm{g} / \mathrm{ml}$ chloramphenicol. Streptomyces venezuelae was propagated on sporulation agar (SPA) plates [65] at $30^{\circ} \mathrm{C}$ while SCM media was used for seed and large scale cultures.

\subsubsection{DNA manipulation and construction of pMAR cosmid}

The pSET1520 plasmid and 8A7 cosmid DNA were isolated from E. coli cells using QIAprep Spin Miniprep kit (Qiagen, Valencia, CA). DNA sequencing was performed at the MMI core facility and at The Primate Center, Oregon Health and Sciences University (Portland, OR). Primer design and analysis of DNA sequences was performed using MacVector (MacVector Inc., Cary, NC) and Accelrys DS gene (Accelrys Inc., San Diego, CA) software.

In order to allow the integration of the $8 \mathrm{~A} 7$ cosmid carrying the putative mar cluster into the genome of Streptomyces, the 8A7 cosmid was first transformed into E. coli BW25113/pIJ790 (recombination strain) via electroporation according to standard protocol [19]. Then, the bla gene encoding resistance to ampicillin antibiotic in the $8 A 7$ cosmid was replaced with three genes using PCR targeted recombination (Figure 11): oriT which is an origin of transfer, $\Phi C 31$ integrase gene which allows for integration of the cosmid at the attB site in Streptomyces genome, and aac(3)IV gene which allows for selection of exconjugants expressing the mar cluster by conferring resistance to apramycin antibiotic (Figure 11). 


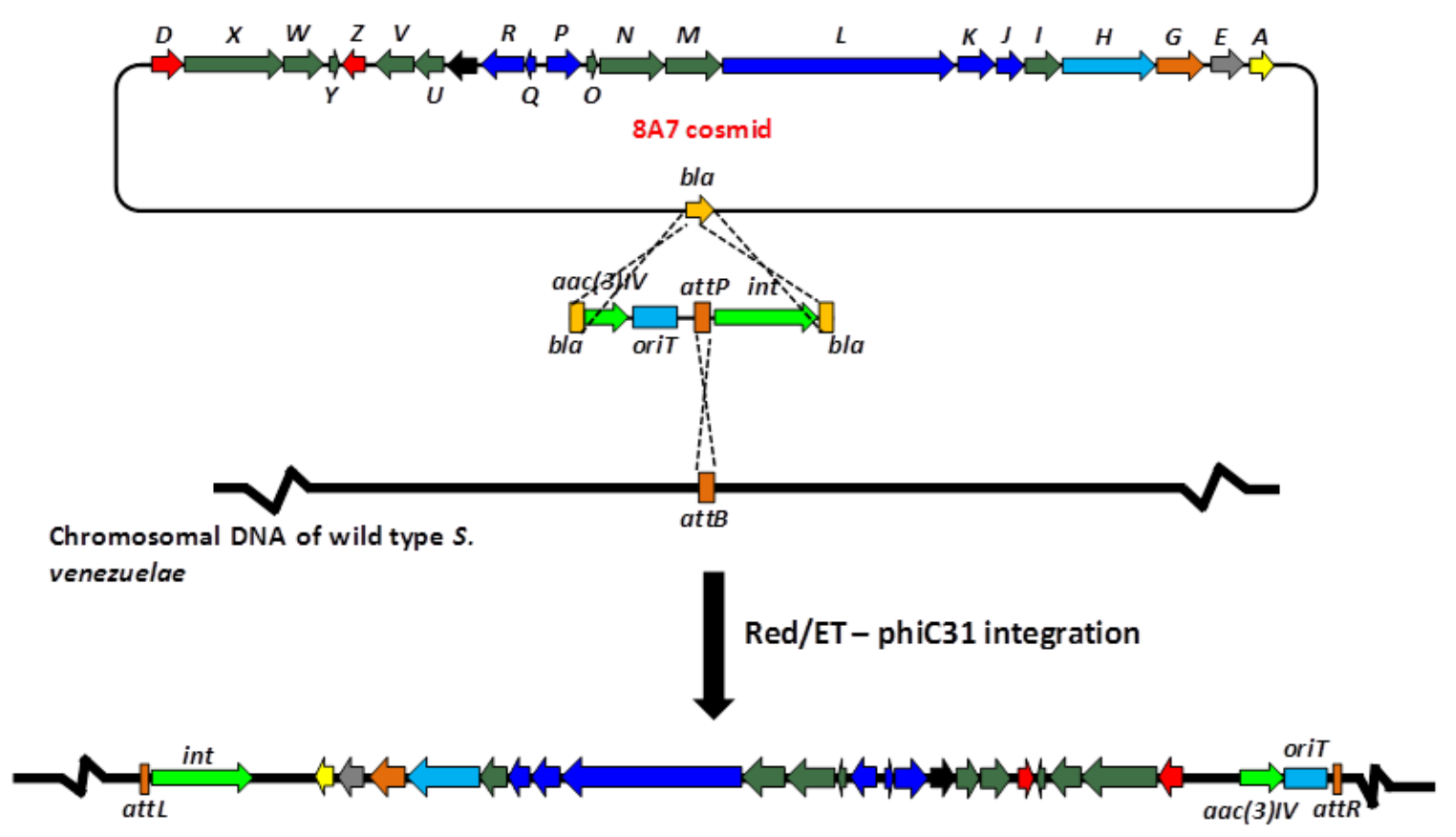

Chromosomal DNA of JND2 (mutant S. venezuelae)

Figure 11: Recombination strategy employed to generate an integrative mar gene cluster. pSET 1520 plasmid was used as a template for PCR amplification of oriT, phiC31 integrase and aac(3)IV. The PCR product was used to replace the bla gene in cosmid 8A7 via PCR targeted recombination followed by site-specific integration of the modified $8 \mathrm{~A} 7$ cosmid into $S$. venezuelae. bla $=\beta$-lactamase; aac $(3) \mathrm{IV}=$ apramycin resistance gene; oriT = origin of transfer; $\operatorname{attP} /$ aat $B=$ phiC31 attachment site of phage/bacteria; int = phiC31 integrase.

The three genes aac(3)IV, oriT, and $\Phi C 31$ int were amplified from pSET1520 plasmid template using 5'- TGA TAA ATG CTT CAA TAA TAT TGA AAA AGG AAG AGT ATG GTG CAA TAC GAA TGG CGA AA -3' as the forward primer and 5'- AAT CTA AAG tAT ATA TGA GTA AAC TTG GTC TGA CAG TTA CTA CGC CGC TAC GTC TTC C -3' as the reverse primer with the bases in bold italic homologous to the bla gene of SuperCos1. Amplification of the three-gene 3966 bp long PCR product, was achieved using GeneAmp PCR system 2700 (Applied Biosystems) according to the following protocol: initial denaturation at $98^{\circ} \mathrm{C}$ for 30 seconds followed by 30 cycles of amplification (denaturation at $98^{\circ} \mathrm{C}$ for 10 
seconds, and annealing at $72^{\circ} \mathrm{C}$ for 1 minute) followed by a final extension step for 10 minutes at $72^{\circ} \mathrm{C}$. The PCR product was purified using QIAquick PCR Purification kit (Qiagen, Valencia, CA) and the PCR was eluted using $10 \mu \mathrm{l}$ of EB buffer. A poly-A tail was added to the purified blunt-ended PCR product by incubating it with Platinum PCR High Fidelity Supermix (Invitrogen) at $72^{\circ} \mathrm{C}$ for 10 minutes. The PCR product was cloned into pCR8/GW/TOPO vector (Invitrogen) to generate TOPO-pS1 that was transformed into Mach1 E. coli (Invitrogen). After confirmation of the TOPO-pS1 plasmid DNA sequence, the plasmid was digested with EcoRI and loaded onto a 1\% agarose gel and subjected to gel electrophoresis. The fragment corresponding to $\sim 4 \mathrm{kbp}$ three-gene was excised from the gel and purified using QIAquick Gel Purification kit (Qiagen). The linear purified aac(3)IV, oriT, and $\Phi C 31$ int tri-gene was used in PCR targeted recombination of $8 \mathrm{~A} 7$ cosmid according to standard Red/ET recombination protocol [19] to generate the pMAR cosmid which has the ability to integrate at the attB site in the Streptomyces genome (Figure 11). The recombination of pMAR cosmid was confirmed by PCR amplification of aac(3)IV, oriT, and ФC31int tri-gene using the same primers used above. The pMAR cosmid was transformed into E. coli ET12537/pUZ8002 (donor strain) to generate ET/pMAR donor strain which is apramycin resistant and ampicillin sensitive and capable of conjugation with Streptomyces venezuelae (receiving strain). 


\subsubsection{Conjugation of E.coli ET/pMAR and S. venezuelae}

The conjugation between the E.coli ET/pMAR and S. venezuelae was done according to standard protocol with minor modifications [65]. S. venezuelae was propagated on SPA agar and incubated at $30^{\circ} \mathrm{C}$ for 7 days. Fresh spores were used to inoculate $25 \mathrm{ml}$ of SGGP media [66] and was allowed to grow for 3 days at $30^{\circ} \mathrm{C}$. On day $3,1 \mathrm{ml}$ of the SGGP culture was used to inoculate $9 \mathrm{ml}$ of TSB media and was incubated at $30^{\circ} \mathrm{C}$ for 18 hours. At the same time, E. coli ET/pMAR was streaked on LB-agar plates supplied with $50 \mu \mathrm{g} / \mathrm{ml}$ of apramycin and $25 \mu \mathrm{g} / \mathrm{ml}$ of chloramphenicol and was incubated at $37^{\circ} \mathrm{C}$ for 18 hours. The next day, $2 \mathrm{ml}$ of the overnight $S$. venezuelae TSB culture was used to inoculate $18 \mathrm{ml}$ of fresh TSB media and incubated at $30^{\circ} \mathrm{C}$ for 18 hours while a single colony from the E. coli ET/pMAR LB agar plate was used to inoculate $2 \mathrm{ml}$ of TSB media containing $50 \mu \mathrm{g} / \mathrm{ml}$ of apramycin and $25 \mu \mathrm{g} / \mathrm{ml}$ of chloramphenicol. The next day, $1 \mathrm{ml}$ of the overnight $S$. venezuelae TSB culture was used to inoculate $9 \mathrm{ml}$ of fresh TSB media and incubated at $30^{\circ} \mathrm{C}$ for 3 hours while $100 \mu \mathrm{l}$ of the overnight $E$. coli $\mathrm{ET} / \mathrm{pMAR}$ LB culture was used to inoculate $10 \mathrm{ml}$ of TSB media supplied with $50 \mu \mathrm{g} / \mathrm{ml}$ of apramycin and $25 \mu \mathrm{g} / \mathrm{ml}$ of chloramphenicol. $E$. coli $\mathrm{ET} / \mathrm{pMAR}$ was allowed to grow at $37^{\circ} \mathrm{C}$ until $\mathrm{O} . \mathrm{D}_{600} \sim 0.4$ was reached. Both E. coli $\mathrm{ET} / \mathrm{pMAR}$ and S. venezuelae cultures were centrifuged at $4^{\circ} \mathrm{C}$ and 5000 rpm for 5 minutes to recover the cells. The recovered cells were washed twice with fresh TSB media to remove any inhibiting antibiotics and cells were collected by centrifuge again. The cells of E. coli ET/pMAR (donor) and S. venezuelae 
(recipient) were finally suspended in $2 \mathrm{ml}$ of TSB and mixed together in 1:1, 1:9 and 9:1 donor: receiver ratios and $100 \mu \mathrm{l}$ of each mixture was spread onto predried AS1 media containing $10 \mathrm{mM} \mathrm{MgCl}$. After overnight incubation at $30^{\circ} \mathrm{C}$, each plate was overlaid with $1 \mathrm{ml}$ of LB media containing $500 \mu \mathrm{g} / \mathrm{ml}$ nalidixic acid, $500 \mu \mathrm{g} / \mathrm{ml}$ of apramycin and $500 \mu \mathrm{g} / \mathrm{ml}$ of kanamycin and plates were returned to incubation at $30^{\circ} \mathrm{C}$ for an additional 7-14 days [65]. Colonies were visible after approximately 3-5 days. The exconjugants expressing the mar cluster were characterized by a distinctive red color and were propagated on SPA plates supplied with $50 \mu \mathrm{g} / \mathrm{ml}$ apramycin. The new strain was named JND2.

\subsubsection{LC/MS and MS/MS analysis of JND2 crude extract}

To prepare extracts for MS analysis, fresh spores of $S$. venezuelae (wild type) and S. venezuelae JND2 strain was used to inoculate $10 \mathrm{ml}$ of SCM media. After 72 hrs, the cells were harvested and the cells' organic constituents were extracted with acetone. The organic content of the supernatant obtained after cell harvest was extracted by a solid-phase extraction method using Amberlite XAD-7 resin where the supernatant was stirred with the resin for 2 hours followed by filtration to collect the resin. The resin was washed with water and then the organic content of the resin was obtained by washing with acetone. The acetone extract was dried under vacuum and stored at $-20^{\circ} \mathrm{C}$ till further analysis. The dry extracts from wild type $S$. venezuelae and JND2 were dissolved in MS-grade methanol and were injected directly into the mass spectrometer. Direct MS and 
Tandem MS experiments were conducted using a ThermoElectron LTQ-Orbitrap high resolution mass spectrometer equipped with Accela HPLC system (ThermoFinnigan) (Mass Spectrometry Facility, Portland State University). Data was analyzed using Xcalibur software. For LC/MS analysis, the crude extract from JND2 strain was dissolved in methanol and $20 \mu \mathrm{l}$ of $0.5 \mathrm{mg} / \mathrm{ml}$ extract was injected into MicroToF-Q mass spectrometer (Bruker, Billerica, MA) equipped with an Agilent 1100 series HPLC (Agilent technologies, Santa Clara, CA) with MWD detector (Mass Spectrometry Facility, Portland State University) using 2.1 x $250 \mathrm{~mm}$, 5um, reverse phase Supelco ${ }^{18} \mathrm{C}$-column (Supelco, St. Louis, MO) and using a 50 min gradient from $5 \% \mathrm{ACN} / \mathrm{H}_{2} \mathrm{O}$ to $100 \% \mathrm{ACN}$ containing $0.05 \%$ formic acid at flow rate of $200 \mu \mathrm{l} / \mathrm{min}$.

\subsubsection{Purification and characterization of marineosin from S. venezuelae JND2}

Fresh spores of S. venezuelae JND2 were used to innoculate $10 \mathrm{ml}$ of SCM media containing $50 \mu \mathrm{g} / \mathrm{ml}$ of apramycin to generate a seed culture that was incubated at $30^{\circ} \mathrm{C}, 220 \mathrm{rpm}$ for 48 hours. $1 \%$ of the seed culture was used to inoculate larger scale fermentations that were grown for an additional 7 days at $30^{\circ} \mathrm{C}$, and $220 \mathrm{rpm}$.

The JND2 cells were harvested by centrifugation at $10000 \mathrm{rpm}, 6^{\circ} \mathrm{C}$ for 10 minutes. The harvested cells were disrupted by the addition of acetone followed by sonication for 5 minutes. After filtration using cotton wool, the acetone extract was dried under vacuum and stored at $-20^{\circ} \mathrm{C}$ till further analysis. The crude cell 
extract from JND2 strain was dissolved in methanol and purified using a Waters HPLC equipped with a DWD detector using $20.0 \times 250.0 \mathrm{~mm}, 10 \mu \mathrm{m}$, reverse phase Ascentis ${ }^{18} \mathrm{C}$-column (Supelco, St. Louis, MO) using buffer A: water/acetonitrile/methanol $(5: 1: 4)$ and buffer B: $100 \%$ methanol using the gradient specified in Table 2.

\begin{tabular}{|c|c|c|c|}
\hline Time $(\mathrm{min})$ & $\begin{array}{c}\text { Flow } \\
(\mathrm{ml} / \mathrm{min})\end{array}$ & $\% \mathrm{~A}$ & $\% \mathrm{~B}$ \\
\hline 0 & 10.0 & 90.0 & 10.0 \\
\hline 2.0 & 10.0 & 90.0 & 10.0 \\
\hline 40.0 & 10.0 & 0.0 & 100.0 \\
\hline 50.0 & 10.0 & 0.0 & 100.0 \\
\hline 51.0 & 10.0 & 90.0 & 10.0 \\
\hline 60.0 & 10.0 & 90.0 & 10.0 \\
\hline
\end{tabular}

Table 2: HPLC gradient for first purification of marineosin

The peak eluting at 45 minutes was collected, dried under vacuum and subjected to another round of purification using an Agilent HPLC equipped with a MWD detector using $4.6 \times 150.0 \mathrm{~mm}, 3.5 \mu \mathrm{m}$, reverse phase Zorbax SB- ${ }^{18} \mathrm{C}$-column (Agilent technologies, Santa Clara, CA) using buffer A: water acidified with 0.05 $\%$ formic acid and buffer B: acetonitrile acidified with $0.05 \%$ formic acid using the gradient specified in Table 3. The peak with retention time of 12 minutes was collected and dried under vacuum to yield pure marineosin. 


\begin{tabular}{|c|c|c|c|}
\hline Time $(\mathrm{min})$ & $\begin{array}{c}\text { Flow } \\
(\mathrm{ml} / \mathrm{min})\end{array}$ & $\% \mathrm{~A}$ & $\% \mathrm{~B}$ \\
\hline 0.0 & 1.0 & 75.0 & 25.0 \\
\hline 7.5 & 1.0 & 75.0 & 25.0 \\
\hline 8.0 & 1.0 & 50.0 & 50.0 \\
\hline 13.0 & 1.0 & 50.0 & 50.0 \\
\hline 13.5 & 1.0 & 25.0 & 75.0 \\
\hline 21.0 & 1.0 & 25.0 & 75.0 \\
\hline 21.5 & 1.0 & 0.0 & 100.0 \\
\hline 25.0 & 1.0 & 0.0 & 100.0 \\
\hline 25.5 & 1.0 & 75.0 & 25.0 \\
\hline 30.0 & 1.0 & 75.0 & 25.0 \\
\hline
\end{tabular}

\section{Table 3: HPLC gradient used in second purification of marineosin}

The dried marineosin was dissolved in acetone- $d_{6}$ for characterization by ${ }^{1} \mathrm{H}-$ NMR. ${ }^{1} \mathrm{H}-\mathrm{NMR}$ spectra was generated using a Bruker AMX-400 $\mathrm{MHz}$ spectrometer (Bruker Daltonics), calibrated using TMS as an internal standard.

\subsection{RESULTS AND DISCUSSION}

2.4.1 Identification of the gene cluster responsible for the biosynthesis of marineosin: The mar cluster

Heterologous expression of the putative mar gene cluster was pursued to verify the role of the presumed cluster in the biosynthesis of marineosin. The $8 \mathrm{~A} 7$ cosmid carrying the putative cluster was genetically engineered into the $p M A R$ cosmid which has the ability to integrate in the genome of $S$. venezuelae. Conjugation was used to deliver pMAR cosmid into $S$. venezuelae to generate the JND2 strain. Unlike the wild type S. venezuelae which is grey in color (Figure 
12), the JND2 strain is characterized by a distinctive red color. This change in phenotype indicates that the expression of the gene cluster in question leads to the accumulation of red-colored metabolites, although marineosin itself is not red [53]. The red-colored metabolites could be undecylprodiginine (7) (Figure 4) or other prodiginine analogs. S. venezuelae JND2 is also apramycin resistant unlike the wild type, which is apramycin sensitive.

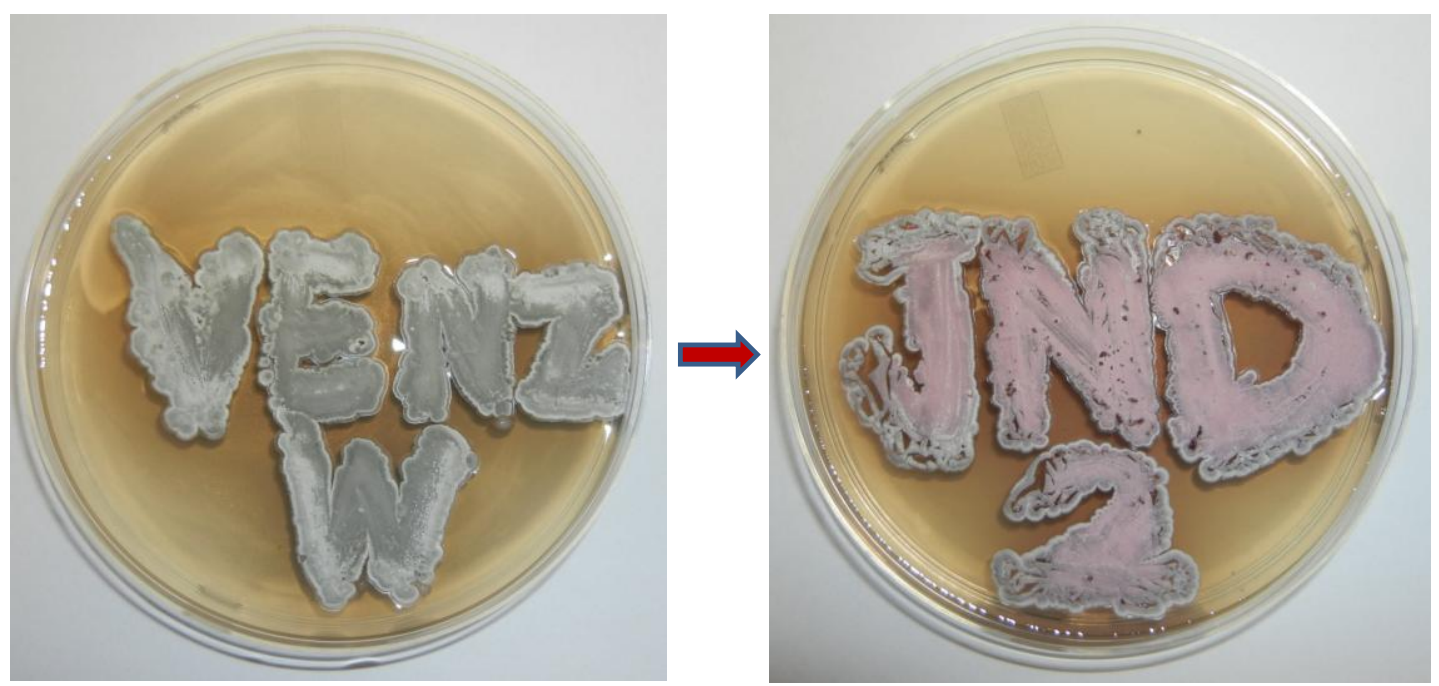

Figure 12: SPA agar plates showing change in phenotype of wild type S. venezuelae (left panel, grey) as a result of expression of the mar gene cluster to yield S. venezuelae JND2 (right panel, red).

The MS profile of acetone extracts from wild type S. venezuelae shows the expected $[\mathrm{M}+\mathrm{H}]^{+}$of $\mathrm{m} / \mathrm{z} 470.31$ and 526.34 corresponding to methymycin and pikromycin antibiotics respectively, naturally produced by the strain [67] (Figure 13). However, the MS profile of $S$. venezuelae JND2 strain indicates the presence of multiple new compounds in addition to methymycin and pikromycin 
that are absent from the wild type strain (Figure 13). Among the new compounds detected in JND2 extract MS spectrum, is a compound with $[\mathrm{M}+\mathrm{H}]^{+}$of $\mathrm{m} / z 410.28$ corresponding to molecular formula of $\mathrm{C}_{25} \mathrm{H}_{36} \mathrm{O}_{2} \mathrm{~N}_{3}$ which matches the published mass and molecular formula of marineosin [53].

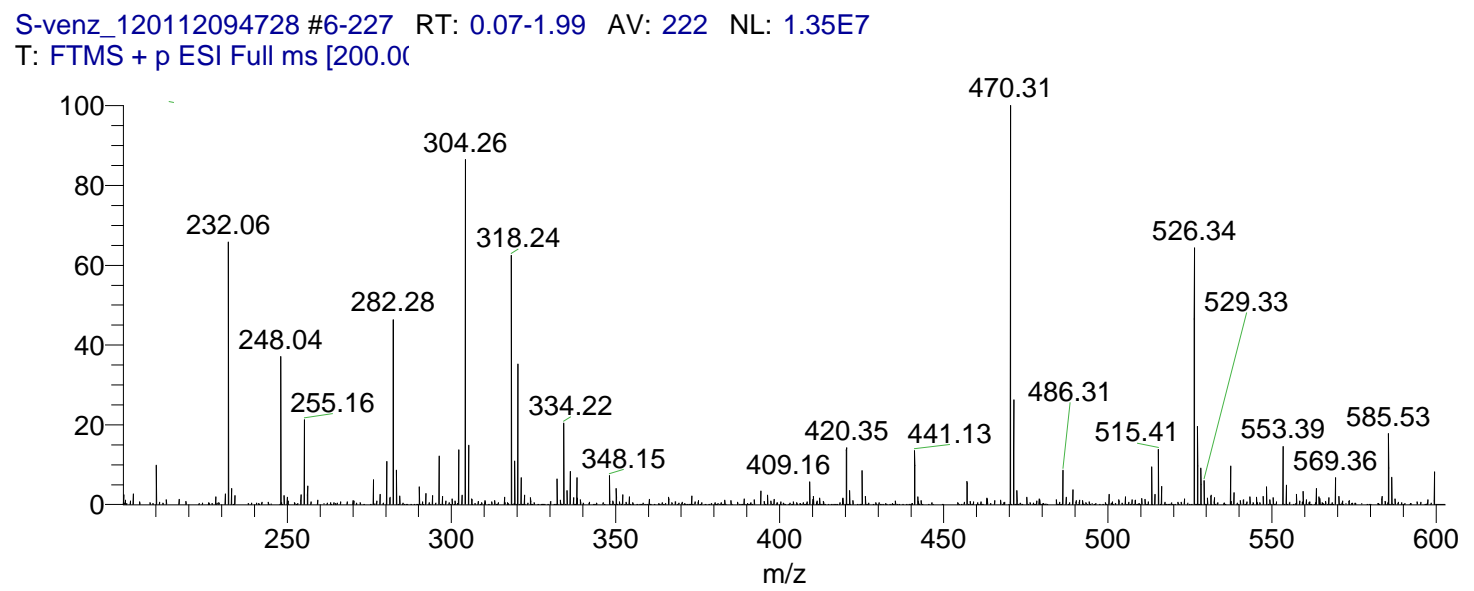

JND2_120112095025 \#7-230 RT: 0.07-2.00 AV: 224 NL: 1.13E7 T: FTM $\mathrm{MS}+\mathrm{p}$ ESI Full ms [200.0C

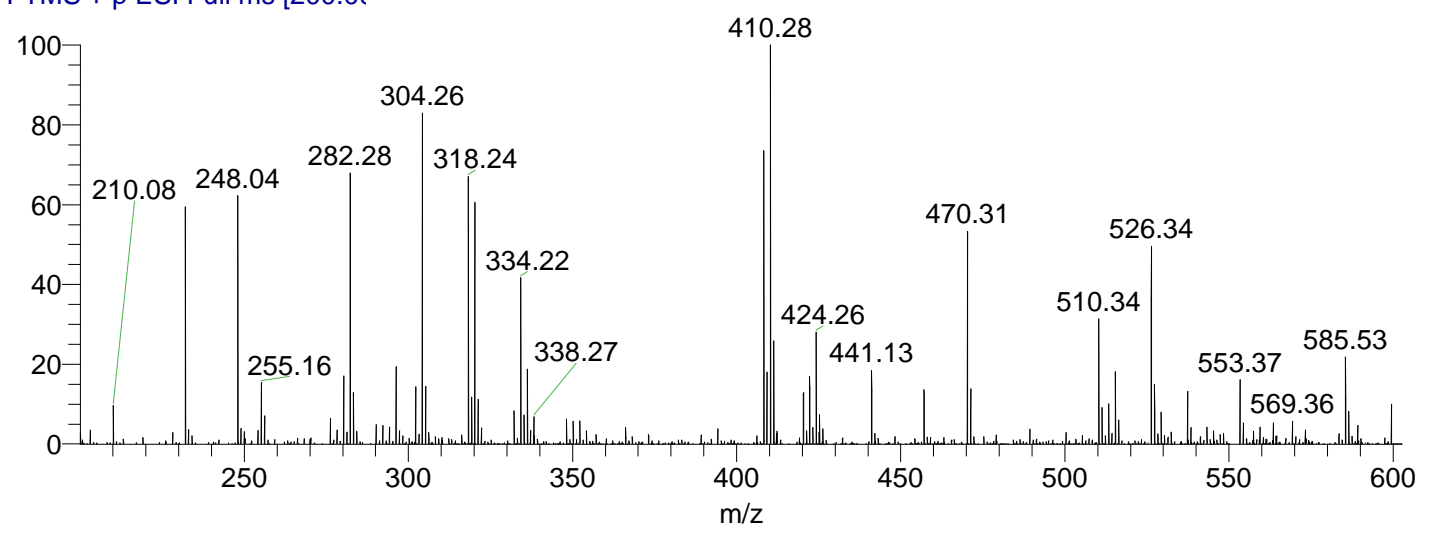

Figure 13: A comparison between the total ion spectrum of wild type S. venezuelae (top panel) and $S$. venezuelae JND2 (bottom panel). The MS profile of the wild type S. venezuelae (top panel) shows the presence of methymycin and pikromycin antibiotics with $[\mathrm{M}+\mathrm{H}]^{+}$of $m / z$ 470.31 and 526.34 respectively, while the MS profile of $S$. venezuelae JND2 shows the putative presence of marineosin with $[\mathrm{M}+\mathrm{H}]^{+}$of $\mathrm{m} / \mathrm{z} 410.28$ in addition to methymycin, pikromycin and other new compounds. 
Comparing the MS/MS profile of the $\mathrm{m} / \mathrm{z} 410.28$ in the JND2 extract (Figure 14, bottom panel) to that of a standard marineosin (Figure 14, top panel), reveals that both compounds have exactly the same MS/MS profile where both compounds have daughter fragments $\mathrm{m} / \mathrm{z} 378.26$ and 230.19 corresponding to structures 20 and 21 (Figure 15), respectively.

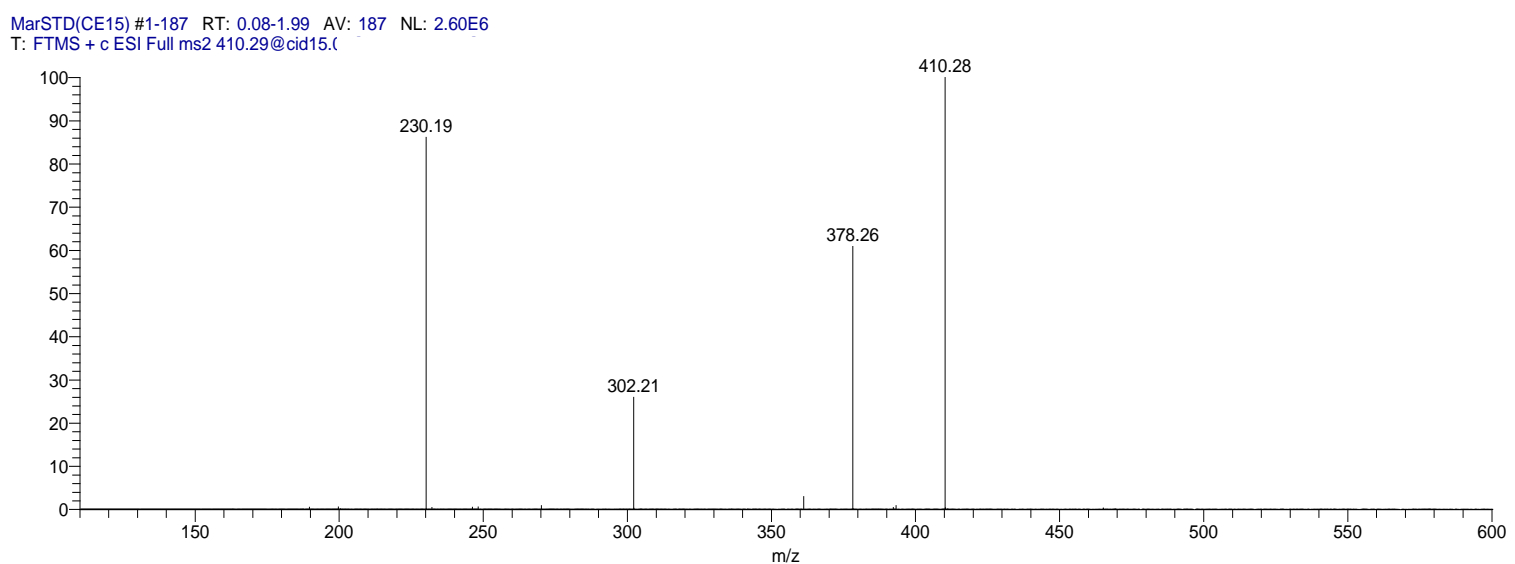

JND2cells(CE15) \#3-186 RT: 0.10-2.00 AV: 184 NL: 1.36E6

T: FTMS + c ESI Full ms2 410.28@cid15.
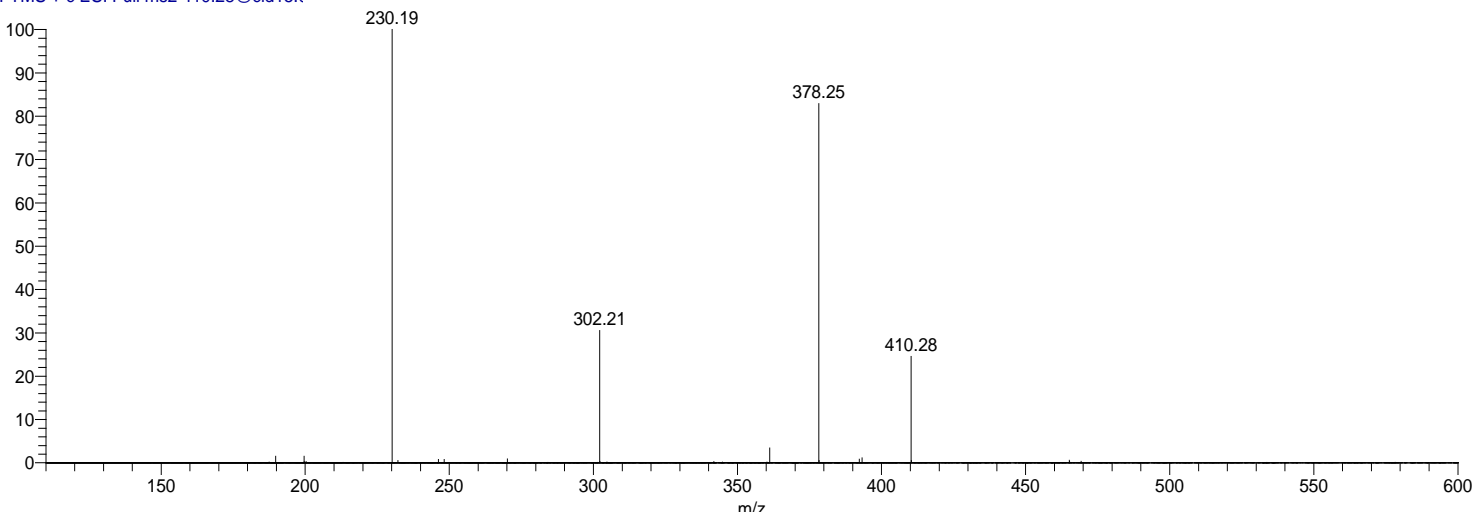

Figure 14: A comparison between the MS/MS profile of marineosin standard (top panel) and the compound with $\mathrm{m} / \mathrm{z} 410.28$ in $S$. venezuelae JND2 extract (bottom panel). Compounds in both top and bottom panels show the presence of $\mathrm{m} / \mathrm{z} 230.19, \mathrm{~m} / \mathrm{z} 302.21$ and $\mathrm{m} / \mathrm{z}$ 378.25 . 


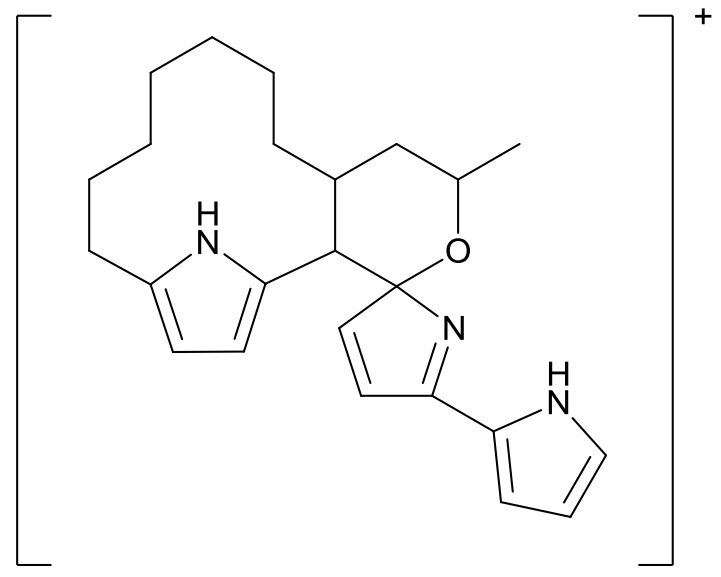

20

$\mathrm{m} / \mathrm{z} 378 . .25$
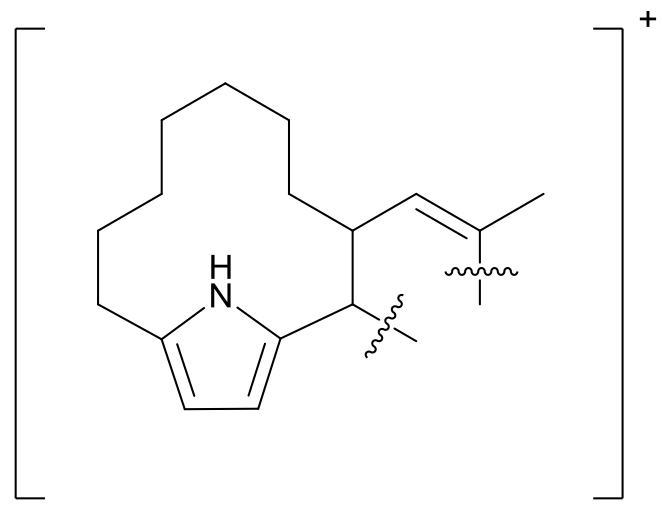

21

$\mathrm{m} / \mathrm{z} 230.19$

Figure 15: Fragment ions observed in the MS/MS profile of marineosin. Figure is adapted from reference 53 .

Moreover, LC/MS analysis (Figure 16) of the JND2 extract and a standard marineosin sample shows that both marineosin standard (Figure 16, top panel) and $m / z 410.28$ compound in the JND2 extract (Figure 16, bottom panel) have almost the same retention time with only 0.2 minute difference. 


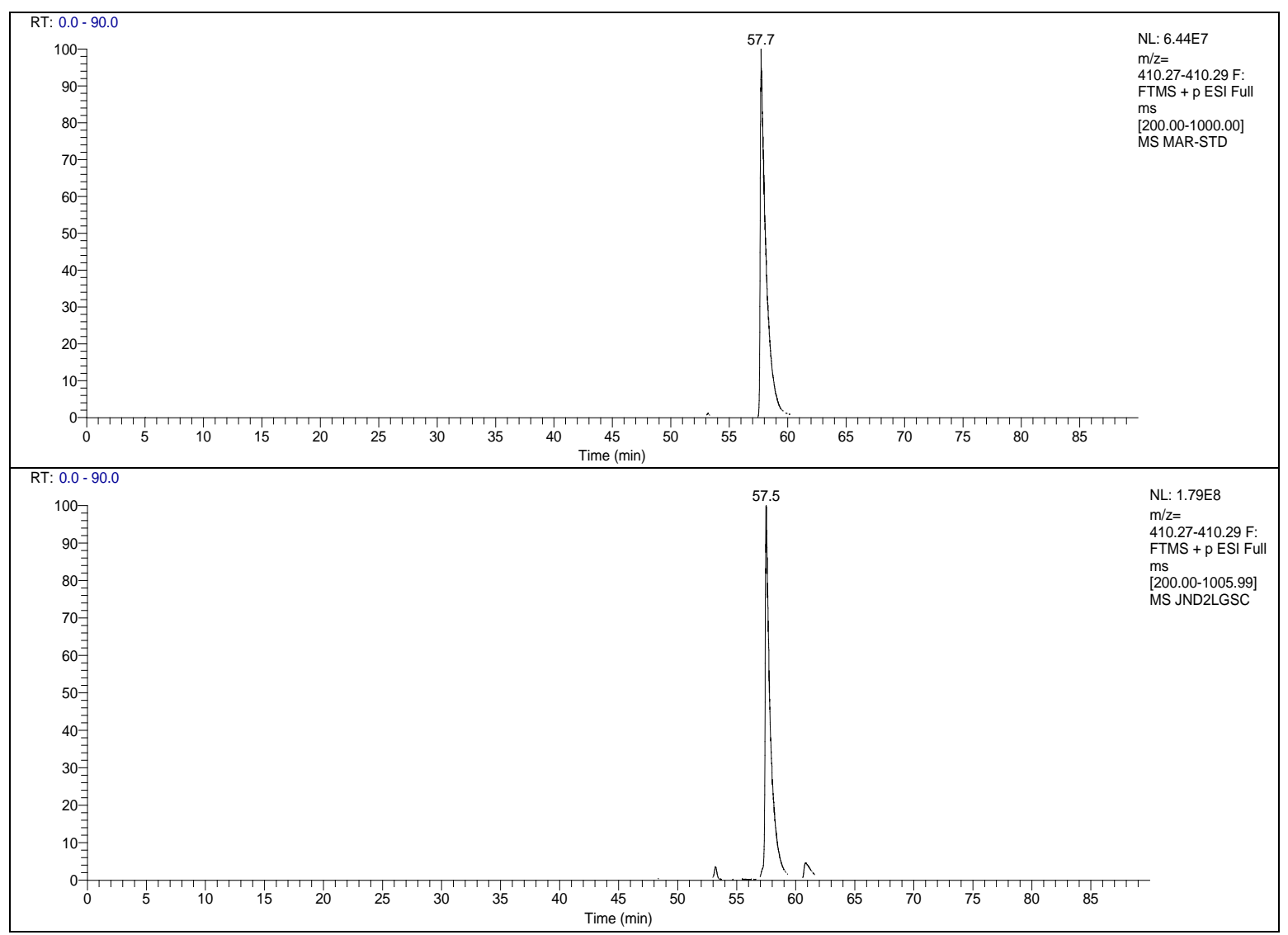

Figure 16: An LC/MS comparison between marineosin standard and JND2 extract. An extracted ion chromatogram (EIC) of $\mathrm{m} / \mathrm{z} 410.28$ for marineosin standard (top panel) and JND2 extract (bottom panel).

The compound with $[\mathrm{M}+\mathrm{H}]^{+} \mathrm{m} / \mathrm{z} 410.28$ produced by $S$. venezuelae JND2, was purified from the acetone extract via 2 rounds of HPLC purifications (Figure 17). ${ }^{1} \mathrm{H}-\mathrm{NMR}$ spectral data $\left(400 \mathrm{MHz}\right.$, acetone- $d_{6}$ ) of the purified compound (Figure 18) was found to be:

$\delta 10.99(\mathrm{br}, 1-\mathrm{NH}), \delta 8.26(\mathrm{br}, 1-\mathrm{NH}), \delta 6.98(\mathrm{dd}, J=1.5 \mathrm{~Hz}$ and $2.5 \mathrm{~Hz}, 1 \mathrm{H}), \delta$ $6.38(\mathrm{dd}, J=1.5 \mathrm{~Hz}$ and $3.5 \mathrm{~Hz}, 1 \mathrm{H}), \delta 6.1(\mathrm{dd}, J=2.5 \mathrm{~Hz}$ and $3.5 \mathrm{~Hz}, 1 \mathrm{H}), \delta$ $5.69(\mathrm{t}, J=2.5 \mathrm{~Hz}, 1 \mathrm{H}), \delta 5.45(\mathrm{t}, J=3 \mathrm{~Hz}, 1 \mathrm{H}), \delta 4.24(\mathrm{~m}, J=6.5 \mathrm{~Hz}, 1 \mathrm{H}), \delta$ 
3.86 (t, $J=8.5 \mathrm{~Hz}, 1 \mathrm{H}$ ), $\delta 3.41(\mathrm{~s}, 3 \mathrm{H}), \delta 2.91(\mathrm{~d}, J=12 \mathrm{~Hz}, 1 \mathrm{H}), \delta 2.88$ (dd, $J=$ $8.5 \mathrm{~Hz}$ and $16 \mathrm{~Hz}, 2 \mathrm{H}), \delta 2.32(\mathrm{~m}, 1 \mathrm{H}), \delta 2.23(\mathrm{~m}, 2 \mathrm{H}), \delta 1.88(\mathrm{dd}, J=8.5 \mathrm{~Hz}$ and $16 \mathrm{~Hz}, 2 \mathrm{H}), \delta 1.77(\mathrm{~m}, J=12 \mathrm{~Hz}, 2 \mathrm{H}), \delta 1.61(\mathrm{td}, J=6.5 \mathrm{~Hz}$ and $12 \mathrm{~Hz}, 2 \mathrm{H}), \delta$ $1.51(\mathrm{~d}, J=7 \mathrm{~Hz}, 3 \mathrm{H}), \delta 1.64(\mathrm{~m}, 2 \mathrm{H}), \delta 1.52(\mathrm{~m}, 2 \mathrm{H}), \delta 1.37(\mathrm{~m}, 2 \mathrm{H}), \delta 1.35(\mathrm{~m}$, $2 \mathrm{H}), \delta 1.34(\mathrm{~m}, 2 \mathrm{H}), \delta 1.28(\mathrm{~m}, 2 \mathrm{H}), \delta 1.18(\mathrm{~m}, 2 \mathrm{H}), \delta 1.02(\mathrm{~m}, 2 \mathrm{H}), \delta 0.88(\mathrm{~m}$, $2 \mathrm{H}), \delta 0.88(\mathrm{~m}, 2 \mathrm{H}), \delta 0.69(\mathrm{~m}, 2 \mathrm{H}), \delta 0.52(\mathrm{~m}, 2 \mathrm{H})$.

This data is consistent with the published data for marineosin [53] which proves the identity of the $[\mathrm{M}+\mathrm{H}]^{+} \mathrm{m} / \mathrm{z} 410.28$ compound produced in $\mathrm{S}$. venezuelae JND2 as marineosin. Streptomyces venezuelae JND2 strain produces $2 \mathrm{mg} / \mathrm{L}$ of marineosin vs. $0.4 \mathrm{mg} / \mathrm{L}$ from the original producer Streptomyces CNQ-617 [53]. Comparing the MS profile of JND2 cell extract to that of JND2 XAD-extract reveals that marineosin is primarily located inside the cell and is not secreted into the media. 


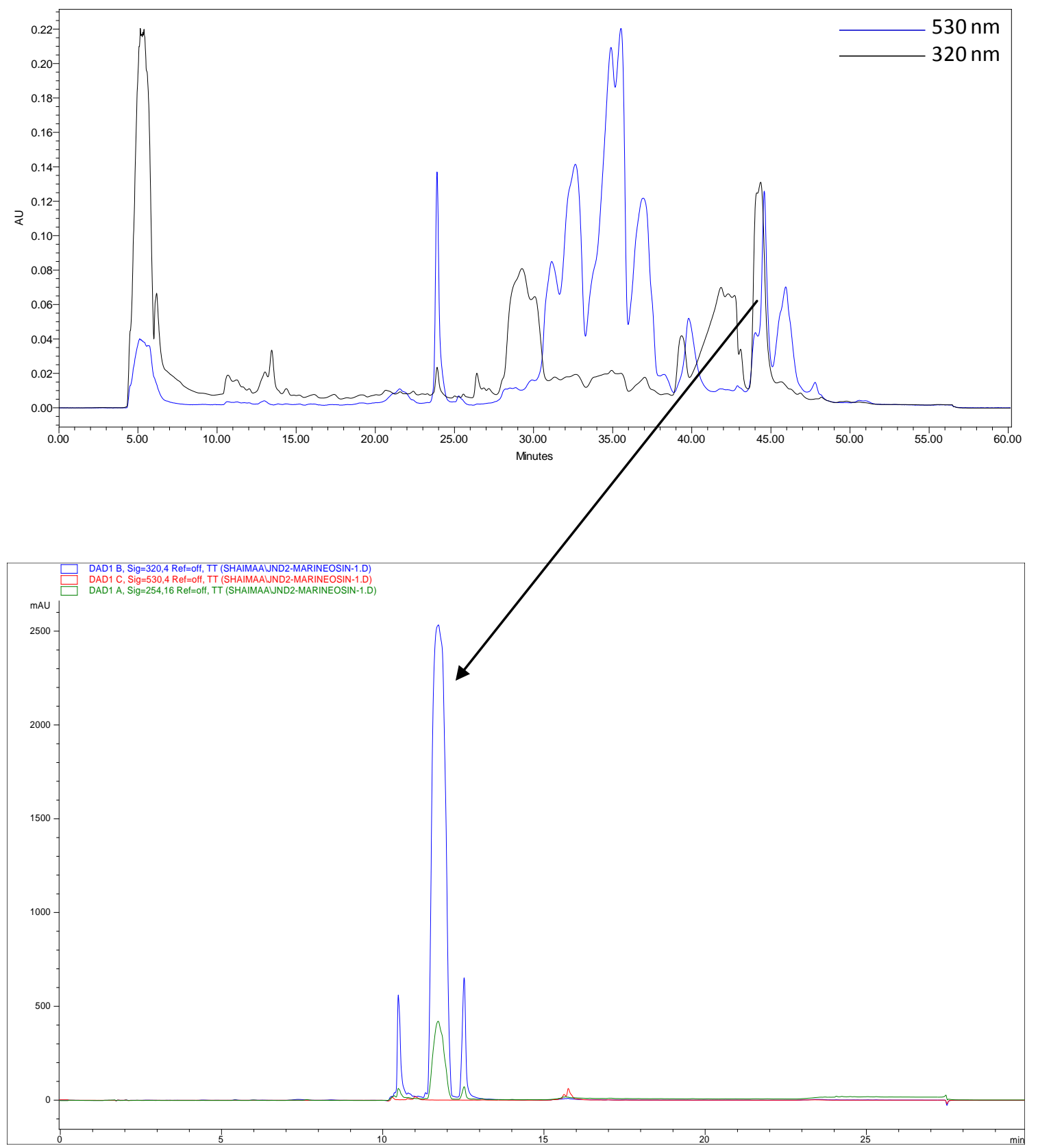

Figure 17: HPLC purrification of marineosin from S. venezuelae JND2. Marineosin was purified from JND2 extract in 2 HPLC purification steps. The peak at 45 min from the first purification (top panel) was collected and subjected into another round of HPLC purification (bottom panel) to yield marineosin. 


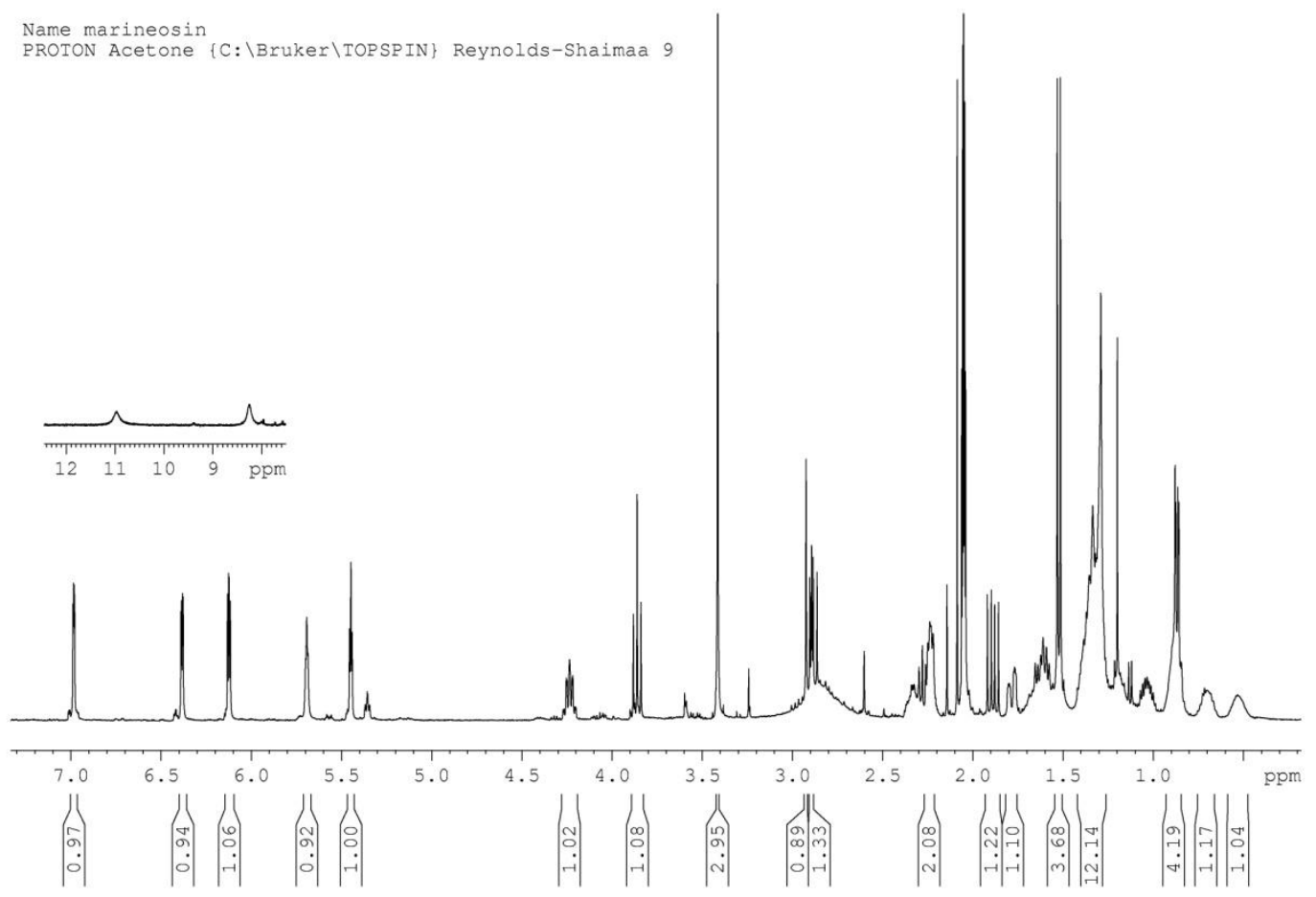

Figure 18: ${ }^{1} \mathrm{H}-\mathrm{NMR}$ of marineosin isolated from S. venezuelae JND2.

The successful production of marineosin in the heterologous host, $S$. venezuelae provides the first experimental evidence that marineosin is biosynthesized via a red gene cluster homolog which raises interesting questions about the origin of the spiroaminal ring oxygen of marineosin. To the best of our knowledge, the mar cluster is also the first identified gene cluster to be involved in the biosynthesis of a spiroaminal ring containing compound which will provide a wealth of information on the biosynthesis of this unique and important class of natural products. Having the mar cluster expressed in a heterologous host such as $S$. venezuelae facilitates the engineering of marineosin analogs and allows for yield 
improvements of marineosin using methods such as over-expression of regulatory genes in the mar gene cluster.

\subsubsection{Hypotheses explaining the origin of the spiroaminal ring oxygen}

As mentioned earlier in section 1.5.3, the mar gene cluster shows striking homology and displays the same architecture of the red gene cluster responsible for the biosynthesis of undecylprodiginine and streptorubin B in S. coelicolor $A(3) 2$, with the presence of only one extra dehydratase-encoding gene named, marA (Figure 9). Interestingly, the results of all the studies presented in this section indicate that the expression of the mar gene cluster in the heterologous host, S. venezuelae, was successful and that the new strain, S. venezuelae JND2, is fully capable of producing marineosin with three times higher yield than the original producer. Therefore, the cloned mar gene cluster encodes most if not all of the genes required to direct the biosynthesis of marineosin. We hypothesize that the intramolecular cyclization and spiroaminal ring formation is catalyzed by the dehydratase, MarA. However, the mar gene cluster lacks any dedicated oxidases or p450 homologs that can explain the origin of the hydroxyl group in the acyl chain of marineosin which is required for the biosynthesis of the spiroaminl moiety (Figure 4) (10 and 11). There are four hypotheses (Figure 19) that can explain the origin of that hydroxyl group:

1. The marG gene, which encodes the Rieske-oxygenase MarG, plays a dual role in the biosynthesis of marineosin. In this case, MarG catalyzes the oxidative 
cyclization of the acyl chain of undecylprodiginine, like it normally does in the biosynthesis of streptorubin B (Figure 5) [52] and also introduces the second hydroxyl group required to initiate the biosynthesis of the spiroaminal moiety of marineosin. If this hypothesis is correct, a deletion of marG gene from the mar gene cluster should lead to the accumulation of undecylprodiginine as an intermediate (Hypothesis no. 1, Figure 19).

2. An unidentified Mar enzyme catalyzes the required hydroxylation. The mar gene cluster, as well as its red gene cluster homolog, encodes two genes of unknown function named marT and marE and therefore were annotated as hypothetical proteins. Deletion of one or both genes can be used to probe their roles in the biosynthesis of marineosin (hypothesis no. 2, Figure 19).

3. Marineosin production in the original producer, Streptomyces CNQ-617 requires the presence of an extra tailoring oxidase enzyme which is not clustered with the mar gene cluster. In this case, the biosynthesis of marineosin in $S$. venezuelae can be explained by the presence of a promiscuous p450 oxidase capable of hydroxylating the acyl chain of undecylprodiginine (7) to yield 2hydroxy-undecylprodiginine (25) and thus rescue marineosin production (hypothesis no. 3, Figure 19). However, there is no evidence that $S$. venezuelae harbors such an enzyme. 
4) Different Starter Unit<smiles>CC(O)CC(=O)O</smiles>

22

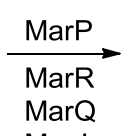

MarJ<smiles>CC(O)C(=O)[O-]</smiles>

23<smiles>CC(O)C1=CC(=O)CN1</smiles>

24
Subunit

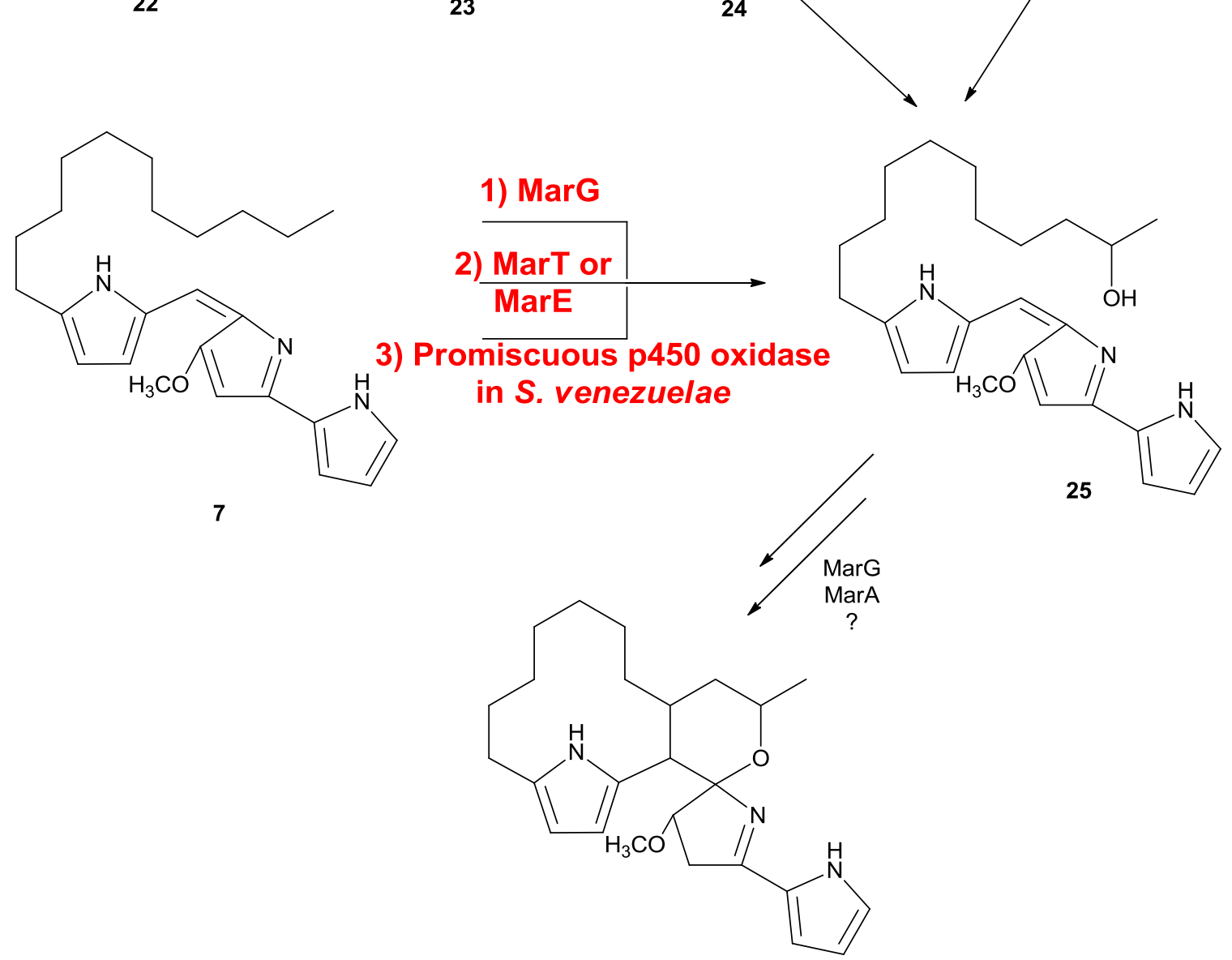

Marineosin A and B

Figure 19: Hypotheses explaining the biosynthetic origin of the spiroaminal oxygen of marineosin. For details, please refer to text.

4. The hydroxyl group is incorporated early in the biosynthetic pathway due to the incorporation of a 3-hydroxy-butyric acid starter unit (22) by the RedP homolog, MarP, which is a 3-ketoacyl-ACP-synthase, to yield 2-hydroxy-dodecanoic acid (23). 2-hydroxy-dodecanoic acid (23) becomes a substrate for the polyketide 
synthase, MarL to yield a 2-hydroxy-undecylpyrrole (2-hydroxy-UP) subunit (24). MarH then catalyzes the condensation of the 2-hydroxy-UP subunit (24) with the MBP subunit (14) (Figure 4), which leads to the biosynthesis of 2-hydroxy-

undecylprodiginine (25) rather than undecylprodiginine (7) (hypothesis no. 4, Figure 19). In this case, all enzymes involved in the biosynthesis of 2-hydroxy-UP subunit (24) as well as MarH and MarG must accept hydroxylated substrates unlike their Red enzymes counterparts. If this hypothesis is correct, deletion of marG gene from the mar gene cluster will lead to the accumulation of 2-hydroxyundecylprodiginine (25).

\subsubsection{New compounds observed in S. venezuelae JND2}

The prodiginine family of compounds is characterized by having a maximum UV absorbance $(\lambda \max )$ of $530 \mathrm{~nm}$ due to aromatic ring system conjugation, and thus has a distinctive red color. The $\lambda$ max of marineosin standard is $320 \mathrm{~nm}$ due to the reduction of one of the pyrrole rings (ring B, Figure 4) and loss of conjugation. The extract of $S$. venezuelae JND2 was analyzed via MicroToF-Q mass spectrometer using reverse phase HPLC equipped with MWD detector. The LCUV analysis of the extract indicates the presence of two groups of compounds: a group of non-conjugated compounds with a $\lambda \max$ of $320 \mathrm{~nm}$ and a group of conjugated red-colored compounds with a $\lambda \max$ of $530 \mathrm{~nm}$. The non-conjugated compounds include marineosin in addition to three other compounds named JN422, JN424, and JN408 with $[\mathrm{M}+\mathrm{H}]^{+}$of $\mathrm{m} / \mathrm{z} 422.26,424.28$, and 408.26 and 
molecular formulae $\mathrm{C}_{25} \mathrm{H}_{32} \mathrm{O}_{3} \mathrm{~N}_{3}, \mathrm{C}_{25} \mathrm{H}_{34} \mathrm{O}_{3} \mathrm{~N}_{3}$, and $\mathrm{C}_{25} \mathrm{H}_{34} \mathrm{O}_{2} \mathrm{~N}_{3}$, respectively. The conjugated, red-colored compounds include $[\mathrm{M}+\mathrm{H}]^{+} \mathrm{m} / \mathrm{z} 406.25,408.27$, and 410.28 with respective molecular formulae of $\mathrm{C}_{25} \mathrm{H}_{32} \mathrm{O}_{2} \mathrm{~N}_{3}, \mathrm{C}_{25} \mathrm{H}_{34} \mathrm{O}_{2} \mathrm{~N}_{3}$, and $\mathrm{C}_{25} \mathrm{H}_{36} \mathrm{O}_{2} \mathrm{~N}_{3}$ in addition to a mixture of other red compounds (Figure 20).

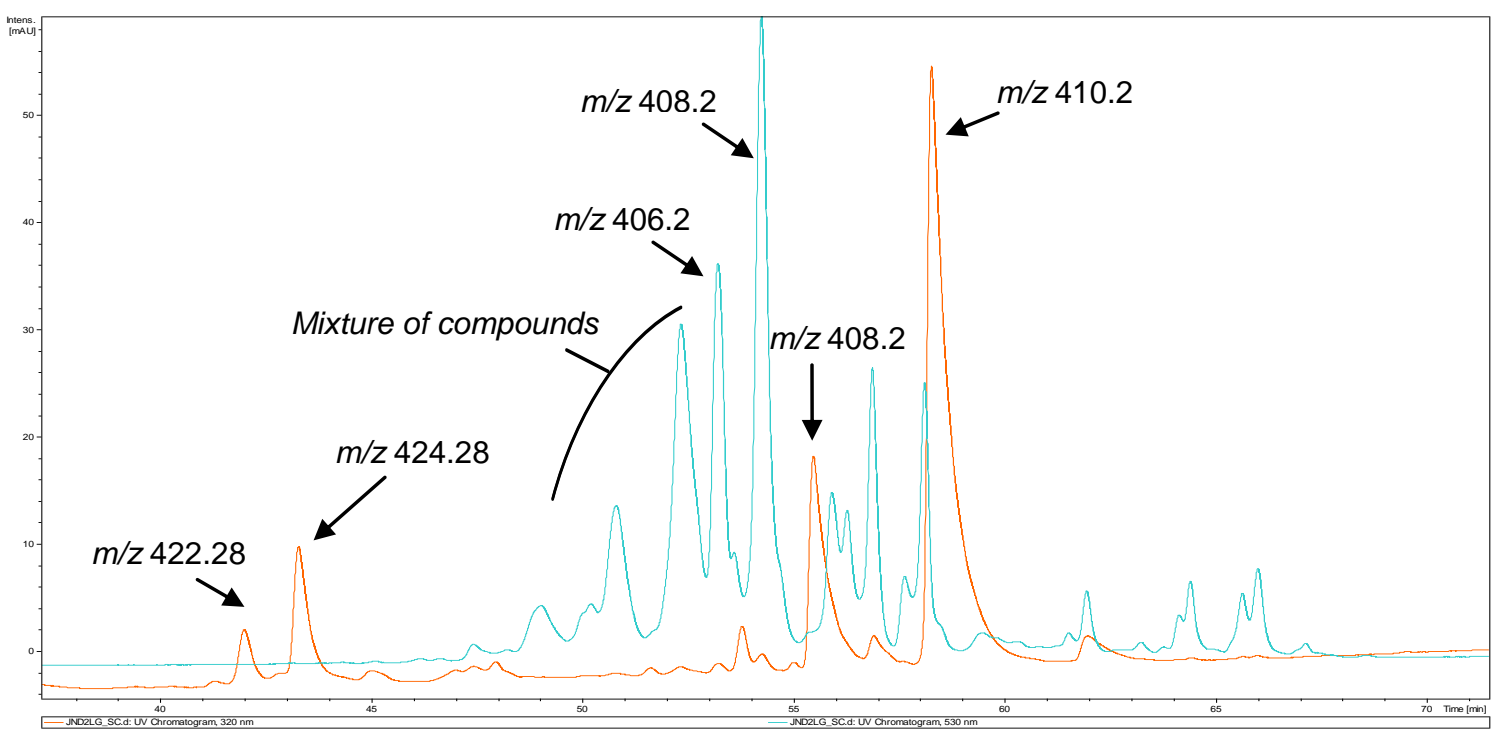

Figure 20: The LC-UV/MS profile S. venezuelae JND2. The blue chromatogram represents absorption at $530 \mathrm{~nm}$ and the orange chromatogram represents absorption at $320 \mathrm{~nm}$.

Based on our knowledge of prodiginines biosynthesis and the fact that marineosin is non-conjugated, the accumulation of conjugated red-colored compounds in S. venezuelae JND2 suggests that the reduction of the pyrrole ring B of marineosin occurs later in the pathway. The detection of JN422 and JN424 compounds via LC/MS, which have extra oxygen in their molecular formulae, is very intriguing as it suggests that these compounds have a second hydroxyl or keto group in their structure. The fact that di-hydroxylated red compounds were not detected suggests that the second hydroxylation occurs later in the pathway, 
due to the activity of either a Mar enzyme or a promiscuous p450 oxidase in $S$. venezuelae. In the latter case, JN422 and JN424 would be artifacts of the heterologous expression of the mar gene cluster and not true intermediates. Undecylprodiginine (7) (Figure 4, Figure 19) production was not observed in this strain which can be explained by two possibilities: either that undecylprodiginine (7) is not an intermediate in the biosynthesis of marineosin altogether, consistent with either hypothesis number 2 or 4 (Figure 19) or undecylprodiginine (7) is produced but is converted to marineosin very quickly by the action of a Mar enzyme or an additional p450 oxidase in S. venezuelae, which is consistent with the other two hypotheses (Figure 19).

2.4.3 Comparison between the fragmentation patterns of undecylprodiginine, marineosin, and JND2 compounds

The electrospray tandem mass spectrometry ES-MS/MS profile of the prodiginines family of natural products is characterized by the neutral loss of $\mathrm{m} / \mathrm{z}$ 15 which corresponds to the loss of a methyl radical from the pyrrole ring $B$ to generate odd electron fragments [68]. Upon ESI-CID fragmentation of undecylprodiginine, protonation first occurs at the nitrogen atom of pyrrole ring B which leads to electron delocalization and the subsequent formation of a pseudoseven-membered ring which is stabilized by conjugation. Therefore, the loss of a methyl radical provides the most stable ground state $[\mathrm{M}+\mathrm{H}]^{+}$(Figure 21, top panel). This fragmentation pattern was used to determine the structure of a 
prodiginine analog present in low concentration in Hahella chejuensis extract without prior purification [68]. The same experiment was attempted using undecylprodiginine and marineosin in order to understand the differences between the two compounds when subjected to ESI-CID. This knowledge can then be used to gain preliminary insight into the structure of other compounds accumulated in S. venezuelae JND2 and other engineered strains, which will be discussed in more detail in chapter 3.

In case of undecylprodiginine (Figure 21, top panel), a daughter fragment of $\mathrm{m} / \mathrm{z}$ 379.26 corresponding to the neutral loss of $m / z 15(\mathrm{NL}=15)$ was observed as expected (Figure 21, top panel). However, in case of marineosin, a daughter fragment of $\mathrm{m} / \mathrm{z} 378.26$ corresponding to the neutral loss of $\mathrm{m} / \mathrm{z} 32$ (NL=32) rather than 15 was observed (Figure 21, bottom panel). In case of marineosin (Figure 21, bottom panel), pyrrole ring $B$ is not conjugated and therefore, protonation of the nitrogen in ring $B$ does not lead to charge delocalization and subsequently, the pseudo-seven-membered ring, if formed, will not be stabilized by conjugation as in the case of undecylprodiginine. Therefore, marineosin favors the loss of a methanol molecule, $\mathrm{NL}=32$ from ring $\mathrm{B}$ which probably creates the most stable resonance-stabilized ground state $[\mathrm{M}+\mathrm{H}]^{+}$pyrrole ring and thus, the generation of even electron fragments in ES-MS/MS (Figure 21). 
A)
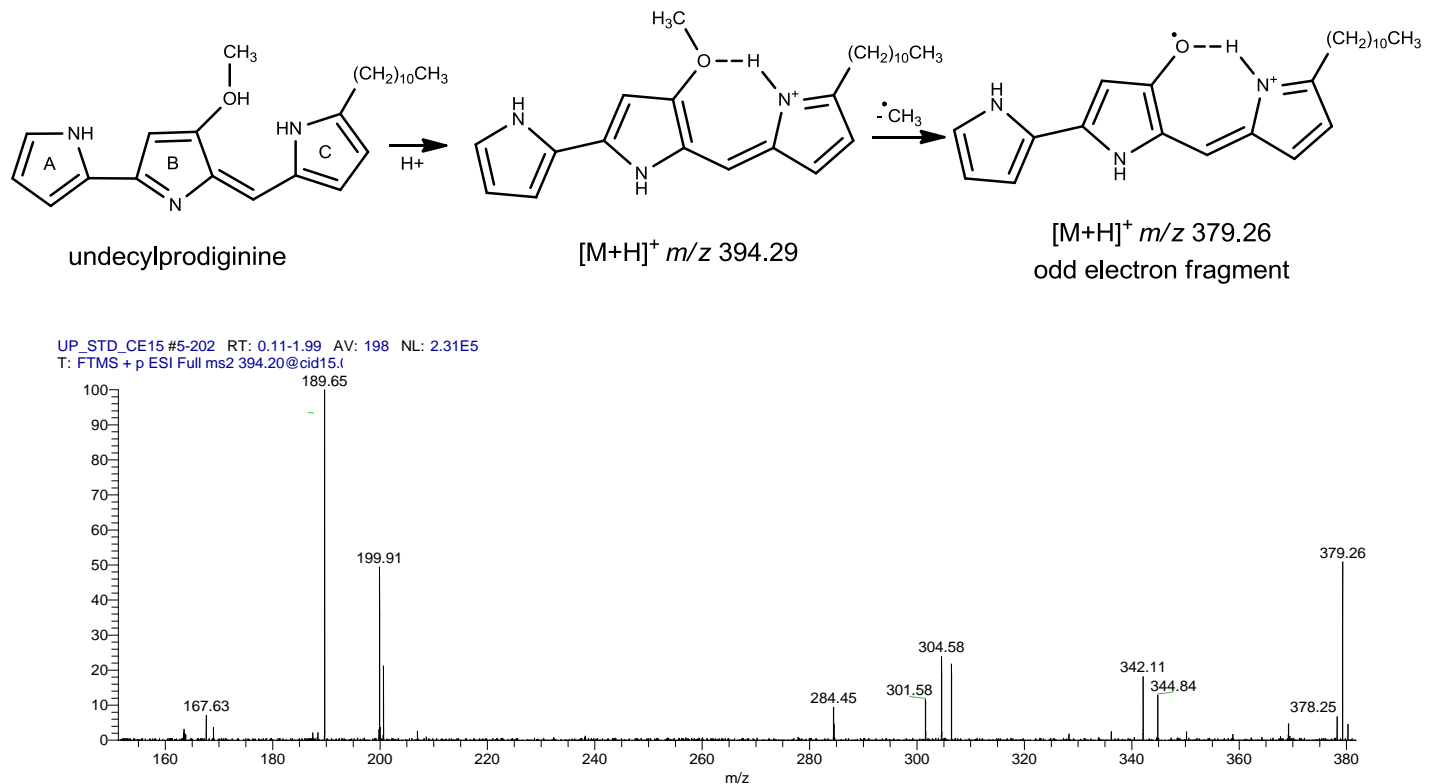

B)
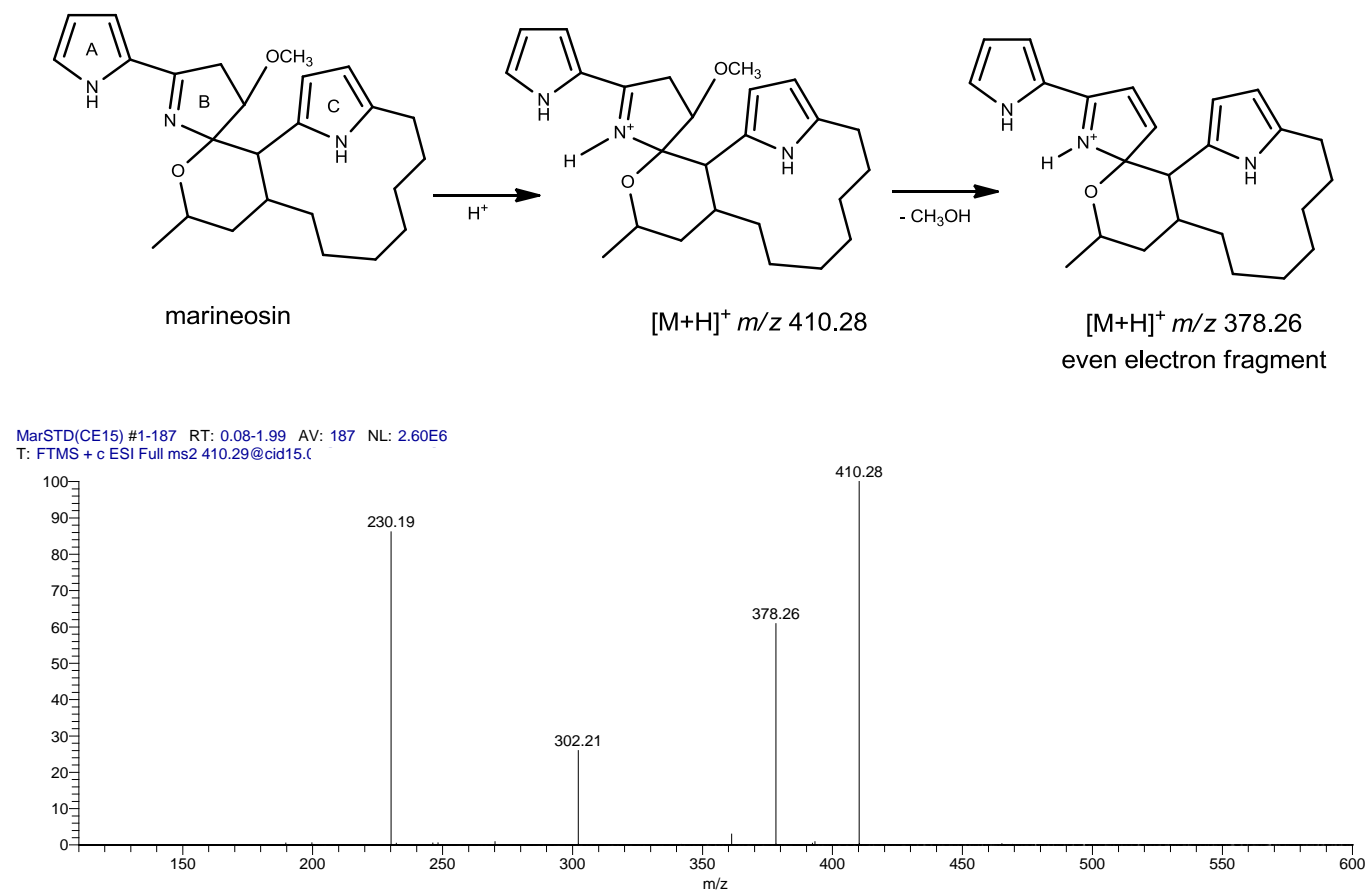

Figure 21: Mechanism and comparison between the MS/MS profile of undecylprodiginine standard (top panel) and marineosin (bottom panel). A) The mechanism and MS/MS profile of undecylprodiginine (top panel) show a daughter fragment of $\mathrm{m} / \mathrm{z} 379.26$ corresponding to the neutral loss of $m / z 15(\mathrm{NL}=15)$. The parent ion of undecylprodiginine, $m / z 394.29$ is not shown. $\mathrm{B})$ The mechanism and MS/MS profile of marineosin (bottom panel) show daughter fragments of $\mathrm{m} / \mathrm{z}$ 378.26 corresponding to the neutral loss of $\mathrm{m} / \mathrm{z} 32(\mathrm{NL}=32)$. 


\subsection{CONCLUSION}

A genomic library of Streptomyces CNQ-617 was generated by Reynolds KA and co-workers and a red gene cluster homolog was identified and proposed to be responsible for the biosynthesis of marineosin but that assumption was not tested experimentally. The putative mar gene cluster has only one extra gene named marA, encoding a dehydratase. We hypothesize that MarA is involved in the biosynthesis of the spiroaminal ring of marineosin. The putative gene cluster was expressed in the heterologous host $S$. venezuelae and the production of marineosin was confirmed via tandem mass spectrometry, LC/MS and ${ }^{1} \mathrm{H}-\mathrm{NMR}$ of marineosin purified from the engineered $S$. venezuelae JND2 strain. $S$. venezuelae provides 3 times higher yield of marineosin than the original producer, Streptomyces CNQ-617.

Four hypotheses were proposed to explain the origin of the hydroxyl group required for the biosynthesis of the spiroaminal ring of marineosin. Deletion of marG gene, encoding the Rieske oxygenase MarG, is necessary to provide evidence supporting any of the proposed hypotheses and deletion of marA gene, encoding the dehydratase MarA, is necessary to probe its role in the biosynthesis of the spiroaminal ring.

A number of pathway intermediates and possibly some shunt metabolites were observed in the acetone extract of $S$. venezuelae JND2. The intermediates were either conjugated with bright red color or non-conjugated compounds. 


\subsection{SIGNIFICANCE}

We are reporting the first gene cluster experimentally proved responsible for the biosynthesis of marineosin and the first gene cluster involved in the biosynthesis of a spiroaminal natural product. The identification of the mar gene cluster and its expression in a heterologous host will facilitate studying the biosynthesis of this intriguing class of secondary metabolites by probing the role of individual genes along the pathway. Engineering of gene deletion and/or replacement mutants and analysis of the accumulating metabolites can provide analogs of marineosin. 


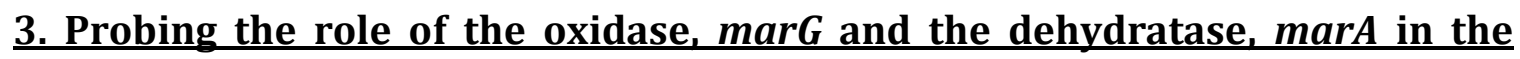
biosynthesis of marineosin

\subsection{SUMMARY}

The role of MarG and MarA in the biosynthesis of marineosin was investigated via gene replacement experiments, and the major metabolites accumulated in the resultant mutant strains were purified and identified. The deletion of MarG, a non-heme iron Rieske oxygenase led to the accumulation of 2hydroxyundecylprodiginine (26). This data disproves the hypothesis that MarG catalyzes the introduction of the hydroxyl group required to initiate the biosynthesis of the spiroaminal ring of marineosin, and suggests that the origin of such - $\mathrm{OH}$ group is either a 3-hydroxybutyric acid starter unit recruited via MarP or an unidentified hydroxylase potentially in the mar gene cluster. The deletion of MarA, a putative dehydratase led to the accumulation of 2 marineosin analogs named JN408 (31) and JN422 (32) with molecular formulae $\mathrm{C}_{25} \mathrm{H}_{33} \mathrm{O}_{2} \mathrm{~N}_{3}$ and $\mathrm{C}_{25} \mathrm{H}_{31} \mathrm{O}_{3} \mathrm{~N}_{3}$, respectively. JN408 (31) is an oxidized marineosin, where ring $\mathrm{B}$ is a pyrrole ring rather than dihydropyrrole, and JN422 (32) is a 9-keto derivative of JN408. This suggested that MarA is not involved in the biosynthesis of the spiroaminal ring of marineosin but is rather involved in the reduction of pyrrole ring $B$. We propose that spiroaminal ring formation happens via a concerted nonenzymatic mechanism. Marineosin production was not observed in either marG 
or marA deletion mutants which suggest that MarG and MarA are crucial for the biosynthesis of marineosin. From the above data, an experimentally-supported scheme for the biosynthesis of marineosin was proposed.

\subsection{INTRODUCTION}

From our work detailed in Chapter 2, the gene cluster directing the biosynthesis of marineosin; the mar gene cluster was expressed in the heterologous host $S$. venezuelae and marineosin production was confirmed via mass spectrometry and ${ }^{1} \mathrm{H}-\mathrm{NMR}$ of purified marineosin. The identified mar gene cluster has a high degree of homology to the red gene cluster directing the biosynthesis of undecylprodiginine (7) and streptorubin B (8) in S. coelicolor A(3)2. The current knowledge of prodiginines biosynthesis does not explain the origin of the spiroaminal ring or the enzymes involved in the reduction of pyrrole ring $B$ of marineosin. We proposed four hypotheses (Figure 19) to explain the biosynthesis of marineosin in which MarG and MarA were proposed to have important roles in the biosynthesis of marineosin. Additional experiments were needed to test these hypotheses. In this study, we sought the deletion of marG and marA genes to probe the role of their respective enzymes in the biosynthesis of marineosin as well as propose a scheme for marineosin biosynthesis. 


\subsection{MATERIALS AND METHODS}

\subsubsection{Antibiotics, enzymes and bacterial strains}

All antibiotics, chemicals and HPLC-grade solvents were purchased from SigmaAldrich (St. Louis, MO) unless otherwise stated. HPLC-purified DNA-primers were purchased from Integrated DNA technologies (Corvallis, IA). Phusion highfidelity polymerase was purchased from New England Biolabs (Ipswich, MA). Information regarding bacterial strains used in recombination was detailed in section 2.3.2.

\subsubsection{Targeted gene disruption of marG and marA genes}

The 1150 bp aadA gene and its promoter were amplified from plJ788 spectinomycin resistance cassette [19], [20] using Phusion polymerase and primers specified in Table 4 and according to the protocol in Table 5.

\begin{tabular}{|l|l|}
\hline \multicolumn{2}{|l|}{ Primers for amplification of aadA gene } \\
\hline aadA_FWD & 5'- GTATACGGCTGACGCCGTTGGATA -3' \\
\hline aadA_REV & 5'- GTATACTTATTTGCCGACTACCTTGGT -3' \\
\hline
\end{tabular}

Table 4: Primers used for PCR amplification of aadA gene from plJ788. Bold, italicized and underlined font represents restriction endonuclease site for Bstz17I.

\begin{tabular}{|c|c|c|c|c|c|}
\hline & \multicolumn{3}{|c|}{$30 \mathrm{X}$} & \\
\hline $98{ }^{\circ} \mathrm{C}$ & $98{ }^{\circ} \mathrm{C}$ & $64{ }^{\circ} \mathrm{C}$ & $72{ }^{\circ} \mathrm{C}$ & $72{ }^{\circ} \mathrm{C}$ & $4{ }^{\circ} \mathrm{C}$ \\
\hline $30 \mathrm{sec}$ & $10 \mathrm{sec}$ & $15 \mathrm{sec}$ & $17 \mathrm{sec}$ & $10 \mathrm{~min}$ & $\infty$ \\
\hline
\end{tabular}

Table 5: Protocol used in PCR amplification of aadA gene 
The PCR product was purified using QIAquick PCR Purification kit (Qiagen, Valencia, CA) and was eluted using $10 \mu \mathrm{l}$ of EB buffer. The PCR product was directly used as a template for another PCR reaction using primers specified in Table 6 and the protocol specified in Table 7.

\begin{tabular}{|l|l|}
\hline \multicolumn{2}{|l|}{ Primers used for marG disruption } \\
\hline marG_KO_FWD & $\begin{array}{l}\text { 5'- GTGCTCGGCGGGAAACTCGAAAGAGAGAGGGACTG } \\
\text { CATGGTATACGGCTGACGCCGTTG -3' }\end{array}$ \\
\hline marG_KO_REV & $\begin{array}{l}\text { 5'-GCCGTACCATGCGTCTTCGTCCGGGACGCCGCCGC } \\
\text { GTCAGTATACTTATTTGCCGACT-3' }\end{array}$ \\
\hline Primers used for marA disruption \\
\hline marA_KO_FWD & $\begin{array}{l}\text { 5'- TTGTACGCCCACGCTCCGGTGCACAGAATCGTGGCC } \\
\text { ATGGTATACGGCTGACGCCGTTG -3' }\end{array}$ \\
\hline marA_KO_REV & $\begin{array}{l}\text { 5'-AGAGGCGACGGAGATCATGACGGGATACTTCTGGC } \\
\text { GTCAGTATACTTATTTGCCGACT -3' }\end{array}$ \\
\hline
\end{tabular}

Table 6: Primers used for disruption of marG and marA genes. Homology to the nucleotide sequence flanking marG or marA is indicated by bold underlined font while the italicized font, indicates homology to aad $A$ gene.

\begin{tabular}{|c|c|c|c|c|c|}
\hline & \multicolumn{3}{|c|}{$30 \mathrm{X}$} & \\
\hline $98{ }^{\circ} \mathrm{C}$ & $98{ }^{\circ} \mathrm{C}$ & $64{ }^{\circ} \mathrm{C}$ & $72{ }^{\circ} \mathrm{C}$ & $72{ }^{\circ} \mathrm{C}$ & $4{ }^{\circ} \mathrm{C}$ \\
\hline $30 \mathrm{sec}$ & $30 \mathrm{sec}$ & $19 \mathrm{sec}$ & $10 \mathrm{sec}$ & $10 \mathrm{~min}$ & $\infty$ \\
\hline
\end{tabular}

Table 7: PCR protocol used in targeted disruption of marG and marA genes

The new generated PCR product was used, according to protocol, in the Red/ET mediated targeted gene disruption [20] of either marG or marA genes in pMAR 
cosmid where the genes in question were replaced by aadA gene, a spectinomycin resistance marker (Figure 22). 


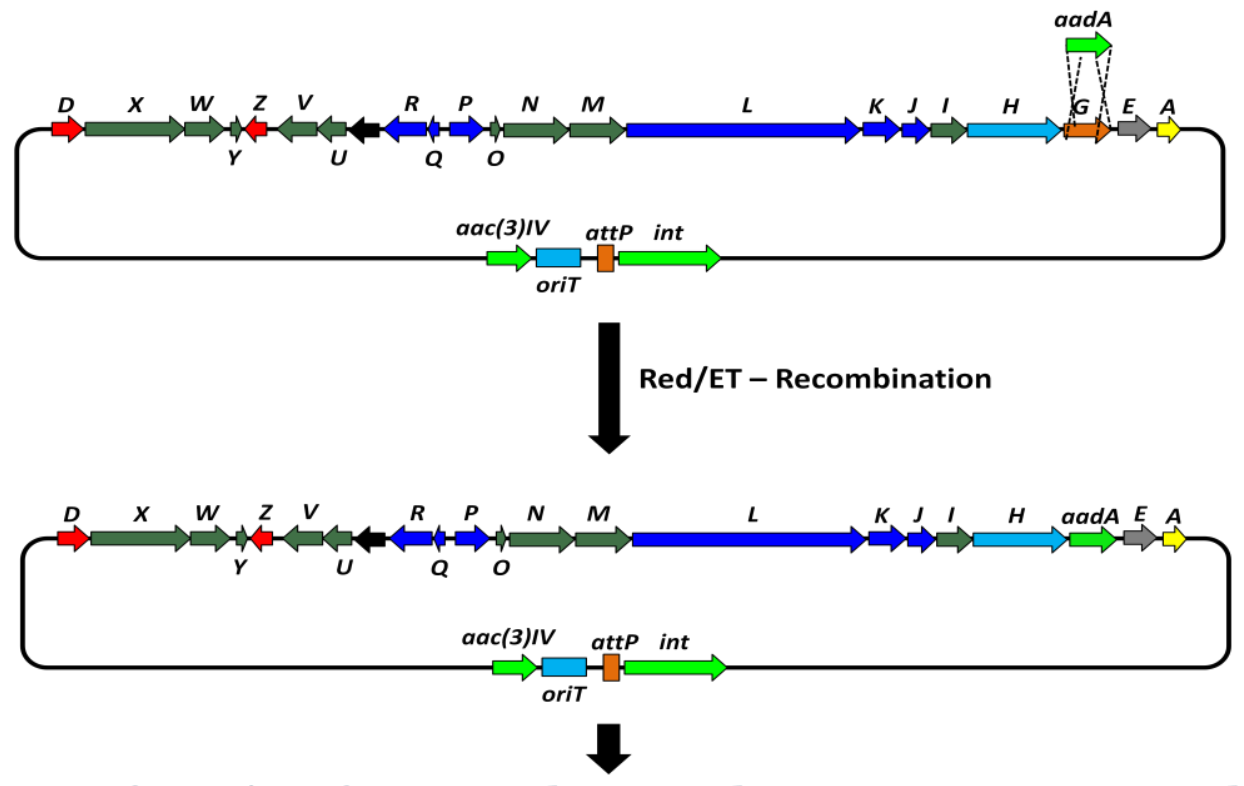

Transformation of $S$. venezuelae protoplasts to generate $S$. venezuelae

JND2 $\Delta G$ mutant

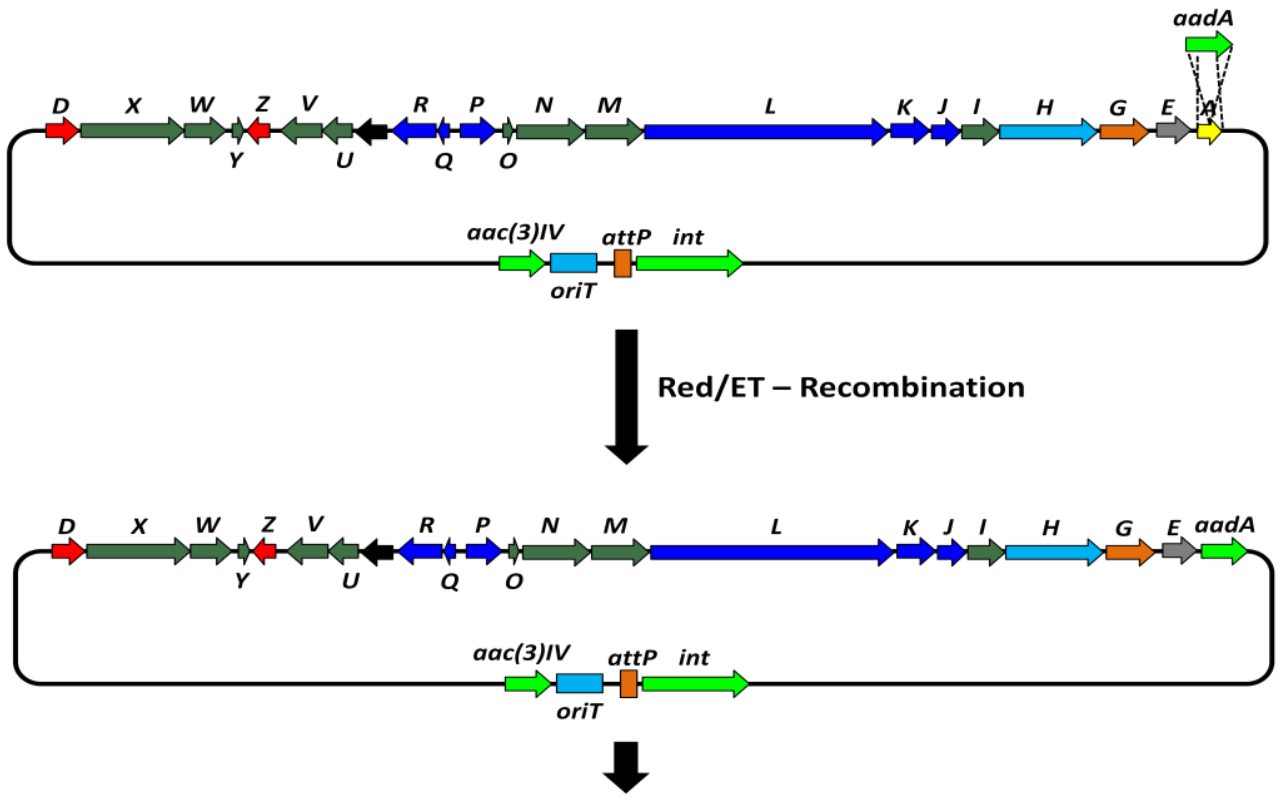

Conjugation into $S$. venezuelae to generate $S$. venezuelae JND2AA mutant

Figure 22: Recombination strategy used to generate $S$. venezuelae JND2 $\Delta G$ (top panel) and S. venezuelae JND2 $\Delta$ A (bottom panel). plJ788 plasmid was used as a template for PCR amplification of aadA gene, conferring resistance to spectinomycin antibiotic. The PCR product was used to replace marG gene (top panel) and marA (bottom panel) in pMAR cosmid via PCR targeted recombination. The mutated cosmids were transferred to $S$. venezuelae by either protoplast transformation ( $m a r G$, top panel) or by conjugation ( $m a r A$, bottom panel) to generate $S$. venezuelae JND2 $\Delta \mathrm{G}$ and $S$. venezuelae JND2 $\Delta \mathrm{A}$ respectively. aadA = adenyltransferase gene. 
marG and marA gene replacements were confirmed by PCR using outer primers that bind $\sim 200$ bp upstream and $\sim 200$ bp downstream of the amplified gene (Table 8). The mutant cosmids were named pMAR $\Delta G$ and $p M A R \triangle A$.

\begin{tabular}{|l|l|}
\hline \multicolumn{2}{|l|}{ Outer primers used to verify gene deletion } \\
\hline marG_Out_FWD & 5'- ACACCGACGCGACATGGACC -3' \\
\hline marG_Out_REV & 5'- CGGGCAGCTCCTCGTCCT -3' \\
\hline marA_Out_FWD & 5'- GTCGGCCGGTGACGGTGC -3' \\
\hline marA_Out_REV & 5'- GGAACGCGACGACAGCTAT -3' \\
\hline
\end{tabular}

Table 8: Primers used to verify marG and marA gene deletions

\subsubsection{Generation of $S$. venezuelae JND2 $\Delta G$ and $S$. venezuelae JND2 $\Delta A$ mutants}

\subsubsection{Generation of S. venezuelae JND2 $\Delta$ G mutant}

To generate $S$. venezuelae JND2 $\Delta \mathrm{G}$ mutant, the pMAR $\Delta \mathrm{G}$ cosmid was transformed into dam ${ }^{-} / \mathrm{dcm}^{-}$methylation deficient E. coli (New England Biolabs, Ipswich, MA) and the dam/dcm cosmid was purified. Protoplasts of wild type $S$. venzuelae were prepared according to the following protocol modified from reference [69]:

S. venezuelae spores were propagated onto SPA agar and incubated at $30{ }^{\circ} \mathrm{C}$ for 7 days. Fresh spores were used to inoculate $30 \mathrm{ml}$ of SGGP media, in $300 \mathrm{ml}$ baffled flask, and the culture was allowed to grow overnight at $30{ }^{\circ} \mathrm{C}$. Mycelia were harvested by centrifugation at room temperature. The harvested mycelia 
were suspended in $8 \mathrm{ml} \mathrm{P}$-buffer (sucrose, $\mathrm{K}_{2} \mathrm{SO}_{4}, \mathrm{MgCl}_{2} \cdot 6 \mathrm{H}_{2} \mathrm{O}$, and trace elements) containing $1 \mathrm{mg} / \mathrm{ml}$ of lysozyme and then was incubated for $45 \mathrm{~min}$ at $30{ }^{\circ} \mathrm{C}$. The mycelia suspension was mixed by pipetting up and down for 3 times using a $5 \mathrm{ml}$ pipette then returned for $30^{\circ} \mathrm{C}$ incubation for an additional $15 \mathrm{~min} .5$ $\mathrm{ml}$ of fresh P-buffer were added followed by pipetting up and down for 3 times using a $5 \mathrm{ml}$ pipette followed by filtration through sterile cotton wool. The filtrate was centrifuged for $7 \mathrm{~min}$ at room temperature at $3000 \mathrm{rpm}$ and the precipitated protoplasts were washed twice with fresh P-buffer. The protoplasts were finally suspended in $5 \mathrm{ml} \mathrm{P-buffer} \mathrm{and} \mathrm{aliquoted} \mathrm{as} 250 \mu \mathrm{l}$ volumes. For transformation of $\mathrm{dam}^{-} / \mathrm{dcm}^{-} \mathrm{pMAR} \Delta \mathrm{G}$ cosmid, the following protocol, modified from reference [69], was used:

$1 \mathrm{ml}$ of sterile PEG 8000 was melted in microwave for $20 \mathrm{sec}$ and then mixed with $3 \mathrm{ml}$ of fresh P-buffer to form a 25\% PEG 8000 solution. Quick-thawed protoplasts were centrifuged at room temperature for $2 \mathrm{~min}$ at $3000 \mathrm{rpm}$, decanted and the precipitated cells were suspended in the $100 \mu \mathrm{l}$ left. $1 \mu \mathrm{g}$ of $\mathrm{dam}^{-} / \mathrm{dcm}^{-} \mathrm{pMAR} \Delta \mathrm{G}$ cosmid were added to the protoplasts immediately followed by the addition of $600 \mu \mathrm{l}$ of $25 \%$ PEG 8000 solution. $50 \mu \mathrm{l}$ transformation mixture was spread onto pre-dried R2YE plates and incubated overnight at room temperature. Plates were overlaid with $1 \mathrm{ml}$ LB broth containing $500 \mu \mathrm{g} / \mathrm{ml}$ spectinomycin and $500 \mu \mathrm{g} / \mathrm{ml}$ of apramycin and plates were incubated at $30{ }^{\circ} \mathrm{C}$ for 5-7 days. Transformants were red in color and was propagated onto SPA agar plates supplied with $50 \mu \mathrm{g} / \mathrm{ml}$ spectinomycin and $50 \mu \mathrm{g} / \mathrm{ml}$ apramycin. 


\subsubsection{Generation of S. venezuelae JND2 $\Delta$ A mutant}

To generate $S$. venezuelae JND2 $\triangle \mathrm{A}$ mutant, pMAR $\triangle \mathrm{A}$ cosmid was transformed into E. coli $\mathrm{ET} 12537 / \mathrm{pUZ8002}$ (donor strain) which was later used in conjugation with wild type $S$. venezuelae as specified in section 2.3.4 with the addition of 50 $\mu \mathrm{g} / \mathrm{ml}$ of spectinomycin and $50 \mu \mathrm{g} / \mathrm{ml}$ of apramycin.

\subsubsection{LC/MS and MS/MS analysis of $S$. venezuelae JND2 $\Delta G$ and $S$.}

\section{venezuelae JND2 $\Delta$ A}

S. venezuelae JND2 $\Delta G$ and $S$. venezuelae JND2 $\Delta A$ strains were propagated on SPA agar containing $50 \mu \mathrm{g} / \mathrm{ml}$ of apramycin and spectinomycin antibiotics. Fresh spores were used to inoculate $10 \mathrm{ml}$ of SCM media containing the same antibiotics. The mycelia were harvested after 72 hours by centrifugation at 5000 rpm, $4{ }^{\circ} \mathrm{C}$, for 10 minutes. The cells were lysed by the addition of acetone followed by sonication. The acetone extract was concentrated under vacuum and the dried acetone extract was dissolved in methanol prior to MS analysis. The acetone extract of $S$. venezuelae JND2 $\Delta \mathrm{G}$ was analyzed using ThermoElectron LTQ-Orbitrap mass spectrometer equipped with an Agilent MWD HPLC using buffer A: water/acetonitrile/methanol $(5: 1: 4)$ and buffer B: $100 \%$ methanol according to protocol specified in Table 9. The acetone extract of $S$. venezuelae JND2 $\triangle \mathrm{A}$ was analyzed using MicroToF-Q mass spectrometer equipped with an Agilent 1100 series HPLC using buffer A: water with $0.1 \%$ formic acid and buffer B: acetonitrile wilth $0.1 \%$ formic acid and according to protocol specified in Table 
10. The LC/MS analysis of both strains was done using $2.1 \times 250 \mathrm{~mm}, 5 \mu \mathrm{m}$, reverse phase Supelco 18C-column (Supelco, St. Louis, MO).

\begin{tabular}{|c|c|c|c|}
\hline Time $(\mathrm{min})$ & $\begin{array}{c}\text { Flow } \\
(\mathrm{ml} / \mathrm{min})\end{array}$ & $\% \mathrm{~A}$ & $\% \mathrm{~B}$ \\
\hline 0 & 0.2 & 90.0 & 10.0 \\
\hline 5.0 & 0.2 & 90.0 & 10.0 \\
\hline 40.0 & 0.2 & 0.0 & 100.0 \\
\hline 50.0 & 0.2 & 0.0 & 100.0 \\
\hline 51.0 & 0.2 & 90.0 & 10.0 \\
\hline 60.0 & 0.2 & 90.0 & 10.0 \\
\hline
\end{tabular}

Table 9: HPLC conditions used in the LC/MS analysis of S. venezuelae JND2 $\Delta G$

\begin{tabular}{|c|c|c|c|}
\hline Time $(\mathrm{min})$ & $\begin{array}{c}\text { Flow } \\
(\mathrm{ml} / \mathrm{min})\end{array}$ & $\% \mathrm{~A}$ & $\% \mathrm{~B}$ \\
\hline 0 & 0.2 & 95.0 & 5.0 \\
\hline 2.0 & 0.2 & 95.0 & 5.0 \\
\hline 25.0 & 0.2 & 0.0 & 100.0 \\
\hline 30.0 & 0.2 & 0.0 & 100.0 \\
\hline 31.0 & 0.2 & 95.0 & 5.0 \\
\hline 36.0 & 0.2 & 95.0 & 5.0 \\
\hline
\end{tabular}

Table 10: HPLC conditions used in the LC/MS analysis of $S$. venezuelae JND2 $A A$ 


\subsubsection{Purification and structure elucidation of compounds isolated from $S$.}

\section{venezuelae JND2 $\Delta \mathrm{G}$ and S. venezuelae JND2 $\Delta \mathrm{A}$}

\subsubsection{Purification and structure elucidation of G410 from $S$.}

venezuelae JND2AG

Spores of $S$. venezuelae JND2 $\Delta G$ were propagated onto SPA agar plates supplied with $50 \mu \mathrm{g} / \mathrm{ml}$ of apramycin and $50 \mu \mathrm{g} / \mathrm{ml}$ of spectinomycin antibiotics. The plates were incubated at $30{ }^{\circ} \mathrm{C}$ for 7 days and fresh spores were used to inoculate $10 \mathrm{ml}$ of SCM media, in $50 \mathrm{ml}$ flasks, supplied with $50 \mu \mathrm{g} / \mathrm{ml}$ of apramycin and $50 \mu \mathrm{g} / \mathrm{ml}$ of spectinomycin antibiotics to form a seed culture. Once the seed culture started to produce a red color, approximately 48-72 hours after incubation, it was used to inoculate large scale fermentations of SCM media, $1 \mathrm{~L}$ each in a $4 \mathrm{~L}$ baffled flasks, at $1 \% \mathrm{v} / \mathrm{v}$. Large fermentations were also supplied with the same antibiotics, at the same concentrations, and were incubated at $30{ }^{\circ} \mathrm{C}$ for 6 days and 220 rpms. The mycelia were harvested by centrifugation at $10000 \mathrm{rpm}, 6{ }^{\circ} \mathrm{C}$ for $10 \mathrm{~min}$. The harvested cells were disrupted by the addition of acetone followed by sonication 2 times, 5 min each. The acetone extract was dried under vacuum and the residual water was partitioned $3 x$ with ethyl acetate. The ethyl acetate fraction was evaporated under vacuum and the dried extract was stored at $-20^{\circ} \mathrm{C}$ until further use.

The crude extract was dissolved in methanol to yield $10 \mathrm{mg} / \mathrm{ml}$ solution and was purified using a Waters HPLC equipped with a DWD detector using $20.0 \times 250.0$ mm, $10 \mu \mathrm{m}$, reverse phase Ascentis ${ }^{18} \mathrm{C}$-column (Supelco, St. Louis, MO) using 
buffer A: water/acetonitrile/methanol (5:1:4) and buffer B: 100\% methanol using the gradient specified in Table 11.

\begin{tabular}{|c|c|c|c|}
\hline Time $(\mathrm{min})$ & $\begin{array}{c}\text { Flow } \\
(\mathrm{ml} / \mathrm{min})\end{array}$ & $\% \mathrm{~A}$ & $\% \mathrm{~B}$ \\
\hline 0 & 10.0 & 90.0 & 10.0 \\
\hline 2.0 & 10.0 & 90.0 & 10.0 \\
\hline 40.0 & 10.0 & 0.0 & 100.0 \\
\hline 50.0 & 10.0 & 0.0 & 100.0 \\
\hline 51.0 & 10.0 & 90.0 & 10.0 \\
\hline 60.0 & 10.0 & 90.0 & 10.0 \\
\hline
\end{tabular}

Table 11: HPLC conditions for first round of G410 purification

The peak eluting at retention time 25 min (Figure 23) was collected, dried under vaccum and the residual water was removed by lyophilization. The $25 \mathrm{~min}$ fraction was dissolved in choloroform and loaded onto $20 \times 20 \mathrm{~cm}$ preparative silica gel 60A TLC plates (Whatman). The TLC plate was developed using $50 \%$ ethyl acetate/hexane mixture. The bottom layer was excised from the TLC plate and extracted with acetone (Figure 24). 


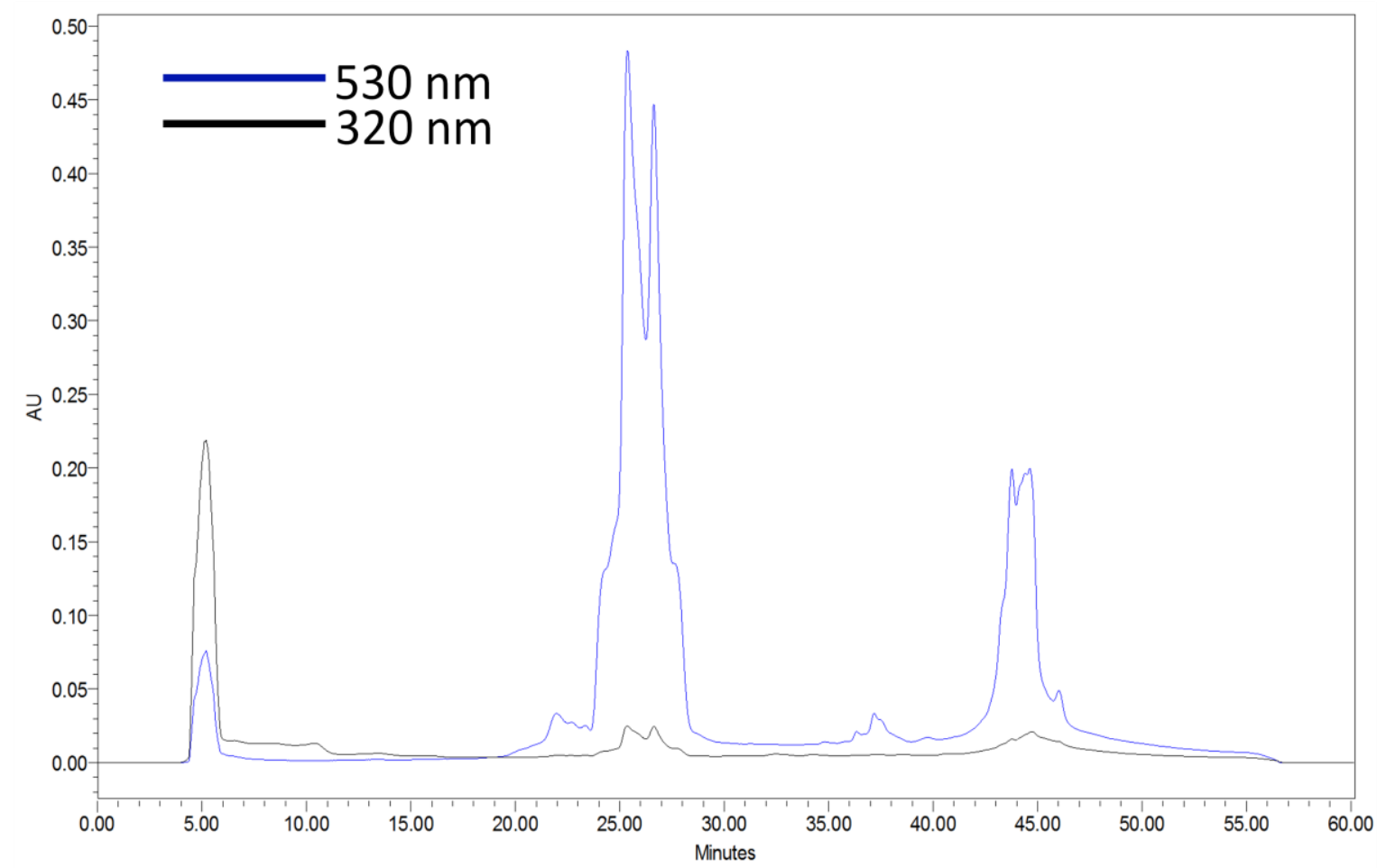

Figure 23: First HPLC purification of G410. Peak at retention time 25 minutes was collected, concentrated and subjected to preparative TLC.

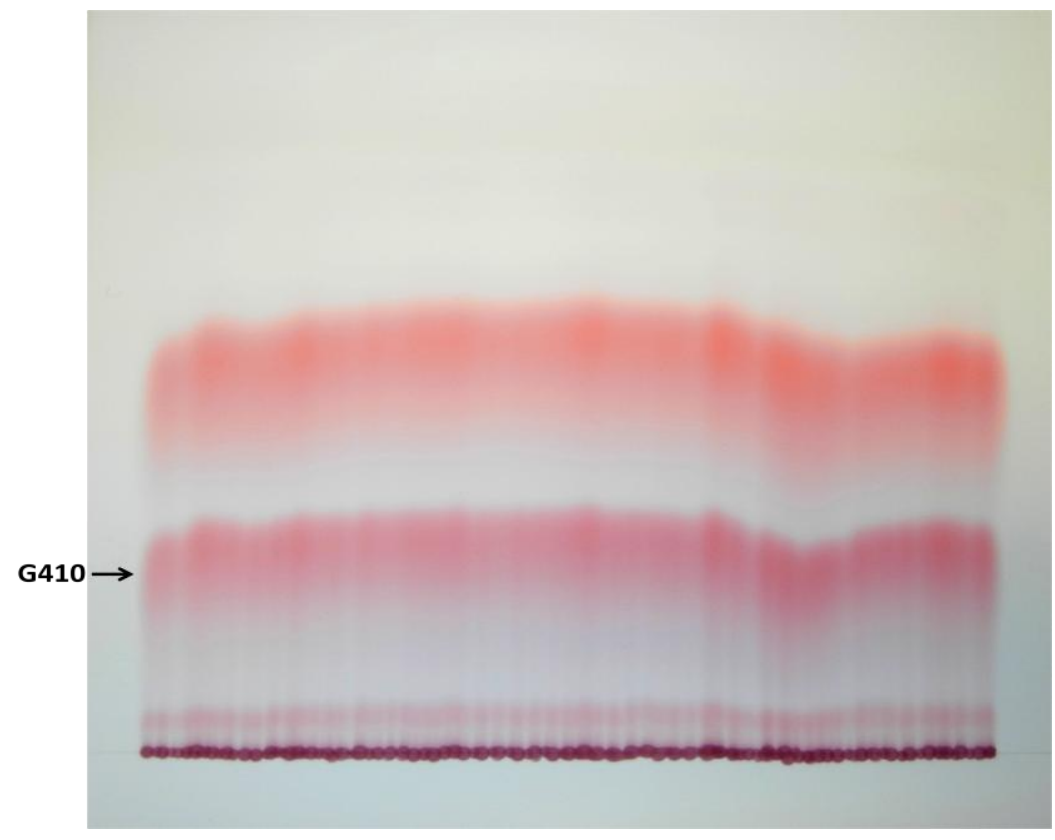

Figure 24: Preparative TLC purification of G410. The arrow show the layer that was later excised from the TLC plate and subjected to another round of HPLC purification. 
The semi-pure G410 was subjected to a final round of HPLC purification using an Agilent HPLC equipped with a MWD detector using $10.0 \times 250.0 \mathrm{~mm}, 5 \mu \mathrm{m}$, and reverse phase ${ }^{18} \mathrm{C}$-phenomenex column using method specified in Table 12.

\begin{tabular}{|c|c|c|c|}
\hline Time $(\mathrm{min})$ & $\begin{array}{c}\text { Flow } \\
(\mathrm{ml} / \mathrm{min})\end{array}$ & $\% \mathrm{~A}$ & $\% \mathrm{~B}$ \\
\hline 0 & 4.0 & 95.0 & 5.0 \\
\hline 25.0 & 4.0 & 0.0 & 100.0 \\
\hline 30.0 & 4.0 & 0.0 & 100.0 \\
\hline 31.0 & 4.0 & 95.0 & 5.0 \\
\hline 40.0 & 4.0 & 95.0 & 5.0 \\
\hline
\end{tabular}

Table 12: HPLC method for final purification of G410

Peak eluting at retention time 14 min was collected, dried under vacuum and the residual water was eliminated via lyophilization to yield $1 \mathrm{mg}$ of pure G410.

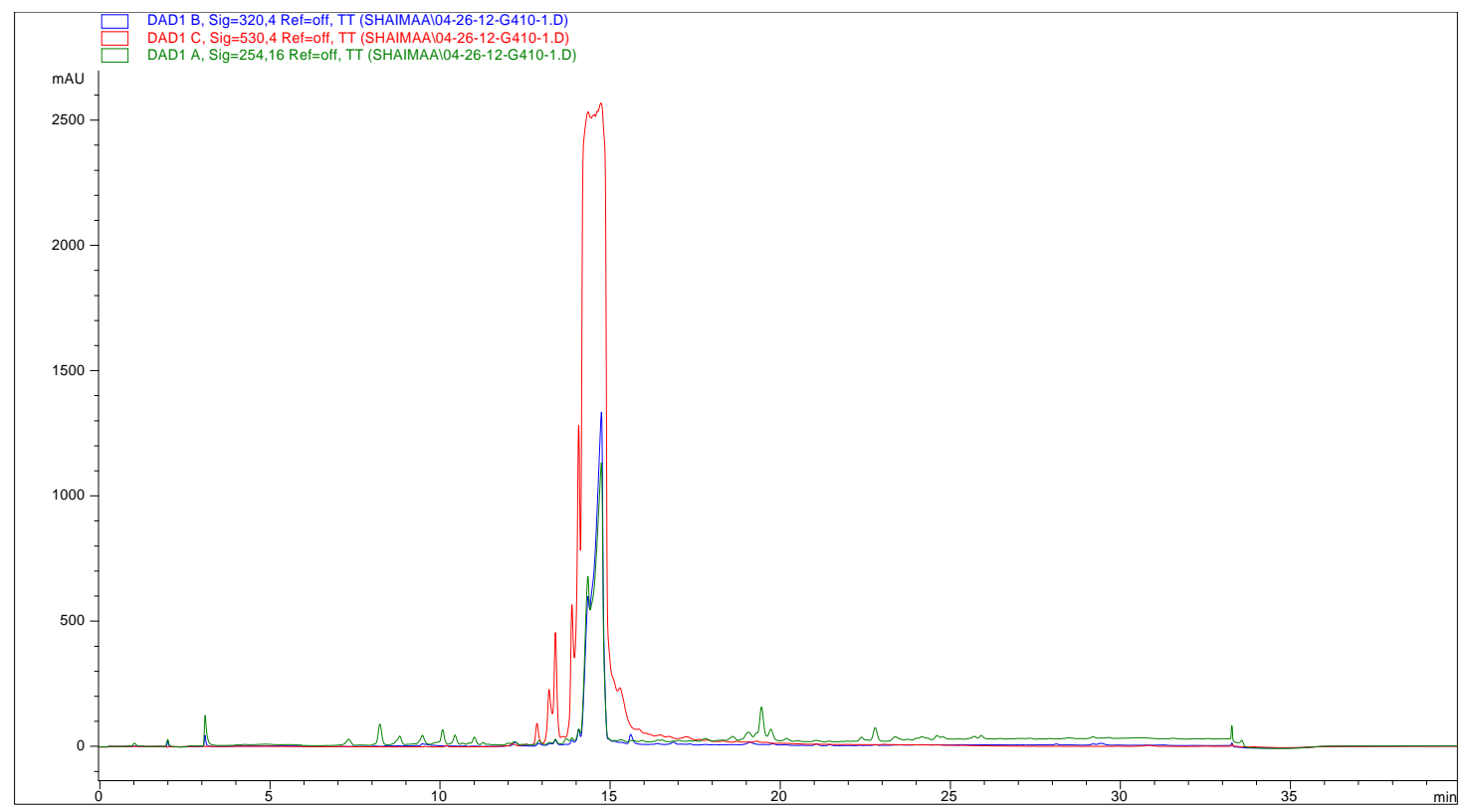

Figure 25: Final HPLC purification of G410. The peak eluting at 14 min was collected and evaporated to yield pure G410. 
The $98 \%$ pure G410 was dissolved in acetone- $d_{6}$ for NMR characterization. NMR spectra were obtained using a Bruker AMX - $600 \mathrm{MHz}$ spectrometer (Bruker Daltonics) calibrated using residual acetone peak at $2.05 \mathrm{ppm}$.

\subsubsection{Purification and structure elucidation of JN422 and JN408 from}

\section{S. venezuelae JND2 $\Delta A$}

Spores of $S$. venezuelae JND2 $\triangle A$ were propagated onto SPA agar plates supplied with $50 \mu \mathrm{g} / \mathrm{ml}$ of apramycin and $50 \mu \mathrm{g} / \mathrm{ml}$ of spectinomycin antibiotics. For large scale purification, plates were incubated at $30{ }^{\circ} \mathrm{C}$ for 7 days and fresh spores were directly used to inoculate $60-100 \mathrm{ml}$ of SCM media, in $300-500 \mathrm{ml}$ flasks, supplied with $50 \mu \mathrm{g} / \mathrm{ml}$ of apramycin and $50 \mu \mathrm{g} / \mathrm{ml}$ of spectinomycin antibiotics. Large scale production from seed culture or using bigger flasks was unsuccessful for this strain. Flasks were incubated at $30{ }^{\circ} \mathrm{C}$ for 6 days and 220 rpm. The mycelia were harvested by centrifugation at $10000 \mathrm{rpm}, 6{ }^{\circ} \mathrm{C}$ for 10 min. The harvested cells were disrupted by the addition of acetone followed by sonication 2 times, 5 min each. The acetone extract was dried under vacuum and the residual water was removed by lyophilization. The crude acetone extract was stored at $-20{ }^{\circ} \mathrm{C}$ until further use. At time of purification, the extract was dissolved in methanol and the extract was partially purified using Agilent HPLC equipped with a MWD detector using $10.0 \times 250.0 \mathrm{~mm}, 5 \mu \mathrm{m}$, and reverse phase ${ }^{18} \mathrm{C}$ phenomenex column using the method specified in Table 13. 


\begin{tabular}{|c|c|c|c|}
\hline Time $(\mathrm{min})$ & $\begin{array}{c}\text { Flow } \\
(\mathrm{ml} / \mathrm{min})\end{array}$ & $\% \mathrm{~A}$ & $\% \mathrm{~B}$ \\
\hline 0 & 4.0 & 95.0 & 5.0 \\
\hline 30.0 & 4.0 & 15.0 & 85.0 \\
\hline 35.0 & 4.0 & 15.0 & 85.0 \\
\hline 36.0 & 4.0 & 95.0 & 5.0 \\
\hline 46.0 & 4.0 & 95.0 & 5.0 \\
\hline
\end{tabular}

Table 13: HPLC method used in the purification of JN422 and JN408 from S. venezuelae JND2 $\Delta$ A.

The peaks with retention time $15 \mathrm{~min}$ and $21 \mathrm{~min}$ (Figure 26); corresponding to JN422 and JN408 respectively, were collected and concentrated under vacuum. The residual water was removed via lyophilization and the semi-pure compounds were each subjected to another round of HPLC purification using the same conditions as specified in Table 13 (Figure 27).

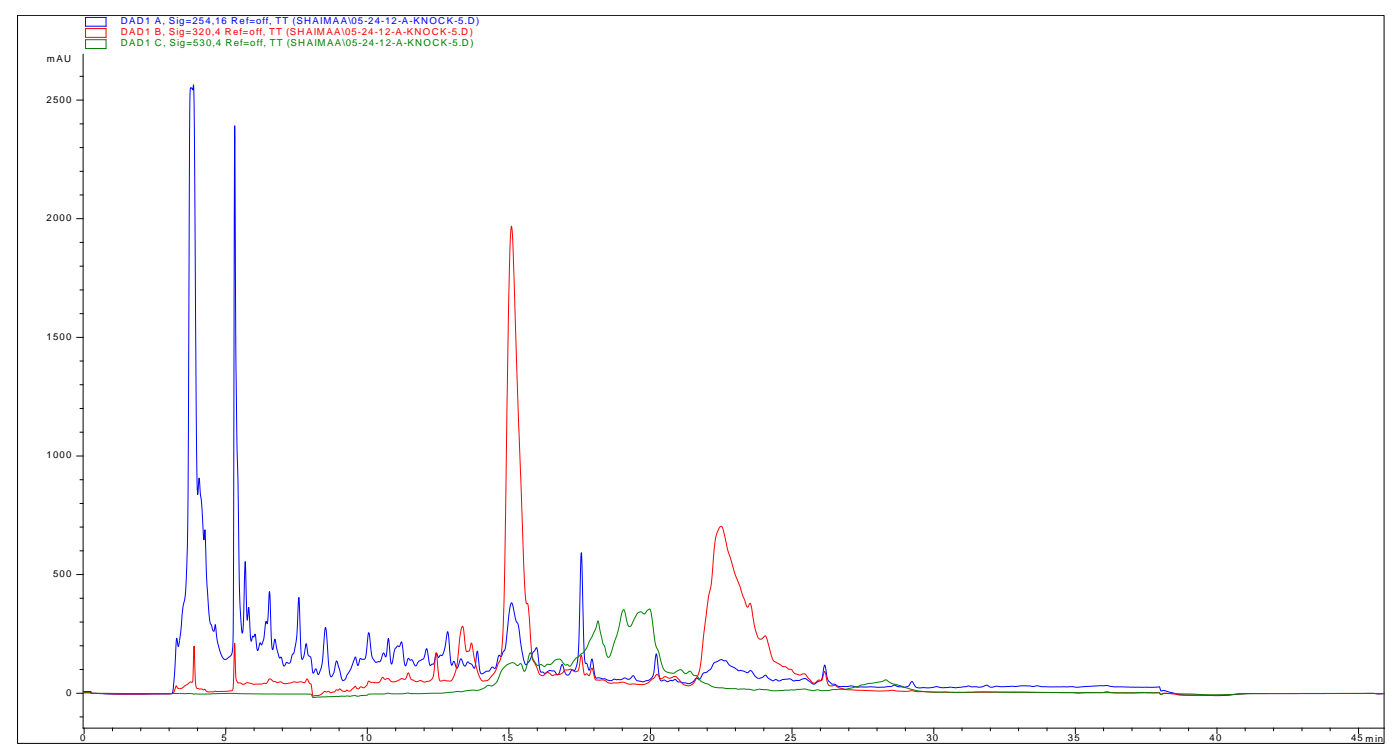

Figure 26: First HPLC purification of JN422 and JN408 from S. venezuelae JND2 $\Delta$ A. The peak with retention time of 15 minutes corresponds to JN422 while, the peak with retention time of 21 minutes corresponds to JN408. Both peaks were collected and subjected to another round of HPLC purification. 

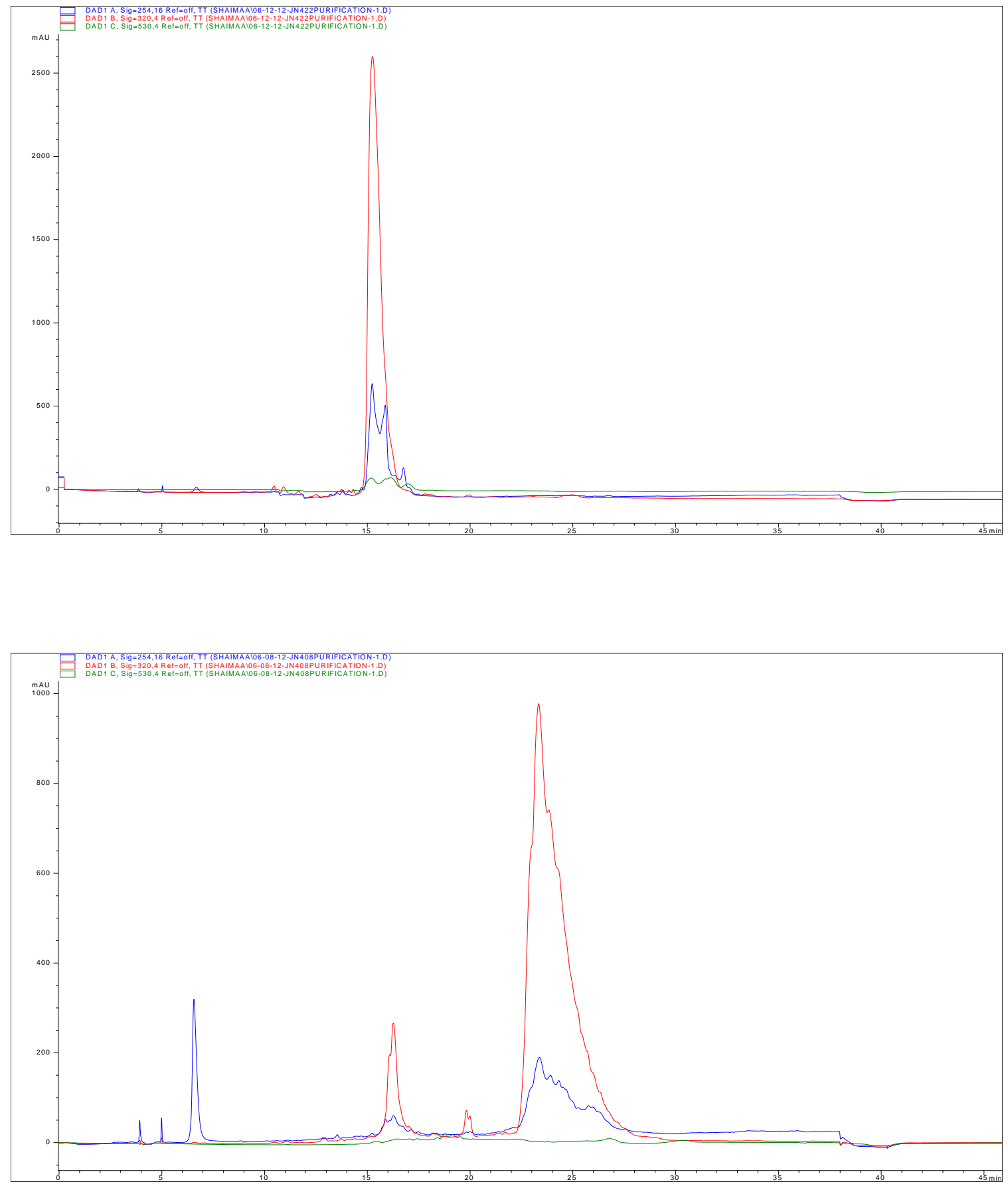

Figure 27: Second HPLC purification of JN422 (top panel) and JN408 (bottom panel). The peak with retention time of 15 minutes (top panel) corresponds to JN422. The peak with retention time of 22 minutes (bottom panel) corresponds to JN408. 
The peak with retention time 15 min (top chromatogram, Figure 27) was collected and dried under vacuum. Residual water was removed via lyophilization to yield $1 \mathrm{mg}$ of $90 \%$ pure JN422 (Figure 28) while collection of peak with retention time of $21 \mathrm{~min}$ (bottom chromatogram, Figure 27) and lyophilization yielded $0.5 \mathrm{mg}$ of $95 \%$ pure JN408 (Figure 29). Purity estimations were based on HPLC, MS and NMR data.

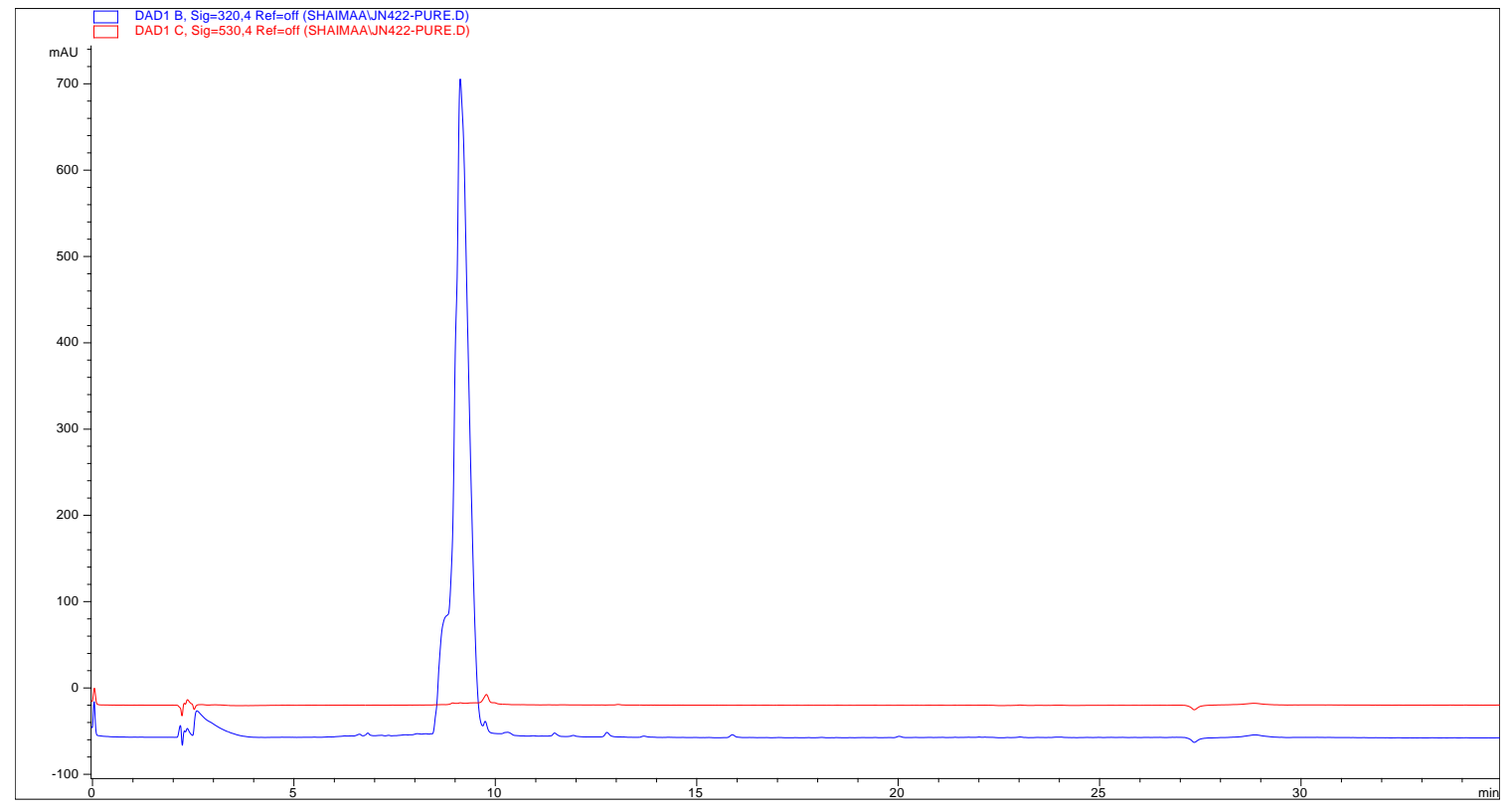

Figure 28: HPLC chromatogram of pure JN422 


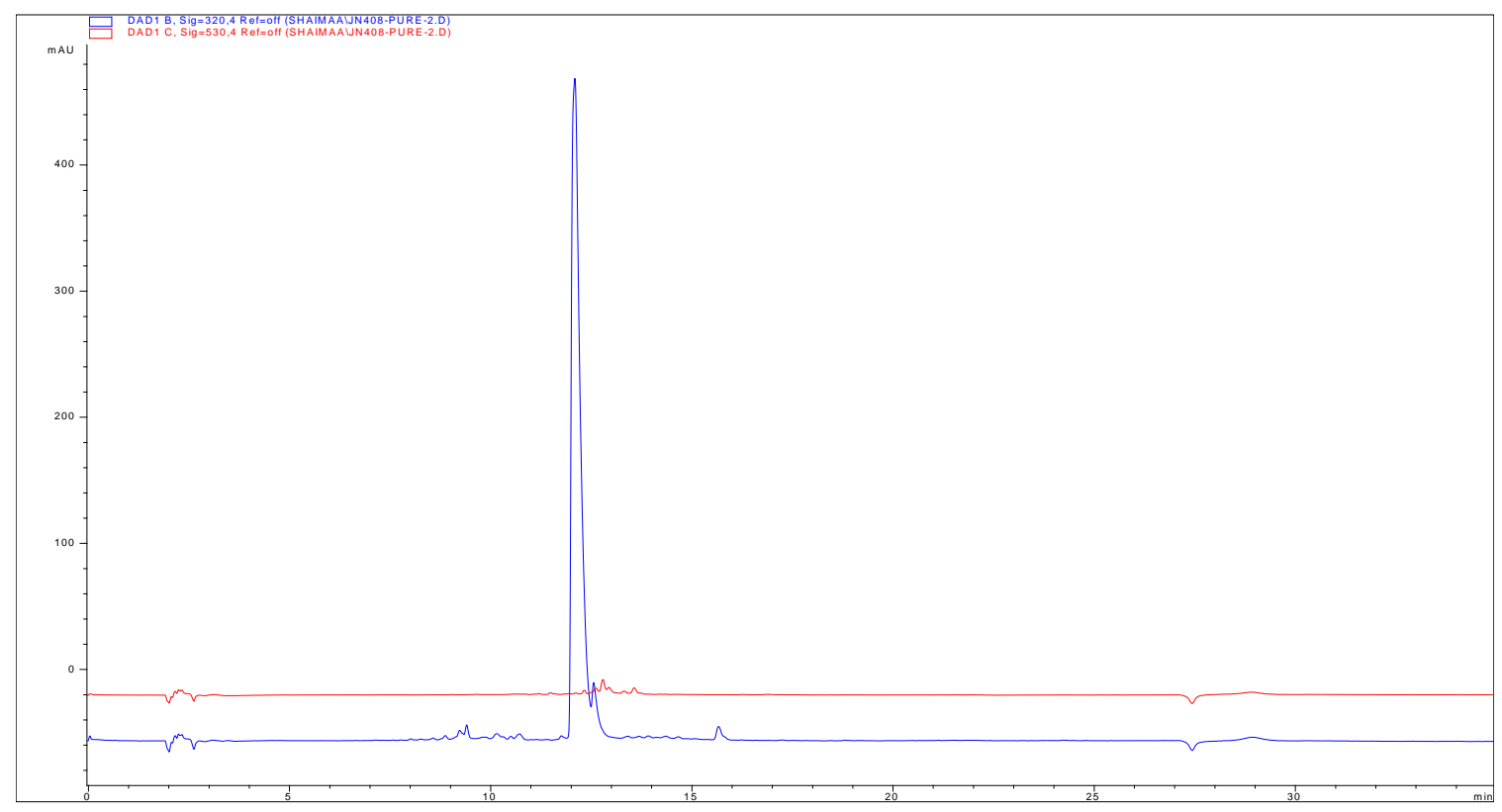

Figure 29: HPLC chromatogram of pure JN408

Pure dried JN422 and JN408 were each dissolved in acetone- $d_{6}$ for NMR characterization. NMR spectra were obtained using a Bruker AMX - $600 \mathrm{MHz}$ spectrometer (Bruker Daltonics) calibrated using residual acetone peak at 2.05 ppm. 


\subsection{RESULTS AND DISCUSSION}

\subsubsection{The role of MarG and MarA in the biosynthesis of marineosin}

\subsubsection{The role of MarG in the biosynthesis of marineosin}

\subsection{Sequence analysis of marG}

The marG gene is $1356 \mathrm{bp}$ long with a predicted protein sequence consists of 450 amino acids, corresponding to a calculated molecular weight of $50.96 \mathrm{kDa}$. MarG shares a relatively lower degree of annotated identity (65\% identity) to its red gene cluster counterpart, RedG when compared to homologies among other red and mar homologs (Table 1). Both enzymes belong to the family of nonheme iron Rieske oxygenases.

Typically, non-heme iron Rieske-oxygenases are multi-component enzyme systems consisting of a reductase and an oxygenase component. The oxygenase component of the Rieske-oxygenases is characterized by the presence of highly conserved $\mathrm{CXH}, \mathrm{CXXH}$ and $\mathrm{DXHX}{ }_{4} \mathrm{H}$ motifs. The histidine amino acid residues in the $\mathrm{CXH}$ and $\mathrm{CXXH}$ motifs are required to coordinate one iron of the [2Fe-2S] cluster while the cysteine amino acid residues are responsible for the coordination of the second iron atom [70] , [71]. It should be

noted that the histidine-liganded iron is the one undergoing reduction from $\mathrm{Fe}^{3+}$ to $\mathrm{Fe}^{2+}$ after the gain of an electron [72-75]. The histidine amino acid residue in the $\mathrm{DXHX}_{4} \mathrm{H}$ motif is required to coordinate a mononuclear non-heme iron center, which performs the catalysis. The Rieske center transfers electrons from reductive component to the mononuclear iron center via the aspartate amino acid 
residue in the $\mathrm{DXHX}_{4} \mathrm{H}$ motif [52]. The mononuclear iron forms a 2-His-1carboxylate facial triad that allows the iron center to bind three exogenous ligands, one of which is molecular oxygen [76]. The activated metal-oxygen intermediate can catalyze numerous kinds of reactions such as mono- and dihydroxylations of aromatic rings and oxidative ring cyclizations [77]. It has been proposed from numerous structural analyses of this class of enzymes, that the identity of the ligand trans to the oxygen dictates the type of reaction this class of enzymes catalyze. While both MarG and RedG have conserved $\mathrm{CXH}$ and $\mathrm{CXXH}$ motifs at their $\mathrm{N}$-terminal end, both enzymes have $\mathrm{EXHX}_{4} \mathrm{H}$ motif at their $\mathrm{C}$ terminal end rather than $\mathrm{DXHX}_{4} \mathrm{H}$ motif characteristic to other Rieskeoxygenases (Figure 30). Comparison of MarG and RedG with RphG and McpG, another two Rieske oxygenases proposed to be involved in the biosynthesis of roseophilin (26) and metacycloprodiginine (9) (Figure 31), both cyclic prodiginine analogs, indicates that all four enzymes have the same aspartate to glutamate modification. Although both amino acids have acidic nature and should catalyze the same types of reactions, an aspartate to glutamate mutation of naphthalene dioxygenase Rieske enzyme yielded an inactive enzyme [78]. Based on that study, we are proposing that the $\mathrm{EXHX}_{4} \mathrm{H}$ motif at the $\mathrm{C}$-terminal end of MarG and other Rieske oxygenases involved in carbon-carbon ring closures may be crucial for catalysis. 


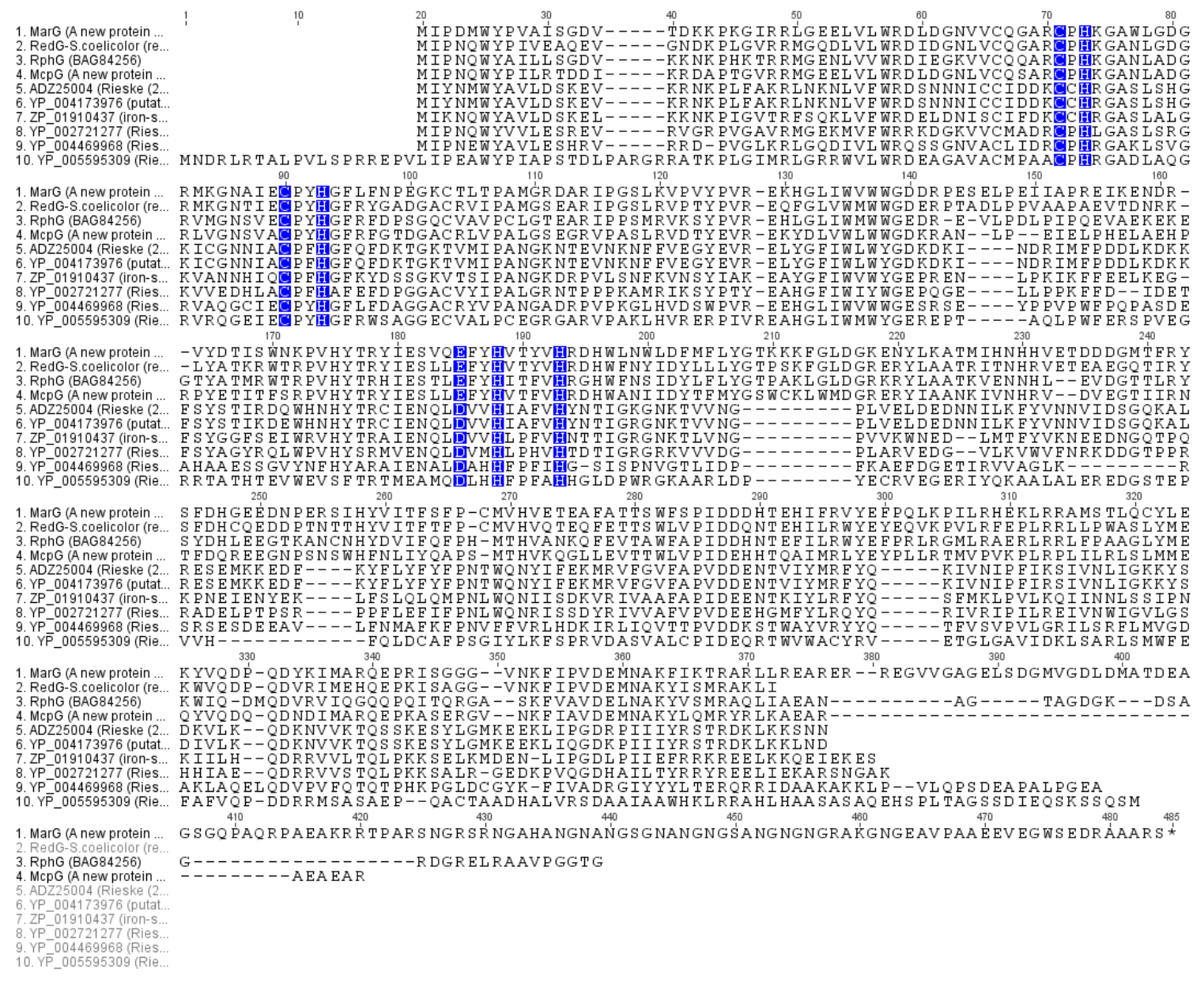

Figure 30: Sequence alignment of MarG and RedG with other Rieske-oxygenases. MarG and RedG share the $\mathrm{CXH}, \mathrm{CXXH}$ motifs of other Rieske-oxygenases at their $\mathrm{N}$-terminal end and $\mathrm{DXXHX}{ }_{4} \mathrm{H}$ motif at the $\mathrm{C}$-terminal end. It should be noted that the conserved aspartate (D) is glutamate (E) in MarG and RedG.

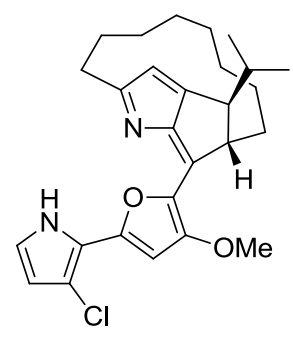

Roseophilin

(26)

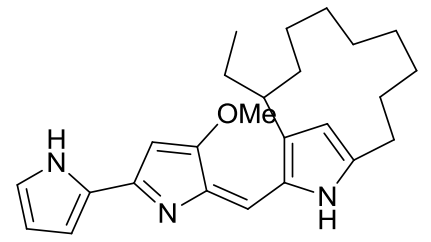

Metacycloprodiginine

(9)

Figure 31: Structure of roseophilin and metacycloprodiginine: two cyclic prodiginine analogs. 


\subsection{Targeted gene replacement of marG and the generation of $S$. venezuelae JND2AG: A marG knockout strain}

In Section 2.4.2, we proposed that undecylprodiginine (7) is a possible intermediate along the pathway that leads to the biosynthesis of marineosin. We also hypothesized that MarG enzyme, a Rieske oxygenase, could be involved in the introduction a hydroxyl group to the acyl chain of undecylprodiginine (7) intermediate. This hydroxylation is essential for the biosynthesis of the spiroaminal moiety of marineosin in hypothesis No. 1 (Figure 19). To test this hypothesis, marG gene encoding the Rieske-oxygenase MarG in the pMAR cosmid, was replaced with a spectinomycin resistance marker gene called aadA. The gene replacement was confirmed via PCR using primers designed to amplify the region flanking the marG gene. The PCR of pMAR cosmid using these primers led to the amplification of a fragment of $\sim 1800 \mathrm{bp}$ corresponding to marG gene (1356 bp) plus the flanking 400 bp (lane C, Figure 32). When the PCR done using the same primers using marG replacement mutant cosmid, $p M A R \triangle G$ led to the amplification of $\sim 1500 \mathrm{bp}$ fragment corresponding to $\mathrm{aad} A$ gene (1150 bp) plus the flanking $400 \mathrm{bp}$ (lane $\Delta \mathrm{G}$, Figure 32). 


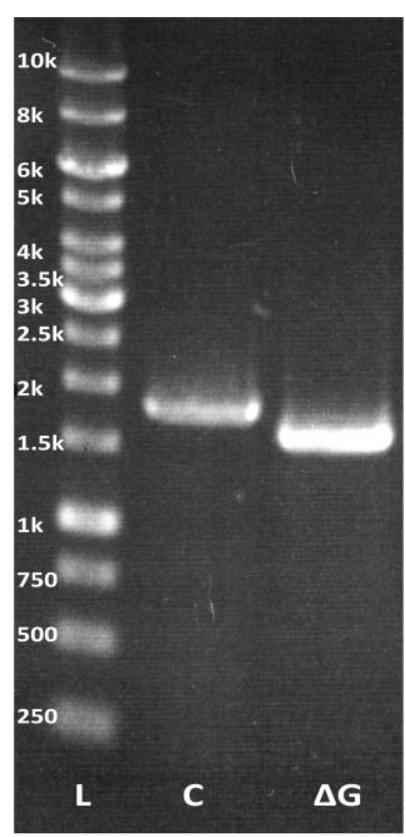

Figure 32: Confirmation of marG replacement, from pMAR cosmid, with aadA gene conferring resistance to spectinomycin antibiotic. Lane $L=D N A$ ladder, lane $C=P C R$ control performed using pMAR cosmid, lane $\Delta G=P C R$ performed using pMAR $\Delta G$ cosmid.

The mutant cosmid, $p M A R \Delta G$ was delivered to wild type $S$. venezuelae via protoplast transformation and the new strain was named $S$. venezuelae JND2 $\Delta G$. The new mutant strain is apramycin and spectinomycin resistant and is bright red in color.

\subsection{MS, LC/MS and LC-UV/MS analysis of S. venezuelae JND2 $\Delta G$}

In order to determine the main metabolites accumulated as a result of marG replacement, the MS profile of the crude acetone extract of $S$. venezuelae JND2 $\Delta G$ was determined using ThermoElectron LTQ-Orbitrap high resolution mass analyzer. The analysis was run side by side with crude acetone extracts of 
both, wild type $S$. venezuelae and $S$. venezuelae JND2, marineosin producer strain (Figure 33).

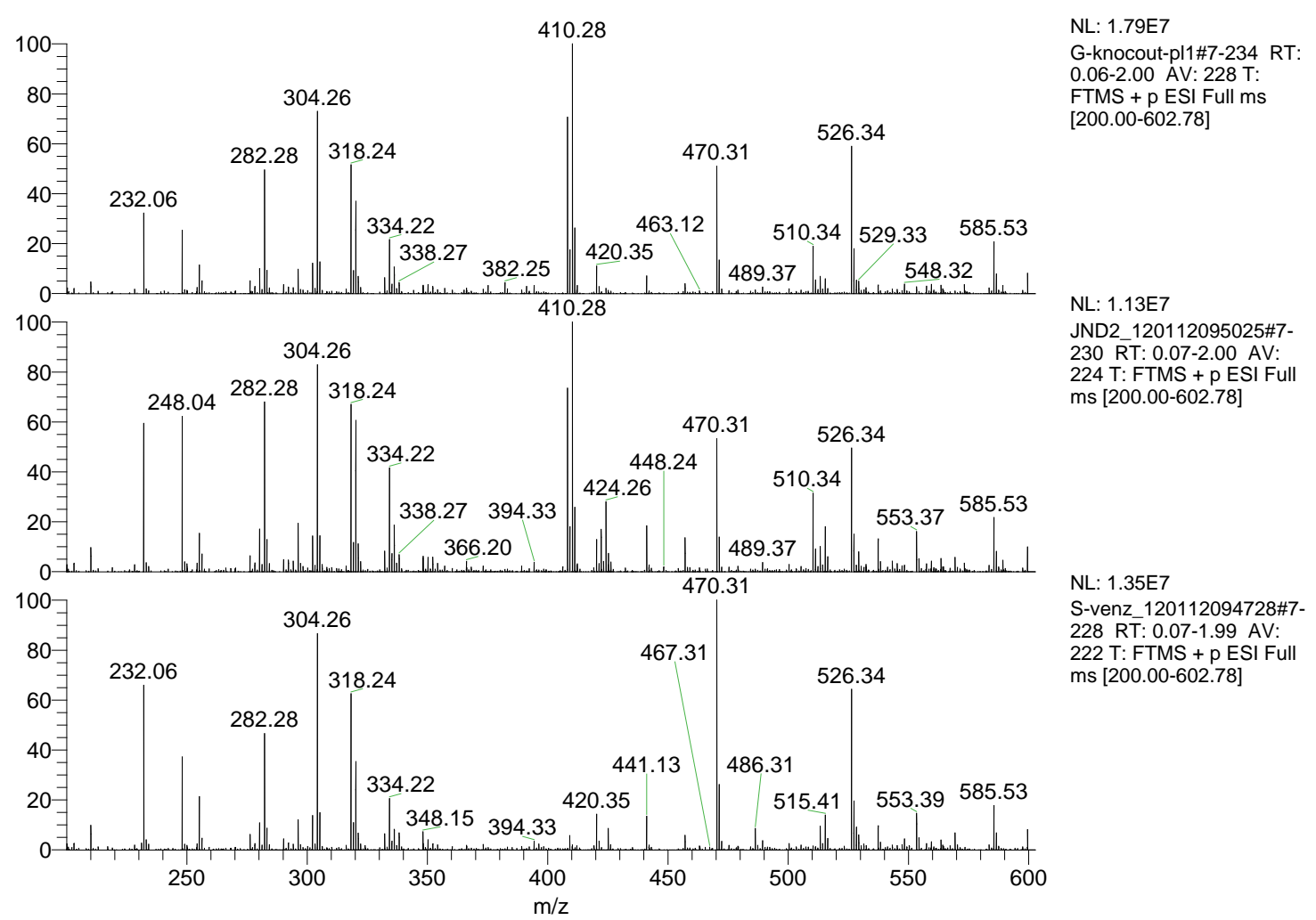

Figure 33: Comparison of the MS profiles of $S$. venezuelae JND2 $\Delta G$ (top panel), JND2 strain (middle) and wild type S. venezuelae (bottom). JND2 $\Delta$ G (top panel) and JND2 (middle panel) strains have the same MS profile where both strains show a compound of $\mathrm{m} / z 410.28$ in addition to the metabolites normally produced by the wild type $S$. venezuelae (bottom) such as methymycin and pikromycin, $\mathrm{m} / z 470.31$ and 526.34 respectively.

The MS profile of both JND2 $\Delta G$ and JND2 strains was found to be different from that of wild type $S$. venezuelae. In addition to methymycin and pikromycin antibiotics, both strains share the accumulation of a compound of $[\mathrm{M}+\mathrm{H}] \mathrm{m} / \mathrm{z}$ 410.28 and corresponding molecular formula $\mathrm{C}_{25} \mathrm{H}_{36} \mathrm{O}_{2} \mathrm{~N}_{3}$, which is the same as that reported for marineosin [53]. Since production of marineosin by JND2 strain 
was already demonstrated in section 2.4 .1 , this preliminary data suggested that JND2 $\Delta G$ mutant strain also produces marineosin and therefore, MarG is not required for the biosynthesis of marineosin. However, analysis of the same acetone extract using LC/MS indicated that both marineosin in JND2 strain and $\mathrm{m} / \mathrm{z} 410.28$ compound in JND2 $\Delta \mathrm{G}$ mutant strain have different retention times (Figure 34) and that the compounds are different.

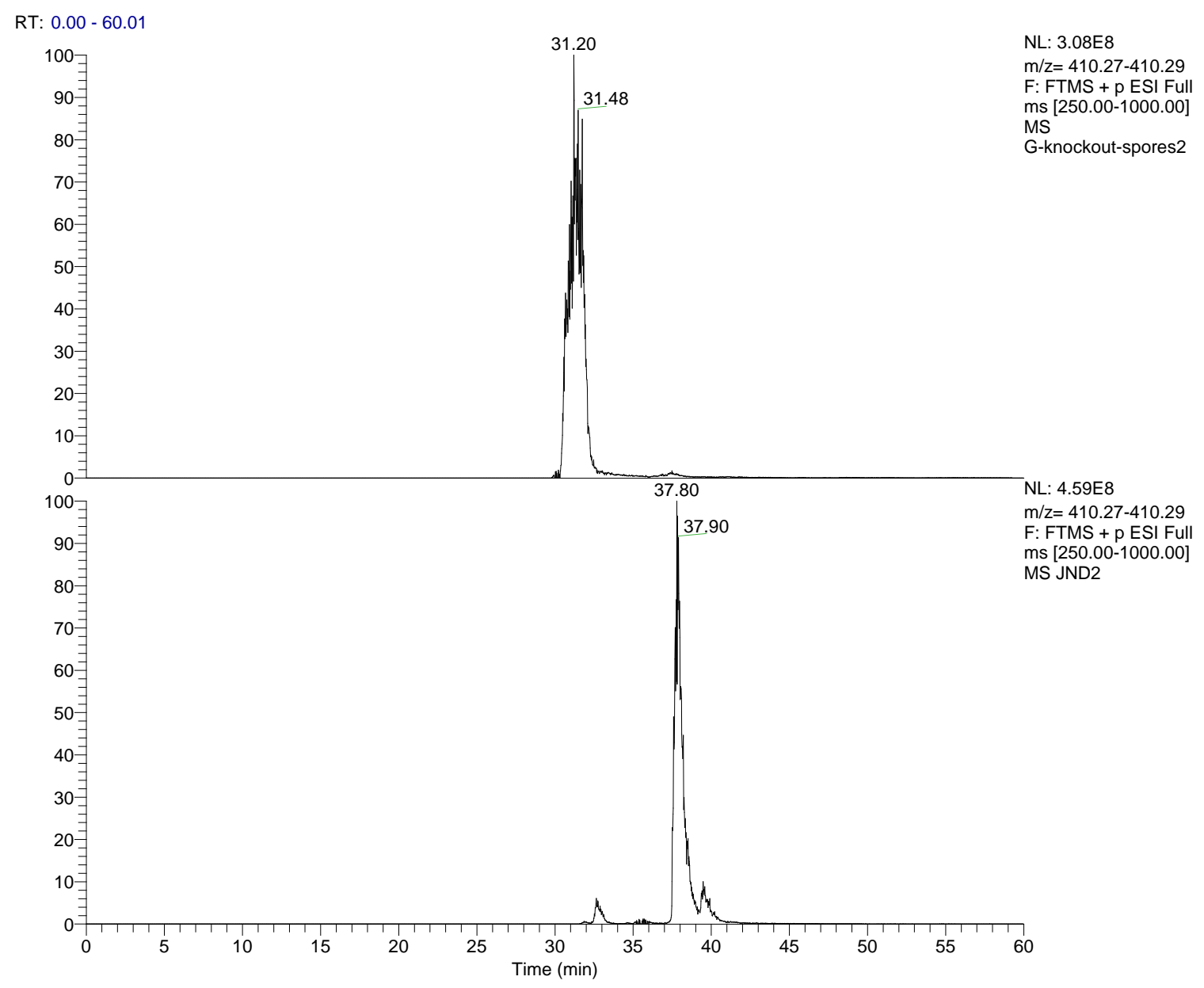

Figure 34: EIC of $m / z 410.28$ in S. venezuelae JND2 $\Delta$ G (top panel) and S. venezuelae JND2 (bottom panel). The extracted ion chromatogram (EIC) of $\mathrm{m} / \mathrm{z} 410.28$ from the LC/MS of both marG replacement mutant (top panel) and JND2 strains (bottom). 
As described in section 2.4.3, LC/UV analysis of the crude acetone extract of $S$. venezuelae JND2 indicates the presence of two groups of compounds: a group with a UV $\lambda \max$ of $320 \mathrm{~nm}$ and a group of $\lambda \max$ of $530 \mathrm{~nm}$. The LC-UV/MS chromatogram of $S$. venezuelae JND2 $\Delta G$ on the other hand, has only one group of red-colored compounds characterized with $\lambda \max 530 \mathrm{~nm}$ which indicates that deletion of marG abolishes the production of marineosin and other nonconjugated compounds observed in JND2 strain (Figure 35). These results demonstrate that marG is essential for the biosynthesis of marineosin and supports the hypothesis that the loss of conjugation and hence; the red color, occurs at a later step of the biosynthetic pathway.

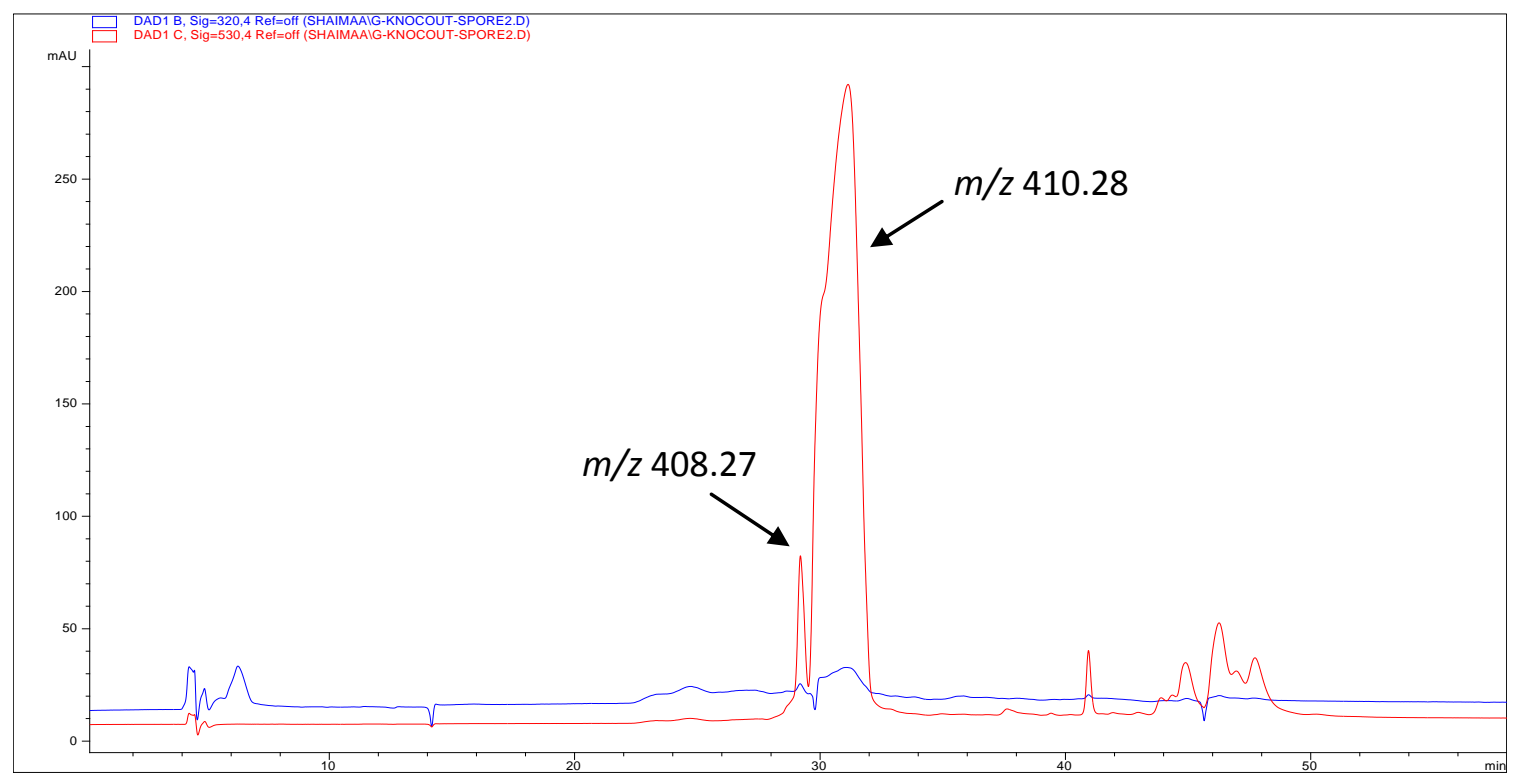

Figure 35: The LC-UV/MS profile of $S$. venezuelae JND2 $\Delta$ G. The red chromatogram represents absorption at $530 \mathrm{~nm}$ while blue chromatogram represents absorption at $320 \mathrm{~nm}$. 
Undecylprodiginine (7) production was not observed in this strain which indicates that MarG is not responsible for the introduction of the hydroxyl group required to initiate the biosynthesis of the spiroaminal ring of marineosin. This observation excludes hypothesis no. 1 proposed in section 2.4.2 (Figure 19). It should be noted that some of the non-conjugated compounds were di-hydroxylated, which may indicate that MarG is responsible for the introduction of that additional hydroxyl group.

\subsection{2-hydroxy-undecylprodiginine is the main metabolite accumulating in S. venezuelae JND2 $\Delta G$}

The main compound produced by $S$. venezuelae JND2 $\Delta$ G; a marG mutant, was named G410 (27) (Figure 36). The compound was isolated from the crude acetone extract of $S$. venezuelae JND2 $\Delta$ G using ethyl acetate extraction, HPLC, preparative TLC and a final HPLC purification step to yield $~ 0.5 \mathrm{mg}$ of $95 \%$ pure compound (Figure 37). Detailed analysis of the MS, UV, IR and NMR spectral data of G410 compound indicated its identity to be 2-hydroxyundecylprodiginine (27) (Figure 36).

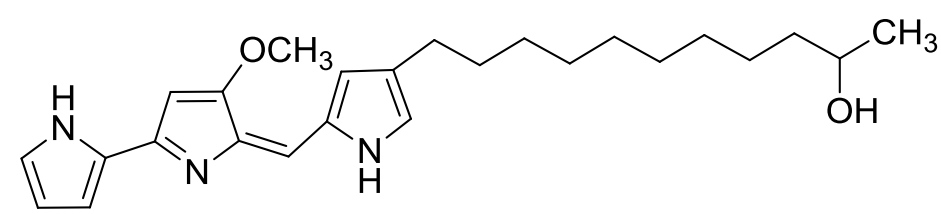

G410

(27)

Figure 36: Structure of 2-hydroxyundecylprodiginine, G410 


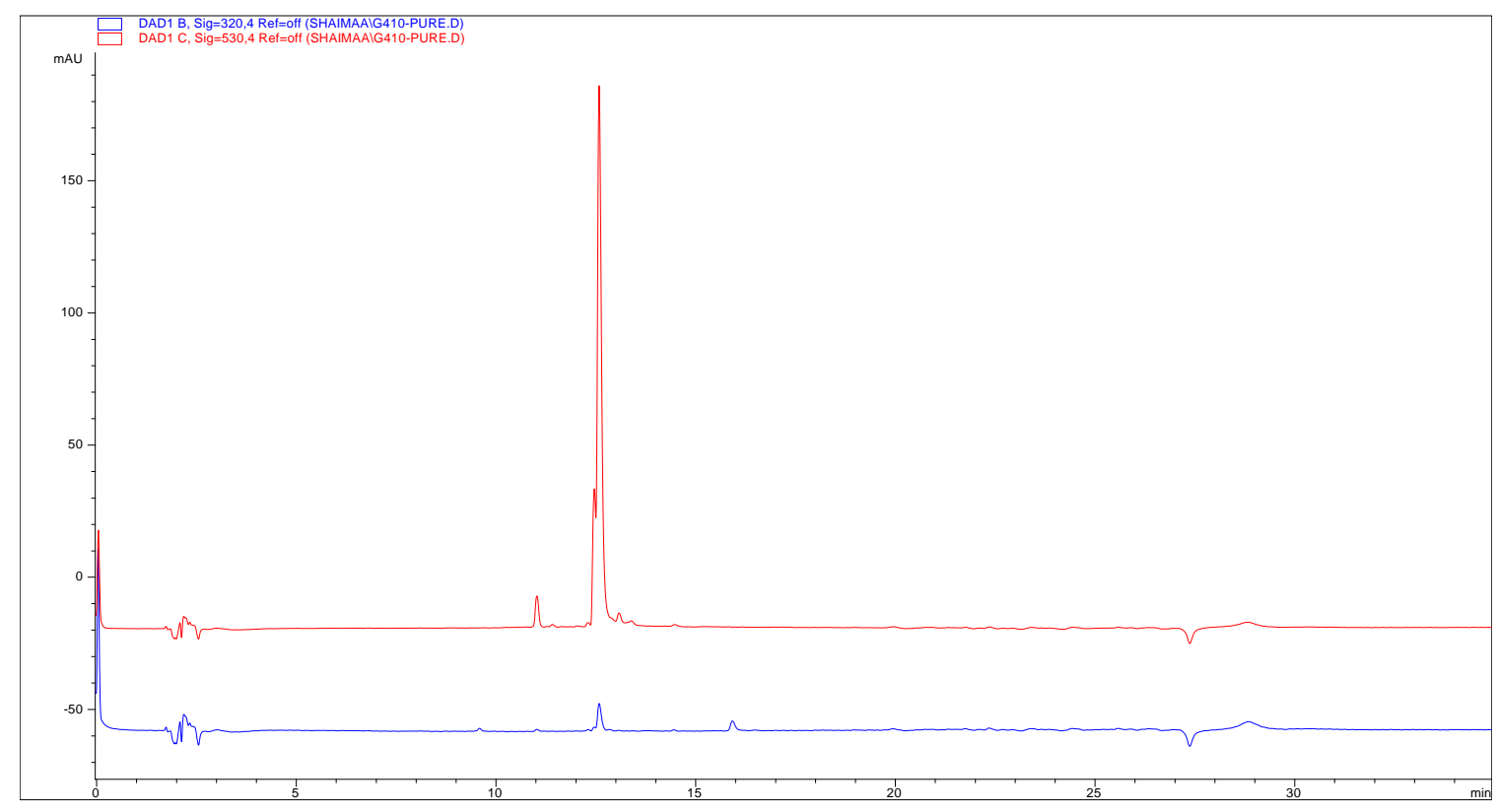

Figure 37: HPLC chromatogram of $95 \%$ pure G410. The red chromatogram represents absorption at $530 \mathrm{~nm}$ while blue chromatogram represents absorption at $320 \mathrm{~nm}$.

The UV spectrum of G410 (27) (Figure 38) has a prominent $\lambda$ max of $530 \mathrm{~nm}$, characteristic to prodiginines family of natural products due to their distinct red color. This observation suggested a fully conjugated tripyrrole skeleton for G410 (27) similar to that of undecylprodiginine (7). 


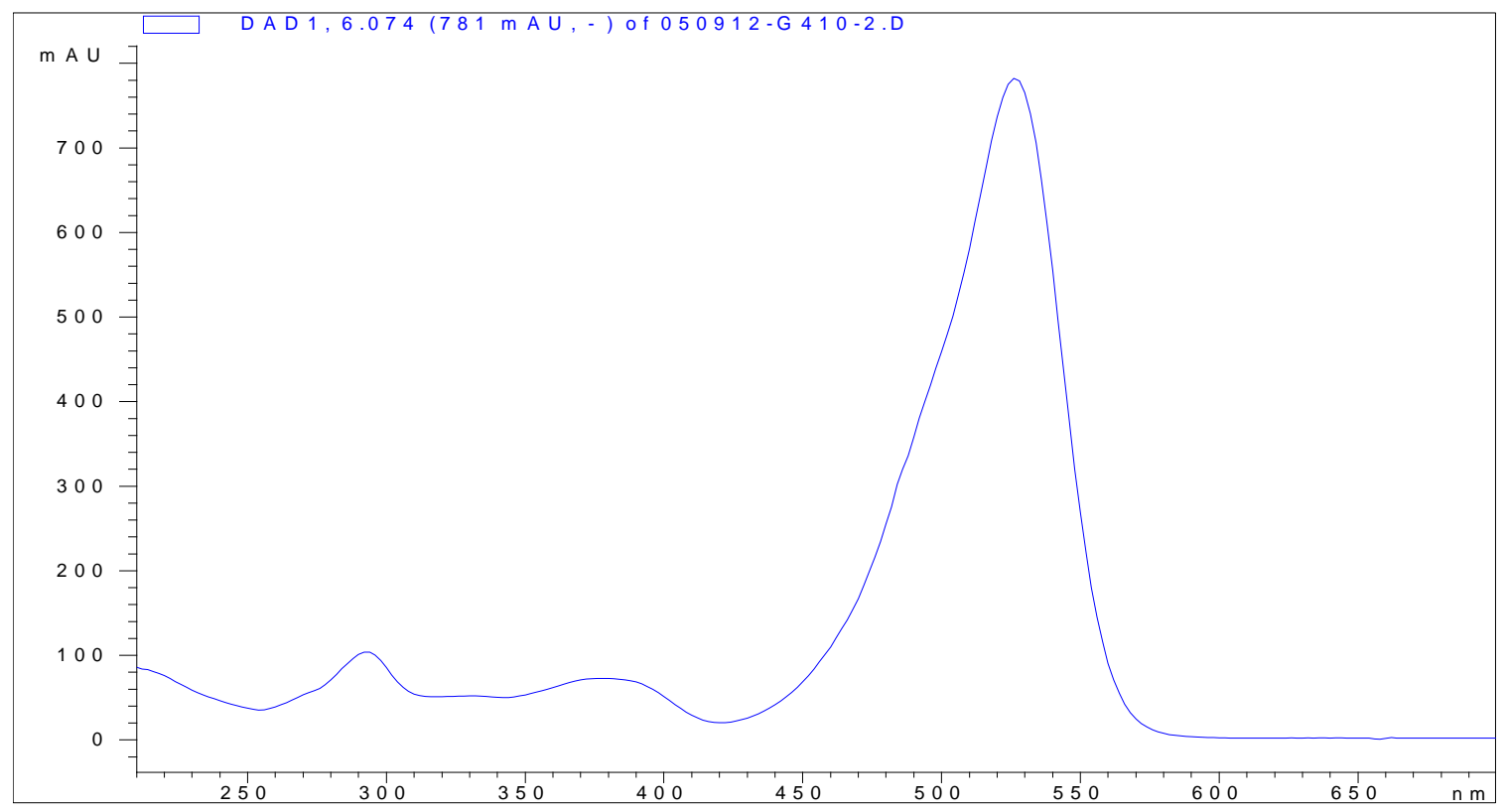

Figure 38: UV spectrum of G410

HR-ESI-MS analysis of G410 (27) exhibits $[\mathrm{M}+\mathrm{H}]^{+}$of $\mathrm{m} / \mathrm{z} 410.2807$ (Figure 39). The acquired mass was analyzed for molecular formula $\mathrm{C}_{25} \mathrm{H}_{36} \mathrm{O}_{2} \mathrm{~N}_{3}$ or, $\mathrm{C}_{25} \mathrm{H}_{35} \mathrm{O}_{2} \mathrm{~N}_{3}$ without the $\mathrm{H}$-adduct. The difference between the mass acquired for G410 and the mass of the predicted molecular formula is only $\mathrm{m} / \mathrm{z} 0.0005$ (Figure 40). The theoretical isotope pattern of the predicted molecular formula was found to be identical to the isotope pattern acquired for G410 (27) (Figure 40). This molecular formula indicates an index of hydrogen deficiency equivalent to ten or the presence of ten degrees of unsaturation. 


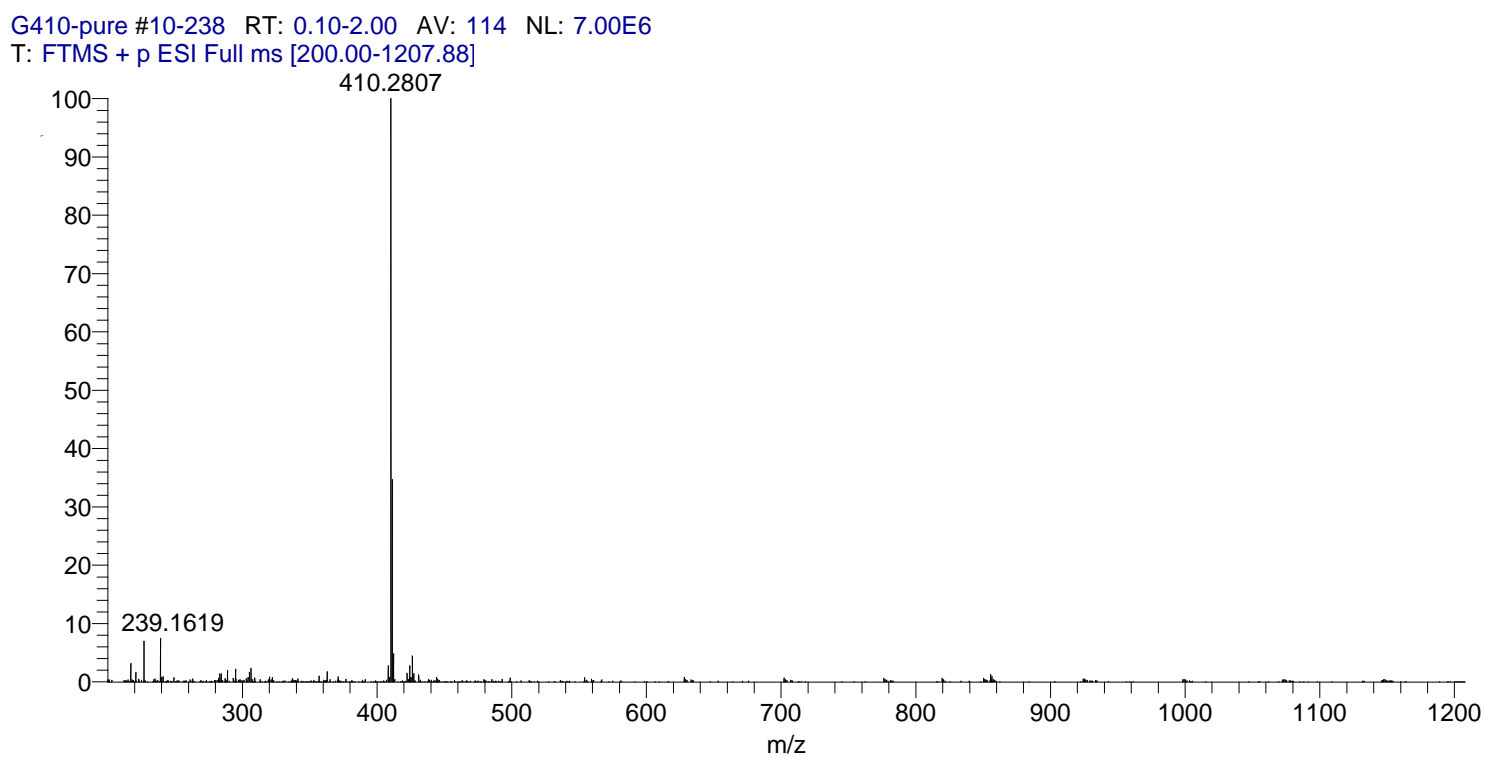

Figure 39: HR-ESI-MS of G410

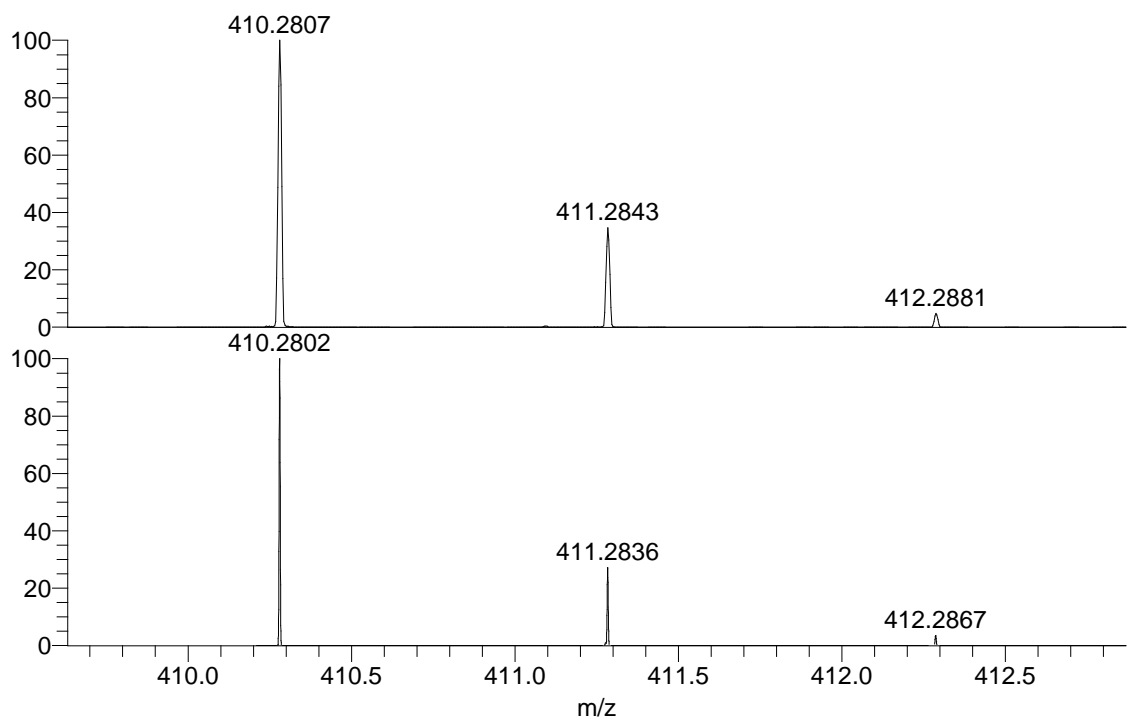

NL:

7.00E6

G410-pure\#10-238 RT:

0.10-2.00 AV: $114 \mathrm{~T}$

FTMS + p ESI Full ms

[200.00-1207.88]

$\mathrm{NL}$

4.06E4

$\mathrm{C}_{25} \mathrm{H}_{36} \mathrm{O}_{2} \mathrm{~N}_{3}$ :

$\mathrm{C}_{25} \mathrm{H}_{36} \mathrm{O}_{2} \mathrm{~N}_{3}$

p (gss, s /p:40) Chrg 1

R: 50000 Res .Pwr.@5\%

Figure 40: Comparison between the acquired (top panel) mass and isotope pattern of G410 and predicted mass and isotope pattern for molecular formula, $\mathrm{C}_{25} \mathrm{H}_{36} \mathrm{O}_{2} \mathrm{~N}_{3}$ (bottom panel). There is a difference of only $\mathrm{m} / \mathrm{z} 0.0005$ between the acquired and the predicted formula. 
The MS/MS fragmentation profile of G410 (27) has daughter fragments of $m / z$ $395.33,392.33$, and 378.33 equivalent to the loss of $\mathrm{m} / \mathrm{z} 18,15$ and 32 respectively (Figure 41). This fragmentation is consistent with the loss of water, a methyl radical and/or methanol, respectively (Figure 42). As described in section 2.4.3, The loss of a methyl radical or $m / z 15$ is characteristic to prodiginines family of natural products such as undecylprodiginine (7) but was not observed for marineosin (Figure 21) [68].

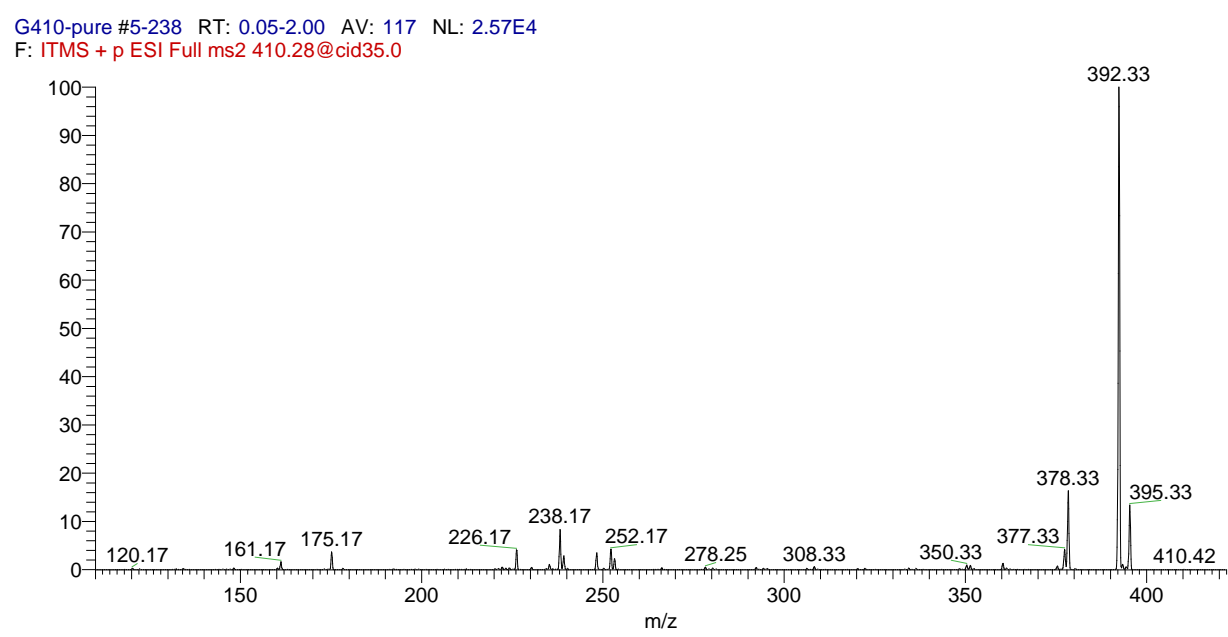

Figure 41: The MS/MS profile of G410. Daughter fragments of $\mathrm{m} / \mathrm{z} 395.33,392.33$, and 378.33 equivalent to the loss of $m / z 18,15$ and 32 respectively. The parent ion, $m / z 410.28$ is not shown.

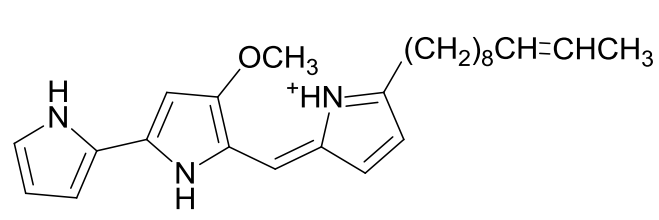

28<smiles>CC(O)CCC1=[N+]2[CH]Oc3cc(-c4ccc[nH]4)[nH]c3C=C2C=C1</smiles>

29<smiles></smiles>

Figure 42: Fragment ions observed in the MS/MS profile of G410 
The IR spectrum of G410 (27) (Figure 43) provided additional evidence supporting the presence of a hydroxyl group as the spectrum has a broad peak at $v_{\max } 3354 \mathrm{~cm}^{-1}$ and $1710 \mathrm{~cm}^{-1}$ which is characteristic for $\mathrm{O}-\mathrm{H}$ stretch and C-O stretch, respectively. Other peaks were observed at $v_{\max } 2921,2852,1630,1605$, $1550,1464,1367,1264,1185,1041,959$, and $797 \mathrm{~cm}^{-1}$.

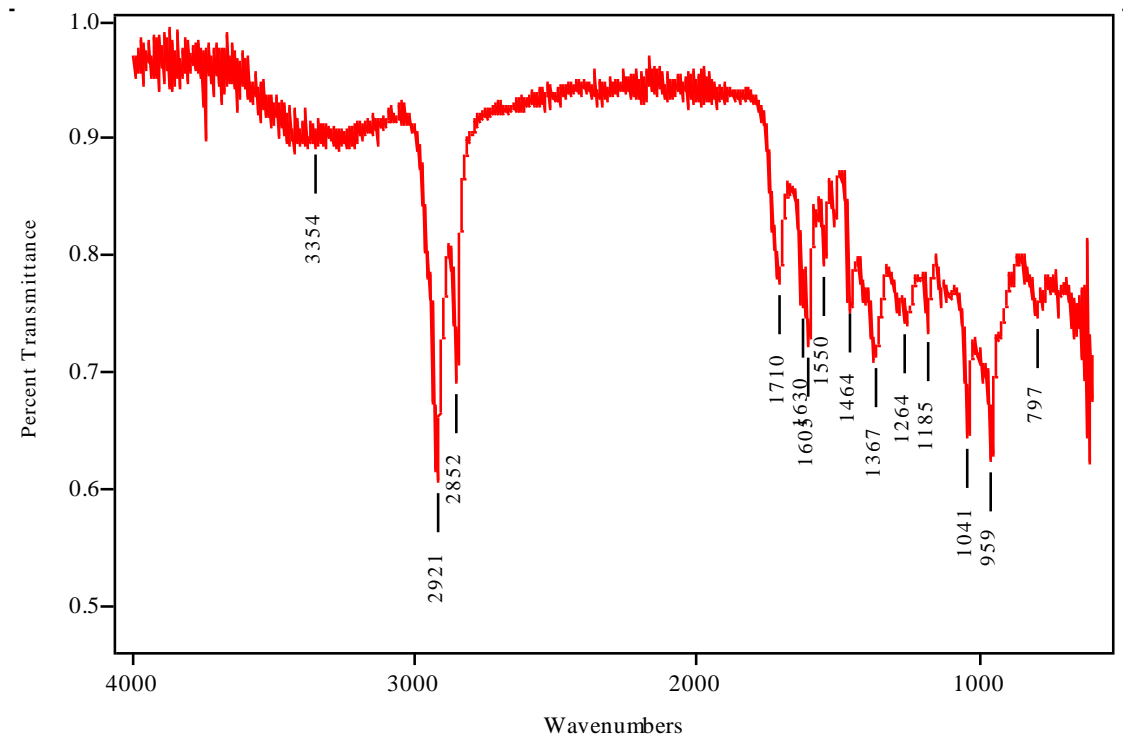

Figure 43: IR spectrum of G410

All of these spectral analyses suggested that G410 is an undecylprodiginine analog with a $-\mathrm{OH}$ substituent, and therefore, further NMR spectral analyses were done side by side with undecylprodiginine standard (7) (Table 14), to facilitate structure comparison. The ${ }^{1} \mathrm{H}-\mathrm{NMR}$ spectrum (Figure 44) of G410 (27) has 7 peaks with chemical shifts $\delta 6-7$ ppm which indicates the presence of 7 aromatic protons at $\delta 6.02(d, J=5.16 \mathrm{~Hz}), \delta 6.15(s), \delta 6.24(t, J=4.87$ and 8.89 
$\mathrm{Hz}), \delta 6.58(d, J=5.2 \mathrm{~Hz}), \delta 6.74(s), \delta 6.78(d, J=5.78 \mathrm{~Hz})$, and $\delta 7.02(b r)$. This is similar to the 7 aromatic protons present in ${ }^{1} \mathrm{H}$-NMR (Figure 45) of undecylprodiginine (7). ${ }^{1} \mathrm{H}-{ }^{1} \mathrm{H}$ 2D TOCSY correlations among these aromatic protons (Figure 46), and comparing it to the ${ }^{1} \mathrm{H}-{ }^{1} \mathrm{H}$ 2D TOCSY correlations of undecylprodiginine (Figure 47), illustrated that the 7 aromatic protons were components of three pyrrole rings. 

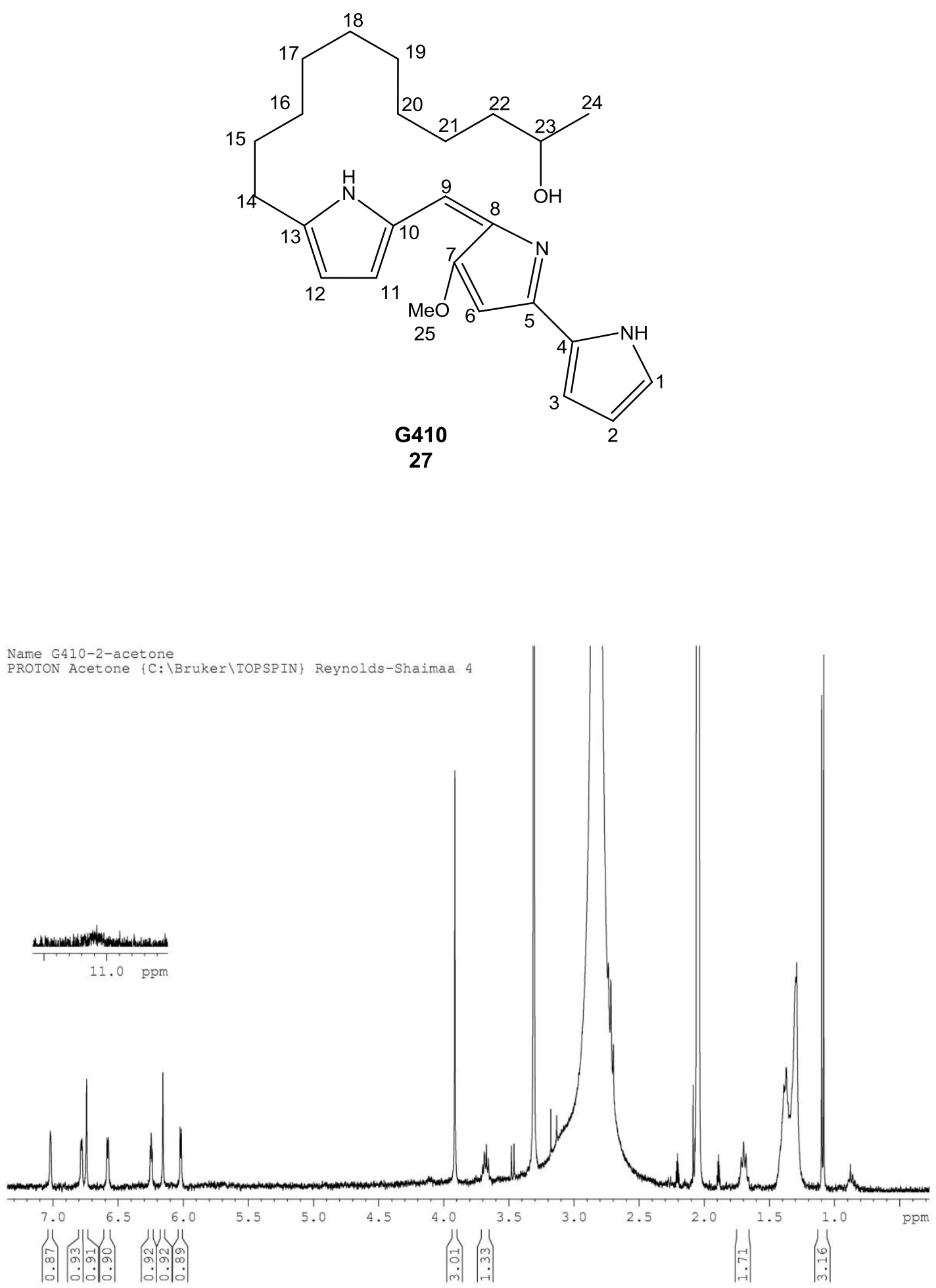

Figure 44: ${ }^{1} \mathrm{H}$-NMR spectrum of G410. Structure shown above. 

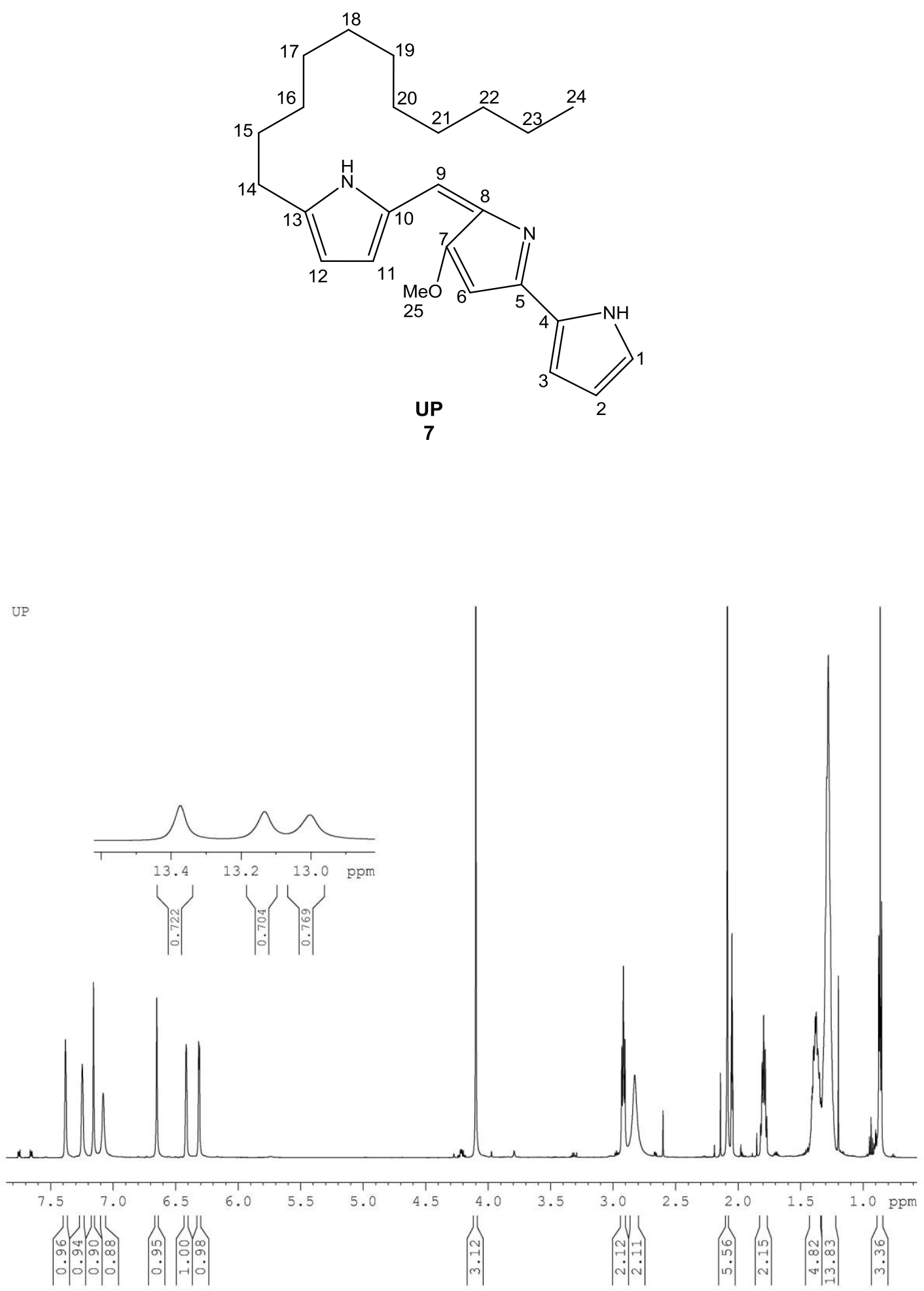

Figure 45: ${ }^{1} \mathrm{H}-\mathrm{NMR}$ spectrum of the $\mathrm{HCl}$ salt of undecylprodiginine standard. Structure shown above. 

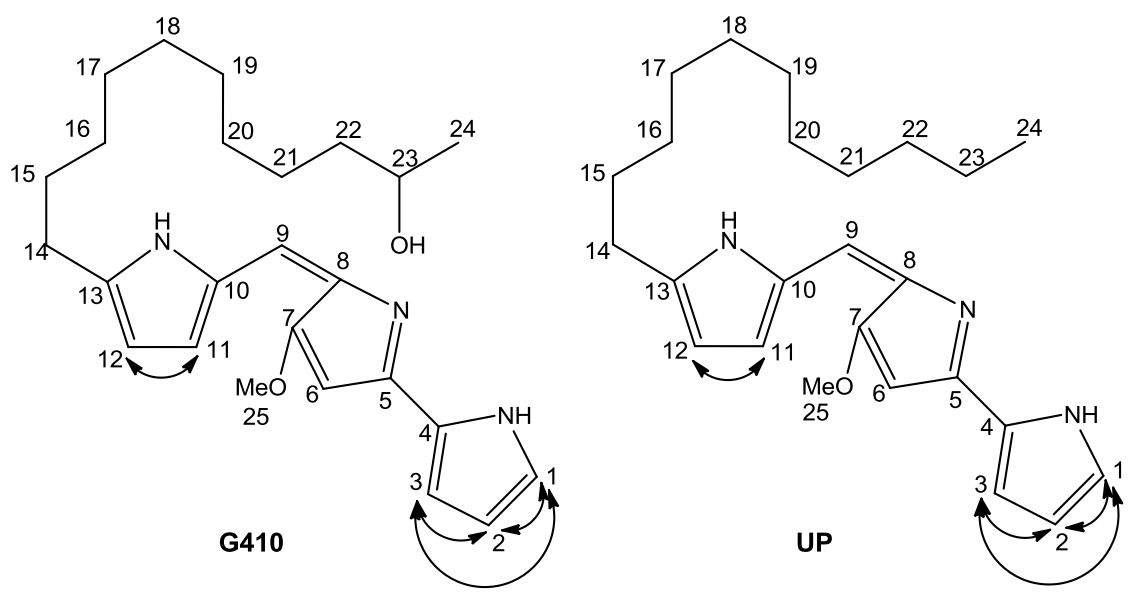

Figure 46: ${ }^{1} \mathrm{H}-{ }^{1} \mathrm{H}$ 2D TOCSY correlations among aromatic protons of G410 and UP 

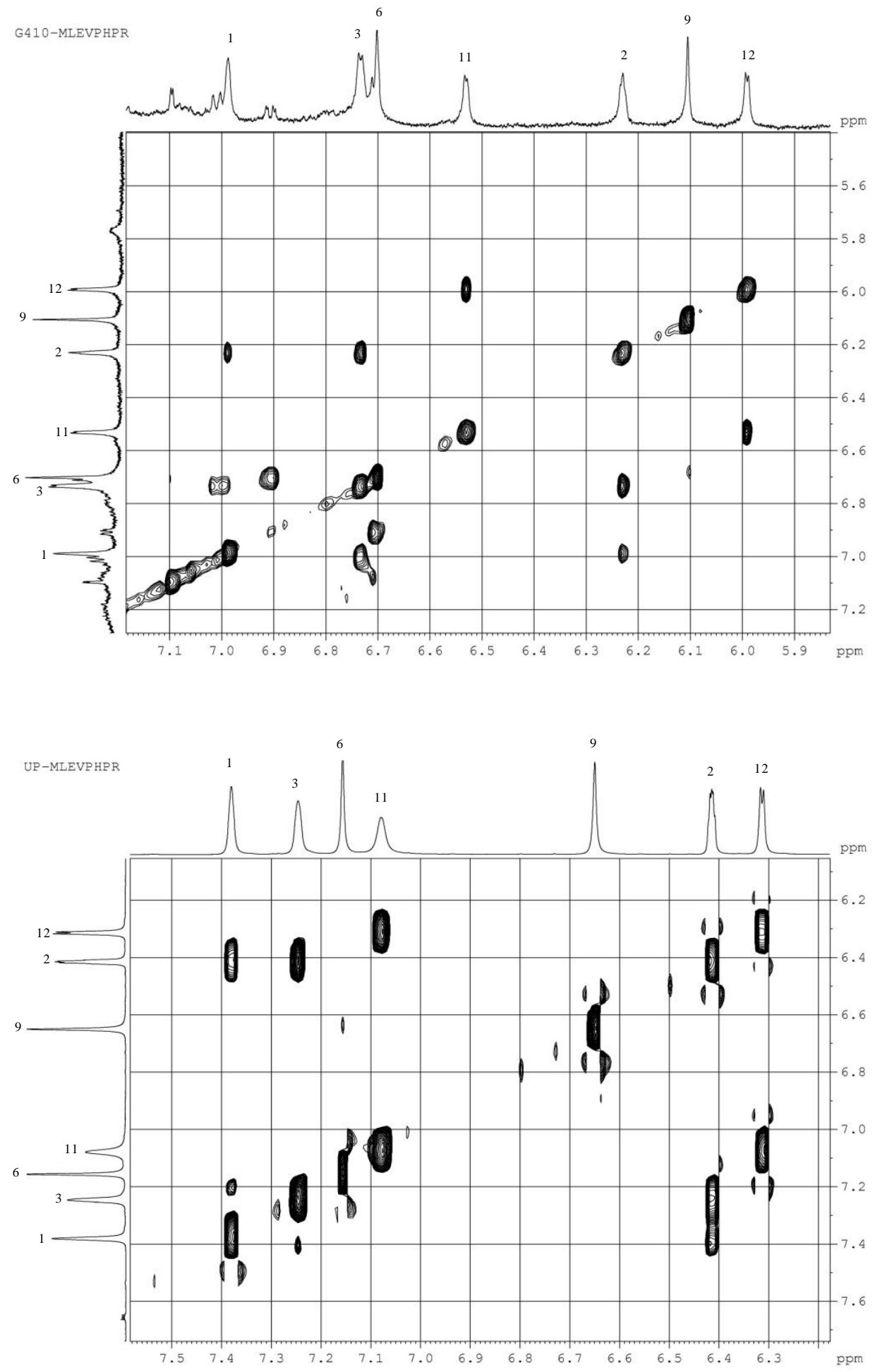

Figure 47: ${ }^{1} \mathrm{H}-{ }^{1} \mathrm{H}$ 2D TOCSY NMR spectrum of G410 (top panel) and UP (bottom panel) aromatic region expanded. 
Comparison of the ${ }^{1} \mathrm{H}-\mathrm{NMR}$ of the aliphatic region of both compounds, revealed that G410 (27) has an extra proton with chemical shift $\delta 3.67 \mathrm{ppm}(\mathrm{m})$, consistent with a $-\mathrm{CH}-\mathrm{OH}$ (Figure 44). The characteristic methyl protons at C-24 in G410 (26) are slightly shifted downfield $(\delta 1.09)$ relative to the same protons in UP (7) ( $\delta$ 0.86) (Figure 48) suggesting their proximity to a heteroatom. Also, the protons at C-24 in G410 show a prominent doublet splitting $(J=9.18 \mathrm{~Hz})$ while the same protons in UP, show a triplet splitting $(J=7.17 \mathrm{~Hz})$. This splitting pattern suggested that the methyl group at position 24 of $\mathrm{G} 410$ is adjacent to a $-\mathrm{CH}$ group rather than a $-\mathrm{CH}_{2}$ group (Figure 48) which is consistent with the presence of $-\mathrm{CH}-\mathrm{OH}$ at $\mathrm{C}-23$ of $\mathrm{G} 410(27)$. 

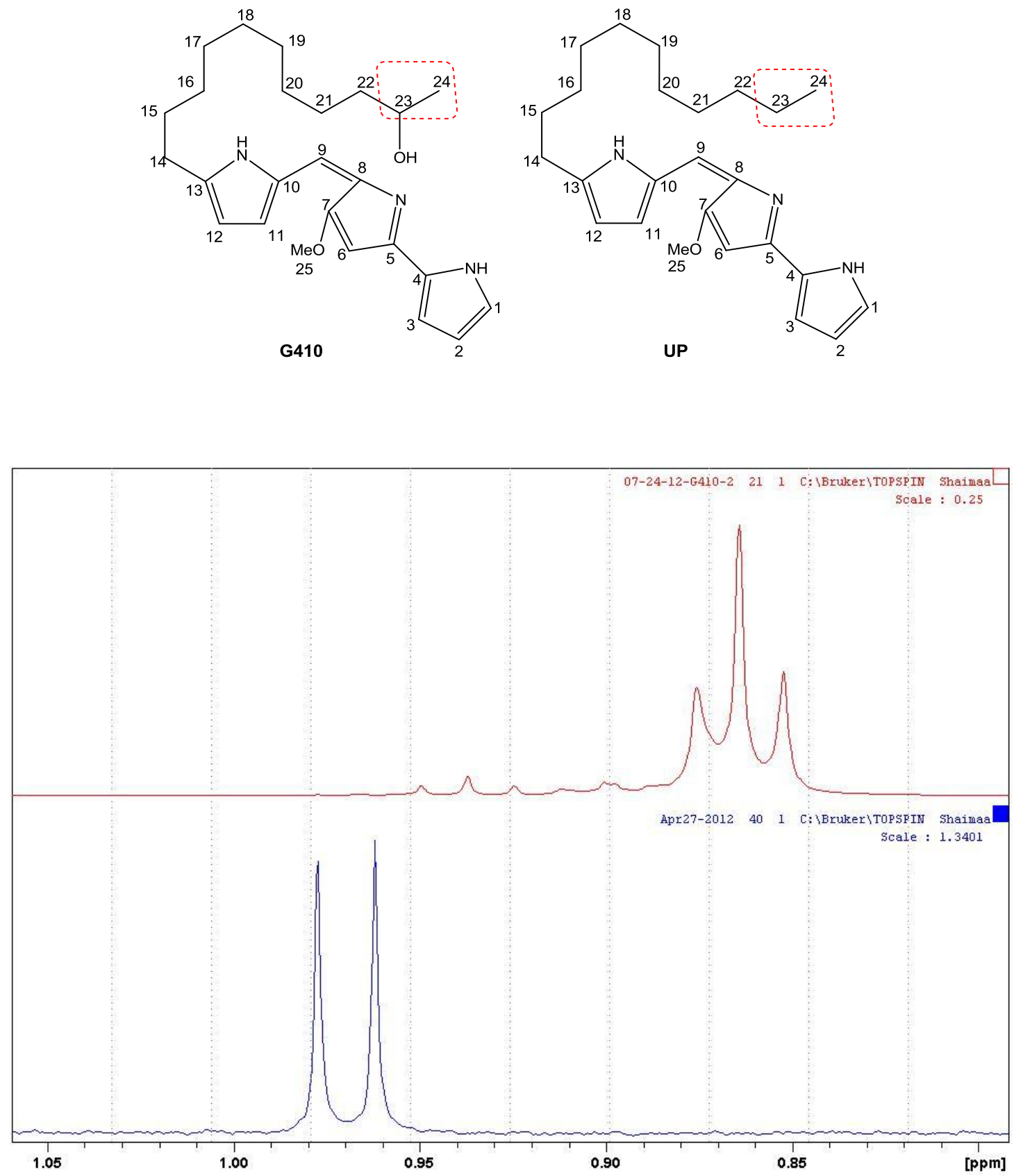

Figure 48: ${ }^{1} \mathrm{H}-\mathrm{NMR}$ spectrum showing comparison between the splitting pattern of methyl protons at C-24 in undecylprodiginine (red, top) and G410 (blue, bottom) 
${ }^{1} \mathrm{H}-{ }^{1} \mathrm{H} 2 \mathrm{D}$ COSY (Figure 49) and ${ }^{1} \mathrm{H}-{ }^{1} \mathrm{H} 2 \mathrm{D}$ TOCSY NMR (Figure 50) correlations between protons at C-24 and C-23 in G410, confirmed the position of $-\mathrm{CH}-\mathrm{OH}$ group to be adjacent to the terminal methyl at C-24 (Figure 49), (Figure 50). Such correlations are absent from the ${ }^{1} \mathrm{H}-{ }^{1} \mathrm{H} \quad 2 \mathrm{D}$ TOCSY NMR spectrum of undecylprodiginine (7) (Figure 51). 

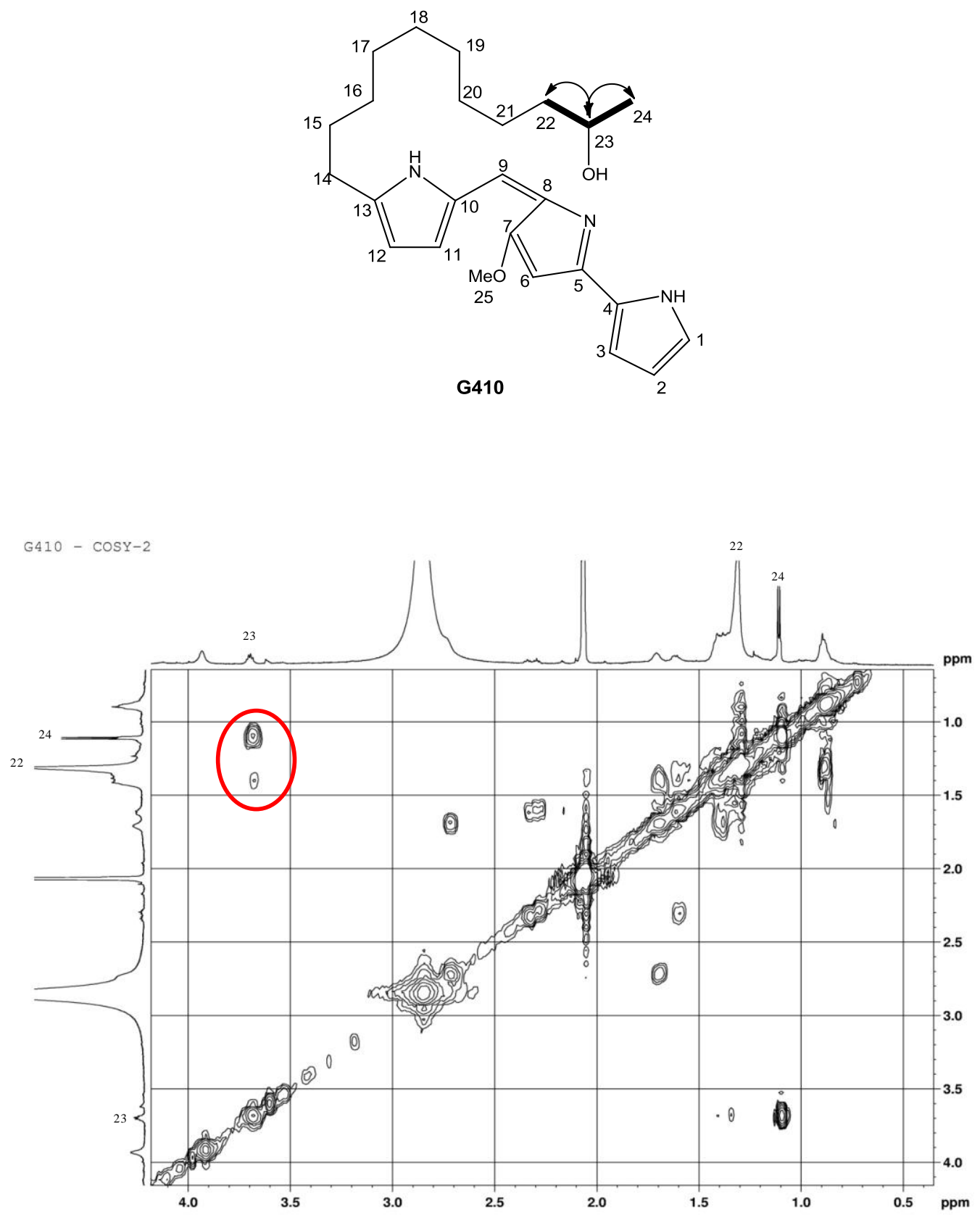

Figure 49: ${ }^{1} \mathrm{H}-{ }^{1} \mathrm{H}$ 2D COSY NMR correlations between C-22, C-23, and C-24 of G410. Structure shown above. 

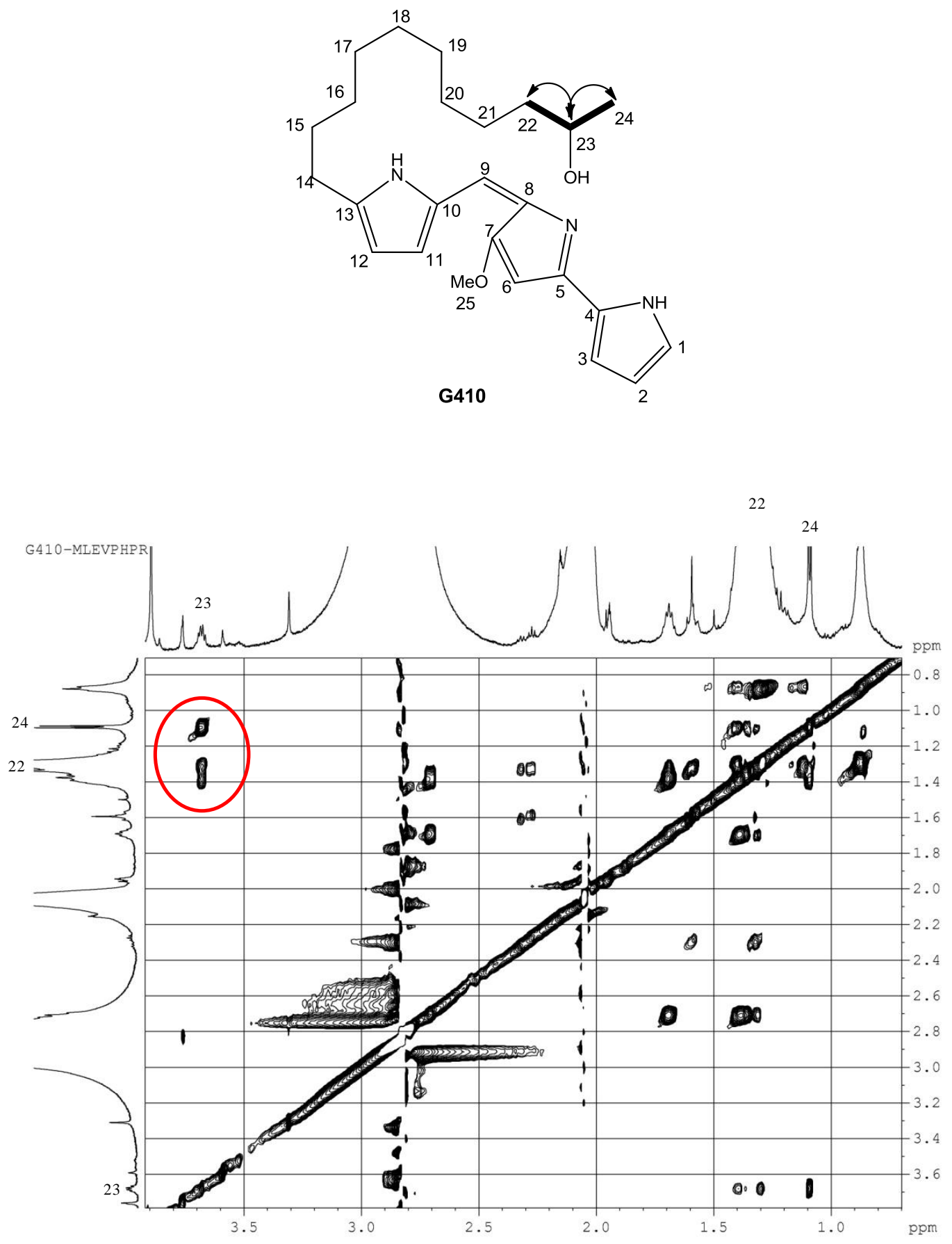

Figure 50: ${ }^{1} \mathrm{H}-{ }^{1} \mathrm{H}$ 2D TOCSY correlations among C-22, C-23 and C-24 of G410. Structure is shown above. 

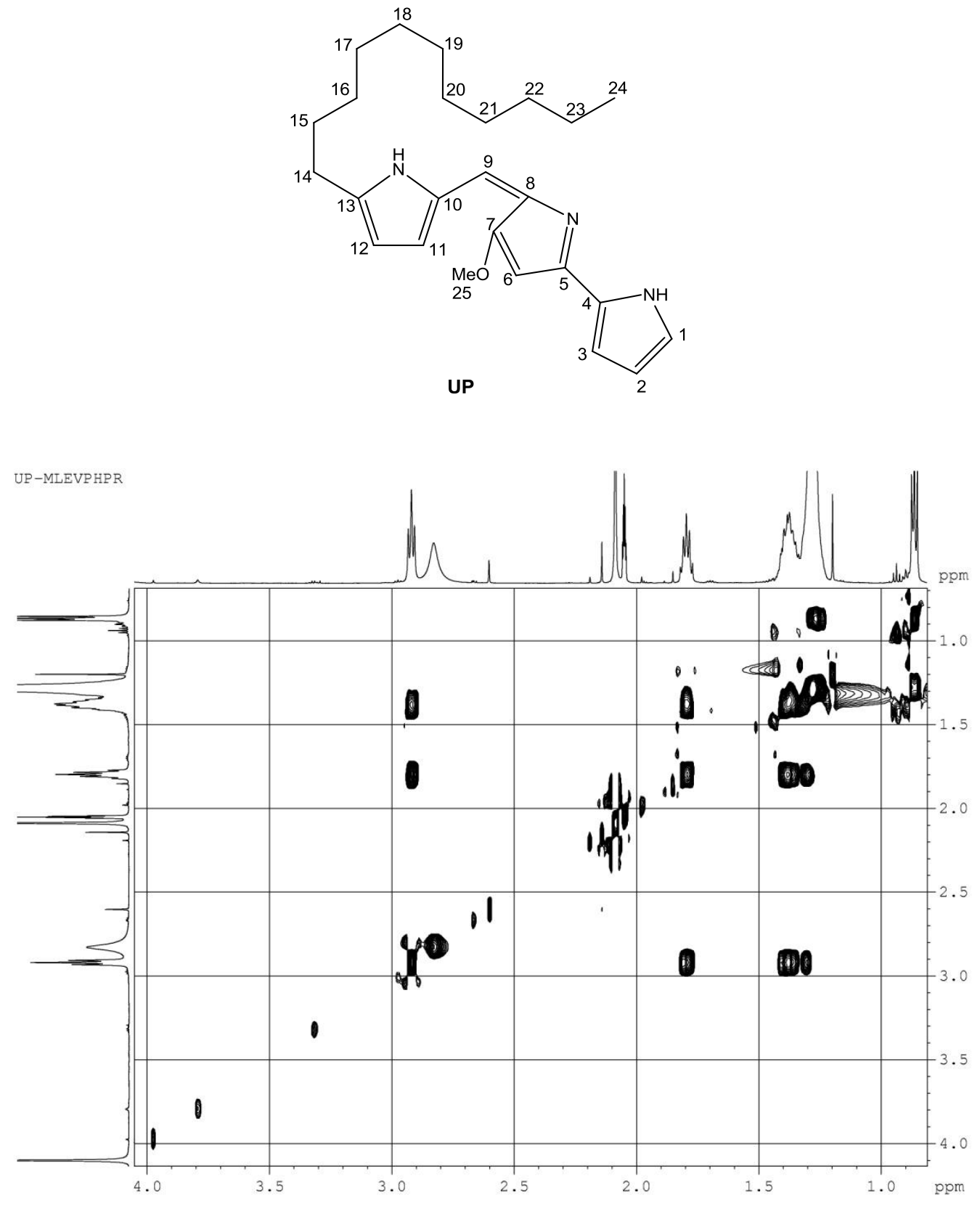

Figure 51: ${ }^{1} \mathrm{H}-{ }^{1} \mathrm{H}$ 2D TOCSY correlations of the aliphatic region of undecylprodiginine 
All the above experiments as well as a detailed comparison between the chemical shifts of both undecylprodiginine (7) and G410 (27) (Table 14), confirmed the identity of G410 as 2-hydroxyundecylprodiginine. It should be noted that the chemical shifts reported for undecylprodiginine (7) protons are slightly shifted downfield as the compound is in the $\mathrm{HCl}$ salt form. The full ${ }^{1} \mathrm{H}-{ }^{1} \mathrm{H}$ 2D TOCSY spectra of G410 (27) and undecylprodiginine (7) is provided in Figure 52 and Figure 53, respectively. 
Table 14: NMR Spectral data for G410 (600 MHz, Acetone-d6) and side by side comparison of G410 and UP
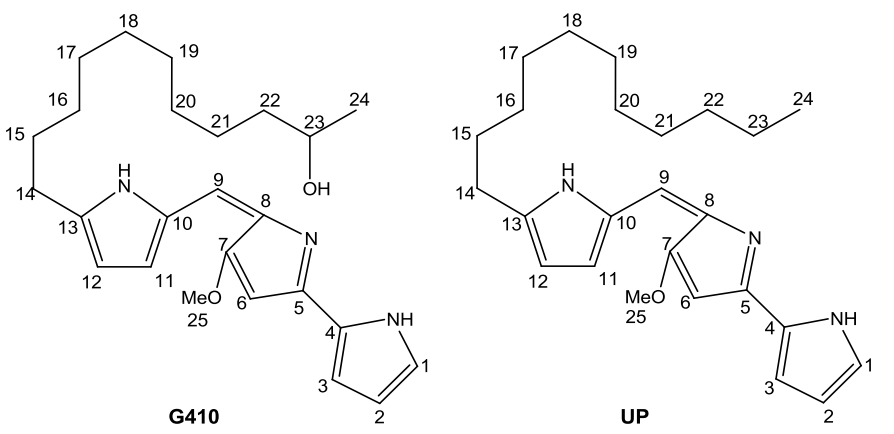

\begin{tabular}{r}
\hline Posit \\
\hline 1 \\
2 \\
3 \\
4 \\
5 \\
6 \\
7 \\
8 \\
9
\end{tabular}

\begin{tabular}{lll}
9 & 6.15 & 6.65 \\
10 & & \\
11 & 6.58 & 7.07 \\
12 & 6.02 & 6.31 \\
13 & & \\
14 & 2.70 & 2.92 \\
15 & 1.69 & 1.79 \\
16 & 1.33 & 1.38 \\
17 & 1.33 & 1.38 \\
18 & 1.33 & 1.38 \\
19 & 1.33 & 1.38 \\
20 & 1.33 & 1.38 \\
21 & 1.33 & 1.38 \\
22 & 1.34 & 1.38 \\
23 & 3.67 & 1.28 \\
24 & 1.09 & 0.86 \\
25 & 3.91 & 4.09 \\
\hline
\end{tabular}

*Assignments are for protons bonded to the specified positions using 1D $\left({ }^{1} \mathrm{H}\right)$, and 2D (COSY, TOCSY) NMR spectroscopy in comparison to UP. ${ }^{* *}$ The chemical shifts reported are for the $\mathrm{HCl}$ salt of UP. 

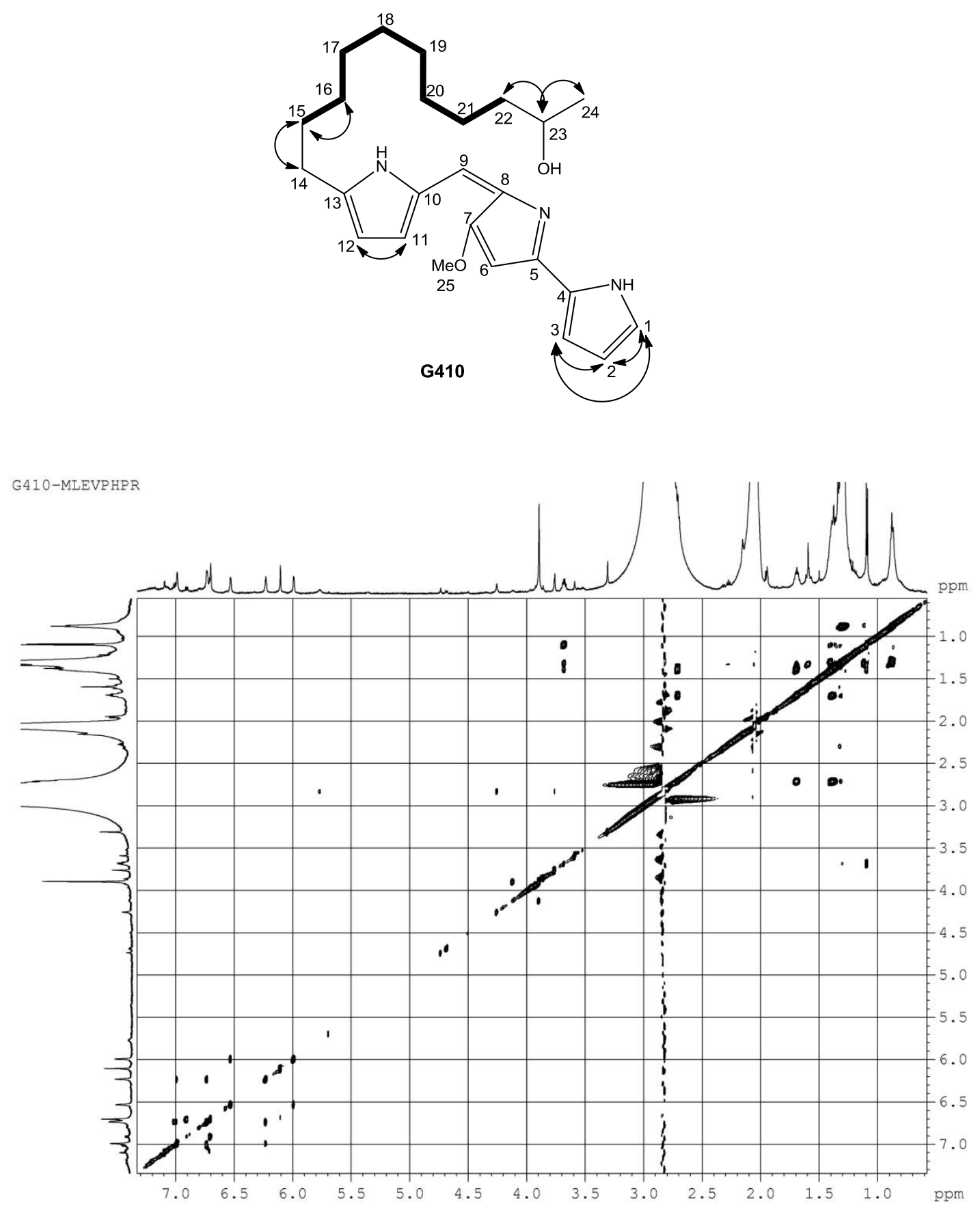

Figure 52: Full ${ }^{1} \mathrm{H}-{ }^{1} \mathrm{H}$ 2D TOCSY correlations and spectrum of G410. The bold bonds indicate $16 \mathrm{H}$ integrated into one large peak at $1.3 \mathrm{ppm}$. 

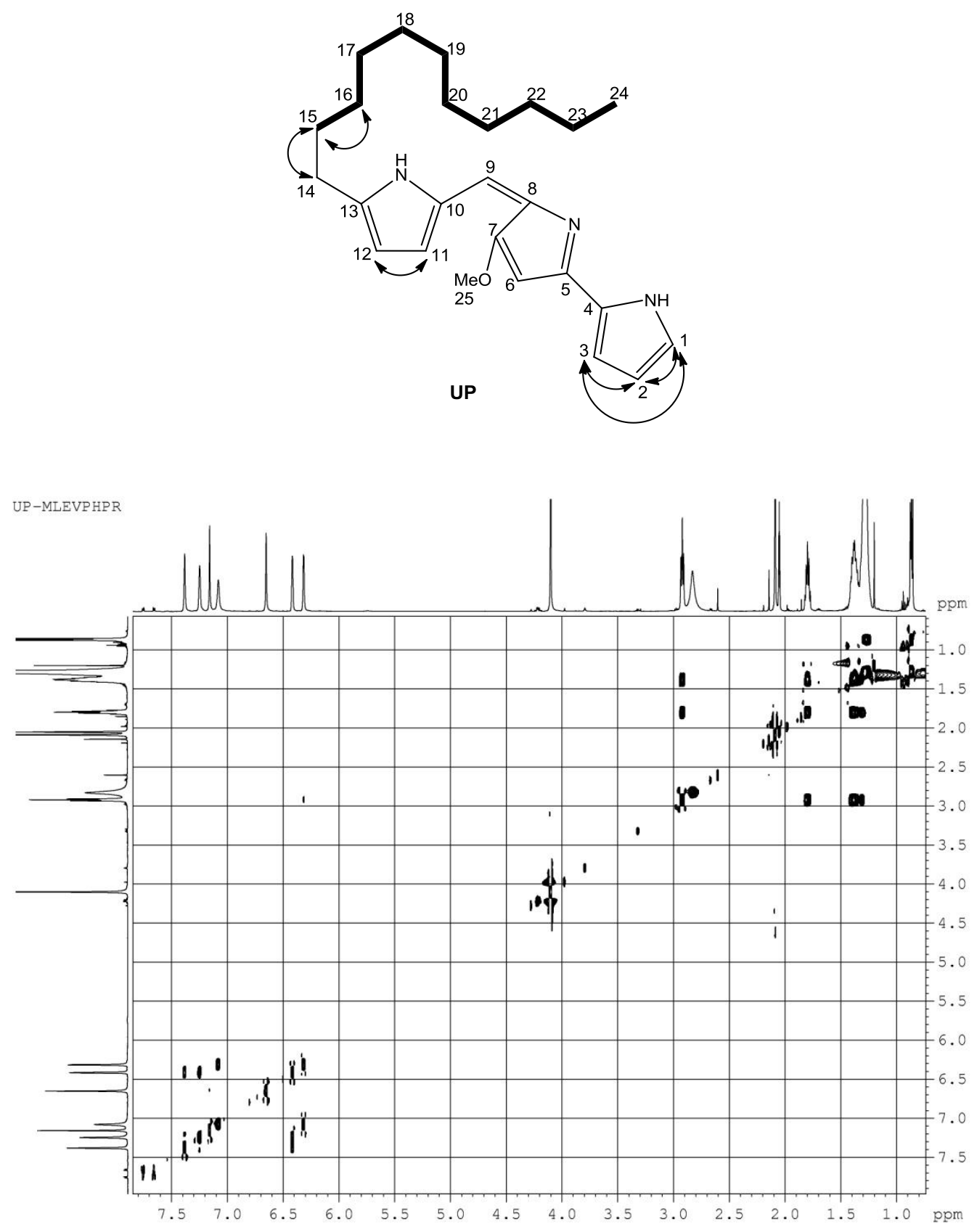

Figure 53: Full ${ }^{1} \mathrm{H}-{ }^{1} \mathrm{H}$ 2D TOCSY correlations and spectrum of undecylprodiginine. The bold bonds indicate $16 \mathrm{H}$ integrated into one large peak. 
The production of 2-hydroxyundecylprodiginine (26), a straight chain undecylprodiginine analog by $S$. venezuelae JND2 $\Delta G$ as a result of marG deletion, indicates that MarG is required for the cyclization of the acyl chain of 2hydroxyundecylprodiginine with the reduction of the double bond at the methine bridge connecting C-8 and C-9 (Figure 54). The absence of undecylprodiginine (7) in this strain is inconsistent with the hypothesis (Figure 19), that MarG is responsible for the introduction of the spiroaminal ring oxygen of marineosin. The production of 2-hydroxyundecylprodiginine (26) suggests other possibilities including (Figure 54):

- A different substrate specificity of MarP, that leads to the incorporation of a hydroxy-butyric acid starter unit in the acyl chain of 2-undecylpyrroline subunit. Or,

- An unknown hydroxylase enzyme, such as MarT or MarE (both annotated as hypothetical proteins), is involved in the introduction of the hydroxyl group to undecylprodiginine structure. 
1)

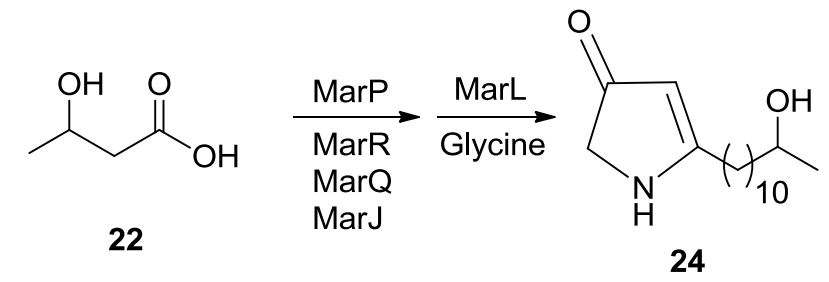

2)

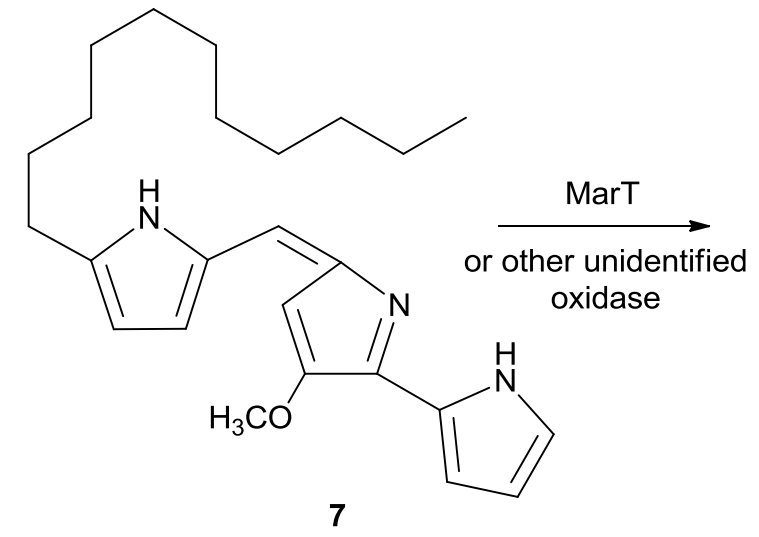

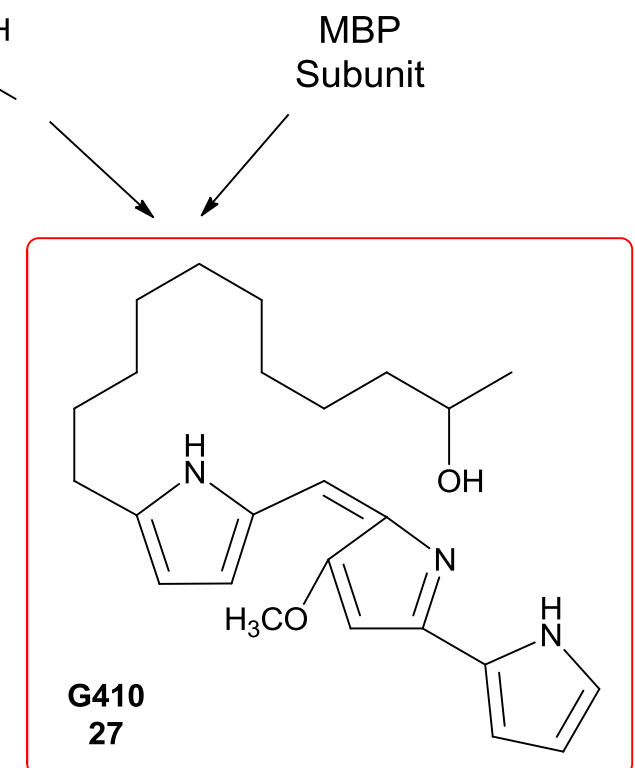

MBP

Subunit

Figure 54: Hypotheses explaining the biosynthesis of G410

\subsubsection{The role of MarA in the biosynthesis of marineosin}

\subsection{Sequence analysis of marA}

The marA gene is $468 \mathrm{bp}$, whose predicted protein sequence consists of 155 amino acids, corresponding to a calculated molecular weight of $16.07 \mathrm{kDa}$. An NCBI BLAST search of MarA protein indicates that MarA has $56 \%$ identity to MaoC-like dehydratase and $45 \%$ identity to enoyl-CoA hydratase, and accordingly, MarA was provisioned as a putative dehydratase (Table 1). A conserved domain data search of MarA primary protein sequence reveals that MarA belongs to the HotDog superfamily of proteins which comprises a wide range of enzymes with distinct catalytic activities such as dehydratases, 
thioesterases, dehydrogenases and acyltransferases. The primary protein sequence of MarA suggests that it specifically belongs to the MaoC dehydrataselike HotDog subfamily which also includes the human $\beta$-hydroxysteroid dehydrogenase and NodN, an enzyme involved in cell signaling of Rhizobium roots [79].
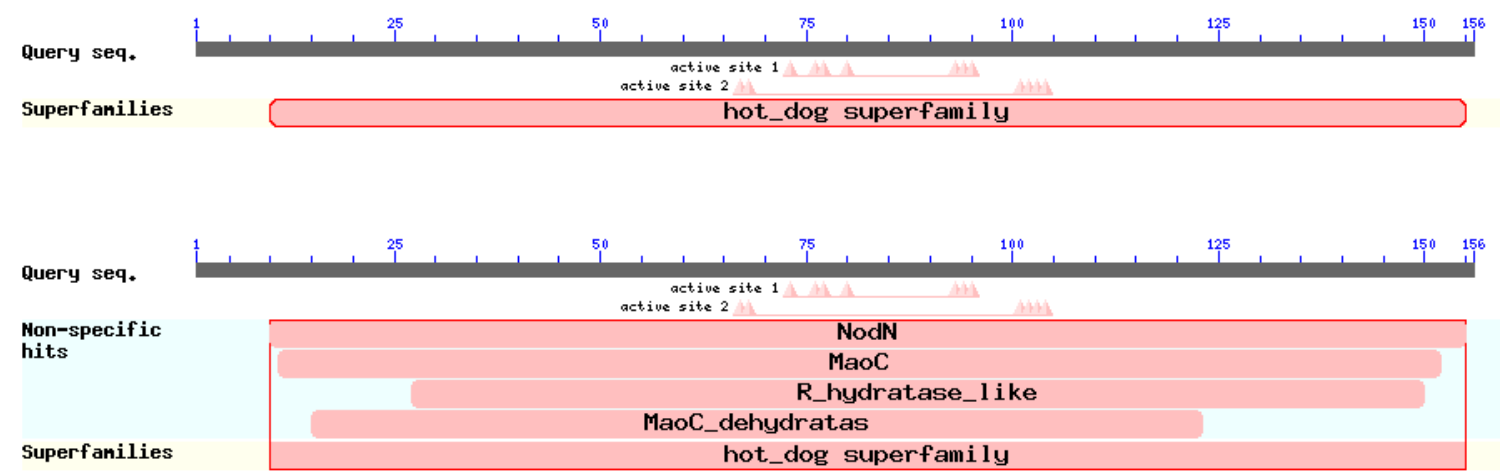

Figure 55: Graphical summary of conserved domain hits obtained after NCBI CDD search. The figure indicates that MarA belong to the HotDog superfamily of enzymes.

3.4.1.2.2 Targeted gene replacement of marA and the generation of $S$. venezuelae JND2 $\triangle A$ : A marA knockout strain

In Section 2.4.2, we proposed that the putative dehydratase, MarA catalyzes the final spiroaminal ring formation of 2-hydroxyundecylprodiginine intermediate (Figure 19). To test our hypothesis, marA gene in pMAR cosmid, was replaced with a spectinomycin resistance marker gene, aadA. Gene replacement was confirmed via PCR using primers designed to amplify the region flanking the marA gene. The PCR of the mutant cosmid $p M A R \triangle A$, a marA replacement 
mutant cosmid led to the amplification of $~ 1500 \mathrm{bp}$ fragment corresponding to $\operatorname{aad} A$ gene $(1150 \mathrm{bp}$ ) plus the flanking $400 \mathrm{bp}$ (lane $\Delta \mathrm{A}$, Figure 56$)$. A PCR done using the same primers but using pMAR cosmid, as a control led to the amplification of a fragment of $~ 1000 \mathrm{bp}$, corresponding to marA gene (468 bp) plus the flanking $400 \mathrm{bp}$ (lane $\mathrm{C}$, Figure 56). The mutant cosmid, $p M A R \triangle A$ was delivered to wild type $S$. venezuelae via conjugation and the new strain was named $S$. venezuelae JND2 $\Delta \mathrm{A}$. The new strain is both apramycin and spectinomycin resistant and is characterized by a faint red color when compared to $S$. venezuelae JND2 $\Delta \mathrm{G}$ mutant strain.

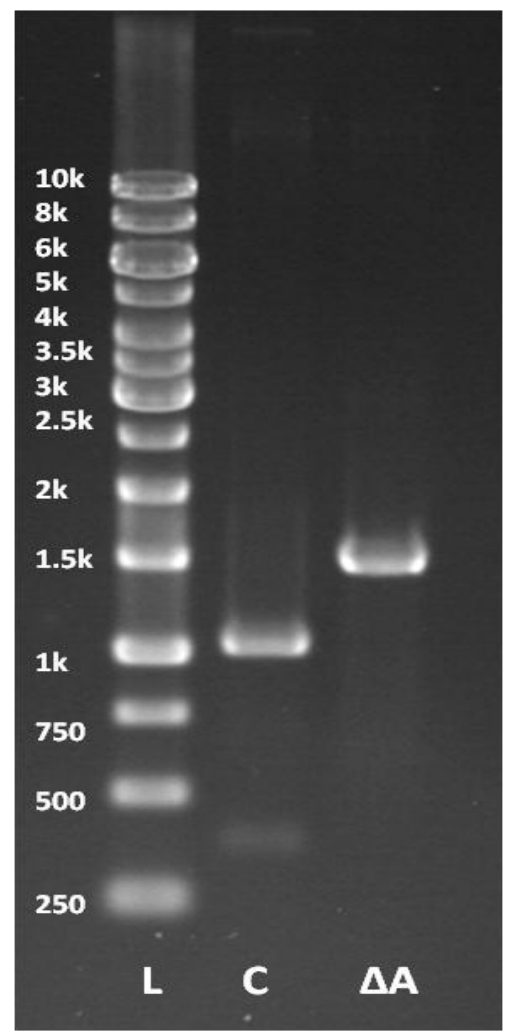

Figure 56: Confirmation of marA replacement, from pMAR cosmid, with aadA gene conferring resistance to spectinomycin antibiotic. Lane $L=D N A$ ladder, lane $C=a$ control $\mathrm{PCR}$ reaction performed using pMAR cosmid, lane $\triangle \mathrm{A}=\mathrm{PCR}$ reaction performed using pMAR $\triangle \mathrm{A}$ cosmid. 


\subsection{MS, LC/MS and LC-UV/MS analysis of S. venezuelae JND2 $A A$}

The MS profile of $S$. venezuelae JND2 $\Delta \mathrm{A}$ strain was monitored via ThermoElectron LTQ-Orbitrap high resolution mass analyzer to determine the main metabolites accumulated as a result of marA gene replacement. The MS profile of the crude acetone extract of $S$. venezuelae JND2 $\Delta$ A was compared to that of the crude acetone extracts of $S$. venezuelae JND2 strain, marineosin producer (Figure 57).

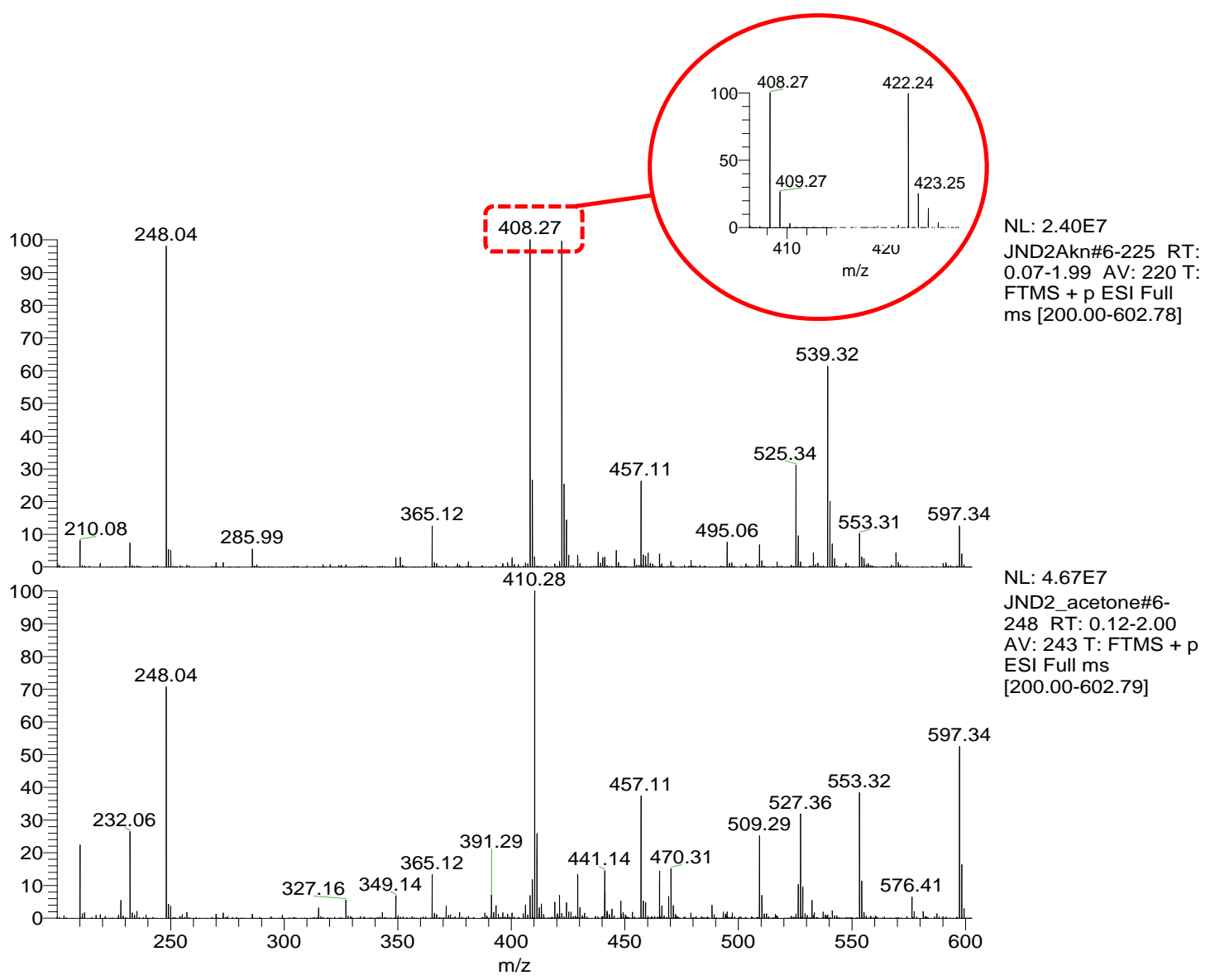

Figure 57: Comparison between the MS profiles of $S$. venezuelae JND2 $\Delta A$ (top panel), and JND2 strain (bottom panel). MS profile of JND $\Delta$ A strain (top panel) shows two main compounds with $\mathrm{m} / \mathrm{z} 408.26$ and 422.24 while the MS profile of JND2 strain shows the same two compounds, to a much lower extent, and mainly marineosin, $m / z 410.28$. 
The MS profile of $S$. venezuelae JND2 $\Delta$ A crude acetone extract is characterized by the presence of two main signals with $[\mathrm{M}+\mathrm{H}]^{+} \mathrm{m} / \mathrm{z} 408.27$ and 422.24 that were named JN408 and JN422, respectively. JN408 and JN422 were also found in S. venezuelae JND2 control but to a much lower extent.

As observed for other JND2 engineered strains, the LC-UV/MS analysis of the acetone extract of JND2 $\Delta \mathrm{A}$ indicates two groups of compounds (Figure 58). One group has a $\lambda \max 320 \mathrm{~nm}$ which indicates non-conjugated, non-red compounds and the other group has a $\lambda \max 530 \mathrm{~nm}$ which characterizes red-colored prodiginine analogs. Marineosin production was not observed in this strain which suggested that MarA is essential for the biosynthesis of marineosin. Undecylprodiginine (7) production was also not observed in this strain which suggests that undecylprodiginine (7) is either not an intermediate along the pathway for the biosynthesis of marineosin, or does not accumulate in the mutant because it gets hydroxylated very quickly by an unidentified oxidase.

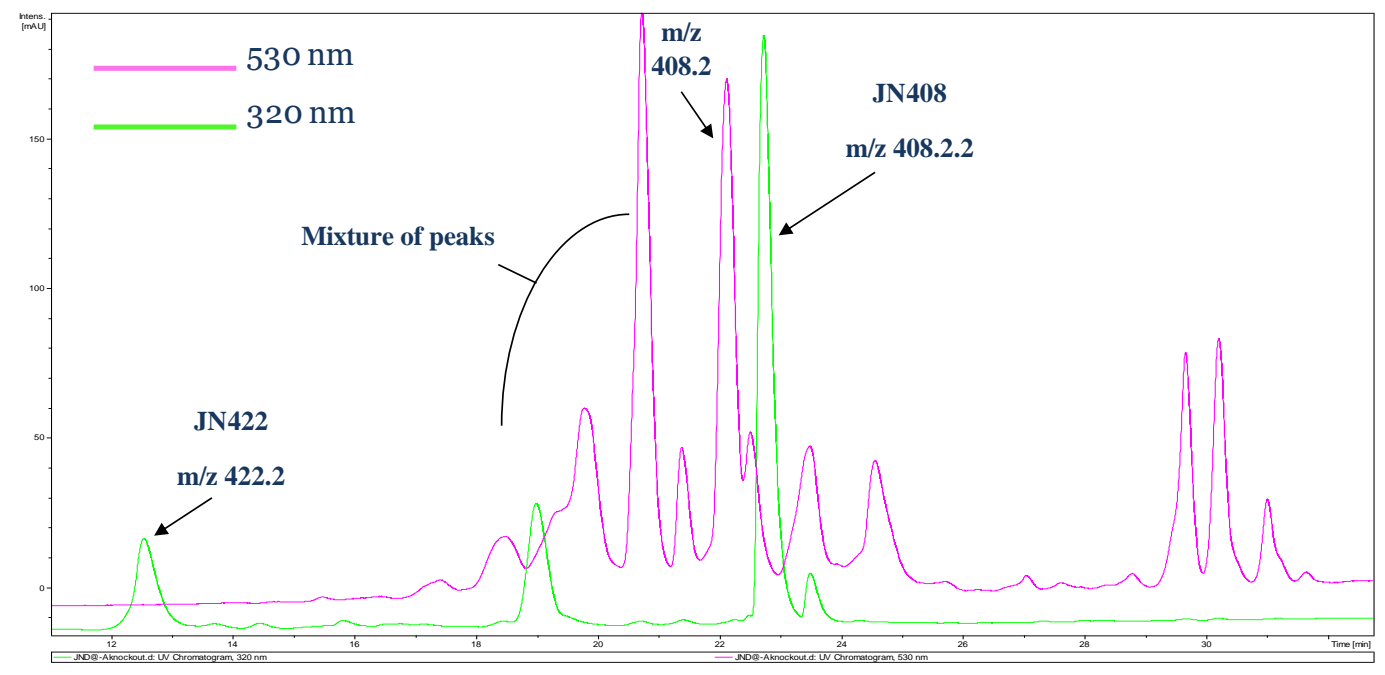

Figure 58: LC-UV/MS analysis of S. venezuelae JND2 $\Delta$ A. Two groups of compounds exist: a group with $\lambda \max 320 \mathrm{~nm}$ (green color) and a group with $\lambda \max 530 \mathrm{~nm}$ (magenta color). 


\subsection{JN408 and JN422 are two marineosin analogs produced by $S$. venezuelae JND2AA}

As mentioned earlier, the deletion of marA from the marineosin gene cluster and the generation of $S$. venezuelae JND2 $\Delta$ A led to the accumulation of two major compounds named JN408 (31) and JN422 (32) (Figure 59). Both compounds

were isolated from the acetone extract of $S$. venezuelae JND2 $\Delta \mathrm{A}$ after two rounds of HPLC purifications to yield $\sim 0.4 \mathrm{mg}$ of JN408 and $\sim 1 \mathrm{mg}$ of JN422 (Figure 60). Detailed analysis of the MS, UV, IR and NMR spectral data of JN408 (31) indicated it to be an oxidized marineosin analog while analysis of JN422 (32) data indicated it to be a 9-keto-derivative of JN408 (Figure 59).

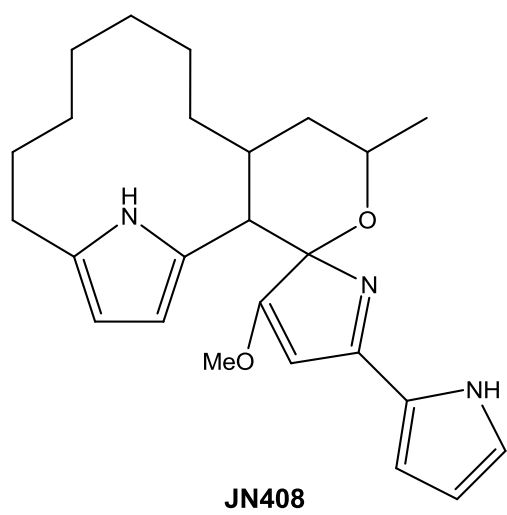

(31)

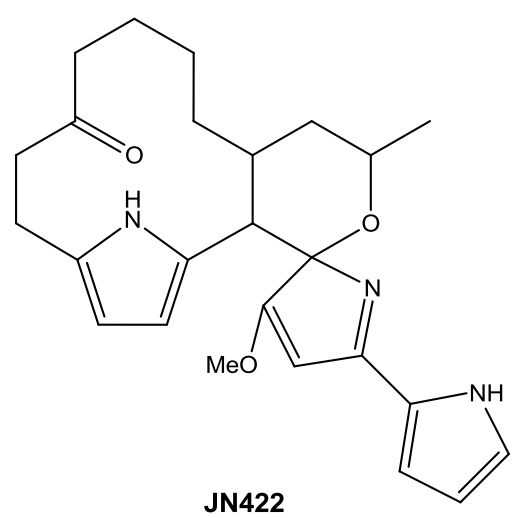

(32)

Figure 59: Structures of JN408 and JN422, produced by S. venezuelae JND2 $\Delta A$ 

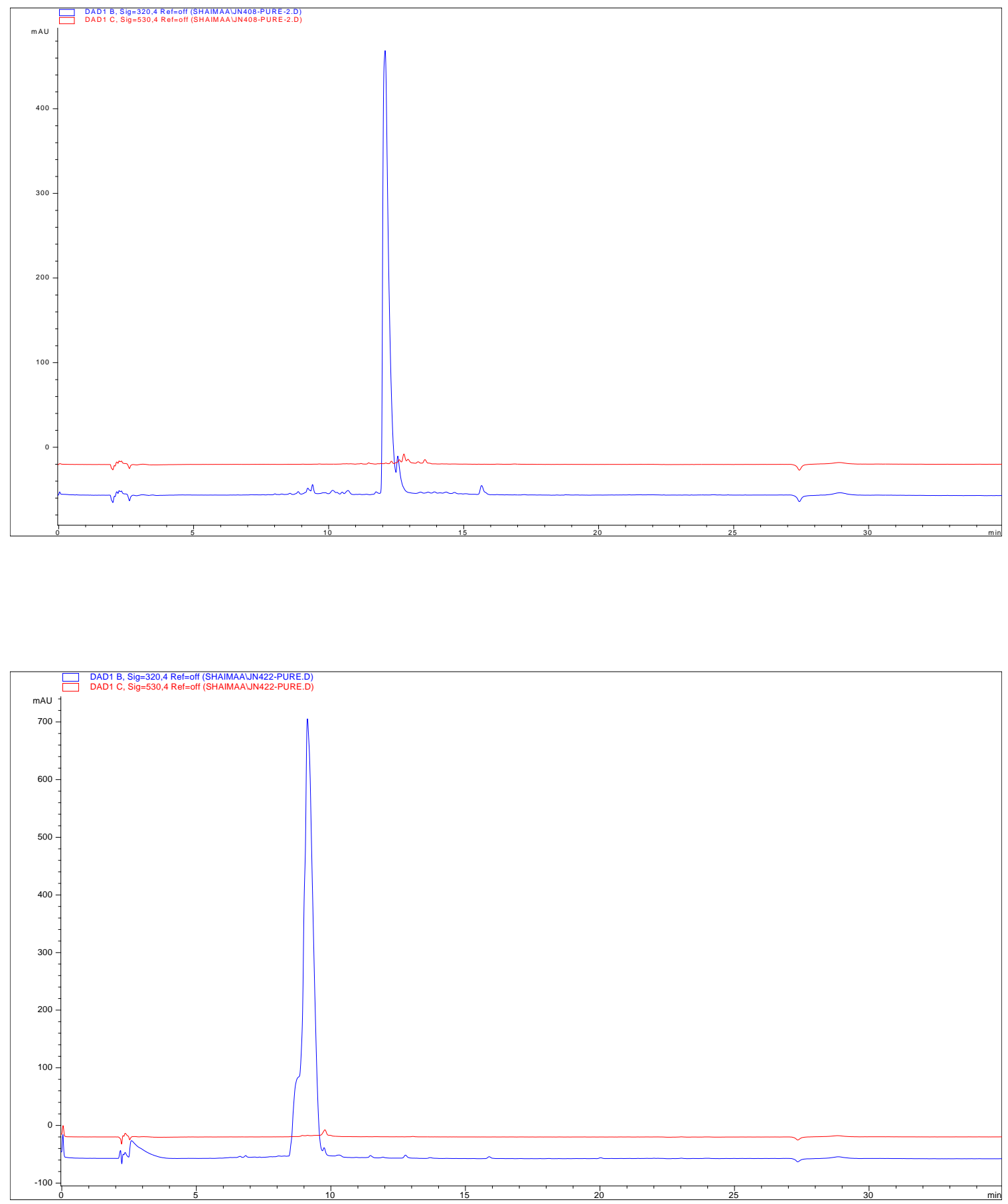

Figure 60: HPLC chromatogram of purified JN408 (top panel) and purified JN422 (bottom panel). The red trace represents absorption at $\lambda \max 530 \mathrm{~nm}$ and blue trace represents absorption at $\lambda \max 320 \mathrm{~nm}$. 
The UV spectrum of both JN408 (31) and JN422 (32) is characterized by Amax $320 \mathrm{~nm}$ similar to the UV spectrum of marineosin (Figure 61). This preliminary data suggested that both compounds have a non-conjugated tri-pyrrole ring system similar to marineosin.
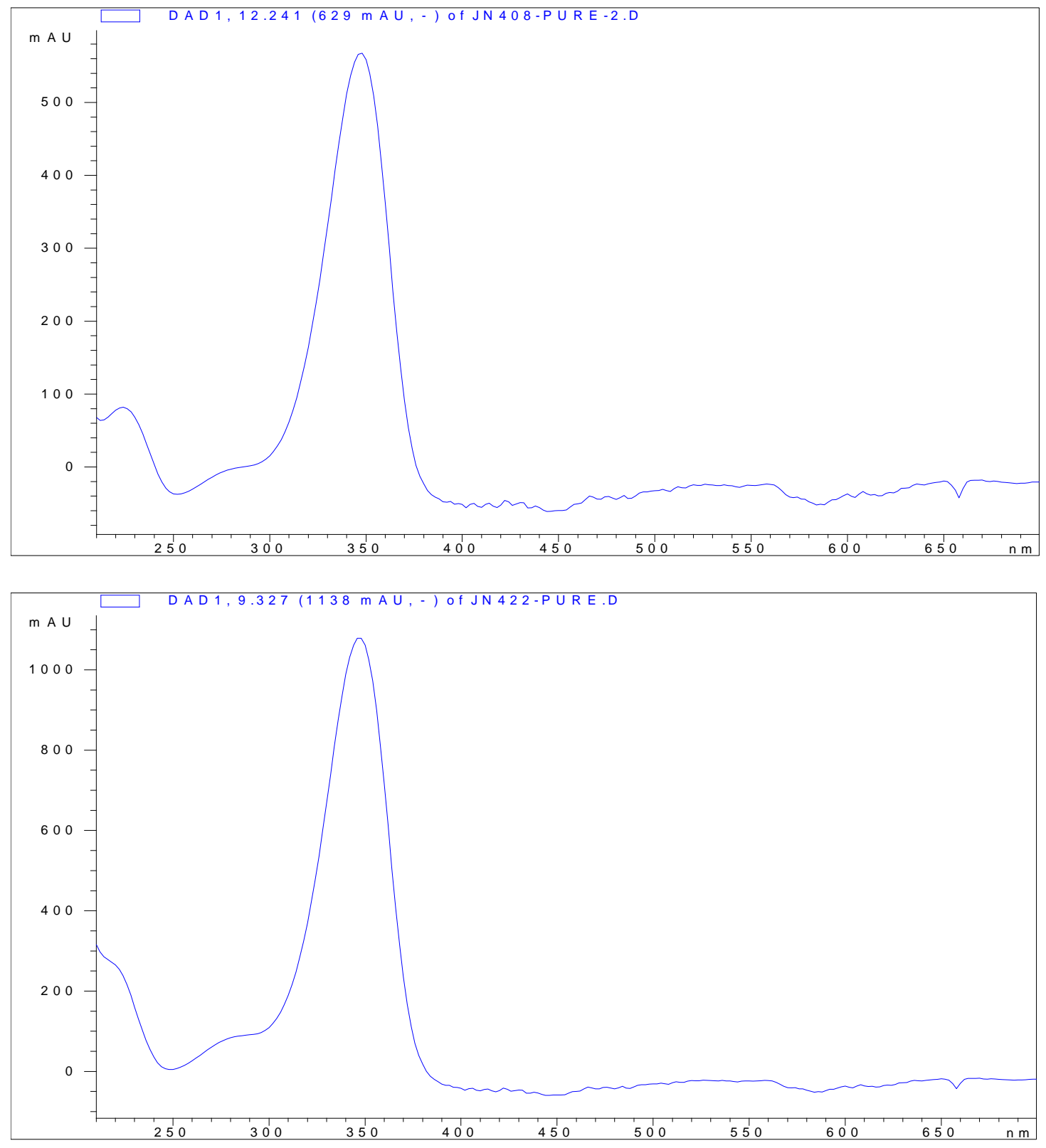

Figure 61: UV spectrum of JN408 (top panel) and JN422 (bottom panel) 
HR-ESI-MS analysis of JN408 (31) exhibits $[\mathrm{M}+\mathrm{H}]^{+}$of $\mathrm{m} / \mathrm{z} 408.2660$ (Figure 62). The acquired mass was analyzed for molecular formula $\mathrm{C}_{25} \mathrm{H}_{34} \mathrm{O}_{2} \mathrm{~N}_{3}$ or $\mathrm{C}_{25} \mathrm{H}_{33} \mathrm{O}_{2} \mathrm{~N}_{3}$ without the $\mathrm{H}$-adduct. The difference between the mass acquired for $\mathrm{JN} 408$ (31), and the mass of the predicted molecular formula is only $\mathrm{m} / \mathrm{z} 0.0014$ (Figure 63). The theoretical isotope pattern of the predicted molecular formula was found to be identical to the isotope pattern acquired for JN408 (31). The molecular formula $\mathrm{C}_{25} \mathrm{H}_{34} \mathrm{O}_{2} \mathrm{~N}_{3}$ corresponds to an index of hydrogen deficiency of 11.

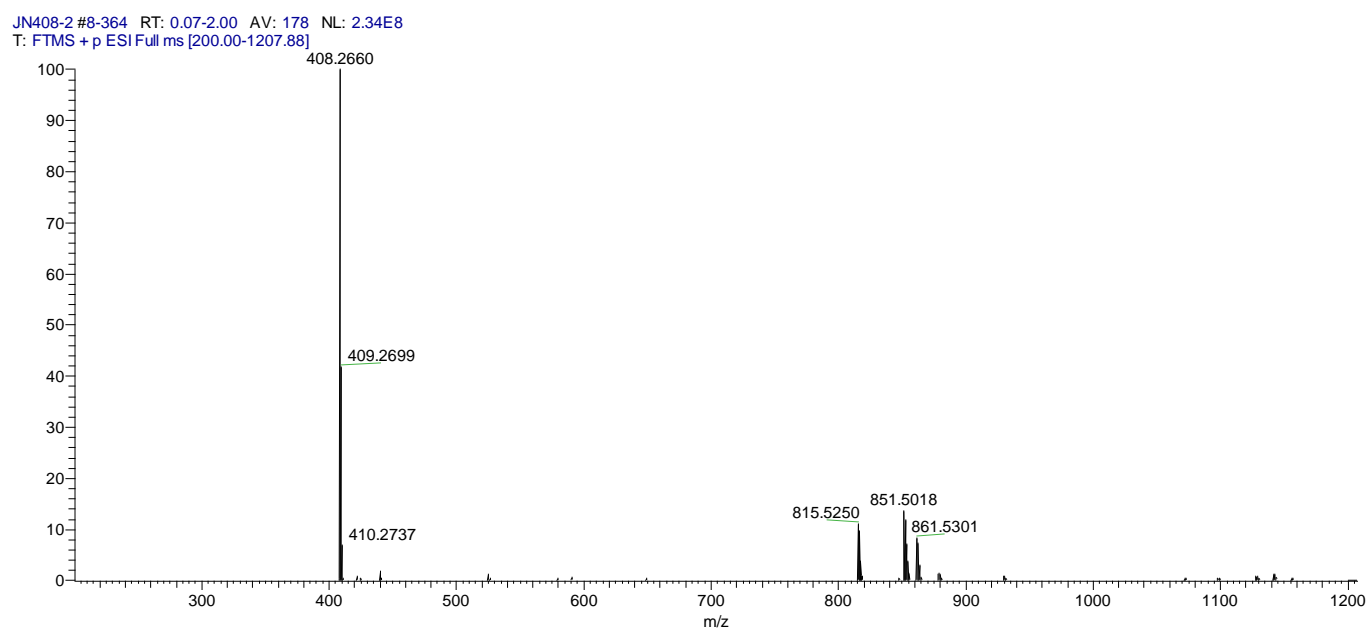

Figure 62: HR-ESI-MS of JN408 


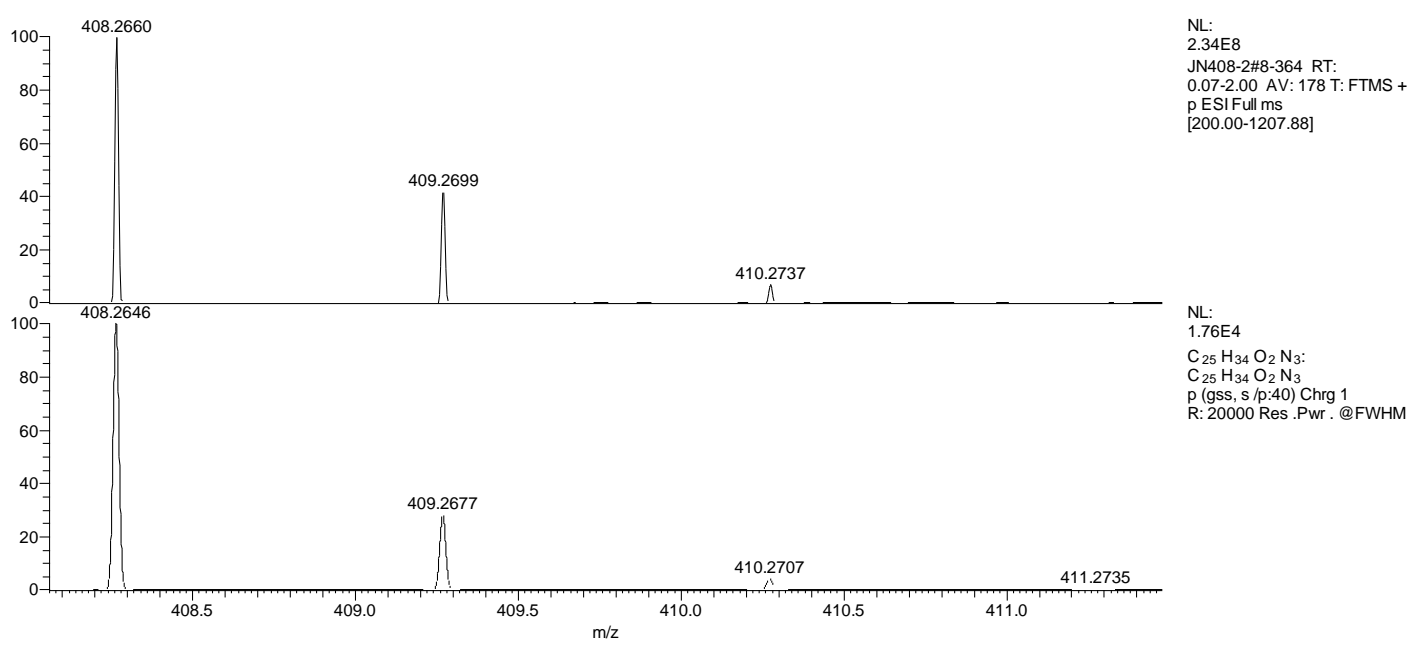

Figure 63: Comparison between the acquired mass and isotope pattern (top panel) and the predicted mass (bottom panel) for JN408. There is a difference of $\mathrm{m} / \mathrm{z} 0.0014$ between the acquired and predicted mass for JN408.

The MS/MS of JN408 (31) is characterized by the presence of daughter fragment ions $m / z 391.33$ (33), and 376.33 (34) corresponding to the loss of $m / z 17$ and 32, respectively (Figure 64) (Figure 65). This profile is consistent with the loss of a hydroxyl radical to generate fragment ion (33) followed by the loss of a methyl radical to generate fragment ion (34) (Figure 65). The generation of $m / z 230.25$ (21) fragment ion was observed previously in the MS/MS profile of marineosin (Figure 14) (Figure 15) which indicated that JN408 and marineosin share similar structures. The neutral loss of $\mathrm{m} / \mathrm{z} 15$ characteristic for conjugated red-colored prodiginines such as undecylprodiginine (7) (Figure 21) or G410 (27) (Figure 41), was not observed in the MS/MS profile of JN408 which further corroborated a structure similar to marineosin rather than undecylprodiginine (7) or G410 (27). 
JN408-2 \#6-363 RT: 0.04-1.99 AV: 179 NL: 6.44E5

F: TMS + p ESI Full ms2 408.26@cid20.00 [110.00-ヶ

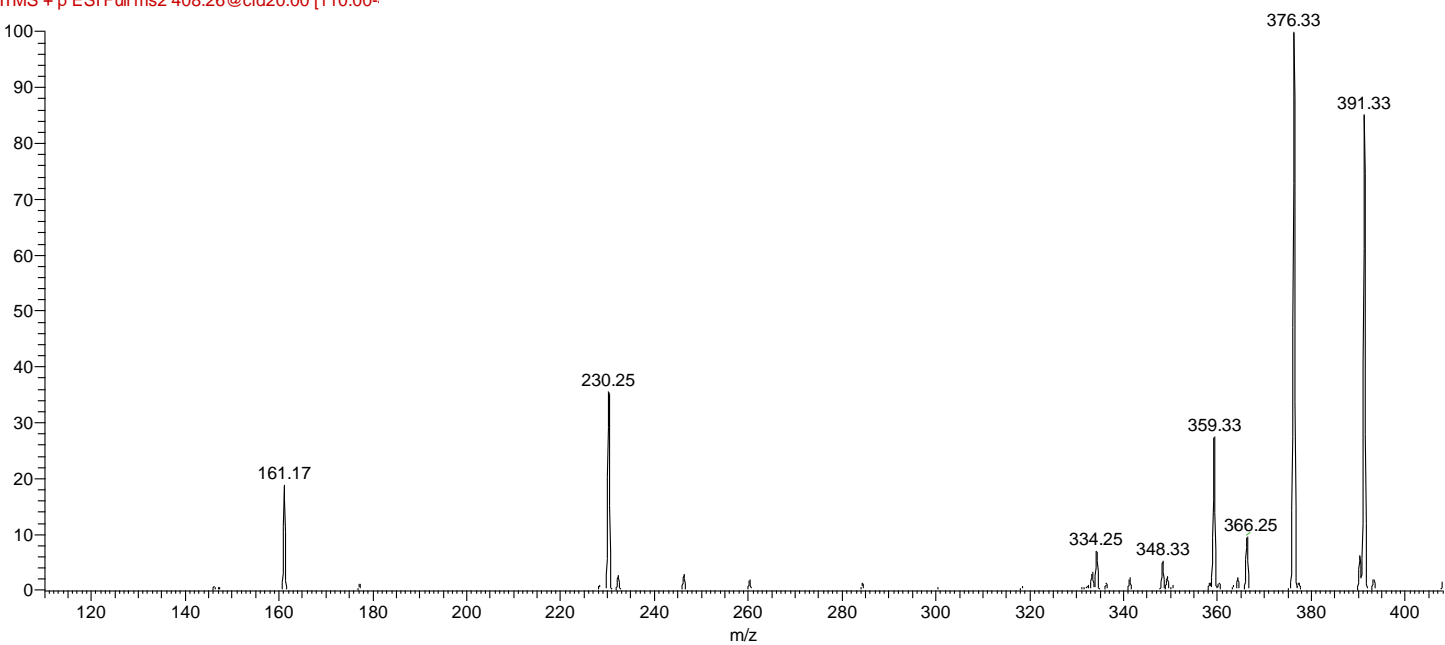

Figure 64: ESI-CID-MS ${ }^{n}$ profile of $\mathrm{JN408}$. The MS/MS profile of JN408 is characterized by the presence of $\mathrm{m} / \mathrm{z} 230.25,376.33$ and 391.33 daughter ion fragments. Parent ion, $\mathrm{m} / \mathrm{z} 408.26$ is not shown. Please refer to text for more details. 


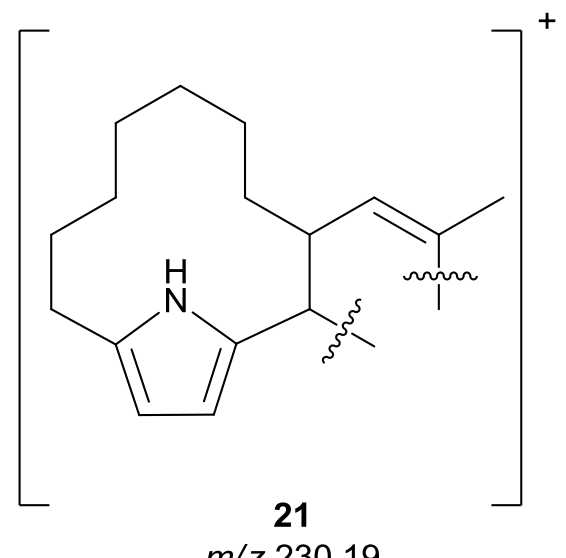

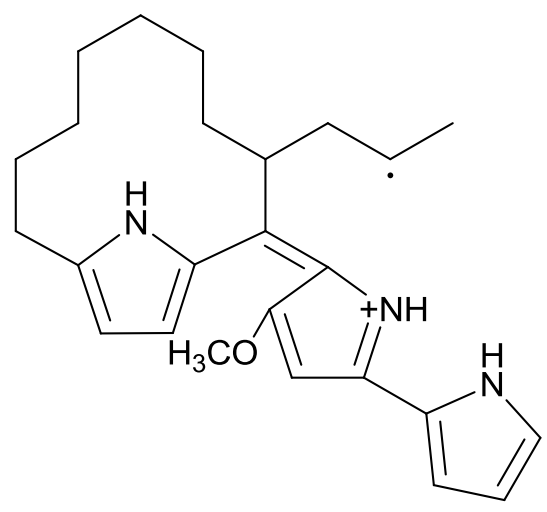

33

$m / z 391.26$

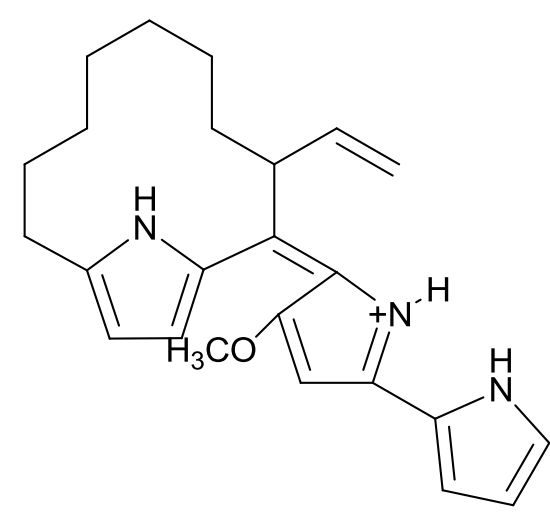

34

$m / z 376.24$

Figure 65: Fragment ions observed in the MS/MS profile of JN408. The daughter fragment $\mathrm{m} / \mathrm{z} 230.19$ was observed before in the MS/MS profile of marineosin which suggested that JN408 is a marineosin analog. The loss of $\mathrm{m} / \mathrm{z} 17$ from JN408, corresponding to the loss of a hydroxyl radical leads to the generation of fragment (33). The consequent loss of a methyl radical from fragment ion (33) leads to the generation of fragment ion (34). It should be noted that the masses recorded in this figure are for the calculated values and are slightly different from the experimentally acquired values shown in Figure 64.

The HR-ESI-MS analysis of JN422 (32) exhibits $[\mathrm{M}+\mathrm{H}]^{+}$of $\mathrm{m} / \mathrm{z} 422.2450$ (Figure 66). The acquired mass was analyzed for molecular formula $\mathrm{C}_{25} \mathrm{H}_{32} \mathrm{O}_{3} \mathrm{~N}_{3}$ or $\mathrm{C}_{25} \mathrm{H}_{31} \mathrm{O}_{3} \mathrm{~N}_{3}$ without the $\mathrm{H}$-adduct. This corresponds to an index of hydrogen 
deficiency of 12 . The difference between the acquired mass of JN422 and the theoretical mass of the predicted molecular formula is only $\mathrm{m} / \mathrm{z} 0.0012$ (Figure 67). From the molecular formula, it was proposed that JN422 is a keto-derivative of $\mathrm{JN} 408$, but the position of that keto group was unclear.

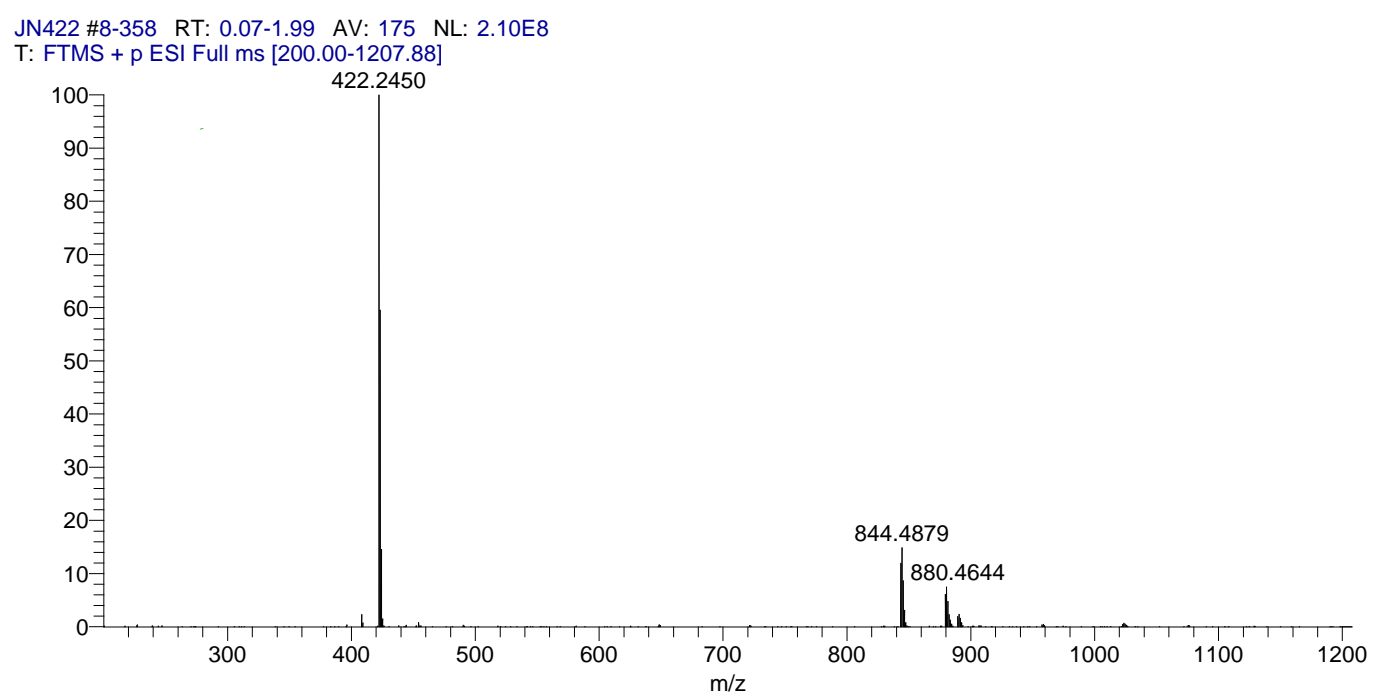

Figure 66: HR-ESI-MS of JN422

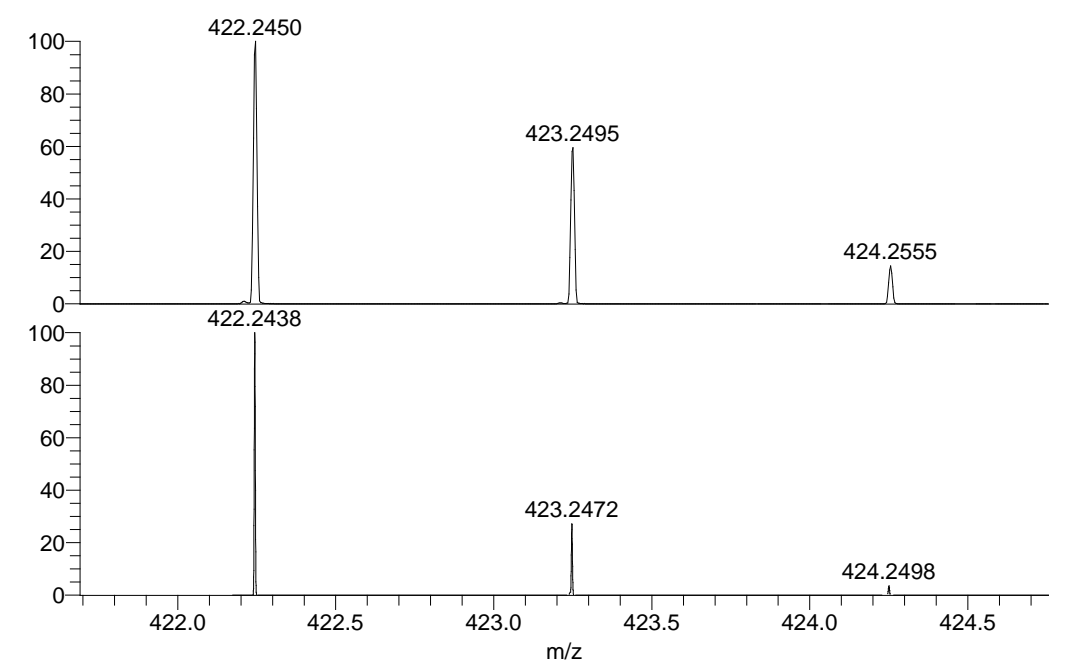

NL:

$2.10 \mathrm{E} 8$

JN422\#8-358 RT:

0.07-1.99 AV: $175 \mathrm{~T}$ :

FTMS + p ESI Full ms

[200.00-1207.88]

NL:

4.05E4

$\mathrm{C}_{25} \mathrm{H}_{32} \mathrm{O}_{3} \mathrm{~N}_{3}$

$\mathrm{C}_{25} \mathrm{H}_{32} \mathrm{O}_{3} \mathrm{~N}_{3}$

p (gss, s/p:40) Chrg 1

R: 50000 Res .Pwr.@5\%

Figure 67: Comparison between the acquired mass and isotope pattern (top panel) and the predicted mass (bottom panel) for JN422. There is a difference of $\mathrm{m} / \mathrm{z} 0.0012$ between the acquired and predicted mass for JN422. 
The MS/MS of JN422 (32) is characterized by the presence of daughter fragment ions $m / z 405.25$ (36), and 390.33 (37) corresponding to the loss of $m / z 17$ and 32, respectively (Figure 68) (Figure 69). This profile is consistent with the loss of a hydroxyl radical from JN422 to generate fragment ion (36) followed by the loss of a methyl radical to generate fragment ion (37) (Figure 69). A daughter fragment ion $m / z 244.25$ (35) is also observed in the MS/MS profile of JN422 which corresponds to the keto-derivative of fragment ion (21) observed in the MS/MS profile of JN408 and marineosin (Figure 65) (Figure 15). From fragment ion (35), we concluded that a keto group is present in the acyl chain of JN422. As observed in JN408 (31), the MS/MS profile of JN422 (32) lacks any daughter fragments representing a neutral loss of $\mathrm{m} / \mathrm{z} 15$ characteristic for conjugated prodiginines and therefore, JN422 was proposed to be a keto-derivative of JN408 rather than undecylprodiginine (7).

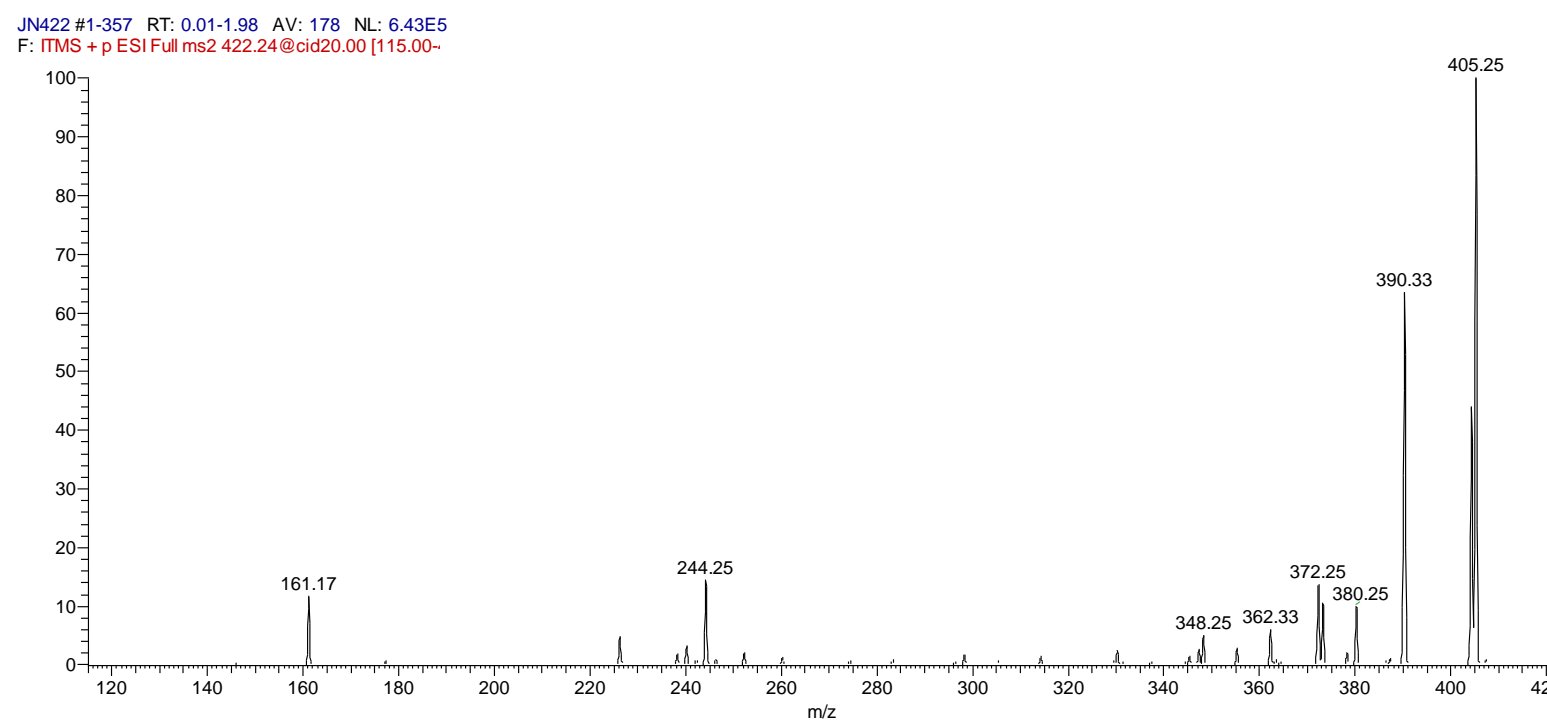

Figure 68: ESI-CID-MS ${ }^{n}$ profile of JN422. Parent ion, $\mathrm{m} / \mathrm{z} 422.24$ is not shown. Please refer to text for more details. 


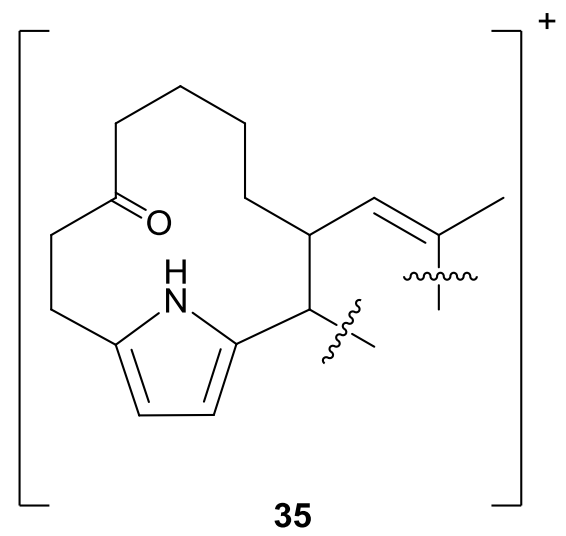

$\mathrm{m} / \mathrm{z} 244.17$

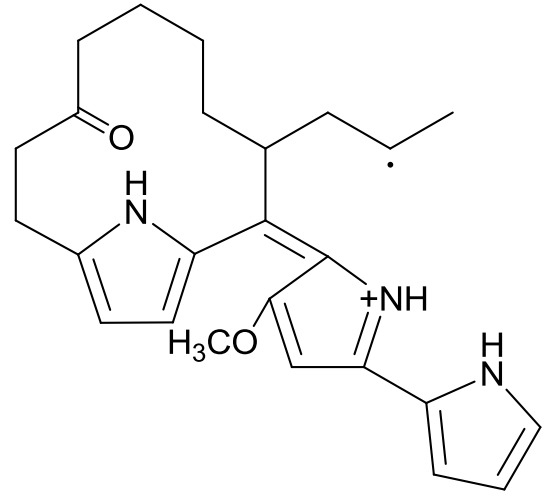

36

$m / z 405.24$

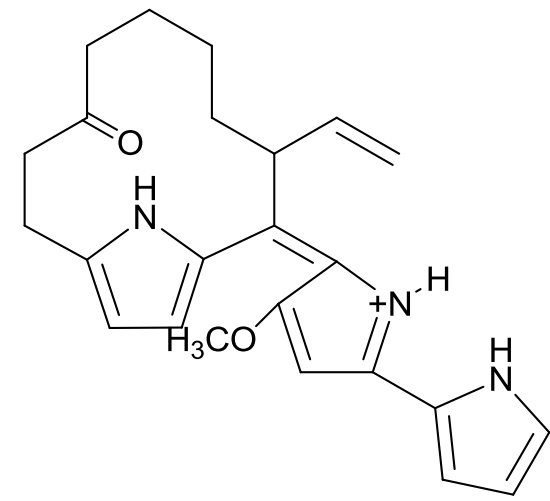

37

$m / z 390.22$

Figure 69: Fragment ions observed in the MS/MS profile of JN422. The daughter fragment $\mathrm{m} / \mathrm{z} 244.17$ (34) is the keto-derivative of fragment ion (21) observed in the MS/MS profile of both marineosin and JN408. The loss of $\mathrm{m} / \mathrm{z} 17$ from JN422, corresponding to the loss of a hydroxyl radical leads to the generation of fragment 35. The consequent loss of a methyl radical from fragment ion 35 leads to the generation of fragment ion 36 . It should be noted that the masses recorded in this figure are for the calculated values and are slightly different from the experimentally acquired values shown in Figure 68. 
The IR spectrum of JN408 (31) compound (Figure 70) has IR $v_{\max } 2925,2855$, $1617,1427,1363,1349,1270,1222,1119,1059,1031,956,771$ and $712 \mathrm{~cm}^{-1}$. JN422 (32) was found to have the same IR $v_{\max }$ (Figure 70) peaks as JN408 with only minor differences in the $v_{\max }$ values of individual peaks. However, the IR spectrum of JN422 is characterized by the presence of an additional characteristic IR $v_{\max }$ peak at $1705 \mathrm{~cm}^{-1}$ corresponding to $\mathrm{C}=\mathrm{O}$ stretch of a keto group. This comparison between the IR spectra of JN408 and JN422 provided additional evidence that both compounds are related and that the predominant difference is the presence of a keto group in JN422.

All UV-profile, HR-ESI-MS, MS/MS profile and IR spectra of JN408 (31) and JN422 (32) indicated that both compounds are marineosin analogs and that are both compounds probably have the same structure except for the presence of an extra keto group in the acyl chain of JN422 (32). Therefore, further NMR spectral analyses of both compounds were done side by side. The structure of JN422 (32) was elucidated using ${ }^{1} \mathrm{H}-\mathrm{NMR},{ }^{1} \mathrm{H}-{ }^{1} \mathrm{H}$ 2D COSY, ${ }^{1} \mathrm{H}-{ }^{1} \mathrm{H}$ 2D TOCSY, 2D HSQC and 2D HMBC experiments. Due to limited quantity of JN408 (31), some cross peak correlations in the 2D HSQC and 2D HMBC spectra were not determined and therefore, the missing correlations were deduced by comparison to JN422 2D HSQC and 2D HMBC spectra. 

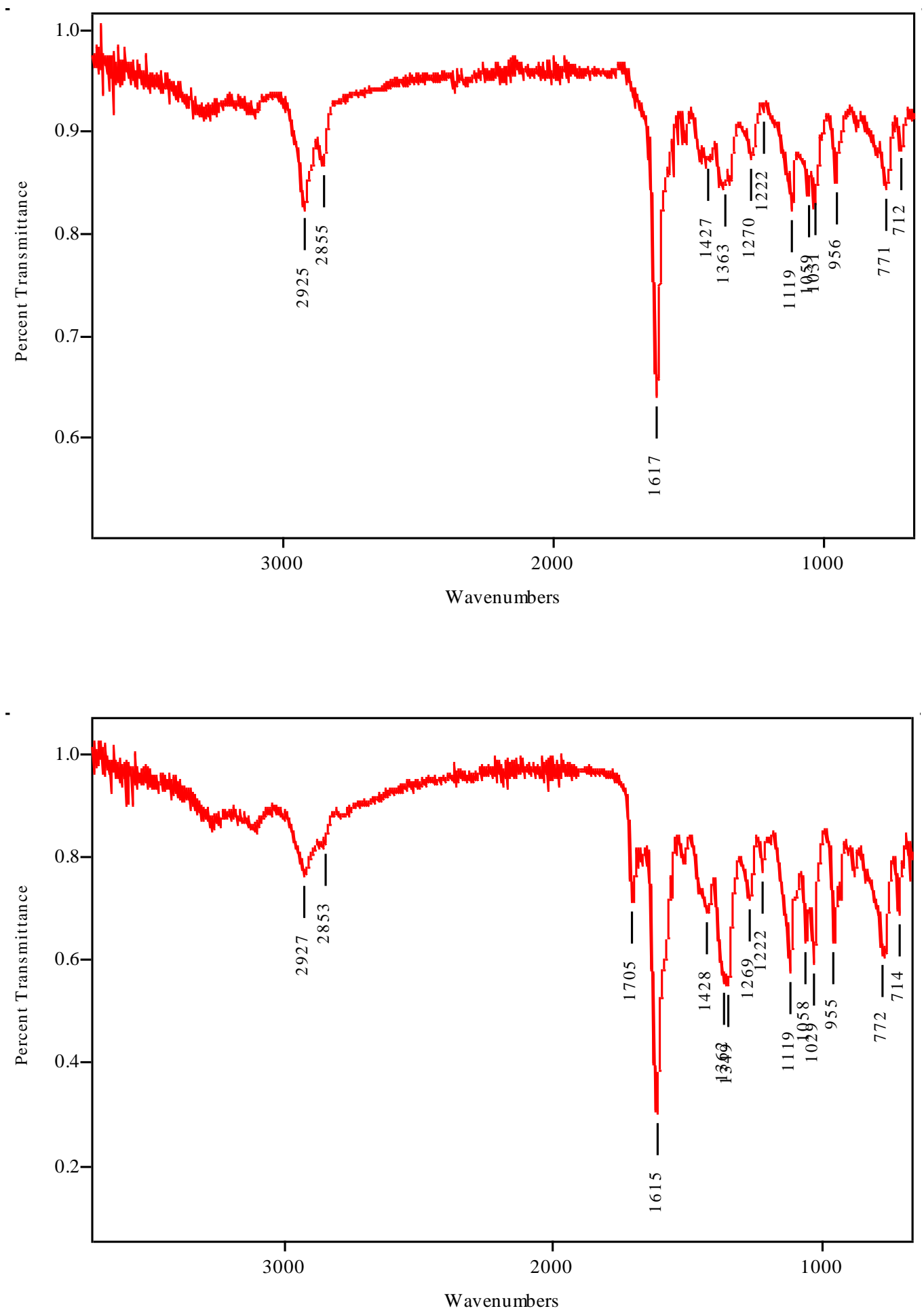

Figure 70: The IR spectrum of JN408 (top panel) and JN422 (bottom panel) 
${ }^{1} \mathrm{H}-\mathrm{NMR}$ spectra of both JN408 and JN422 (Figure 71) (Figure 72) have 6 peaks with chemical shifts, $\delta 5.5-7.5 \mathrm{ppm}$ which indicates the presence of 6 aromatic protons.
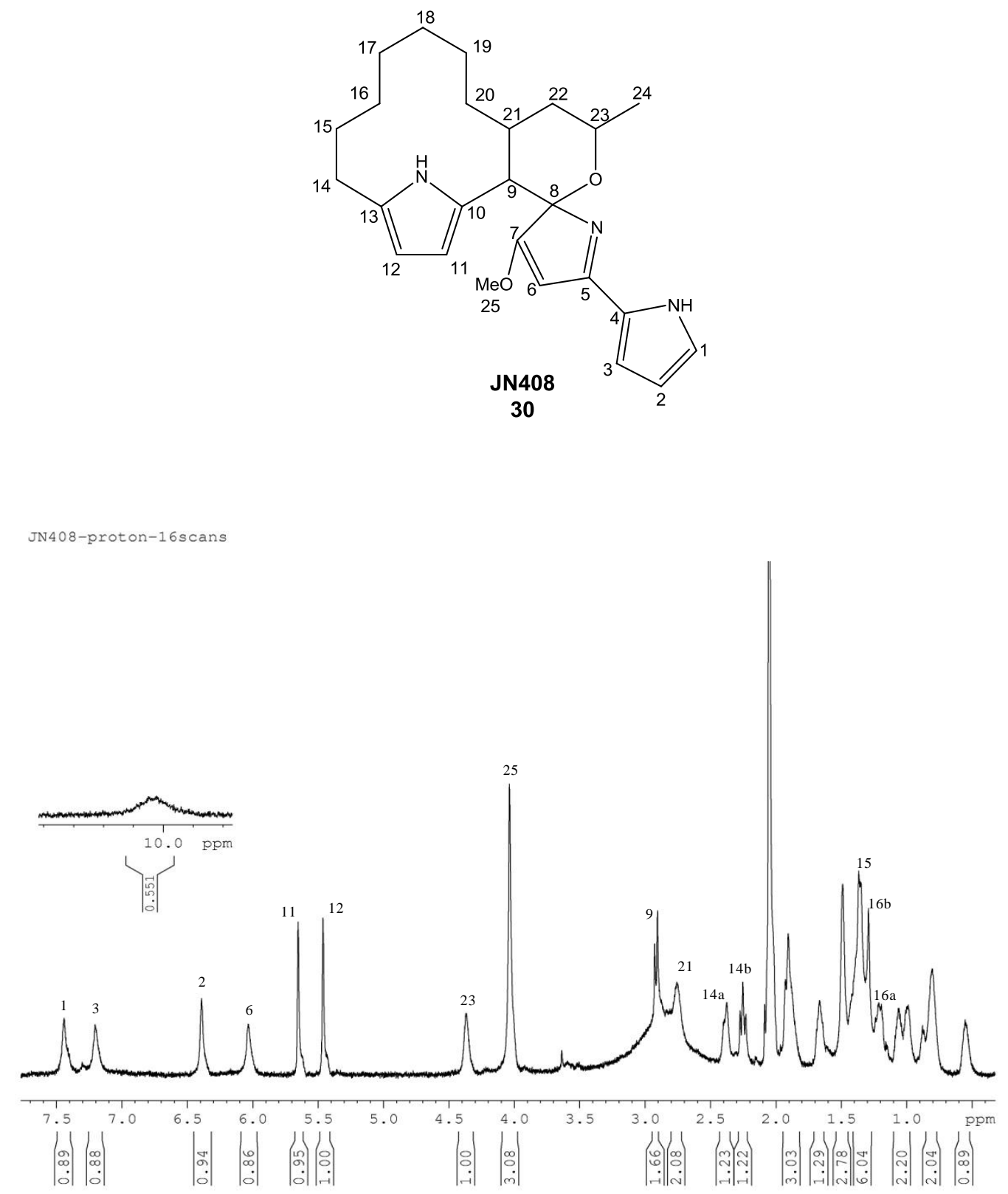

Figure 71: ${ }^{1} \mathrm{H}-\mathrm{NMR}$ spectrum of $\mathrm{JN}$ 408. Key protons peaks are assigned. 


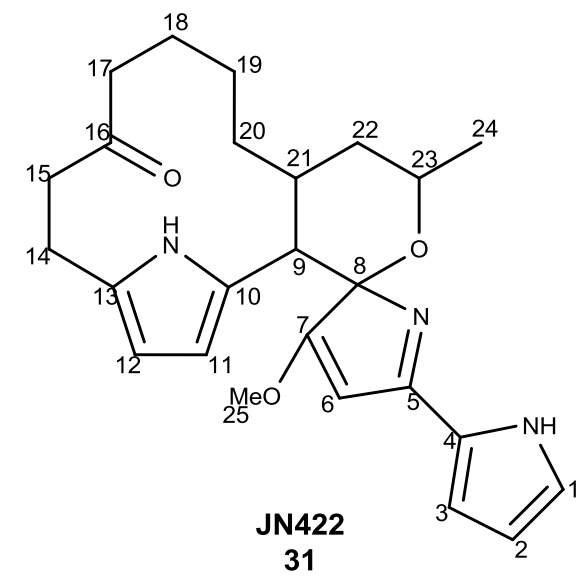

JN422-64scans-nonspin

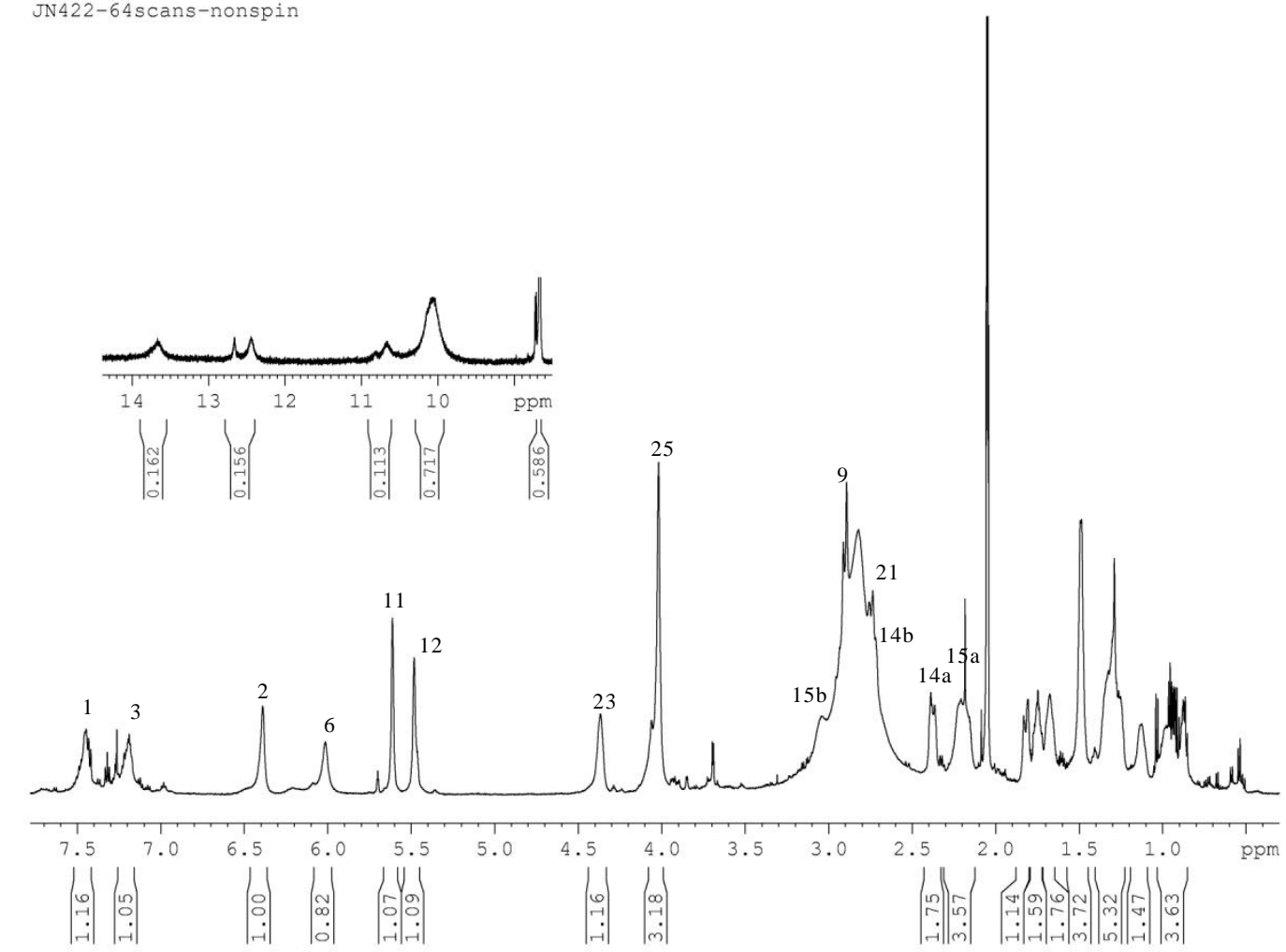

Figure 72: ${ }^{1} \mathrm{H}-\mathrm{NMR}$ spectrum of JN422. Key protons are assigned.

The ${ }^{13} \mathrm{C}$-chemical shifts of JN408 (31) and JN422 (32) were indirectly determined from the 2D HSQC (Figure 73) and 2D HSQCED spectra (Figure 74) of both 
molecules. The 2D HSQCED spectra of JN408 (31) and JN422 (32) confirmed that the 6 protons with chemical shifts $\delta 5.5-7.5$ ppm are attached to carbons with ${ }^{13} \mathrm{C}$-chemical shifts $\delta 93-131$ ppm which is usually observed for carbons part of an aromatic ring system. Detailed ${ }^{1} \mathrm{H}$ - and ${ }^{13} \mathrm{C}$-chemical shifts of JN408 and JN422 is presented in Table 15.

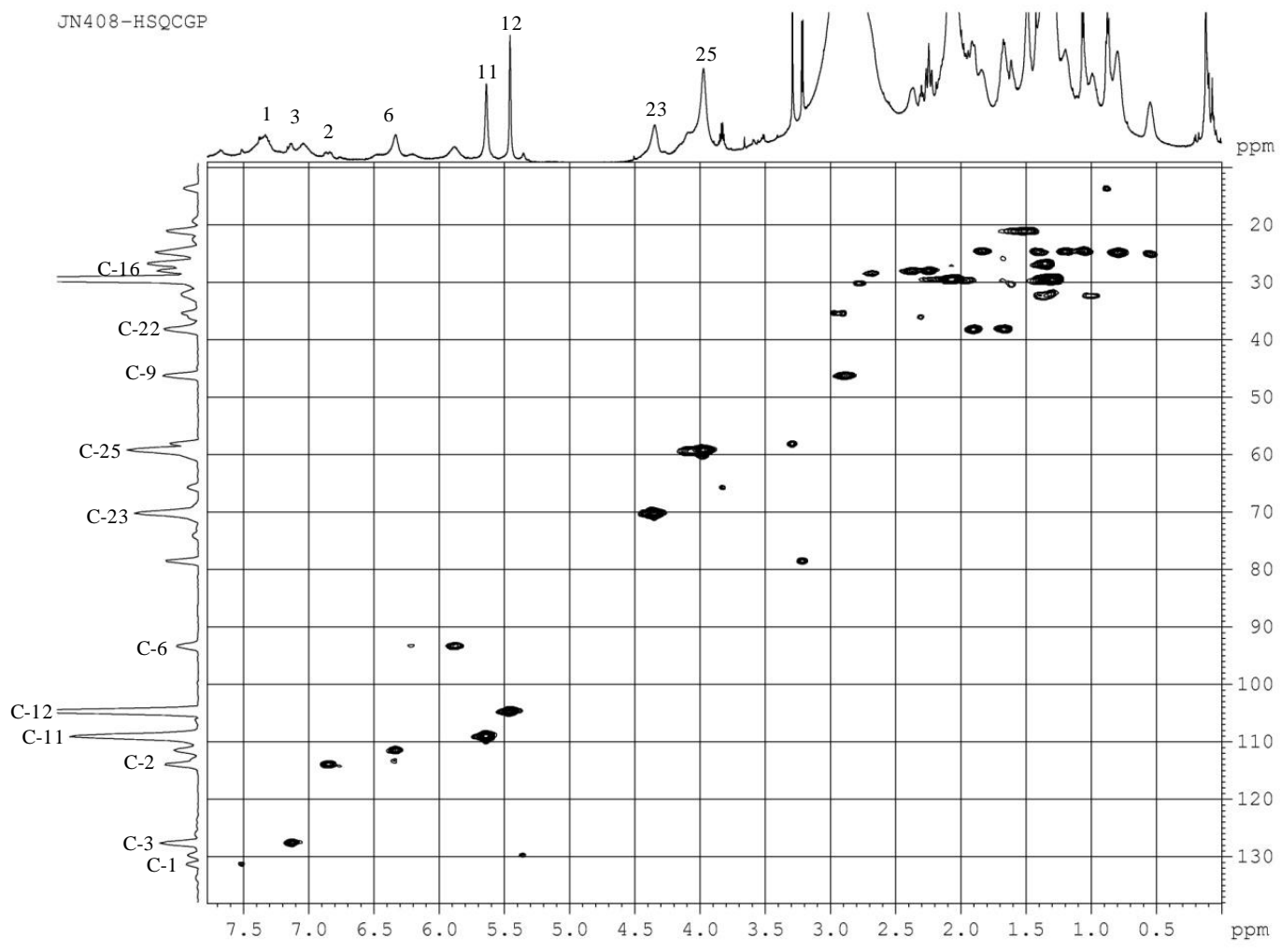

Figure 73: 2D HSQC spectrum of JN408 

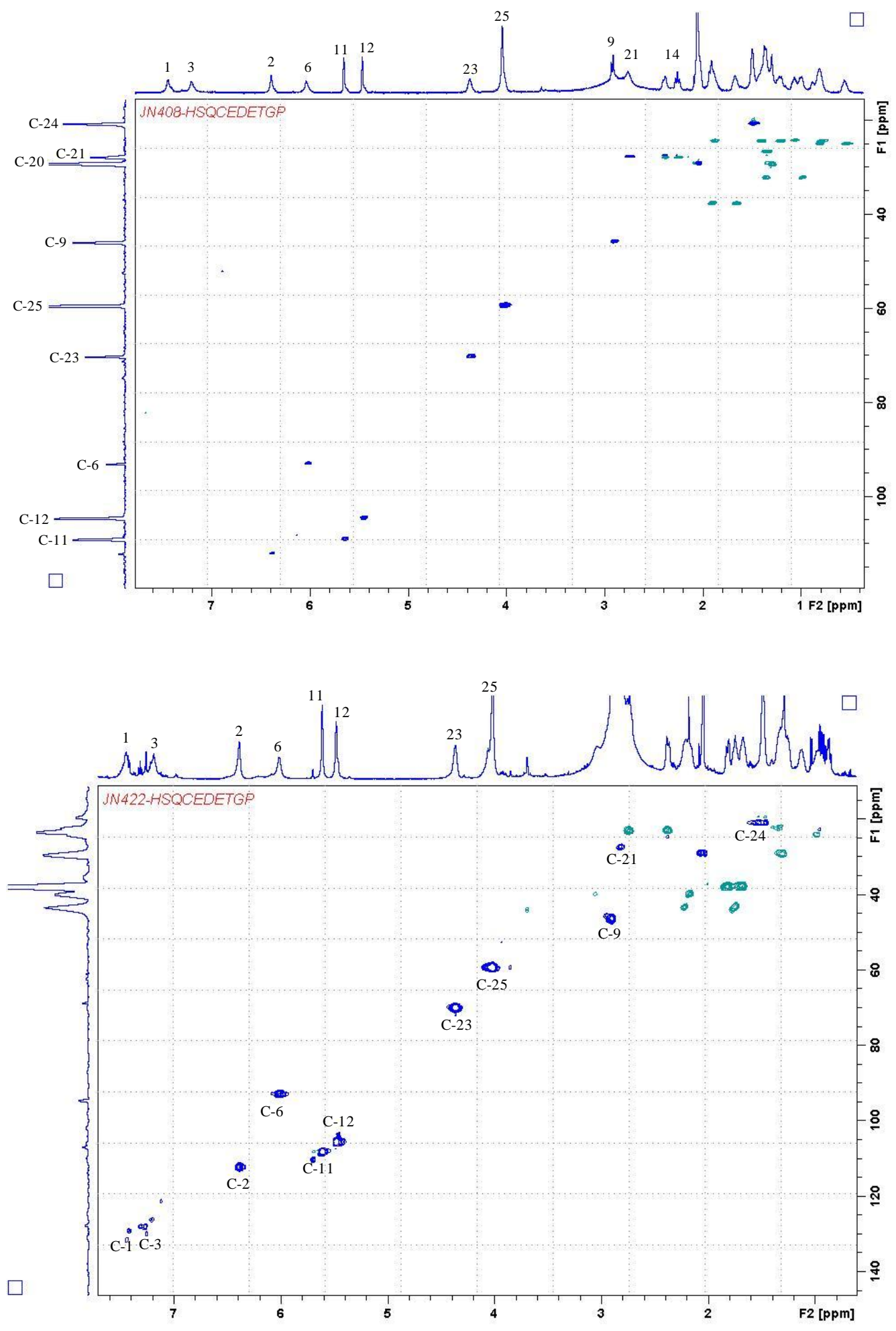

Figure 74: 2D HSQCED spectrum of JN408 (top panel) and JN422 (bottom panel). Key peak assignments are indicated on spectra. 
Table 15: NMR Spectral data for JN408 and JN422 (600 MHz, Acetone-d6)
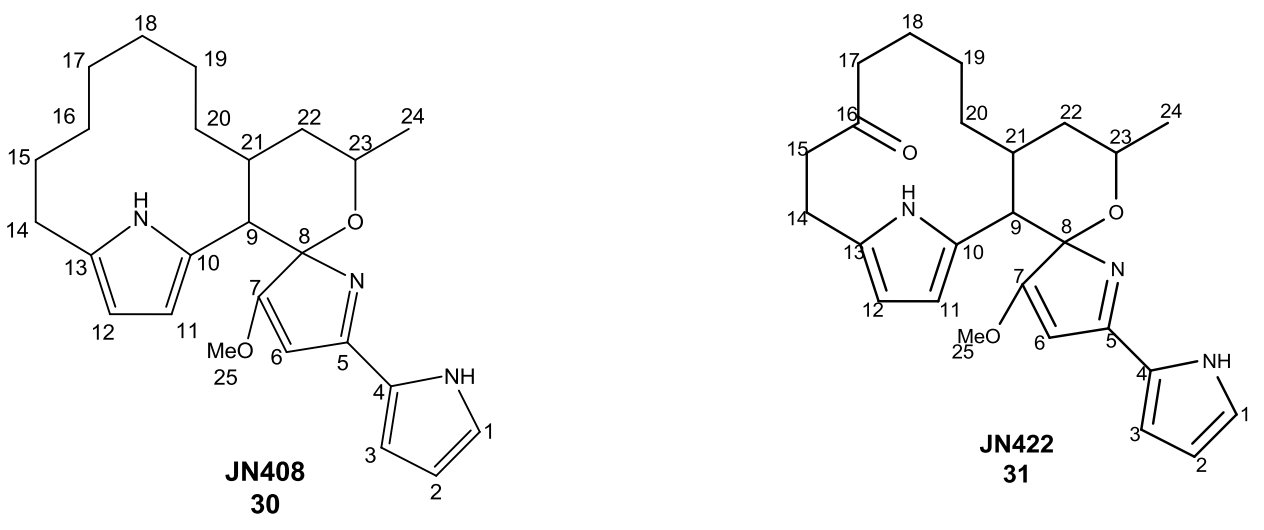

\begin{tabular}{lllll}
\hline Position & $\begin{array}{l}\mathbf{J N 4 0 8} \\
\delta_{\mathrm{H}}{ }^{\mathbf{a}}\end{array}$ & $\begin{array}{l}\mathbf{J N 4 2 2} \\
\delta_{\mathrm{H}}\end{array}$ & $\begin{array}{l}\mathbf{J N 4 0 8} \\
\delta_{\mathrm{C}}{ }^{\mathbf{a}}\end{array}$ & $\begin{array}{l}\mathbf{J N 4 2 2} \\
\delta_{\mathrm{C}}\end{array}$ \\
\hline 1 & 7.37 & 7.45 & 131.3 & 131.5 \\
2 & 6.37 & 6.39 & 111.6 & 112.4 \\
3 & 7.08 & 7.20 & 127.5 & 125.9 \\
4 & & & N.D. & N.D. \\
5 & & & N.D. & N.D. \\
6 & 5.93 & 6.01 & 93.1 & 93.1 \\
7 & & & N.D. & 180.6 \\
8 & & & N.D. & 97.4 \\
9 & 2.89 & 2.90 & 46.1 & 46.3 \\
10 & & & N.D. & 125.7 \\
11 & 5.64 & 5.61 & 109.0 & 108.3 \\
12 & 5.46 & 5.48 & 104.5 & 105.5 \\
13 & & & N.D. & 130.1 \\
14 & $2.24,2.37$ & $2.37,2.73$ & 28.0 & 23.6 \\
15 & 1.37 & $2.16,3.05$ & 26.5 & 39.9 \\
16 & $1.34,1.37$ & & 29.3 & 211.3 \\
17 & $0.54,0.80$ & $1.71,2.21$ & 24.7 & 43.6 \\
18 & $1.42,1.86$ & $1.29,1.31$ & 24.4 & 29.4 \\
19 & $1.05,1.20$ & $0.94,1.33$ & 24.3 & 22.1 \\
20 & $1.00,1.37$ & $1.12,1.26$ & 31.9 & 24.7 \\
21 & 2.71 & 2.80 & 28.1 & 27.3 \\
22 & $1.67,1.91$ & $1.67,1.82$ & 37.8 & 37.9 \\
23 & 4.36 & 4.36 & 70.1 & 70.0 \\
24 & 1.50 & 1.50 & 20.9 & 20.6 \\
25 & 3.99 & 4.02 & 59.1 & 59.4 \\
\hline
\end{tabular}

a Assignment by 1D $\left({ }^{1} \mathrm{H}\right)$, and 2D (COSY, TOCSY, HSQC) NMR spectroscopy; N.D.: not determined. 
${ }^{1} \mathrm{H}-{ }^{1} \mathrm{H}$ 2D TOCSY (Figure 75) aromatic correlations among the 6 aromatic protons observed in both JN408 (31) and JN422 (32) confirms that these protons constitute the tripyrrole ring skeleton characteristic to prodiginines family of natural products. The presence of 6 aromatic protons in JN408 and JN422 vs. only 5 aromatic protons in marineosin suggested that the pyrrole ring B in JN408 (31) and JN422 (32) is oxidized and fully conjugated. It should be noted from Table 15 and ${ }^{1} \mathrm{H}-{ }^{1} \mathrm{H}$ 2D TOCSY spectra (Figure 75) (Figure 76) of JN408 (30) and JN422 (31), that both compounds are identical in their aromatic regions represented by $\mathrm{C} 1, \mathrm{C} 2, \mathrm{C} 3, \mathrm{C} 6, \mathrm{C} 11$ and $\mathrm{C} 12$. Similar 2D TOCSY correlations were observed for G410 (27) and undecylprodiginine (7) (Figure 46) which again confirms that all three pyrrole rings of JN408 (31) and JN422 (32) are nonreduced, unlike that observed in marineosin. 

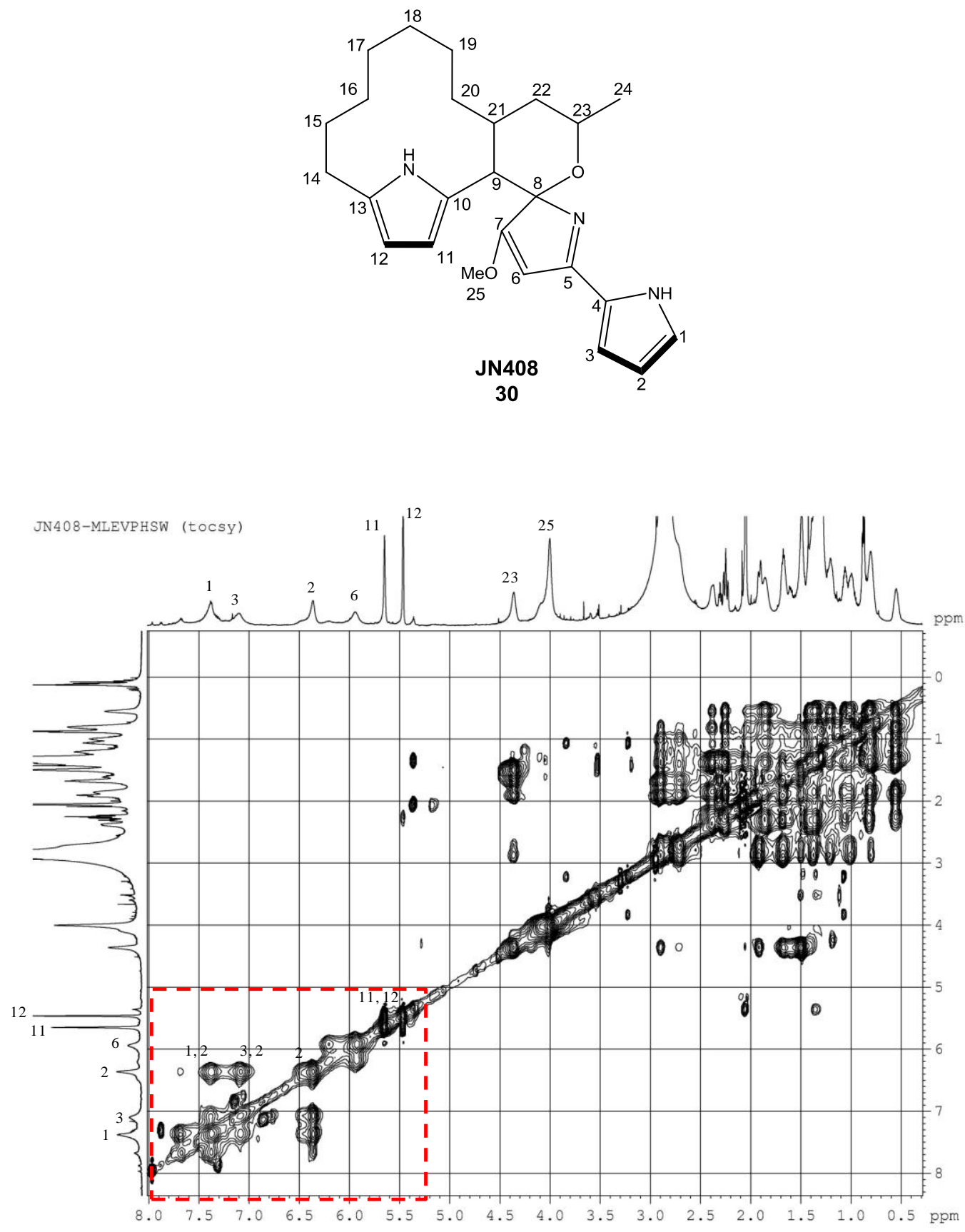

Figure 75: ${ }^{1} \mathrm{H}-{ }^{1} \mathrm{H}$ 2D TOCSY spectrum of JN408. Top panel: JN408 showing selected ${ }^{1} \mathrm{H}-{ }^{1} \mathrm{H} 2 \mathrm{D}$ TOCSY correlations among aromatic protons only, shown in bold. Bottom panel: full ${ }^{1} \mathrm{H}-{ }^{1} \mathrm{H} 2 \mathrm{D}$ TOCSY spectrum of JN408 with the aromatic region correlations boxed and key correlations assigned. 

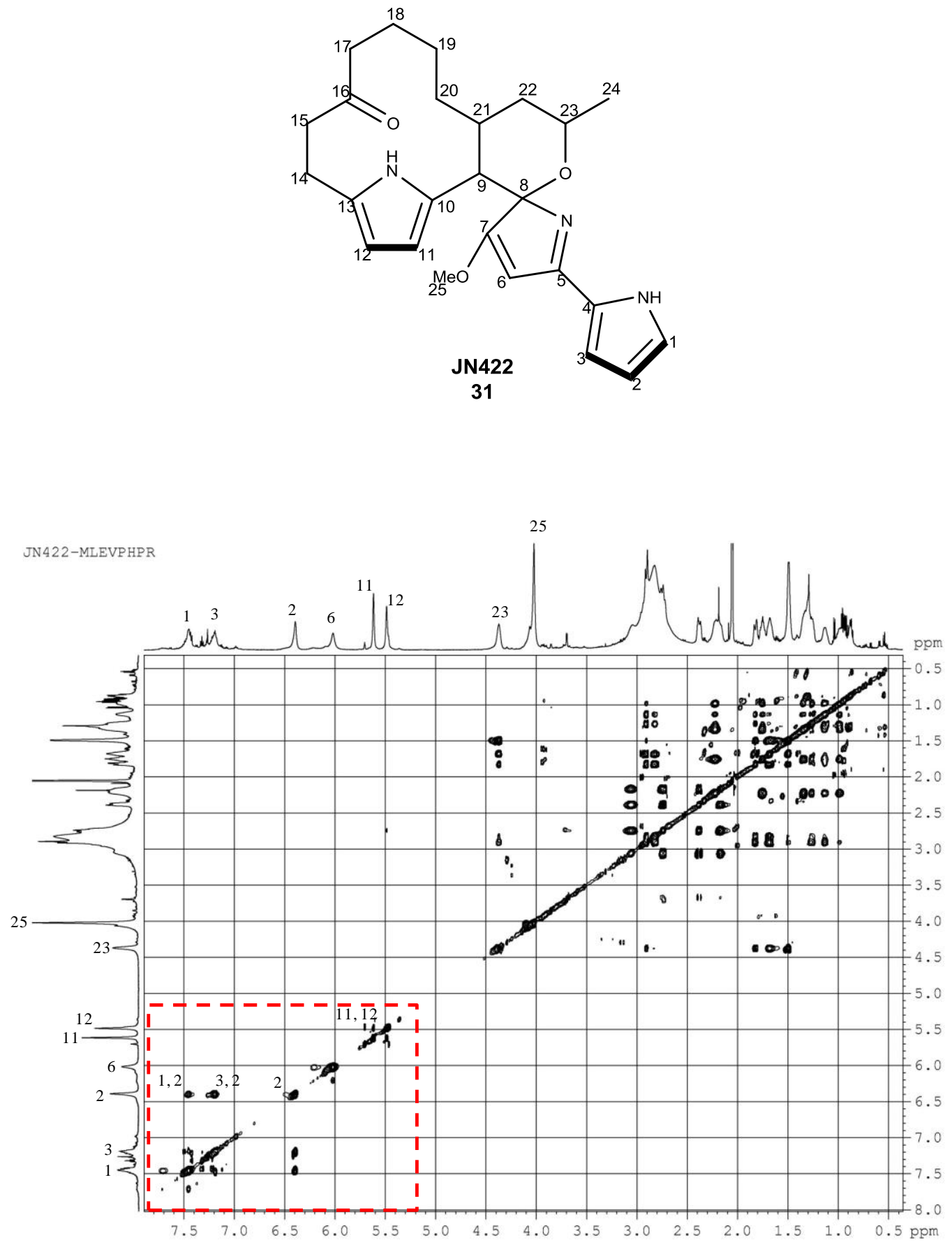

Figure 76: ${ }^{1} \mathrm{H}-{ }^{1} \mathrm{H}$ 2D TOCSY spectrum of JN422 showing correrlations between aromatic protons. Top panel: selected ${ }^{1} \mathrm{H}-{ }^{1} \mathrm{H}$ 2D TOCSY correlations of JN422 among aromatic protons, in bold. Bottom panel: full ${ }^{1} \mathrm{H}-{ }^{1} \mathrm{H}$ 2D TOCSY spectrum of $\mathrm{JN} 422$ with the aromatic region correlations boxed and key correlations assigned. 
The 2D HSQCED of JN408 (31) indicated the presence of 8 methylene groups (Figure 77) while that of JN422 (32) indicated the presence of only 7 methylene groups (Figure 78).
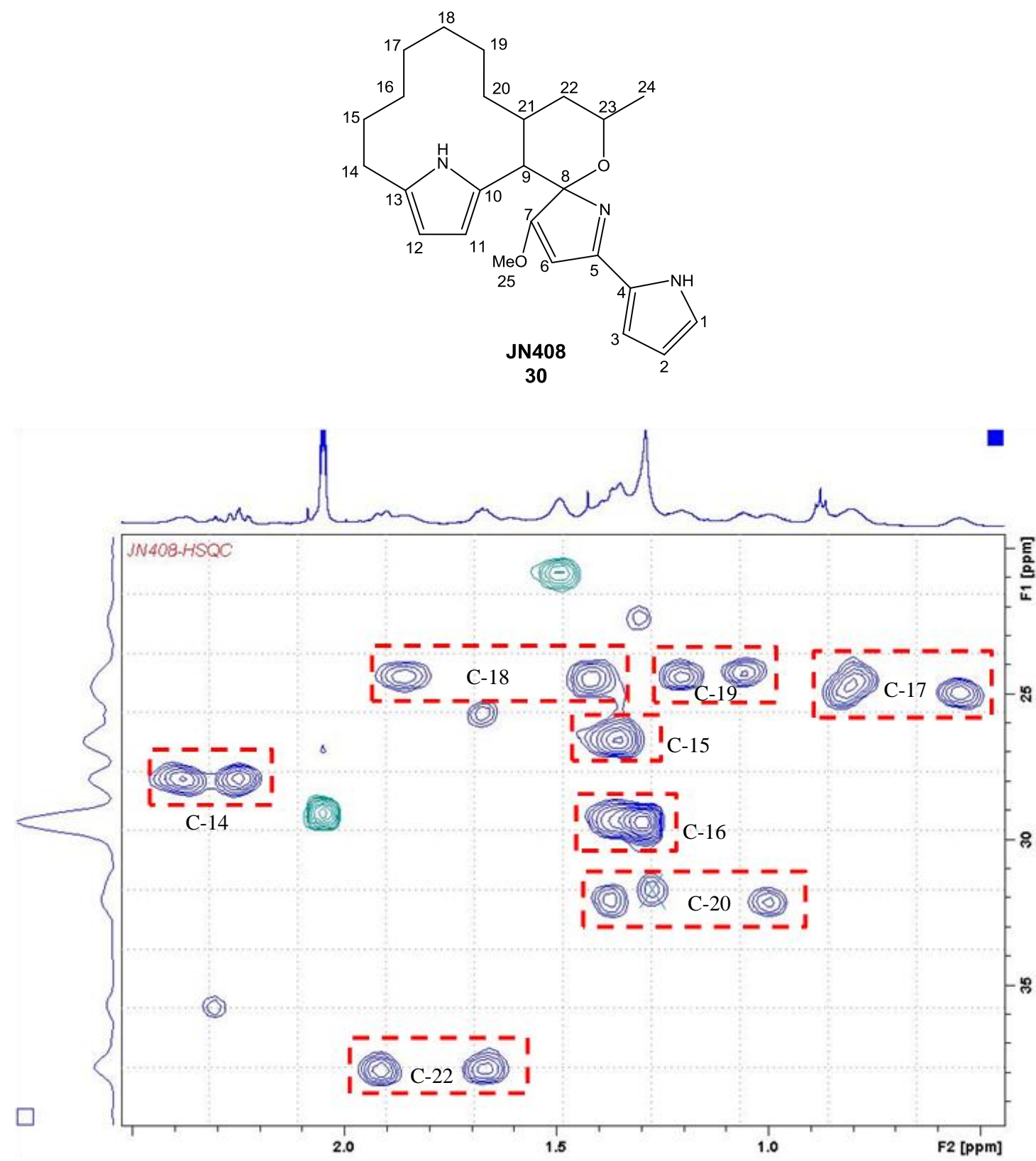

Figure 77: 2D HSQCED spectrum of JN408 - aliphatic region expanded. Carbons bonding even number of protons are shown in blue while carbons bonding odd number of protons are shown in green. Aliphatic $-\mathrm{CH}_{2}$ groups are assigned and boxed. A total of $8-\mathrm{CH}_{2}$ groups are present. 

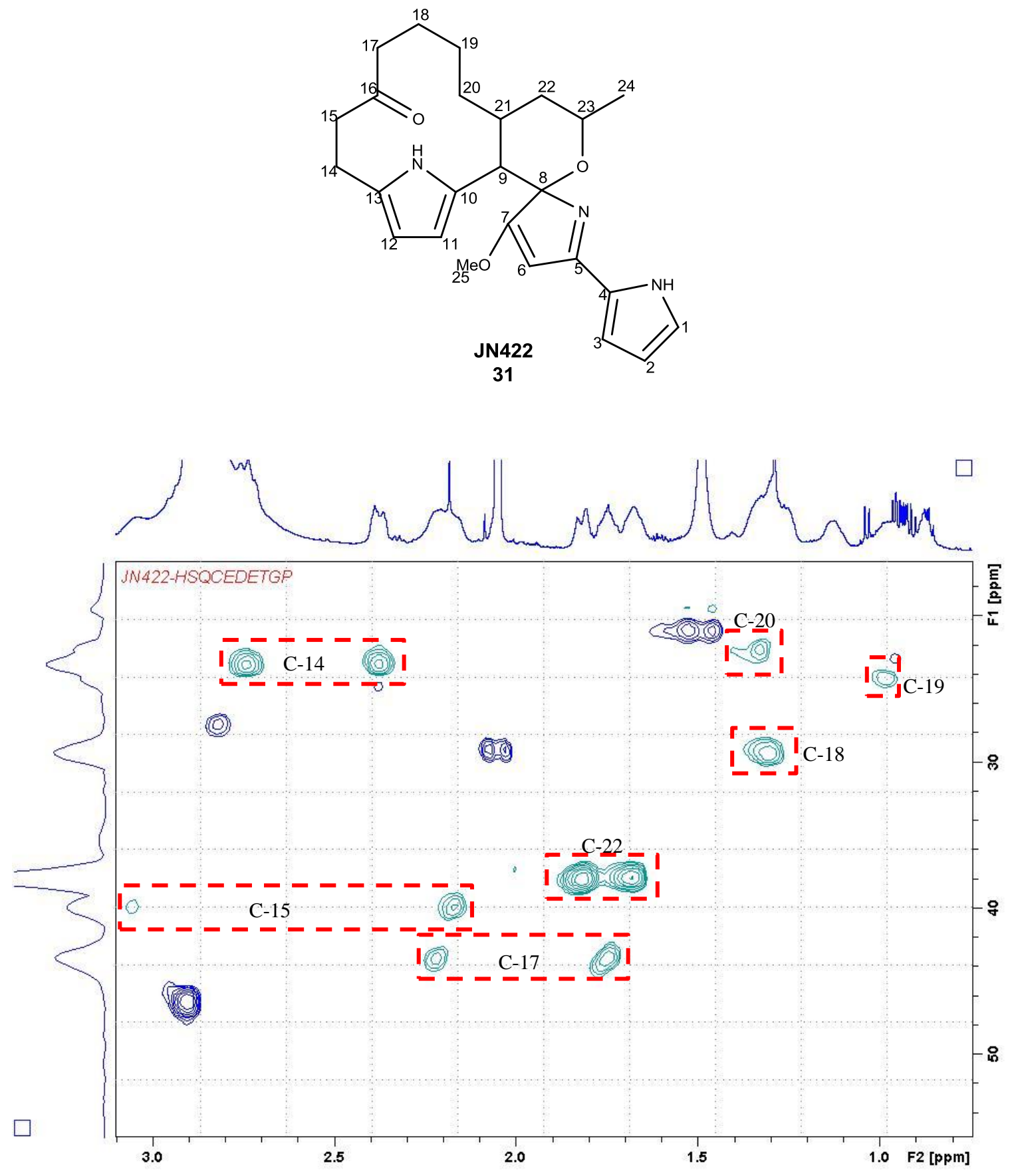

Figure 78: 2D HSQCED spectrum of JN422 - aliphatic region expanded. Carbons bonding even number of protons are shown in green while carbons bonding odd number of protons are shown in blue. Aliphatic $-\mathrm{CH}_{2}$ groups are assigned and boxed. A total of $7-\mathrm{CH}_{2}$ groups are present. A cross peak at $(\mathrm{F} 1=1.12 \mathrm{ppm}, \mathrm{F} 2=24.7 \mathrm{ppm})$, corresponding to the second proton attached to $\mathrm{C}-20$ is not shown in this spectrum. 
In JN422, ${ }^{1} \mathrm{H}-{ }^{1} \mathrm{H}$ 2D TOCSY correlations were found between protons at $\mathrm{C} 9$ and C21 (Figure 79) which suggested that a covalent bond exists between C9 and C21 to form a macrocyclic ring.
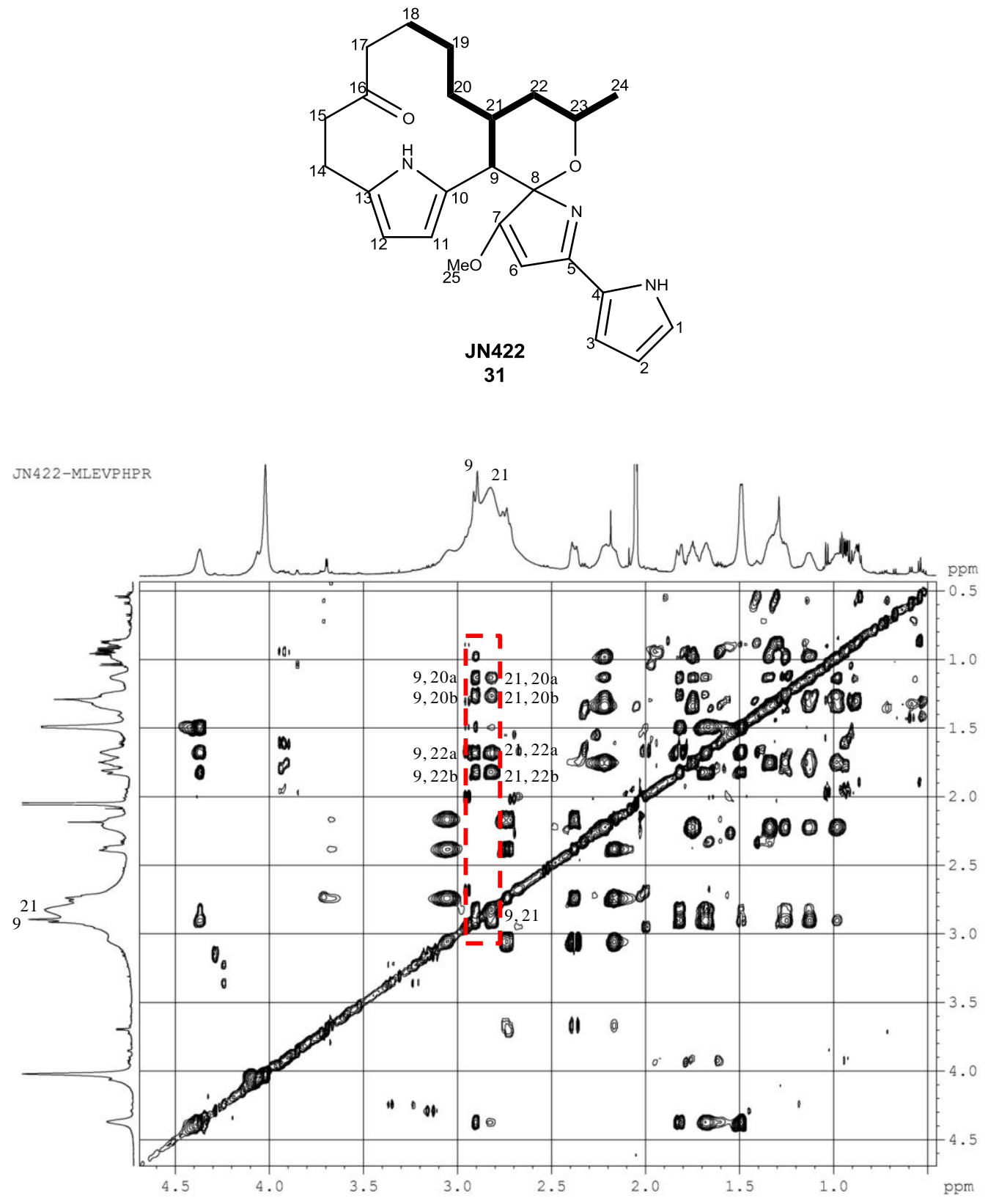

Figure 79: Selected ${ }^{1} \mathrm{H}-{ }^{1} \mathrm{H}$ 2D TOCSY correlations (top panel) and spectrum (bottom) of JN422 - aliphatic region expanded. Correlations between protons at C9 and C21 and neighboring $-\mathrm{CH}_{2}$ groups are represented by bold bonds in JN422 structure (top panel). The same correlations are shown and boxed in the TOCSY spectrum (bottom panel). 
These data were confirmed by 2D HMBC correlations between protons at $\mathrm{C} 9$ and C7, C8, C10, C11, C20, C21 and C22 (Figure 80).
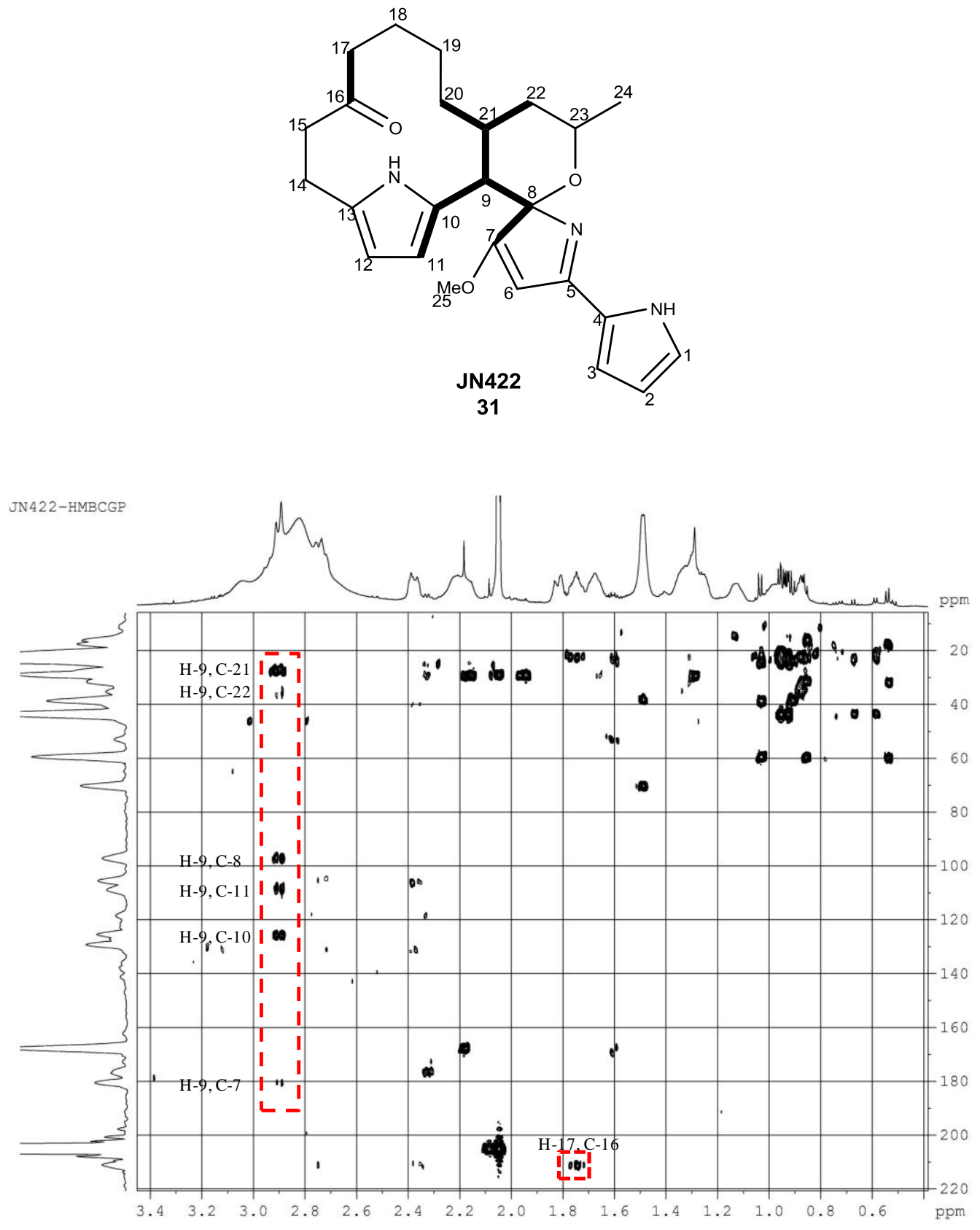

Figure 80: Selected 2D HMBC $\left({ }^{1} \mathrm{H}-{ }^{13} \mathrm{C}\right)$ correlation (top panel) and spectrum (bottom panel) of JN422 - aliphatic region expanded. Correlations between proton at C9 and neighboring carbons are represented by bold bonds in JN422 structure (top panel). Correlations between protons at $\mathrm{C}-17$ and the carbonyl carbon at $\mathrm{C}-16$ are also in bold. The same correlations are boxed and assigned in the 2D HMBC spectrum (bottom panel). 
The same clear correlations between proton at C9 and proton at C21 were observed in the ${ }^{1} \mathrm{H}-{ }^{1} \mathrm{H} 2 \mathrm{D}$ TOCSY spectrum of JN408 (Figure 81).
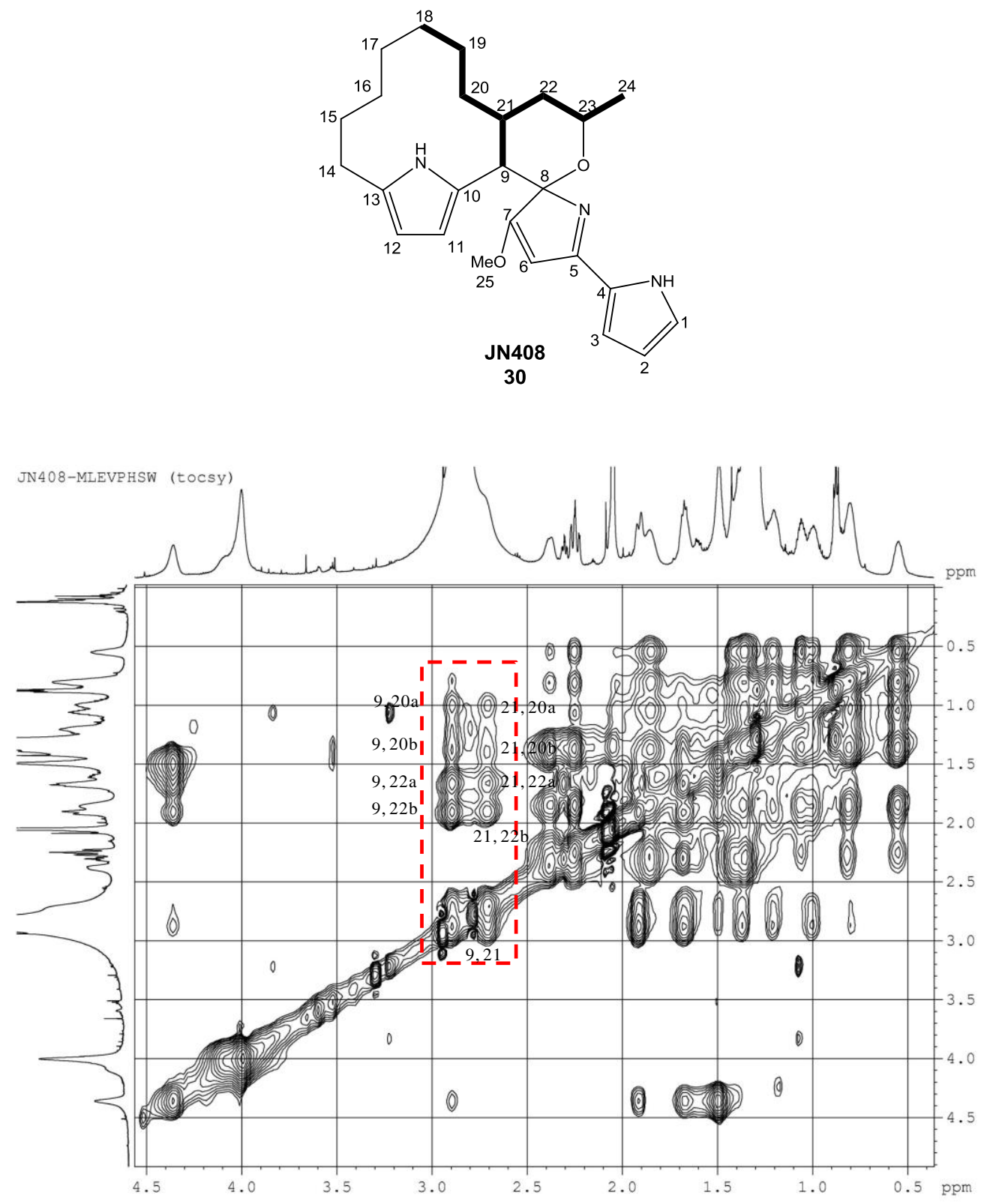

Figure 81: Selected ${ }^{1} \mathrm{H}-{ }^{1} \mathrm{H}$ 2D TOCSY correlations (top panel) and spectrum (bottom) of JN408- aliphatic region expanded. Correlations between protons at C9 and C21 and neighboring $-\mathrm{CH}_{2}$ groups are represented by bold bonds in JN408 structure (top panel). The same correlations are boxed in the TOCSY spectrum (bottom panel). Key correlations for C9 and C21 are indicated. 
Unfortunately, due to limited quantity of JN408 (31), these correlations could not be confirmed by $2 \mathrm{D}$ HMBC data. However, the TOCSY data was sufficient to conclude that JN408 has a macrocyclic ring similar to that present in JN422 (32) and marineosin.

In JN422, weak $\left({ }^{1} \mathrm{H}^{-13} \mathrm{C}\right) \mathrm{HMBC}$ correlations (Figure 80) between a carbonyl carbon at $\delta 211 \mathrm{ppm}$ and protons at $\mathrm{C} 17$ suggested that the carbonyl group observed in the IR spectrum of JN422 exists in the vicinity of $\mathrm{C} 17 .{ }^{1} \mathrm{H}-{ }^{1} \mathrm{H} 2 \mathrm{D}$ TOCSY spectrum of JN422 shows strong correlations between protons at C14 and $\mathrm{C} 15$ but these correlations are not extended to any other proton in the acyl chain of $\mathrm{JN} 422$, suggesting that $\mathrm{C} 15$ is next to either a heteroatom or a quaternary carbon. Also, protons at C15 and C17 in JN422 (32) are slightly shifted downfield relative to their counterparts in JN408 (31) (Table 15). Therefore, we assigned the position of the keto group of JN422 (32) at C16.

Since all protons were accounted for except the protons at C8 and C23, we concluded that a spiroaminal ring exists between C8 and C23 in both JN408 (31) and JN422 (32).

Full spectral data and correlations of JN408 (31) and JN422 (32) are presented in Figure 83, Figure 84, Figure 85, Figure 86 , Figure 87, Table 16, Table 17, and Table 18. 

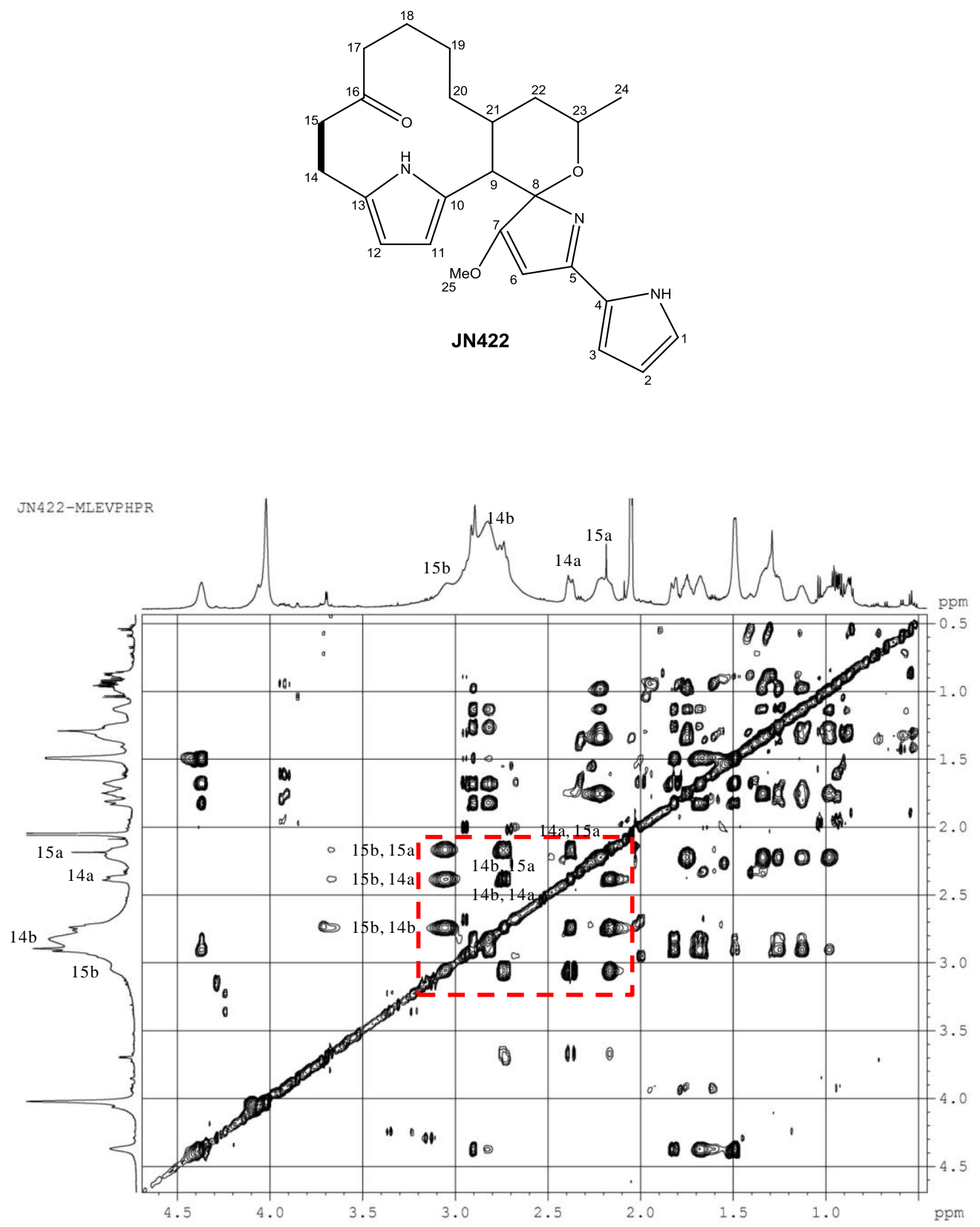

Figure 82: ${ }^{1} \mathrm{H}-{ }^{1} \mathrm{H}$ 2D TOCSY spectrum of JN422 showing correlations between $\mathrm{C} 14$ and C15. Correlations between protons at $\mathrm{C} 14$ and $\mathrm{C} 15$ are indicated. The correlations are not extended to neighboring - $\mathrm{CH} 2$ groups in the TOCSY spectrum indicating that both groups are either adjacent to a heteroatom or a quaternary carbon. 
A)

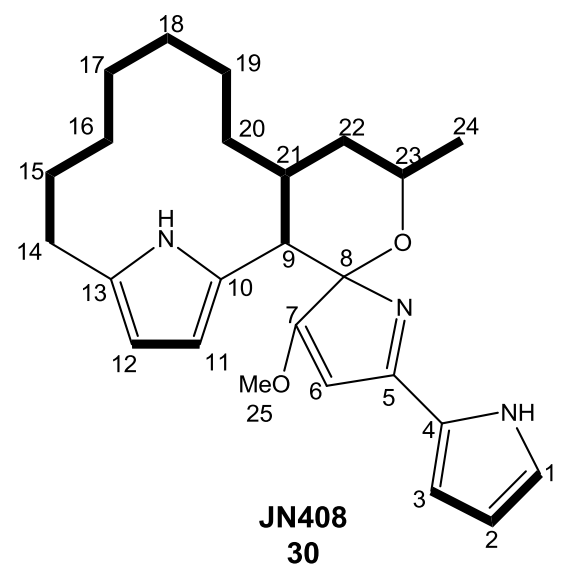

B)

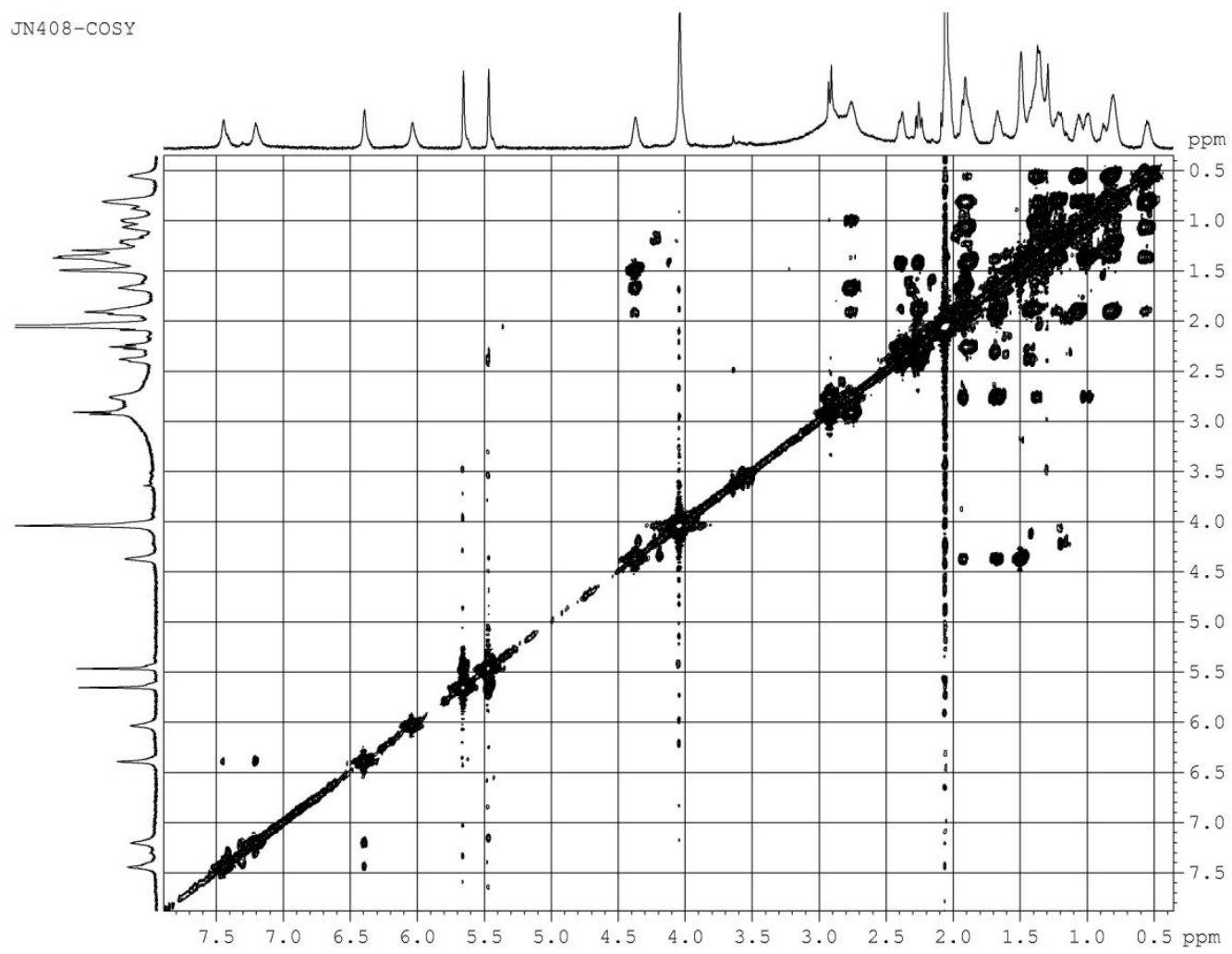

Figure 83: A) ' ${ }^{\mathrm{H}} \mathrm{-}^{\top} \mathrm{H}$ 2D COSY correlations of JN408. B) 2D COSY NMR spectrum of JN422. Selected COSY correlations in JN408 are drawn in bold. 
A)

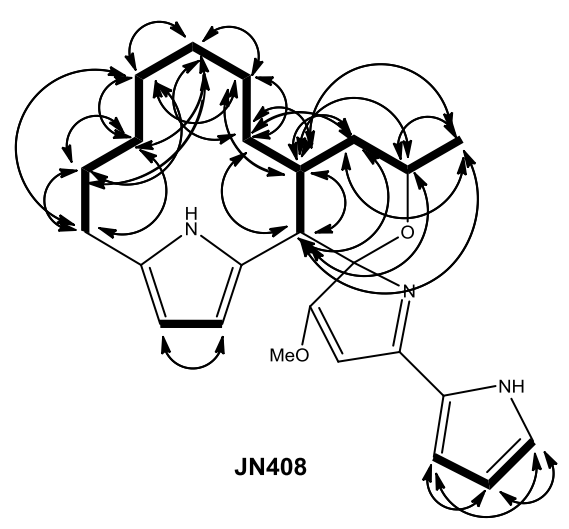

B)

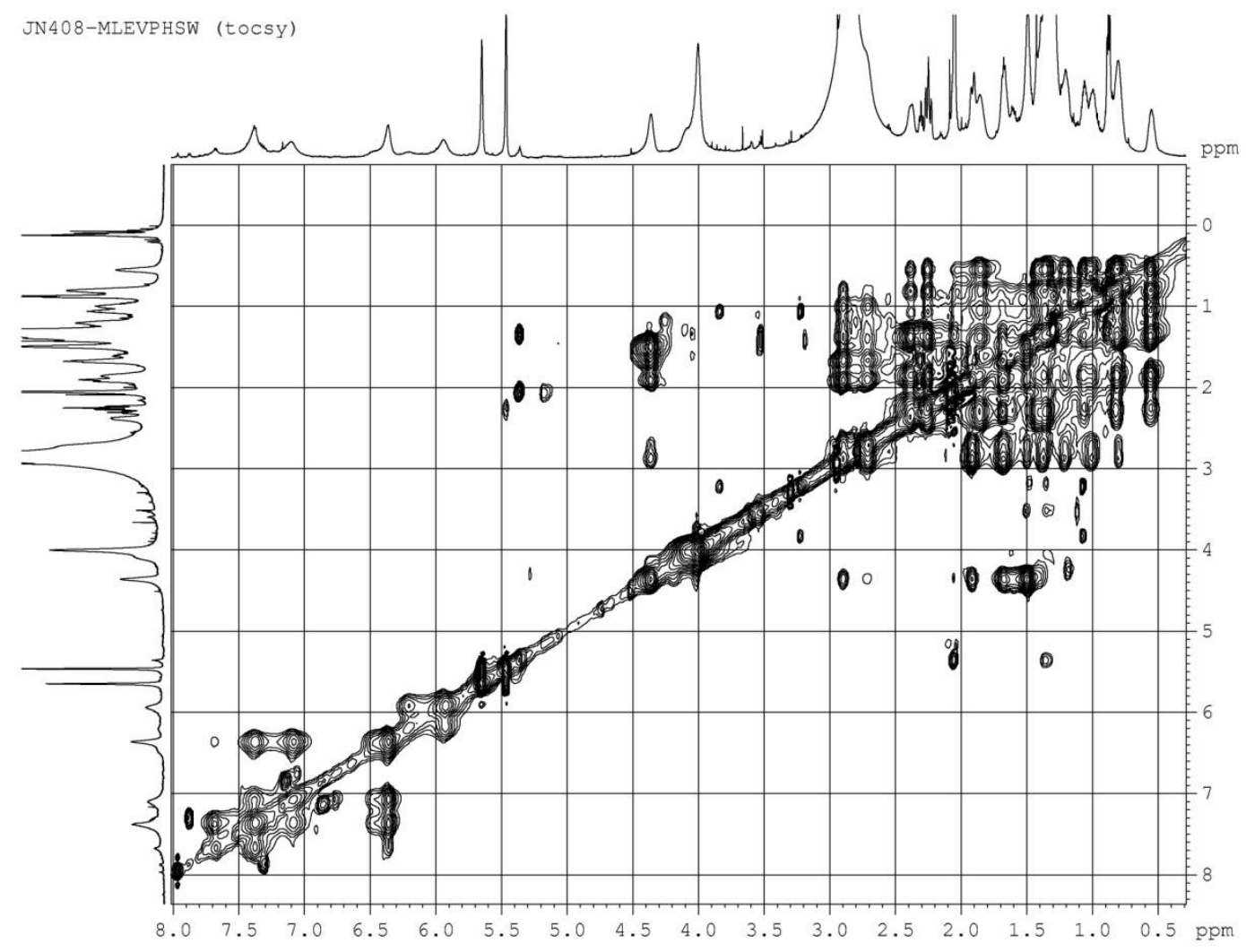

Figure 84: A) Selected COSY $(H \leftrightarrow H$; bold lines) and TOCSY $(H \leftrightarrow H$; double arrows) NMR correlations for JN408. B) 2D TOCSY NMR spectrum of JN408. 


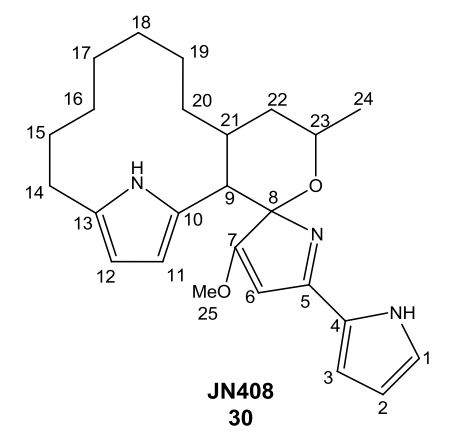

\begin{tabular}{|c|c|c|c|}
\hline Position & $\delta_{\mathrm{H}}$ & COSY & TOCSY \\
\hline 1 & 7.37 & 2,3 & 2,3 \\
\hline 2 & 6.37 & 1,3 & 1,3 \\
\hline 3 & 7.08 & 1,2 & 1,2 \\
\hline \multicolumn{4}{|l|}{4} \\
\hline \multicolumn{4}{|l|}{5} \\
\hline 6 & 5.93 & & \\
\hline \multicolumn{4}{|l|}{7} \\
\hline \multicolumn{4}{|l|}{8} \\
\hline 9 & 2.89 & 21 & $\begin{array}{c}20,21,22,23, \\
24\end{array}$ \\
\hline \multicolumn{4}{|l|}{10} \\
\hline 11 & 5.64 & 12 & 12 \\
\hline 12 & 5.46 & 11 & 11 \\
\hline \multicolumn{4}{|l|}{13} \\
\hline 14 & $2.24,2.37$ & 15 & $15,16,17$ \\
\hline 15 & 1.37 & 14,17 & $14,16,17,18$ \\
\hline 16 & $1.34,1.37$ & 15,18 & $\begin{array}{c}14,15,17,18 \\
19\end{array}$ \\
\hline 17 & $0.54,0.80$ & 16,18 & $\begin{array}{c}15,16,18,19 \\
20\end{array}$ \\
\hline 18 & $1.42,1.86$ & 17,19 & $\begin{array}{c}15,16,17,19 \\
20\end{array}$ \\
\hline 19 & $1.05,1.20$ & 18,20 & $\begin{array}{c}16,17,18,20 \\
21\end{array}$ \\
\hline 20 & $1.00,1.37$ & 19,21 & $\begin{array}{c}9,17,18,19 \\
21,22\end{array}$ \\
\hline 21 & 2.71 & $9,20,22$ & $\begin{array}{c}9,19,20,22 \\
23,24\end{array}$ \\
\hline 22 & $1.67,1.91$ & 21,23 & $\begin{array}{c}9,20,21,23 \\
24\end{array}$ \\
\hline 23 & 4.36 & 22,24 & $\begin{array}{c}9,20,21,22 \\
24\end{array}$ \\
\hline 24 & 1.50 & 23 & $9,21,22,23$ \\
\hline 25 & 3.99 & & \\
\hline
\end{tabular}

Table 16: Selected COSY $(H \leftrightarrow H)$ and TOCSY $(H \leftrightarrow H)$ NMR correlations for JN408 
A)

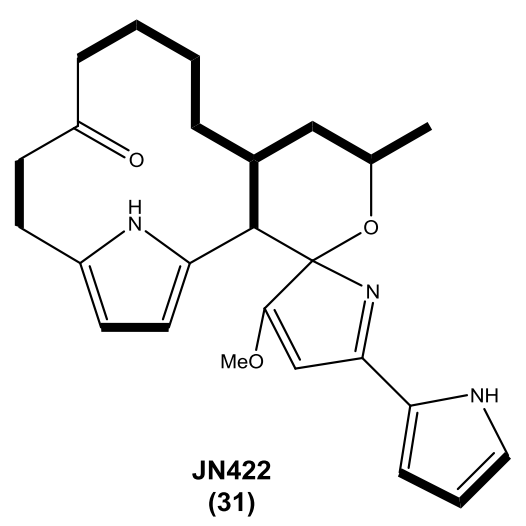

B)

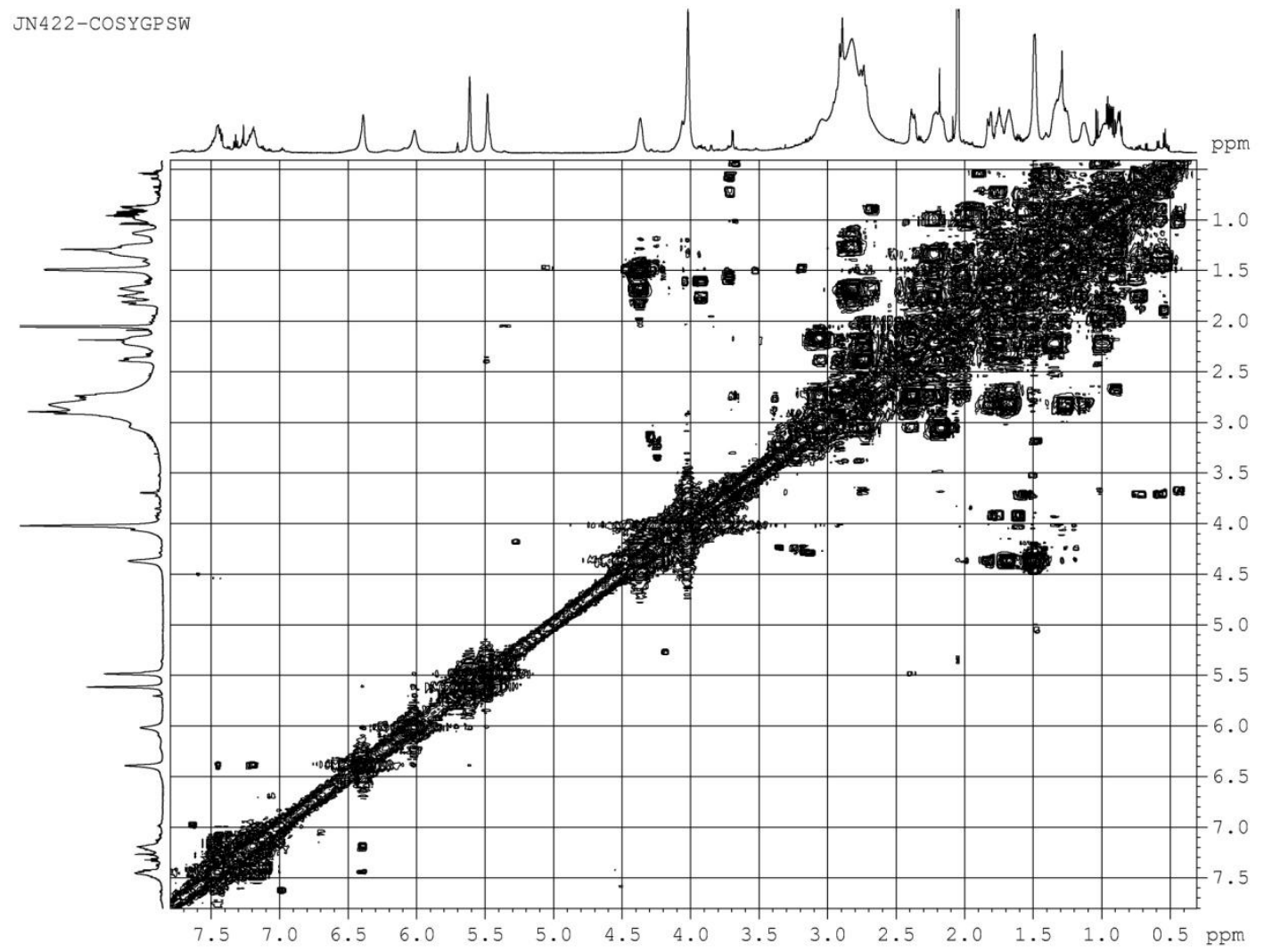

Figure 85: A) 1H-1H 2D COSY correlations of JN422. B) 2D COSY NMR spectrum of JN422. Selected COSY correlations in JN422 are drawn in bold. 
A)

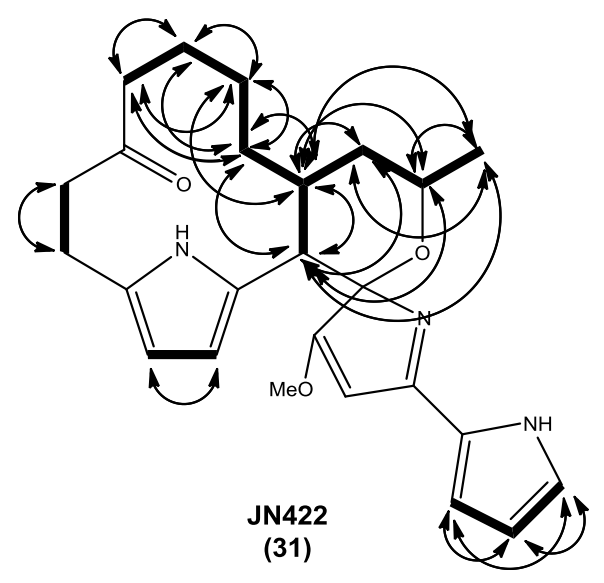

B)

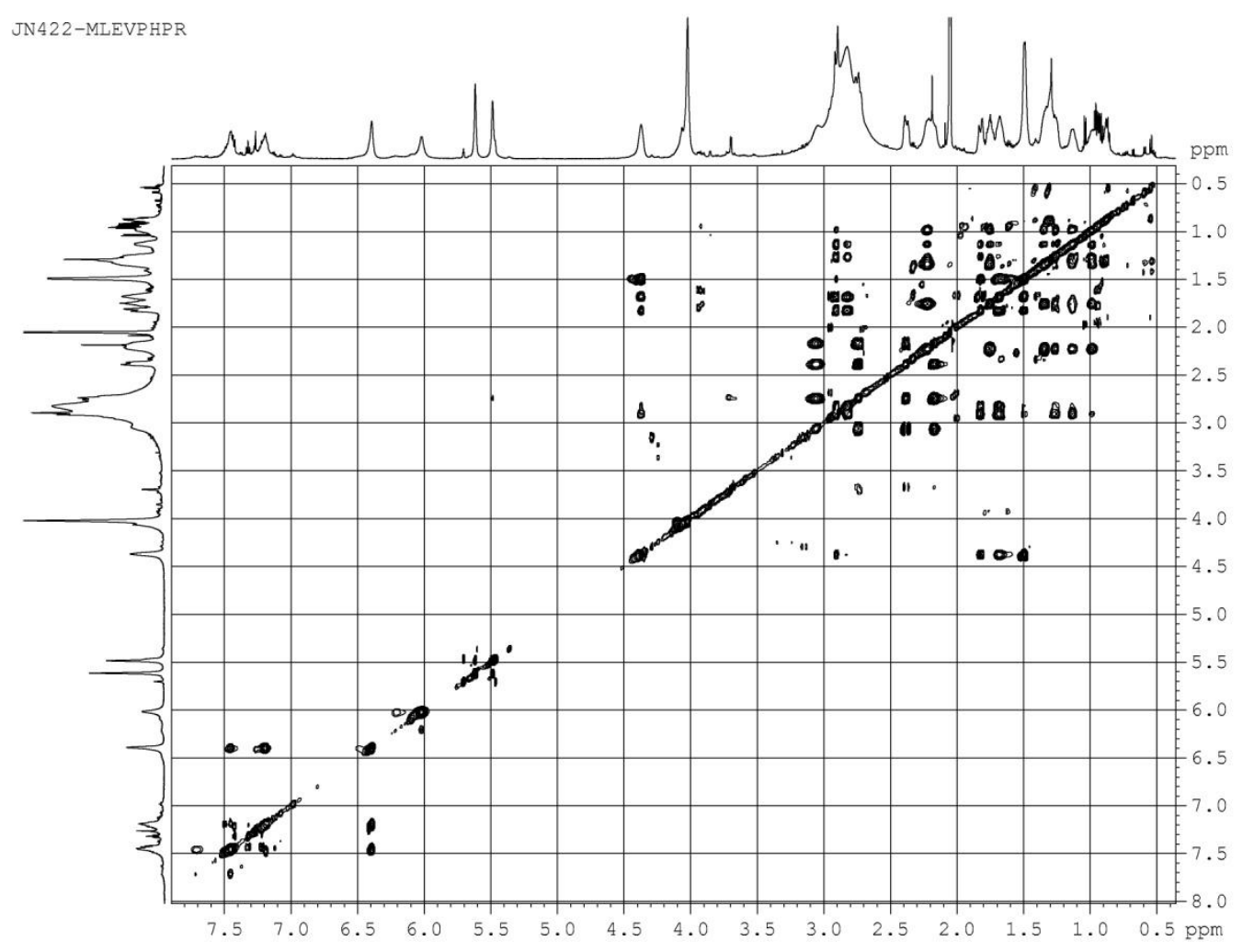

Figure 86: A) Selected COSY $(H \leftrightarrow H$; bold lines) and TOCSY $(H \leftrightarrow H$; double arrows) NMR correlations for JN422. B) 2D TOCSY NMR spectrum of JN422. 
A)

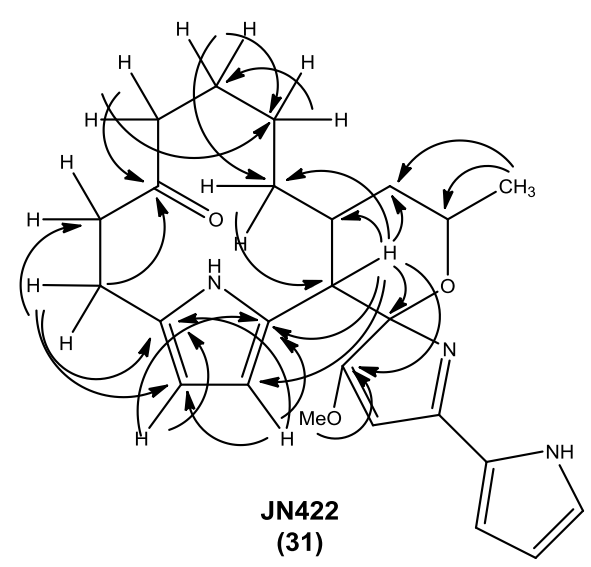

B)

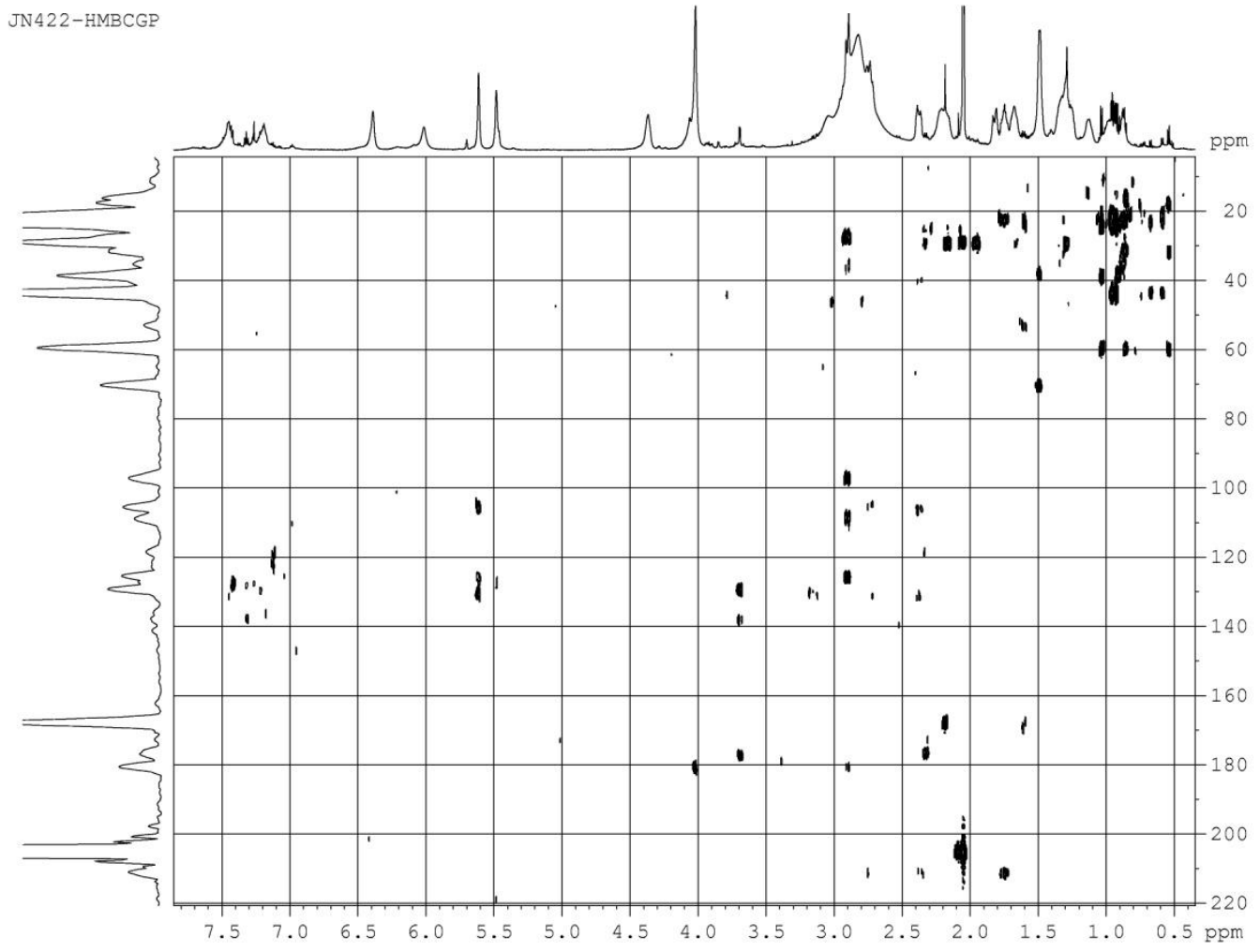

Figure 87: A) Selected HMBC (1H $\rightarrow 13 C)$ NMR correlations for JN422. B) 2D HMBC spectrum of JN422. 


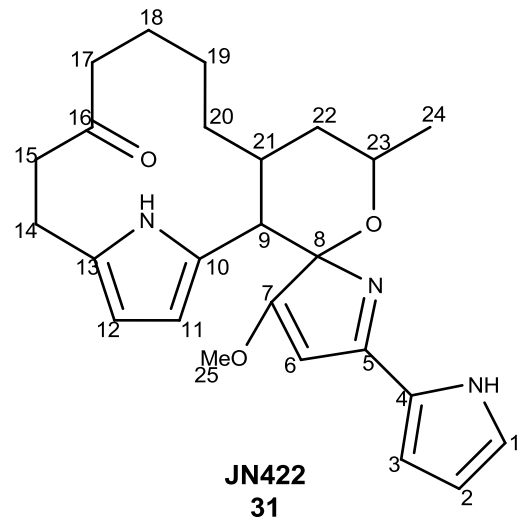

\begin{tabular}{|c|c|c|c|}
\hline Position & $\delta_{\mathrm{H}}$ & COSY & TOCSY \\
\hline 1 & 7.45 & 2,3 & 2,3 \\
\hline 2 & 6.39 & 1,3 & 1,3 \\
\hline 3 & 7.20 & 1,2 & 1,2 \\
\hline \multicolumn{4}{|l|}{4} \\
\hline \multicolumn{4}{|l|}{5} \\
\hline 6 & 6.01 & & \\
\hline \multicolumn{4}{|l|}{7} \\
\hline \multicolumn{4}{|l|}{8} \\
\hline 9 & 2.90 & 21 & $20,21,22,23,24$ \\
\hline \multicolumn{4}{|r|}{, } \\
\hline 11 & 5.61 & 12 & 12 \\
\hline 12 & 5.48 & 11 & 11 \\
\hline \multicolumn{4}{|l|}{13} \\
\hline 14 & $2.37,2.73$ & 15 & 15 \\
\hline 15 & $2.16,3.05$ & 14 & 14 \\
\hline \multicolumn{4}{|l|}{16} \\
\hline 17 & $1.71,2.21$ & 18 & $18,19,20$ \\
\hline 18 & $1.29,1.31$ & 17,19 & $17,19,20$ \\
\hline 19 & $0.94,1.33$ & 18,20 & $17,18,20,21$ \\
\hline 20 & $1.12,1.26$ & 19,21 & $9,17,18,19,21,22$ \\
\hline 21 & 2.80 & $9,20,22$ & $9,19,20,22,23,24$ \\
\hline 22 & $1.67,1.82$ & 21,23 & $9,20,21,23,24$ \\
\hline 23 & 4.36 & 22,24 & $9,20,21,22,24$ \\
\hline 24 & 1.50 & 23 & $9,21,22,23$ \\
\hline 25 & 4.02 & & \\
\hline
\end{tabular}

Table 17: Selected COSY $(H \leftrightarrow H)$ and TOCSY $(H \leftrightarrow H)$ NMR correlations for JN422 


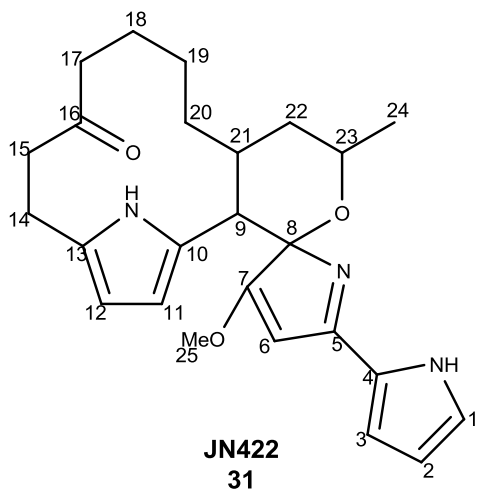

\begin{tabular}{cllll}
\hline Position & $\delta_{\mathrm{H}}{ }^{\mathrm{a}}$ & $\delta_{\mathrm{C}}{ }^{\mathrm{a}}$ & & Selected HMBC correlations \\
\hline 1 & 7.45 & 131.5 & $\mathrm{CH}$ & \\
2 & 6.39 & 112.4 & $\mathrm{CH}$ & \\
3 & 7.20 & 125.9 & $\mathrm{CH}$ & \\
4 & & N.D. & $\mathrm{C}$ & \\
5 & & N.D. & $\mathrm{C}$ & \\
6 & 6.01 & 93.1 & $\mathrm{CH}$ & \\
7 & & 180.6 & $\mathrm{C}$ & \\
8 & & 97.4 & $\mathrm{C}$ & \\
9 & 2.90 & 46.3 & $\mathrm{CH}$ & $7,8,10,11,20,21,22$ \\
10 & & 125.7 & $\mathrm{C}$ & \\
11 & 5.61 & 108.3 & $\mathrm{CH}$ & $10,12,13$ \\
12 & 5.48 & 105.5 & $\mathrm{CH}^{2}$ & 10,13 \\
13 & & 130.1 & $\mathrm{C}$ & \\
14 & $2.37,2.73$ & 23.6 & $\mathrm{CH}_{2}$ & $12,13,15,16$ \\
15 & $2.16,3.05$ & 39.9 & $\mathrm{CH}_{2}$ & \\
16 & & 211.3 & $\mathrm{C}=\mathrm{O}$ & \\
17 & $1.71,2.21$ & 43.6 & $\mathrm{CH}_{2}$ & 16,19 \\
18 & $1.29,1.31$ & 29.4 & $\mathrm{CH}_{2}$ & 19,20 \\
19 & $0.94,1.33$ & 22.1 & $\mathrm{CH}_{2}$ & 18 \\
20 & $1.12,1.26$ & 34.7 & $\mathrm{CH}_{2}$ & 9 \\
21 & 2.80 & 27.3 & $\mathrm{CH}^{2}$ & \\
22 & $1.67,1.82$ & 37.9 & $\mathrm{CH}_{2}$ & \\
23 & 4.36 & 70.0 & $\mathrm{CH}$ & \\
24 & 1.50 & 20.6 & $\mathrm{CH}_{3}$ & 22,23 \\
25 & 4.02 & 59.4 & $\mathrm{CH}_{3}$ & 7 \\
\hline & & & & \\
\hline
\end{tabular}

Table 18: NMR Spectral data for JN422 (600 MHz, Acetone-d6) and Selected HMBC correlations. 


\subsection{CONCLUSIONS}

From the structures of JN408 (31) and JN422 (32), it is evident that MarA does not catalyze spiroaminal ring formation because its deletion led to the accumulation of two spiroaminal marineosin analogs. Although an NADH/NADPH binding site could not be identified from the primary protein sequence of MarA, our data suggests that MarA acts as a dehydrogenase/reductase that is involved in the reduction of pyrrole ring B of $\mathrm{JN} 408$ (31) to yield marineosins. We are proposing that spiroaminal ring formation is either catalyzed by MarG or occurs non-enzymatically via a concerted mechanism. In the latter case, the lone pair of electrons of the $-\mathrm{OH}$ group of 2-hydroxyundecylprodiginine, G410 (27) undergoes a nucleophilic attack on C-8, with the subsequent reduction of the methine bridge between C-8 and C-9 (Figure 88). The -OH group of G410 (27) can be introduced either early in the pathway due to the hydroxylation of 2-UP subunit by an unidentified oxidase (route 1, Figure 88), or the recruitment of hydroxy-butyric acid starter unit by MarP (route 2, Figure 88). The hydroxyl group can be also introduced later in the pathway, due to the presence of an unidentified Mar protein that catalyzes the hydroxylation of undecylprodiginine (7) such as MarT (route 3, Figure 88). The fact that undecylprodiginine (7) intermediate was never detected in any of the strains generated in this study suggests that route 1 or route 2 of our hypothesis are the most likely ones to be correct. Primary protein sequence analysis of MarT and other hypothetical proteins encoded by the mar gene cluster does not show any similarity to known 
p450 oxidases, or non-heme iron Rieske oxygenases. Moreover, homologs of MarT and other hypothetical Mar proteins are also encoded by the red gene cluster but no hydroxylated undecylprodiginine was ever reported before, which makes route 3 of our hypothesis less plausible. We are proposing that JN422 (32) is a shunt metabolite generated from the introduction of a keto group to either JN408 (31), or very early in the pathway due to incorporation of a ketobutyric acid starter unit, or a modified specificity of the fatty acid synthases involved in the biosynthesis of the acyl side chain of marineosin (Figure 88). To the best of our knowledge, JN422 (32) is the first isolated cyclic prodiginine analog with a keto group in the ansa-bridged macrocycle and studying the biological activity of this compound would be very interesting. 
2)

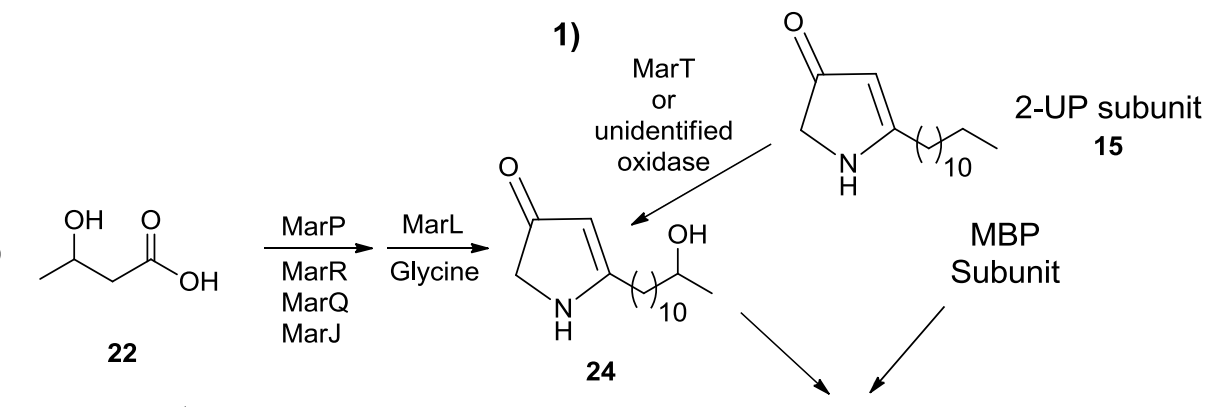

3)
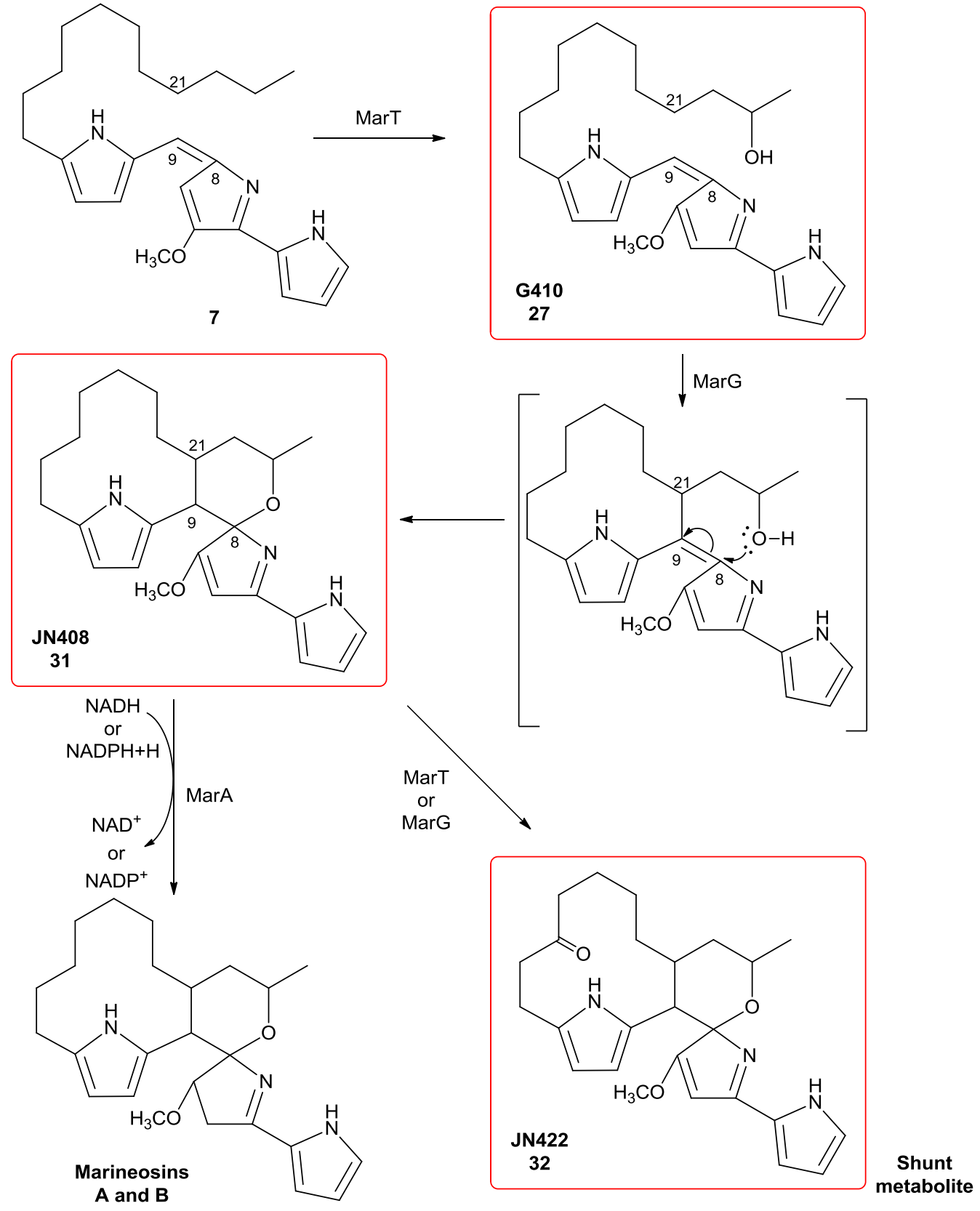

Figure 88: Scheme for the biosynthesis of marineosin. Isolated metabolites are boxed. 


\section{Conclusions and future work recommendations}

The work presented in this dissertation describes the biosynthesis of marineosin, a novel prodiginine analog and how it differs from the biosynthesis of other prodiginines compounds directed by the red gene cluster. It also provides valuable insights into the in vivo role of two key enzymes involved in the biosynthesis of marineosin and proposes an experimentally-supported scheme describing the key steps en route to marineosin.

The present study paves the way to the targeted biosynthesis of a valuable combinatorial library of marineosin and prodiginine analogs and opens up a treasure of research opportunities.

Conclusion 1: Marineosin biosynthesis is directed by a red gene cluster homolog named, mar gene cluster; with the presence of only one extra gene encoding a putative dehydrogenase/reductase named MarA. No additional tailoring enzymes are involved in the biosynthesis of marineosin.

Conclusion 2: MarG, a non-heme iron Rieske-oxygenase catalyzes the oxidative cyclization of the acyl chain of 2-hydroxyundecylprodiginine (27) with the subsequent formation of an ansa-bridged 12-membered carbocyclic ring. MarG does not catalyze the introduction of the $-\mathrm{OH}$ group required to initiate the biosynthesis of the spiroaminal ring of marineosin. Undecylprodiginine (7) is not a 
detectable intermediate along the biosynthetic route to marineosin. The reduction of pyrrole ring B happens later in the pathway, after MarG catalysis step.

Conclusion 3: MarA, a putative dehydrogenase/reductase catalyzes the reduction of pyrrole ring $\mathrm{B}$ of $\mathrm{JN} 408$ (31) intermediate to generate marineosin. MarA is not involved in neither the introduction of the $-\mathrm{OH}$ group of 2hydroxyundecylprodiginine (27) nor the biosynthesis of the spiroaminal ring. Deletion of marA gene leads to the accumulation of a novel marineosin analog.

Conclusion 4: The origin of the spiroaminal ring oxygen is probably due to a different substrate specificity of MarP; the first enzyme involved in the biosynthesis of the acyl chain of marineosin or, an unidentified oxidase that hydroxylates the acyl chain of undecylprodiginine (7).

Conclusion 5: The first experimentally-supported scheme describing the biosynthesis of marineosin was presented.

\section{Future work:}

1. The substrate specificity and mechanism of action of MarG enzyme can be studied after its expression and purification. MarG belongs to a class of Rieske oxygenases whose function is still not fully understood and its characterization could provide a wealth of information on $\mathrm{C}-\mathrm{H}$ bond activation. 
2. The exact function of MarA enzyme can be only be verified through detailed kinetic analysis following its expression as a recombinant protein. The substrate specificity of MarA can be determined by testing its reductase activity with several natural and synthetic, straight chain and cyclic prodiginine analogs.

3. The exact origin of the spiroaminal ring oxygen can be pinned down through the feeding of isotope-labeled hydroxyl-butyric acid starter unit to $S$. venezuelae JND2 $\Delta G$ followed by purification and characterization of isotope labeling patterns of the generated 2-hydroxyundecylprodiginine. Also, the deletion of MarTencoding gene from the mar gene cluster can be used to study whether or not it plays a critical role in the biosynthesis of marineosin. 


\section{References}

[1] R. A. Maplestone, M. J. Stone, and D. H. Williams, "The evolutionary role of secondary metabolites-a review", Gene, vol. 115, no. 1-2, pp. 151-157, 1992.

[2] B. M. Hopkinson and F. M. M. Morel, "The role of siderophores in iron acquisition by photosynthetic marine microorganisms", Biometals, vol. 22, no. 4, pp. 659-669, 2009.

[3] L. C. Vining, "Functions of secondary metabolites", Annu. Rev. Microbiol., vol. 44, pp. 395-427, 1990.

[4] D. J. Newman and G. M. Cragg, "Natural products as sources of new drugs over the last 25 years", J. Nat. Prod, vol. 70, no. 3, pp. 461-477, Mar. 2007.

[5] A. T. Keatinge-Clay, D. A. Maltby, K. F. Medzihradszky, C. Khosla, and R. M. Stroud, "An antibiotic factory caught in action", Nat Struct Mol Biol, vol. 11, no. 9, pp. 888-893, 2004.

[6] D. A. Hopwood, "Soil to genomics: the Streptomyces chromosome", Annu. Rev. Genet., vol. 40, pp. 1-23, 2006.

[7] J. Bérdy, "Bioactive microbial metabolites", J. Antibiot., vol. 58, no. 1, pp. 126, Jan. 2005.

[8] S. Smith and S.-C. Tsai, "The type I fatty acid and polyketide synthases: a tale of two megasynthases", Nat. Prod. Rep., vol. 24, no. 5, p. 1041, 2007.

[9] J. L. Meier and M. D. Burkart, "The chemical biology of modular biosynthetic enzymes", Chem. Soc. Rev., vol. 38, no. 7, p. 2012, 2009.

[10] D. A. Hopwood, "The Leeuwenhoek Lecture, 1987: Towards an Understanding of Gene Switching in Streptomyces, the Basis of Sporulation and Antibiotic Production", P. R. Soc. London., Series B, Biological Sciences, vol. 235, no. 1279, pp. 121-138, 1988.

[11] T. Mahmud, "Isotope tracer investigations of natural products biosynthesis: the discovery of novel metabolic pathways", J. Label. Compd. Radiopharm., vol. 50, no. 11-12, pp. 1039-1051, Oct. 2007. 
[12] E.-S. E. Habib, J. N. Scarsdale, and K. A. Reynolds, "Biosynthetic origin of hygromycin A", Antimicrob. Agents Chemother., vol. 47, no. 7, pp. 20652071, Jul. 2003.

[13] M. Ghatge, N. Palaniappan, S. Das Choudhuri, and K. Reynolds, "Genetic manipulation of the biosynthetic process leading to phoslactomycins, potent protein phosphatase 2A inhibitors", J. Ind. Microbiol. Biotechnol., vol. 33, no. 7, pp. 589-599, Jul. 2006.

[14] M. Rohmer, M. Knani, P. Simonin, B. Sutter, and H. Sahm, "Isoprenoid biosynthesis in bacteria: a novel pathway for the early steps leading to isopentenyl diphosphate", Biochem. J, vol. 295 ( Pt 2), pp. 517-524, Oct. 1993.

[15] L. Frangeul, K. E. Nelson, C. Buchrieser, A. Danchin, P. Glaser, and F. Kunst, "Cloning and assembly strategies in microbial genome projects", Microbiology (Reading, Engl.), vol. 145 ( Pt 10), pp. 2625-2634, Oct. 1999.

[16] B. Gust, "Chapter 7 Cloning and Analysis of Natural Product Pathways", in Complex Enzymes in Microbial Natural Product Biosynthesis, Part A: Overview Articles and Peptides, vol. Volume 458, Academic Press, 2009, pp. $159-180$.

[17] I. A. Darby and T. D. Hewitson, In situ hybridization protocols. Humana Press, 2006.

[18] T. N. Campbell and F. Y. M. Choy, "Approaches to library screening", J. Mol. Microbiol. Biotechnol, vol. 4, no. 6, pp. 551-554, Nov. 2002.

[19] B. Gust, G. L. Challis, K. Fowler, T. Kieser, and K. F. Chater, "PCR-targeted Streptomyces gene replacement identifies a protein domain needed for biosynthesis of the sesquiterpene soil odor geosmin", Proc. Natl. Acad. Sci. U.S.A, vol. 100, no. 4, pp. 1541-1546, Feb. 2003.

[20] B. Gust, G. Chandra, D. Jakimowicz, T. Yuqing, C. J. Bruton, and K. F. Chater, "Lambda red-mediated genetic manipulation of antibiotic-producing Streptomyces", Adv. Appl. Microbiol, vol. 54, pp. 107-128, 2004. 
[21] E. Takano, H. C. Gramajo, E. Strauch, N. Andres, J. White, and M. J. Bibb, "Transcriptional regulation of the redD transcriptional activator gene accounts for growth-phase-dependent production of the antibiotic undecylprodigiosin in Streptomyces coelicolor A3(2)", Mol. Microbiol, vol. 6, no. 19, pp. 2797-2804, Oct. 1992.

[22] H. C. Gramajo, E. Takano, and M. J. Bibb, "Stationary-phase production of the antibiotic actinorhodin in Streptomyces coelicolor $\mathrm{A} 3(2)$ is transcriptionally regulated", Mol. Microbiol, vol. 7, no. 6, pp. 837-845, Mar. 1993.

[23] H. M. Thorpe and M. C. Smith, "In vitro site-specific integration of bacteriophage DNA catalyzed by a recombinase of the resolvase/invertase family", Proc. Natl. Acad. Sci. U.S.A, vol. 95, no. 10, pp. 5505-5510, May 1998.

[24] M. Bierman, R. Logan, K. O'Brien, E. T. Seno, R. N. Rao, and B. E. Schoner, "Plasmid cloning vectors for the conjugal transfer of DNA from Escherichia coli to Streptomyces spp", Gene, vol. 116, no. 1, pp. 43-49, Jul. 1992.

[25] A. S. Eustáquio, B. Gust, U. Galm, S.-M. Li, K. F. Chater, and L. Heide, "Heterologous expression of novobiocin and clorobiocin biosynthetic gene clusters", Appl. Environ. Microbiol, vol. 71, no. 5, pp. 2452-2459, May 2005.

[26] M. Sosio, F. Giusino, C. Cappellano, E. Bossi, A. M. Puglia, and S. Donadio, "Artificial chromosomes for antibiotic-producing actinomycetes", Nat. Biotechnol., vol. 18, no. 3, pp. 343-345, Mar. 2000.

[27] M. Sosio, E. Bossi, and S. Donadio, "Assembly of large genomic segments in artificial chromosomes by homologous recombination in Escherichia coli", Nucleic Acids Res., vol. 29, no. 7, p. E37, Apr. 2001.

[28] F. W. Studier and B. A. Moffatt, "Use of bacteriophage T7 RNA polymerase to direct selective high-level expression of cloned genes", J. Mol. Biol, vol. 189, no. 1, pp. 113-130, May 1986. 
[29] E. Hochuli, W. Bannwarth, H. Dobeli, R. Gentz, and D. Stuber, "Genetic Approach to Facilitate Purification of Recombinant Proteins with a Novel Metal Chelate Adsorbent", Nat. Biotech., vol. 6, no. 11, pp. 1321-1325, Nov. 1988.

[30] N. R. Williamson, P. C. Fineran, F. J. Leeper, and G. P. C. Salmond, "The biosynthesis and regulation of bacterial prodiginines", Nat. Rev. Micro., vol. 4, no. 12, pp. 887-899, Dec. 2006.

[31] J. W. Bennett and R. Bentley, "Seeing red: the story of prodigiosin", Adv. Appl. Microbiol., vol. 47, pp. 1-32, 2000.

[32] R. Pérez-Tomás, B. Montaner, E. Llagostera, and V. Soto-Cerrato, "The prodigiosins, proapoptotic drugs with anticancer properties", Biochem. Pharmacol., vol. 66, no. 8, pp. 1447-1452, 2003.

[33] R. A. Manderville, "Synthesis, proton-affinity and anti-cancer properties of the prodigiosin-group natural products", Curr. Med. Chem. Anticancer Agents, vol. 1, no. 2, pp. 195-218, Aug. 2001.

[34] M. Nguyen, R. C. Marcellus, A. Roulston, M. Watson, L. Serfass, S. R. Murthy Madiraju, D. Goulet, J. Viallet, L. Bélec, X. Billot, and others, "Small molecule obatoclax (GX15-070) antagonizes MCL-1 and overcomes MCL-1mediated resistance to apoptosis", P. Natl. Acad. Sci., vol. 104, no. 49, p. 19512, 2007.

[35] T. Azuma, N. Watanabe, H. Yagisawa, H. Hirata, M. Iwamura, and Y. Kobayashi, "Induction of apoptosis of activated murine splenic $T$ cells by cycloprodigiosin hydrochloride, a novel immunosuppressant", Immunopharmacology, vol. 46, no. 1, pp. 29-37, Jan. 2000.

[36] R. D'Alessio, A. Bargiotti, O. Carlini, F. Colotta, M. Ferrari, P. Gnocchi, A. Isetta, N. Mongelli, P. Motta, A. Rossi, M. Rossi, M. Tibolla, and E. Vanotti, "Synthesis and Immunosuppressive Activity of Novel Prodigiosin Derivatives", J. Med. Chem., vol. 43, no. 13, pp. 2557-2565, Jun. 2000. 
[37] A. Fürstner, "Chemistry and biology of roseophilin and the prodigiosin alkaloids: a survey of the last 2500 years", Angew. Chem. Int. Edit., vol. 42, no. 31, pp. 3582-3603, 2003.

[38] K. Papireddy, M. Smilkstein, J. X. Kelly, Shweta, S. M. Salem, M. Alhamadsheh, S. W. Haynes, G. L. Challis, and K. A. Reynolds, "Antimalarial Activity of Natural and Synthetic Prodiginines", J. Med. Chem., Jul. 2011.

[39] H. H. Wasserman, R. J. Sykes, P. Peverada, C. K. Shaw, R. J. Cushley, and S. R. Lipsky, "Biosynthesis of prodigiosin. Incorporation patterns of carbon-13-labeled alanine, proline, glycine, and serine elucidated by Fourier transform nuclear magnetic resonance", J. Am. Chem. Soc., vol. 95, no. 20, pp. 6874-6875, Oct. 1973.

[40] N. N. Gerber, A. G. McInnes, D. G. Smith, J. A. Walter, J. L. C. Wright, and L. C. Vining, "Biosynthesis of prodiginines. ${ }^{13} \mathrm{C}$ resonance assignments and enrichment patterns in nonyl-, cyclononyl-, methylcyclodecyl-, and butylcycloheptylprodiginine produced by actinomycete cultures supplemented with ${ }^{13} \mathrm{C}$-labeled acetate and ${ }^{15} \mathrm{~N}$-labeled nitrate", Can. J. Chem., vol. 56, no. 9, pp. 1155-1163, 1978.

[41] W. K. Tanaka, L. B. de Medina, and W. R. Hearn, "Labeling patterns in prodigiosin biosynthesis", Biochem. Biophys. Res. Commun., vol. 46, no. 2, pp. 731-737, Jan. 1972.

[42] N. N. Gerber, "Prodigiosin-Like Pigments", Cr. Rev. Microbiol., vol. 3, no. 4, pp. 469-485, Jan. 1975.

[43] J. S. Feitelson, F. Malpartida, and D. A. Hopwood, "Genetic and Biochemical Characterization of the red Gene Cluster of Streptomyces coelicolor A3(2)", J. Gen. Microbiol., vol. 131, no. 9, pp. 2431-2441, Sep. 1985.

[44] F. Malpartida, J. Niemi, R. Navarrete, and D. A. Hopwood, "Cloning and expression in a heterologous host of the complete set of genes for 
biosynthesis of the Streptomyces coelicolor antibiotic undecylprodigiosin", Gene, vol. 93, no. 1, pp. 91-99, Sep. 1990.

[45] S. D. Bentley, K. F. Chater, A.-M. Cerdeño-Tárraga, G. L. Challis, N. R. Thomson, K. D. James, D. E. Harris, M. A. Quail, H. Kieser, D. Harper, A. Bateman, S. Brown, G. Chandra, C. W. Chen, M. Collins, A. Cronin, A. Fraser, A. Goble, J. Hidalgo, T. Hornsby, S. Howarth, C.-H. Huang, T. Kieser, L. Larke, L. Murphy, K. Oliver, S. O’Neil, E. Rabbinowitsch, M.-A. Rajandream, K. Rutherford, S. Rutter, K. Seeger, D. Saunders, S. Sharp, R. Squares, S. Squares, K. Taylor, T. Warren, A. Wietzorrek, J. Woodward, B. G. Barrell, J. Parkhill, and D. A. Hopwood, "Complete genome sequence of the model actinomycete Streptomyces coelicolor A3(2)", Nature, vol. 417, no. 6885, pp. 141-147, May 2002.

[46] A. M. Cerdeno, M. J. Bibb, and G. L. Challis, "Analysis of the prodiginine biosynthesis gene cluster of Streptomyces coelicolor A3 (2): new mechanisms for chain initiation and termination in modular multienzymes", Chem. Biol., vol. 8, no. 8, pp. 817-829, 2001.

[47] M. G. Thomas, M. D. Burkart, and C. T. Walsh, "Conversion of L-proline to pyrrolyl-2-carboxyl-S-PCP during undecylprodigiosin and pyoluteorin biosynthesis", Chem. Biol., vol. 9, no. 2, pp. 171-184, 2002.

[48] A. E. Stanley, L. J. Walton, M. Kourdi Zerikly, C. Corre, and G. L. Challis, "Elucidation of the Streptomyces coelicolor pathway to 4-methoxy-2,2?bipyrrole-5-carboxaldehyde, an intermediate in prodiginine biosynthesis", Chem. Commun., no. 38, p. 3981, 2006.

[49] S. Mo, B. S. Kim, and K. A. Reynolds, "Production of Branched-Chain Alkylprodiginines in S. coelicolor by Replacement of the 3-Ketoacyl ACP Synthase III Initiation Enzyme, RedP", Chem. Biol., vol. 12, no. 2, pp. 191200, Feb. 2005.

[50] S. Mo, P. K. Sydor, C. Corre, M. M. Alhamadsheh, A. E. Stanley, S. W. Haynes, L. Song, K. A. Reynolds, and G. L. Challis, "Elucidation of the 
Streptomyces coelicolor Pathway to 2-Undecylpyrrole, a Key Intermediate in Undecylprodiginine and Streptorubin B Biosynthesis", Chem. Biol., vol. 15, no. 2, pp. 137-148, Feb. 2008.

[51] S. W. Haynes, P. K. Sydor, A. E. Stanley, L. Song, and G. L. Challis, "Role and substrate specificity of the Streptomyces coelicolor RedH enzyme in undecylprodiginine biosynthesis", Chem. Commun., no. 16, p. 1865, 2008.

[52] P. K. Sydor, S. M. Barry, O. M. Odulate, F. Barona-Gomez, S. W. Haynes, C. Corre, L. Song, and G. L. Challis, "Regio- and stereodivergent antibiotic oxidative carbocyclizations catalysed by Rieske oxygenase-like enzymes", Nat. Chem., vol. 3, no. 5, pp. 388-392, May 2011.

[53] C. Boonlarppradab, C. A. Kauffman, P. R. Jensen, and W. Fenical, "Marineosins A and B, cytotoxic spiroaminals from a marine-derived actinomycete", Org. Lett, vol. 10, no. 24, pp. 5505-5508, Dec. 2008.

[54] L. N. Aldrich, E. S. Dawson, and C. W. Lindsley, "Evaluation of the biosynthetic proposal for the synthesis of marineosins A and B", Org. Lett, vol. 12, no. 5, pp. 1048-1051, Mar. 2010.

[55] X.-C. Cai, X. Wu, and B. B. Snider, "Synthesis of the spiroiminal moiety of marineosins A and B", Org. Lett, vol. 12, no. 7, pp. 1600-1603, Apr. 2010.

[56] J. J. Sanglier, V. Quesniaux, T. Fehr, H. Hofmann, M. Mahnke, K. Memmert, W. Schuler, G. Zenke, L. Gschwind, C. Maurer, and W. Schilling, "Sanglifehrins A, B, C and D, novel cyclophilin-binding compounds isolated from Streptomyces sp. A92-308110. I. Taxonomy, fermentation, isolation and biological activity", J. Antibiot., vol. 52, no. 5, pp. 466-473, May 1999.

[57] L. E. Overman and Y. H. Rhee, "Total synthesis of (-)-crambidine and definition of the relative configuration of its unique tetracyclic guanidinium core", J. Am. Chem. Soc., vol. 127, no. 44, pp. 15652-15658, Nov. 2005.

[58] A. Olszewski, K. Sato, Z. D. Aron, F. Cohen, A. Harris, B. R. McDougall, W. E. Robinson Jr, L. E. Overman, and G. A. Weiss, "Guanidine alkaloid 
analogs as inhibitors of HIV-1 Nef interactions with p53, actin, and p56lck", P. Natl. Acad. Sci. U.S.A., vol. 101, no. 39, pp. 14079-14084, Sep. 2004.

[59] A. P. J. Pal, P. Kadigachalam, A. Mallick, V. R. Doddi, and Y. D. Vankar, "Synthesis of sugar-derived spiroaminals via lactamization and metathesis reactions", Org. Biomol. Chem., vol. 9, no. 3, pp. 809-819, Jan. 2011.

[60] M. Sinibaldi, I. Canet, M. Sinibaldi, and I. Canet, "Synthetic Approaches to Spiroaminals, Synthetic Approaches to Spiroaminals", Eur. J. Org. Chem., vol. 2008, 2008, no. 26, 26, pp. 4391, 4391-4399, 4399, Sep. 2008.

[61] C. J. Forsyth, "Asymmetric Synthesis of Cyclic Ketal and SpiroaminalContaining Natural Products", ChemInform., vol. 39, no. 2, p. i, Jan. 2008.

[62] S. Nguyen, J. Xu, and C. J. Forsyth, "Facile biomimetic syntheses of the azaspiracid spiroaminal", Tetrahedron, vol. 62, no. 22, pp. 5338-5346, May 2006.

[63] G. Bertani, "Studies on lysogenesis. I. The mode of phage liberation by lysogenic Escherichia coll', J. Bacteriol., vol. 62, no. 3, pp. 293-300, Sep. 1951.

[64] D. Hanahan, "Studies on transformation of Escherichia coli with plasmids", J. Mol. Biol., vol. 166, no. 4, pp. 557-580, Jun. 1983.

[65] L. Zhao, N. J. Beyer, S. A. Borisova, and H. Liu, "Beta-glucosylation as a part of self-resistance mechanism in methymycin/pikromycin producing strain Streptomyces venezuelae", Biochemistry, vol. 42, no. 50, pp. $14794-$ 14804, Dec. 2003.

[66] D. P. Brown, S. J. Chiang, J. S. Tuan, and L. Katz, "Site-specific integration in Saccharopolyspora erythraea and multisite integration in Streptomyces lividans of actinomycete plasmid pSE101", J. Bacteriol., vol. 170, no. 5, pp. 2287-2295, May 1988.

[67] J. Yan, S. Gupta, D. H. Sherman, and K. A. Reynolds, "Functional dissection of a multimodular polypeptide of the pikromycin polyketide 
synthase into monomodules by using a matched pair of heterologous docking domains", Chembiochem, vol. 10, no. 9, pp. 1537-1543, Jun. 2009.

[68] K. Chen, N. S. Rannulu, Y. Cai, P. Lane, A. L. Liebl, B. B. Rees, C. Corre, G. L. Challis, and R. B. Cole, "Unusual odd-electron fragments from evenelectron protonated prodiginine precursors using positive-ion electrospray tandem mass spectrometry", J. Am. Soc. Mass Spectrom., vol. 19, no. 12, pp. 1856-1866, 2008.

[69] Practical Streptomyces genetics. John Innes Foundation, 2000.

[70] J. S. Rieske, R. E. Hansen, and W. S. Zaugg, "Studies on the electron transfer system properties of a new oxidation-reduction component of the respiratory chain as studied by electron paramagnetic resonance spectroscopy", J. Biol. Chem., vol. 239, pp. 3017-3022, Sep. 1964.

[71] D. J. Ferraro, L. Gakhar, and S. Ramaswamy, "Rieske business: structurefunction of Rieske non-heme oxygenases", Biochem. Biophys. Res. Commun., vol. 338, no. 1, pp. 175-190, Dec. 2005.

[72] J. F. Cline, B. M. Hoffman, W. B. Mims, E. LaHaie, D. P. Ballou, and J. A. Fee, "Evidence for $\mathrm{N}$ coordination to $\mathrm{Fe}$ in the [2Fe-2S] clusters of Thermus Rieske protein and phthalate dioxygenase from Pseudomonas", J. Biol. Chem., vol. 260, no. 6, pp. 3251-3254, Mar. 1985.

[73] J. A. Fee, K. L. Findling, T. Yoshida, R. Hille, G. E. Tarr, D. O. Hearshen, W. R. Dunham, E. P. Day, T. A. Kent, and E. Münck, "Purification and characterization of the Rieske iron-sulfur protein from Thermus thermophilus. Evidence for a [2Fe-2S] cluster having non-cysteine ligands", J. Biol. Chem., vol. 259, no. 1, pp. 124-133, Jan. 1984.

[74] D. Kuila and J. A. Fee, "Evidence for a redox-linked ionizable group associated with the [2Fe-2S] cluster of Thermus Rieske protein", J. Biol. Chem., vol. 261, no. 6, pp. 2768-2771, Feb. 1986.

[75] Y. Zu, M. M.-J. Couture, D. R. J. Kolling, A. R. Crofts, L. D. Eltis, J. A. Fee, and J. Hirst, "Reduction potentials of Rieske clusters: importance of the 
coupling between oxidation state and histidine protonation state", Biochemistry, vol. 42, no. 42, pp. 12400-12408, Oct. 2003.

[76] E. L. Hegg and L. Que Jr, "The 2-His-1-carboxylate facial triad--an emerging structural motif in mononuclear non-heme iron(II) enzymes", Eur. J. Biochem., vol. 250, no. 3, pp. 625-629, Dec. 1997.

[77] L. Que, "One motif — many different reactions", Nat. Struct. Mol. Biol., vol. 7, no. 3, pp. 182-184, Mar. 2000.

[78] R. E. Parales, J. V. Parales, and D. T. Gibson, "Aspartate 205 in the Catalytic Domain of Naphthalene Dioxygenase Is Essential for Activity", J. Bacteriol., vol. 181, no. 6, pp. 1831-1837, Mar. 1999.

[79] S. C. Dillon and A. Bateman, "The Hotdog fold: wrapping up a superfamily of thioesterases and dehydratases", BMC Bioinformatics, vol. 5, p. 109, Aug. 2004. 